\title{
Synthesis Of Novel Pyran Fragments to InCorporate into Peloruside Analogues
}

By

Oliver Bayley

A thesis submitted to Victoria University of Wellington in partial fulfilment of the requirements for the degree of Master of Drug Discovery and Development by thesis.

TE WHARE WĀNANGA O TE ŪPOKO O TE IKA A MĀUI $\underbrace{A}_{\text {UNIVERSITY OF WELLINGTON }}$

School of Chemical and Physical Sciences 
(C) 2019

Oliver Bayley 


\begin{abstract}
Cancer is currently the second largest cause of death globally, leading to a high demand for new and effective chemotherapeutics. For years, natural products have been used as a source of new bioactive compounds; of particular interest in this context, as a source of new chemotherapeutics. One chemotherapeutic candidate which has attracted significant attention in synthetic and medicinal chemistry communities, is peloruside A. Peloruside A is a bioactive secondary metabolite isolated from the New Zealand marine sponge Mycale hentscheli. Since its discovery, peloruside A has shown great promise in cancer studies both in vivo and in vitro with effects observed even at nanomolar concentrations. These chemotherapeutic effects have been shown to occur by halting cell division at the G2/M checkpoint via microtubule stabilisation. Of particular interest is that this stabilisation occurs in a manner distinct from that of the already established taxane class of microtubule stabilising drugs. This means that peloruside $\mathrm{A}$ is able to offer both inhibition of cell division in Taxol ${ }^{\circledR}$ resistant cells and synergistic inhibition alongside the current taxane drugs. Since peloruside A is not abundantly available from its natural source, there is a strong incentive for the development of new synthetic strategies for peloruside A production. Unfortunately attempts at aquaculture and attempts at developing an industrial scale synthesis have both proven unsuccessful thus far. In an attempt to overcome some of the difficulties with the scale up of peloruside, analogues have been developed that are intended to have similar bioactivity to peloruside A but simpler, more concise, synthetic routes. These analogues will also enable further elucidation of the binding properties of peloruside A. This project focuses on the generation of a functionalised pyran fragment, starting from a simple carbohydrate, that may be incorporated into the proposed analogues.
\end{abstract}

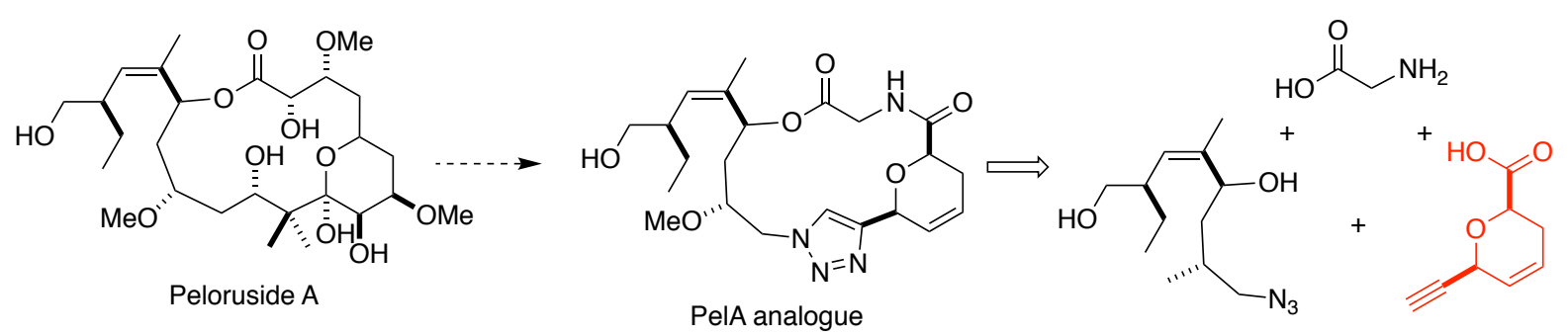




\section{Acknowledgements}

First off, my biggest thanks is definitely dedicated to my two amazing supervisors AProf. Paul-Teesdale Spittle and Dr Joanne Harvey. You guys have been the most amazing supervisors, not just for your near infinite pool of combined knowledge, but because you guys have been so incredibly patient and helpful the whole way through this project. Paul, thank you so much for always being able to help with my 1001 questions no matter how busy your schedule, I'm definitely going to miss all of your dad jokes. Joanne, your enthusiasm and help with all things chemistry as well as general life matters, has been invaluable. Thanks guys.

I would also like to thank my family Chris, Janine and Sierra for your support, emotionally and financially, through all of the ups and downs. I would have never made it to the end of this project intact if it wasn't for you guys. Special thanks to you mum, these past couple months jumping from flat to flat to hotel, while also having to make trips back and forward to Chch in preparation for the shoulder surgery, has been HECTIC. If it wasn't for your amazing organisation with flights, living situations and appointments, none of this would have been remotely possible.

The "Pestie boys" Jordan and Joe, you lads have had both great chat and great advice. Jordan, when I first started working in the lab, I remember you said that during your honours, you found the most useful person to be the $\mathrm{PhD}$ student in the fume hood beside you. I don't think you could have been any more right. You have been an amazing mentor and a great friend. I have lost track of just how many things you've taught me but at this point I'm pretty sure I owe like $99 \%$ of my current lab skills to you. A special thanks to Amira as well, although you weren't around for the whole project you helped me feel at home in the AM lab (as well as Hunter lounge). Cheers.

Next, Ian Vorster who has provided countless hours of support to the NMR and mass spectrometers. This department wouldn't function without you.

I would like to thank all the group members past and present, over the course of this project. Jordan, Amira, Ethan, Tao, Paul H, Sarah, Mike and the rest of the AM lab. I would also like to thank my AM 304 office members for keeping the office so lively. 


\section{Table of Contents}

Abstract................................................................................................... i

Acknowledgements ......................................................................... ii

Table of Contents .......................................................................... iii

List of Figures............................................................................... iv

List of Schemes ........................................................................... vi

List of Tables .....................................................................................vviii

List of Abbreviations ................................................................. ix

Compound Numbering...................................................................... xii

1. Chapter 1. Introduction. .......................................................... 1

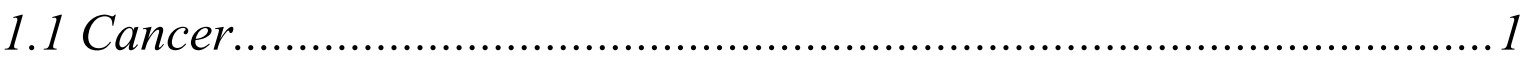

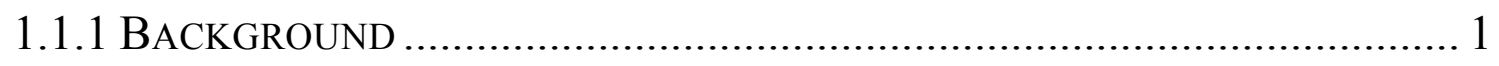

1.1.2 TARgeting CANCERous Cells ........................................................ 1

1.1.3 Anti-Microtubule Chemotherapeutics ......................................... 2

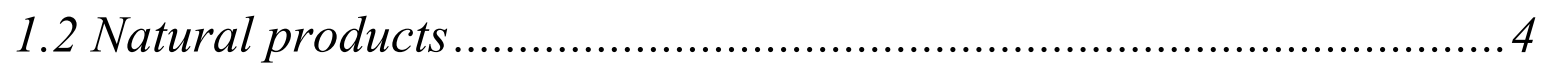

1.2.1 Natural Products As A Source Of New Drugs............................. 4

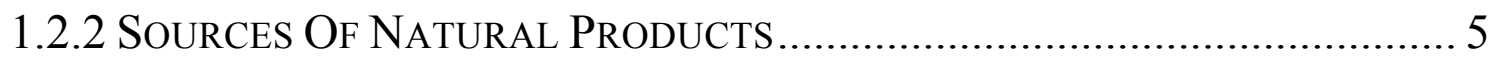

1.3 Analogues in natural product synthesis......................................... 6

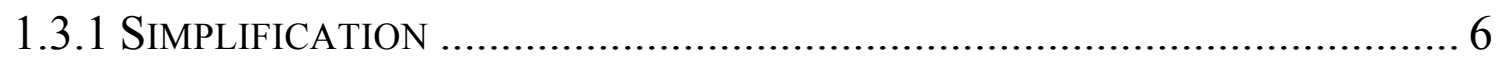

1.3.2 STRUCTURE-ACTIVITY RELATIONSHIP STUDIES ................................... 7

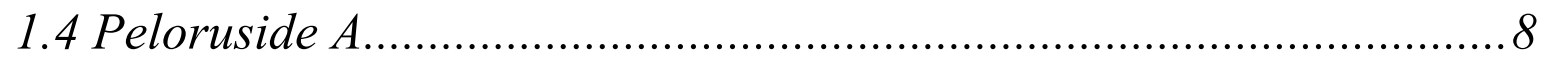

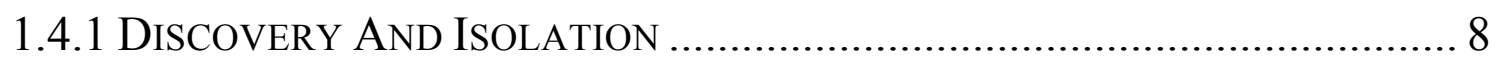

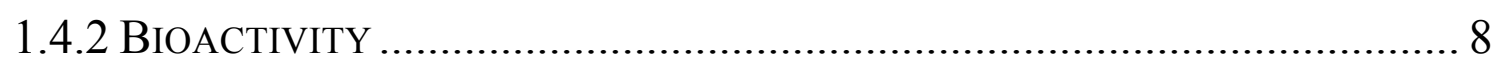

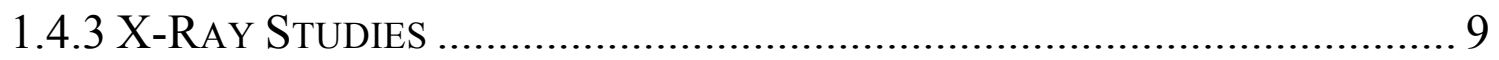

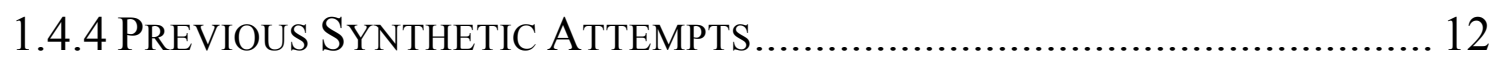

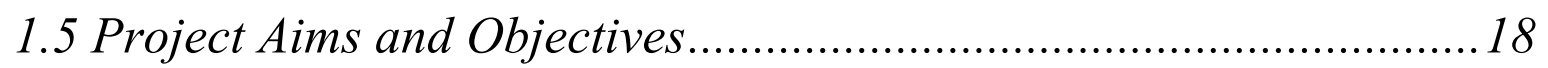

1.5.1 Peloruside A, its KnOWn analogues AND the Proposed NeW

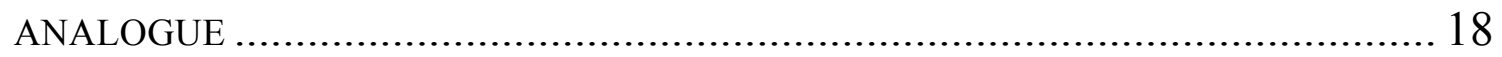

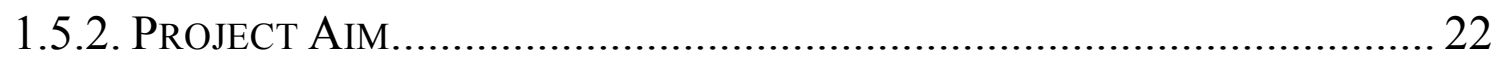

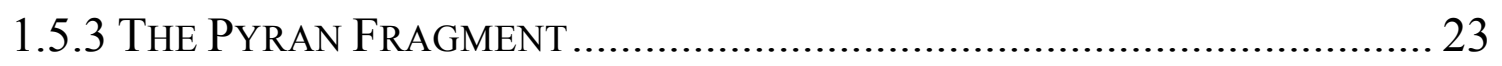


2. Chapter 2. Trityl and Acetal Protecting Group Strategies..... 25

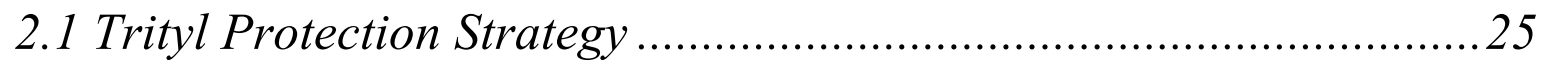

2.1.1 SyNTHESIS OF 6-O-TRITYL-3,4-O-DIACETYL-D-GLUCAL 75 …........... 25

2.1.2 FERRIER-TYPE REACTIONS ON 6-TRITYL-3,4- $O$-DIACETYL-D -GLUCAL 26

2.2 p-Methoxybenzylidine Acetal Protection Strategy.........................29

2.2.1 Proposed Acetal Protection route. ............................................ 29

2.2.2 SYNTHESIS OF 6,4-P-METHOXYBENZYLIDENEACETAL-3-O-ACETYL-D-

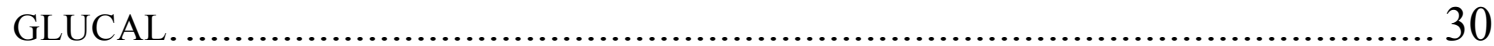

3. Chapter 3. The TBS Protection Strategy................................ 31

3.1 6-O-TBS-3,4-diacetyl-D-glucal synthesis ....................................... 31

3.2 Ferrier reaction of 6-O-TBS-3,4-O-diacetyl-D-glucal ....................37

3.3 Oxidation of the primary hydroxyl group in compound $\mathbf{8 8} \ldots \ldots \ldots . . . .45$

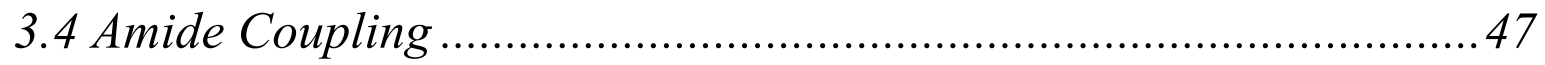

4. Chapter 4. Summary and Future Work..................................50

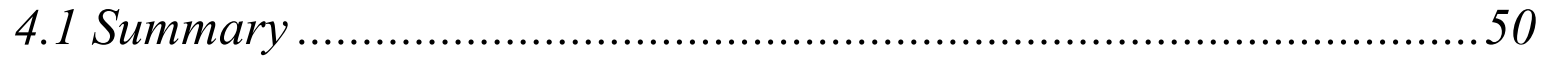

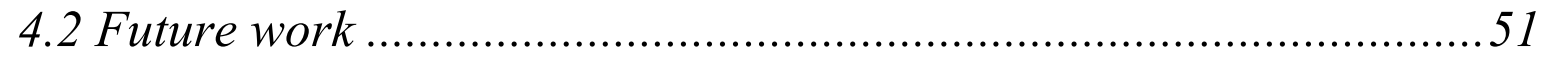

4.2.1 CopPER CATALYZED CyCLOAdDITION REACTION................................ 51

4.2.2 ANOMERIC STEREOCHEMICAL INVERSION ........................................... 51

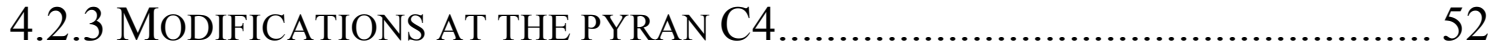

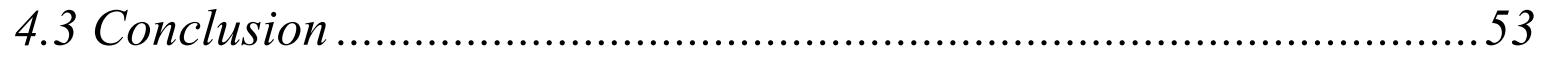

5. Experimental. ........................................................................... 54

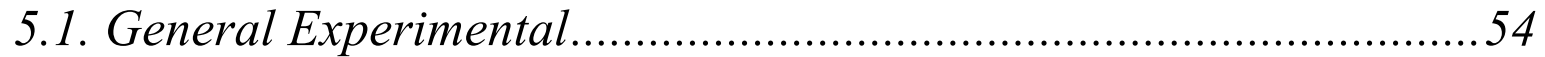

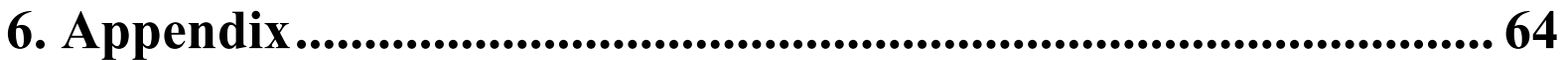

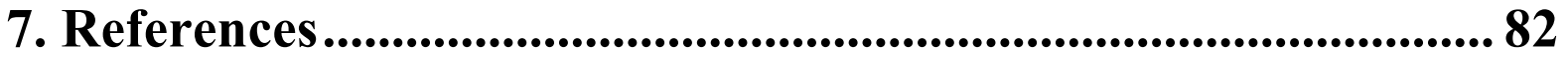




\section{List of Figures}

Figure 1. Helical structure of microtubules showing the $\alpha$ and $\beta$ tubulin subunits, the seam and location of the lateral interfaces. Used with permission (2019) Copyright (C) 2017 Elsevier Ltd. All rights reserved.

Figure 2. Commercially used drugs from the vinca alkaloids drug class. ..............................

Figure 3. Commercially used drugs from the Taxanes and Epothilones drug classes..............3

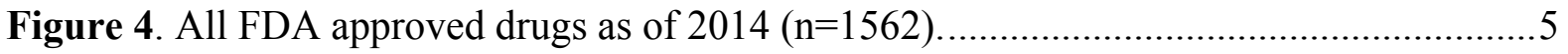

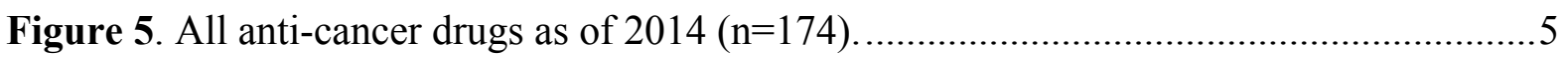

Figure 6. Structures of the natural products halichondrin B and its drug derivative eribulin...6

Figure 7. Bryostatin (left) and the Bryostatin analogue generated by Wender et al. (right) along with the PKC inhibitory concentrations and the number of synthetic steps requires for their respective production ${ }^{[29]}$.

Figure 8. Structure of the secondary metabolites isolated from Mycale hentscheli, peloruside A (top left), mycalamide A and B (top right), pateamine (bottom middle). .8

Figure 9. Structures of laulimalide (top left), epothilone A (top right) and peloruside A (bottom)

Figure 10. Cryo-EM reconstructions of microtubules by Prota et al. showing the binding sites of peloruside A (green) and epothilone A (purple). ${ }^{45}$ Used with permission (2019) Copyright (C) 2014 John Wiley \& Sons, Inc. All rights reserved. 10

Figure 11. Peloruside A sitting in the $\beta$-tubulin subunit binding site. Used with permission (2019) Copyright (C) 2014 John Wiley \& Sons, Inc. All rights reserved. .11

Figure 12. Cryo-EM, peloruside and the protofilament-protofilament interactions. Used with permission (2019) Copyright (C) 2017 Elsevier Ltd. All rights reserved. .12

Figure 13. Peloruside A (left) and the proposed peloruside analogue (right). .18

Figure 14. a) Overall view of the tubulin complex with a tubulin dimer. b and c) Close-up views of the interactions observed between $\beta$-tubulin and laulimalide (dark green; (b)) or peloruside (pale green; (c)). d) Close-up view of the superimposed laulimalide- and peloruside-binding sites showing only the bound ligand. Used with permission (2019) Copyright (C) 2014 John Wiley \& Sons, Inc. All rights reserved.

Figure 15. Selected natural (top row) and synthetic (bottom row) analogues of PelA that show changes in the $\mathrm{C} 3-\mathrm{C} 12$ section.

Figure 16. Stacked ${ }^{1} \mathrm{H}$ NMR of the four isolated one-pot silylation-acetylation products focusing on the $0-2.5 \mathrm{ppm}$ region. .33 
Figure 17. Four compounds isolated from the one-pot synthesis.

Figure 18. Stacked 1H NMR of one-pot silylation-acetylation focusing on the $3.3-6.6 \mathrm{ppm}$ region.

Figure 19.Crude $1 \mathrm{H}$ NMR spectra of the three different Lewis acid catalysed Ferrier style alkynylations focusing on the 2-7 ppm region.

Figure 20. Compounds isolated from the preliminary SnCl4 Ferrier reaction attempt. .39

Figure 21. ${ }^{1} \mathrm{H}$ NMR spectrum of compound 88-89 mixture. .39

Figure 22. Numbered carbon environments of compound 86. 41

Figure 23. Compound 86 showing the ID assignments based on the 1D and 2D NMR data. 43

Figure 24. Numbered carbon environments of compound $\mathbf{8 8}$. 43

Figure 25. Compound $\mathbf{8 8}$ showing the ID assignments based on the 1D and 2D NMR data. 44

Figure 26. Numbered carbon environments of compound 89. 46

Figure 27. Compound 89 showing ID assignments based on the 1D and 2D NMR data......46

Figure 28. ${ }^{1} \mathrm{H}$ NMR spectra of crude glycine adduct reaction (top, teal) and purified glycine adduct (bottom, red). 48

Figure 29. Numbered carbon environments of compound 90. .48

Figure 30. Compound 90 showing ID assignments based on the $1 \mathrm{D}$ and $2 \mathrm{D}$ NMR data 49 


\section{List of Schemes}

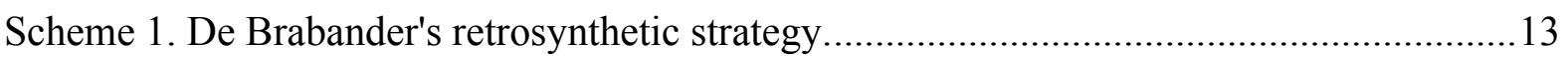

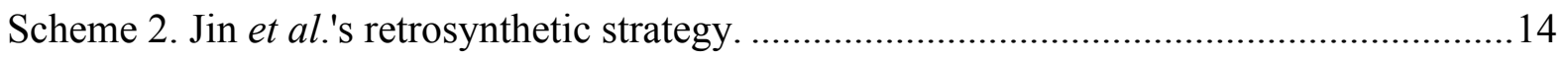

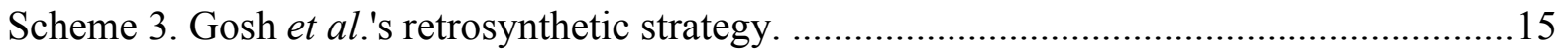

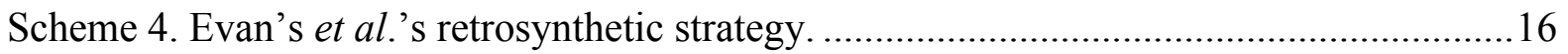

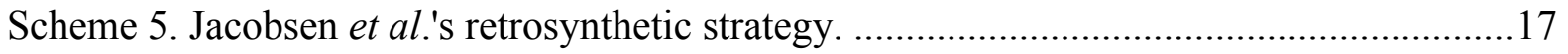

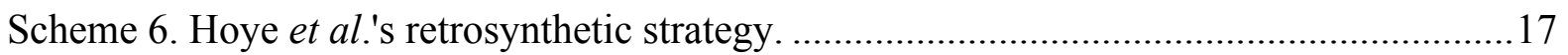

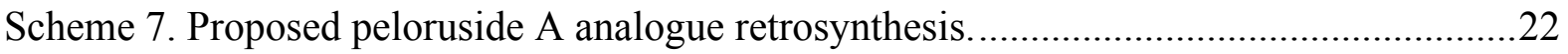

Scheme 8. Proposed peloruside A analogue retrosynthesis with the focus of this project highlighted in red.

Scheme 9.Proposed pyran fragment retrosynthesis using the numbering from the peloruside

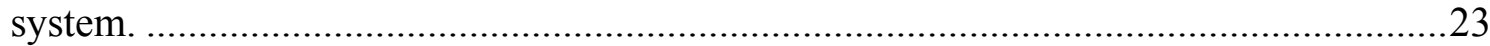

Scheme 10. Ferrier reaction mechanism on a D-glucal derivative .......................................24

Scheme 11. Synthesis of 6-trityl-3,4-diacetate-D-glucal 75 from tri-O-acetal-D-glucal..........25

Scheme 12. Proposed mechanism of TMS acetylene neucleophilic attack. ${ }^{65}$......................27

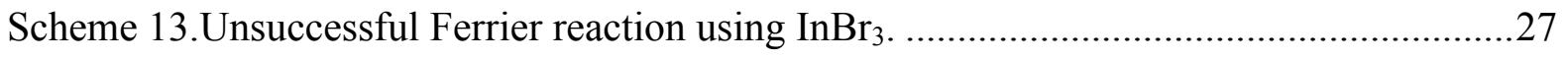

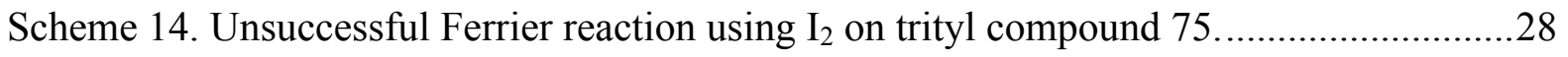

Scheme 15. First potential mechanism of Trityl loss during Ferrier reaction. .......................28

Scheme 16. Second potential mechanism of Trityl loss during Ferrier reaction....................28

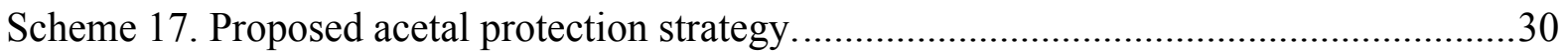

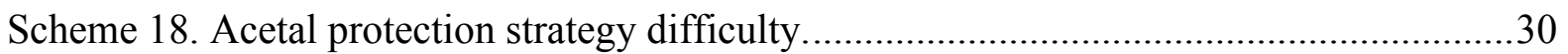

Scheme 19. Proposed synthetic route for the preparation of a TBS protected Ferrier

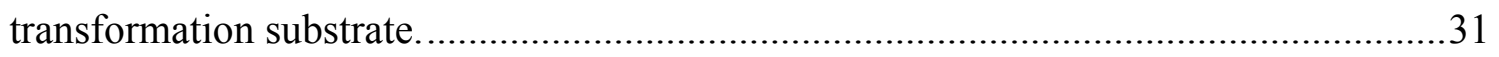

Scheme 20. First proposed Ferrier transformation protocol.............................................. 38

Scheme 21. Proposed mechanism for the acetyl transfer observed in the overnight $\mathrm{SnCl}_{4}$ Ferrier

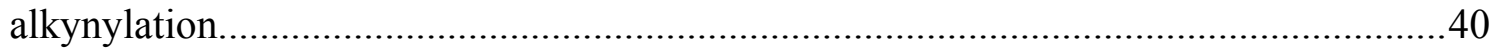

Scheme 22. Second Ferrier alkynylation with shorter, colder conditions. .............................40

Scheme 23. Third attempt at the $\mathrm{SnCl}_{4}$ catalysed Ferrier alkynylation designed to favour the

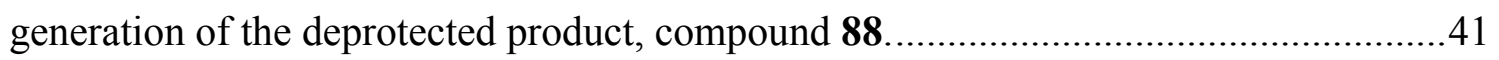

Scheme 24. TEMPO-BAIB oxidation of primary alcohol.................................................45

Scheme 25. Peptide coupling using Woon et al.'s conditions. .............................................. 47 
Scheme 26. Successful synthetic route for the production of the functionalised pyran fragment

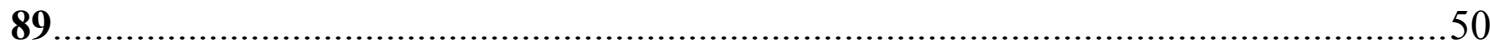

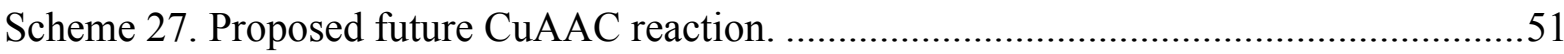

Scheme 28. Proposed stereochemical inversion at the anomeric position using cobalt

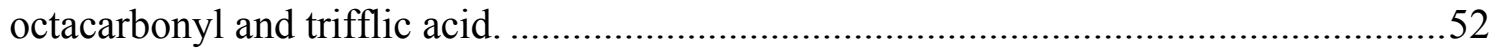

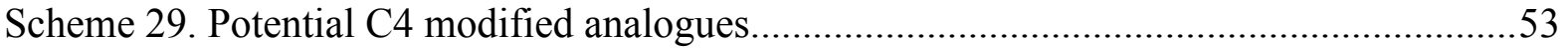




\section{List of Tables}

Table $1 . \mathrm{IC}_{50}$ values $(\mathrm{nM})$ of peloruside analogues in various cell lines. HL-60 = human leukaemia cells, P388 = murine leukaemia cells, 1A9 = human ovarian carcinoma cells,

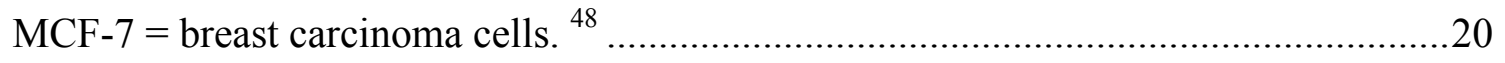

Table 2. Tabulated NMR spectroscopic data $\left(500 \mathrm{MHz}, \mathrm{CDCl}_{3}\right)$ for compound $\mathbf{8 6} \ldots \ldots \ldots \ldots \ldots . . . . .42$

Table 3. Tabulated NMR spectroscopic data $(500 \mathrm{MHz}, \mathrm{CDCl} 3)$ for compound $\mathbf{8 8}$.............44

Table 4. Tabulated NMR spectroscopic data (500MHz, CDCl3) for compound 89.............46

Table 5. Tabulated NMR spectroscopic data (500MHz, CDCl3) for compound 90 .............49 


\section{List of Abbreviations}

$\boldsymbol{\delta}$

${ }^{1}$ H NMR

${ }^{13}$ C NMR

Ac

$\mathrm{AcOH}$

$\mathrm{Ac}_{2} \mathrm{O}$

Aq.

BAIB

br.

cat.

Calc.

Conc.

COSY

CuAAC

Cryo-EM

d

dd

ddd

DIBAL

DIPEA

DNA

DMAP

DMF

DMSO

EDCI

eq.

EtOAc

H441

Hex

HL-60
NMR chemical shift (ppm)

Proton nuclear magnetic resonance

Carbon nuclear magnetic resonance

Acetyl

Acetic acid

Acetic anhydride

Aqueous

Bis(acetoxy)iodobenzene

Broad

Catalytic

Calculated

Concentration

Correlation spectroscopy

Copper catalysed alkyne azide cycloaddition

Cryogenic electron microscopy

Doublet

Doublet of doublets

Doublet of doublet of doublets

Diisobutylaluminium hydride

$N, N$-Diisopropylethylamine

Deoxyribonucleic acid

4-dimethylaminopyridine

$\mathrm{N}, \mathrm{N}$-dimethylformamide

Dimethyl sulfoxide

1-Ethyl-3-(3-dimethylaminopropyl)carbodiimide

Equivalents

Ethyl acetate

A human lung adenocarcinoma cell line

Petroleum ether, hexanes fraction

A human leukaemia cell line 


\begin{tabular}{|c|c|}
\hline HМBC & heteronuclear multi-bond correlation \\
\hline HOBt & Hydroxybenzotriazole \\
\hline HRFABMS & High resolution fast atom bombardment mass spectrometry \\
\hline HRMS & High resolution mass spectrometry \\
\hline HSQC & heteronuclear single quantum correlation \\
\hline HT & High throughput \\
\hline HTS & High throughput screening \\
\hline $\mathbf{H z}$ & Hertz \\
\hline HWE & Horner-Wadsworth-Emmons \\
\hline $\mathbf{I C}_{\mathbf{5 0}}$ & Half maximal inhibitory concentration \\
\hline IR & Infrared \\
\hline L.A & Lewis acid \\
\hline m & Multiplet \\
\hline $\mathbf{M}$ & Moles per litre \\
\hline $\mathbf{m} / \mathbf{z}$ & mass to charge ratio \\
\hline MCF-7 & A human breast carcinoma cell line \\
\hline MDA & Microtubule destabilising agents \\
\hline МeOH & Methanol \\
\hline МOM & Methoxymethyl ethers \\
\hline MSA & Microtubule stabilising agents \\
\hline MT & Microtubule \\
\hline $\mathbf{N E t}_{3}$ & Triethylamine \\
\hline NMR & Nuclear magnetic resonance \\
\hline NOE & Nuclear Overhauser effect \\
\hline OAc & Acetate \\
\hline P388 & A murine leukaemia cell line \\
\hline PC-3 & A human prostate cancer cell line \\
\hline $\mathbf{P F}$ & Protofilament \\
\hline PelA & Peloruside A \\
\hline PelB & Peloruside B \\
\hline PelC & Peloruside C \\
\hline PelD & Peloruside D \\
\hline PKC & Protein Kinase C \\
\hline
\end{tabular}




\begin{tabular}{ll} 
PMB & para-Methoxybenzyl \\
PMP & para-Methoxyphenyl \\
ppm & Parts per million \\
PPTS & Pyridinium $p$-toluenesulfonate \\
RCM & Ring closing metathesis \\
Rf & Retention factor \\
r.t. & Room temperature \\
S & Singlet \\
SAR & Structure-activity relationship \\
sat. & Saturated \\
t & Triplet \\
TBAF & Tetrabutylammonium fluoride \\
TBS & tert-Butyldimethylsilyl \\
TBS & tert-Butyldiphenylsilyl \\
TEMPO & (2,2,6,6-Tetramethylpiperidin-1-yl)oxyl \\
TES & Triethylsilane \\
THF & Tetrahydrofuran \\
Tr & Trityl \\
TLC & Thin layer chromatography \\
TMS & Trimethylsilyl \\
TMSOTf & Trimethylsilyl trifluoromethanesulfonate \\
UV & Ultraviolet \\
WHO & World Health Organization \\
\hline
\end{tabular}




\section{Compound Numbering}

Compounds derived from the glycal ring system were numbered according to IUPAC recommendations for carbohydrate compounds.

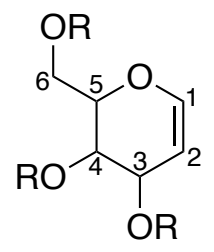

Numbering system used for naming glycal derived compounds.

The numbering system used for C-glycosides herein was based on the numbering system used for glycal derivatives so as to maintain continuity in numbering between compounds.

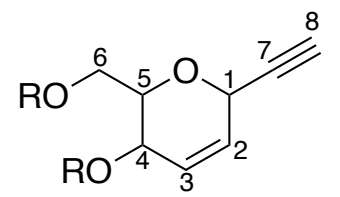

Numbering system used in C-glycosides. 


\section{Chapter 1. Introduction.}

\subsection{Cancer}

\subsubsection{BACKGROUND}

Cancer is a disease which occurs in many forms and is characterised by the ability of the cancer cells to replicate without control. ${ }^{1}$ According to the World Health Organization (WHO), cancer is currently recognised as the second largest cause of death globally, killing an estimated 9.6 million people in 2018 alone. ${ }^{2}$ The onset of cancer has been associated with a large number of different risk factors ranging from tobacco, alcohol and drug intake, to UV exposure and even gender. ${ }^{1}$ By understanding these factors, preventative methods have been developed in an attempt to reduce the incidence of the associated form of cancer. Although these preventative measures have shown a notable reduction in the incidence of certain forms of cancer, there are still around 18 million new cases worldwide every year. ${ }^{2}$ As there are still so many new cases of cancer, with numbers expected to rise due to an aging population, there is a huge demand for effective anti-cancer treatments. ${ }^{1}$

\subsubsection{TARgeting CANCERous Cells}

One of the most distinctive characteristics of cancer cells is their ability to rapidly proliferate, providing a useful feature for anti-cancer drug targeting. ${ }^{3}$ Cancer cells typically proliferate at far higher rates than most, but not all, somatic cells. This means that by targeting rapidly proliferating cells, cancer cells will be killed predominantly but other beneficial cells that also have a high rate of proliferation will also be killed in the process. ${ }^{3}$ There are currently many different methods to target these rapidly proliferating cells, each acting through a different mechanism. These anti-proliferative chemotherapeutics typically fall into one of the following classes: alkylating agents, antimetabolites, anti-microtubule agents, topoisomerase inhibitors or cytotoxic antibiotics. ${ }^{4}$

The alkylating agents used in cancer treatment usually work by cross linking the DNA bases between opposing strands. Once the cell attempts to replicate or repair this crosslinked DNA, it will lead to DNA damage and result in cell death. ${ }^{5}$ Antimetabolites work by mimicking metabolites that are essential for cell division but have a slightly altered structure. For example, nucleotide mimics may be incorporated into DNA during replication and once incorporated, prevent any further replication via inhibition of enzymes involved in DNA synthesis. This leads to incomplete DNA replication during mitosis and therefore apoptosis 'programed cell death'. 6 
Topoisomerase inhibitors normally work by preventing the topoisomerase enzyme from repairing the strand breaks they create during DNA unwinding. When the replication machinery reaches the strand break, the replicated DNA is cleaved leaving damaged and incomplete DNA. This incomplete and damaged DNA will then induce apoptosis. ${ }^{7}$ Cytotoxic antibiotics have a variety of different mechanisms but typically cause DNA damage leading to apoptosis. $^{4}$

\subsubsection{Anti-Microtubule Chemotherapeutics}

Microtubules (MTs) are vital components of the cellular cytoskeleton and play an essential role in proliferation. During cell replication, mitotic spindles form on opposite sides of the cell. Both spindles then extend MTs, some attach to the chromosomes of the cell while others attach to the opposing mitotic spindle. The chromosomes are then separated followed by microtubule shortening to allow for the next phase of the cell cycle. ${ }^{8}$ This means that the ability of MTs to both extend and contract plays a vital role in cell division. This ability is only possible due to the dynamic nature of the microtubules' structure. ${ }^{8}$

Structurally, MTs are made up of a repeated sequence of $\alpha$ and $\beta$ tubulin proteins. These $\alpha$ and $\beta$ tubulin proteins form heterodimers, which assemble longitudinally into protofilaments (PFs). These PFs associate with $\sim 12-14$ others to form a helical microtubule. As there are slight differences between $\alpha$-and $\beta$-tubulin, the helical symmetry of the MT is broken at the "seam", a discontinuity in the lateral contacts where interactions are heterotypic $(\alpha-\beta$ and $\beta-\alpha)$, in contrast with the rest of the lateral contacts. (Figure 1). This seam is thought to be a weak point in the MT lattice and may play a role in microtubule disassembly. To help with this, some stabilisation at the lateral contacts also occurs by a flexible hinge-like mechanism, involving the "M-loop" of the $\beta$-tubulin. This mechanism also helps to accommodate variation in MT diameter.

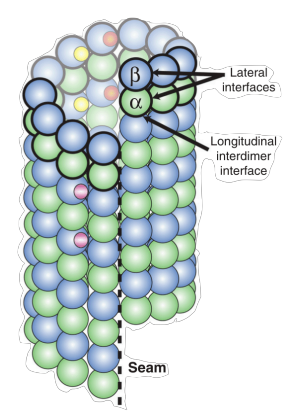

Figure 1. Helical structure of microtubules showing the $\alpha$ and $\beta$ tubulin subunits, the seam and location of the lateral interfaces. Used with permission (2019) Copyright (C) 2017 Elsevier Ltd. All rights reserved. 
As MTs require the ability to alter their length, the polymerisation and depolymerisation properties (i.e. dynamic instability) of these heterodimers is essential to MT function. Inhibition of this dynamic instability will interfere with the growth or contraction of the microtubule, in turn leading to the halting of cell division. ${ }^{4}$ Interrupting cell division in this manner will cause apoptosis of the halted cell, and thus lead to an effective way of killing rapidly proliferating cells.

Currently, two classes of drugs have been widely used as anti-microtubule chemotherapeutics, the microtubule destabilising agents (MDAs) such as the vinca alkaloids (Figure 2), and the microtubule stabilising agents (MSAs) such as the taxanes and epothilones (Figure 3). ${ }^{4}$ The MDAs typically inhibit the growth of the microtubules by increasing the rate of heterodimer dissociation. ${ }^{8}$ Using the opposite approach, the MSAs stabilise the microtubules by preventing the depolymerisation of the tubulin heterodimers, thereby inhibiting the contraction of the microtubules. ${ }^{8}$

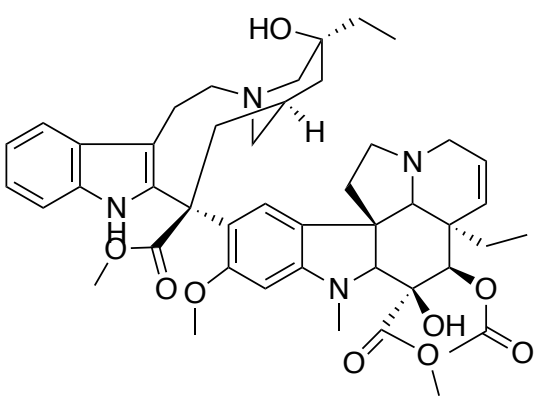

Vinblastine

(2)

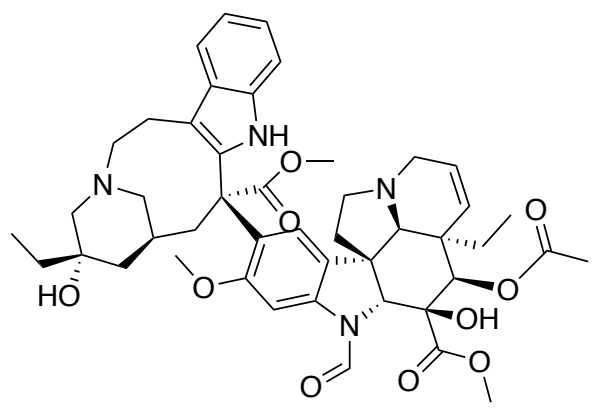

Vincristine

(3)

Figure 2. Commercially used drugs from the vinca alkaloids drug class.

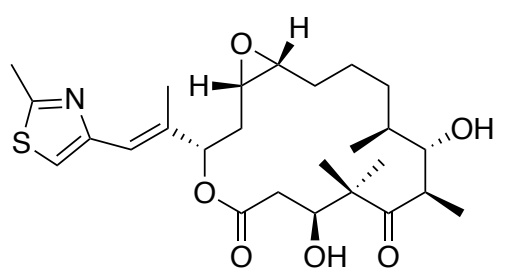

Epothilone A

(4)

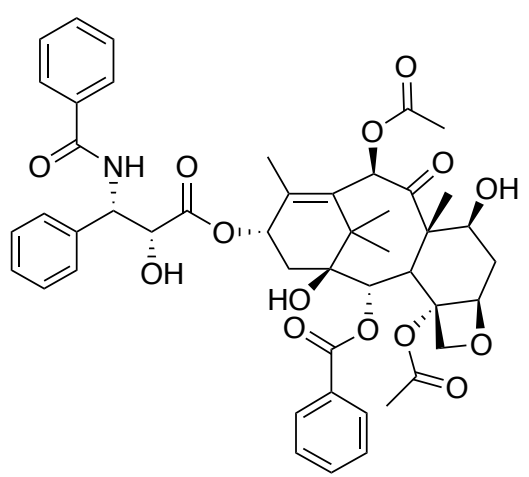

$\operatorname{Taxol}^{\circledR}$

(5)

Figure 3. Commercially used drugs from the Taxanes and Epothilones drug classes. 


\subsection{Natural products}

\subsubsection{Natural Products As A Source Of New Drugs}

Natural products or more precisely, secondary metabolites, have historically been a rich source of lead compounds for drug development programmes. ${ }^{9}$ A secondary metabolite is defined as a biomolecule which is not essential to survival but increases the competitiveness of the organism within its environment. ${ }^{9}$ As the production of these secondary metabolites comes at a metabolic cost to the organism, there would be little to no advantage for it to produce these compounds if they were not biologically active. ${ }^{10}$ Due to this, the chemical space these natural products occupy is typically more biologically relevant than that of the more common synthetic or combinatorial compounds. Essentially, this means that natural products have a greater chance of exhibiting some form of exploitable biological activity, making them more useful starting points for further drug development than their synthetic counterparts. Although useful, this does not guarantee an exploitable biological function for a number of reasons. First, the selective advantage a natural product provides may, in some cases, only be relevant for an earlier stage of evolutionary development. Secondly high affinity and specificity to a target protein requires the small molecule to adhere to strict structural and conformational limitations which will vary heavily between different species.

Although natural products have an advantage over their synthetic counterparts due to their greater initial biological relevance, they have often been overlooked by drug developers due to the number of difficulties they cause during traditional drug development programs. ${ }^{11}$ Due in part to the low yields, molecular complexity as well as cost and difficulty of isolation, natural product extracts were often tested as mixtures of compounds rather than a single purified compound. ${ }^{12}$ This would often cause additive, antagonistic or synergistic effects between compounds in the early bioassays. ${ }^{11}$ Furthermore, the low yields often led to testing the natural product in very low concentrations leading, in turn, to smaller phenotypic responses. These effects, coupled with the rise of high-throughput screening (HTS), which is able to assay libraries of up to five million molecules within weeks and is typically incompatible with natural product-based drug discovery programmes, led to drug developers avoiding natural-product based drug discovery programmes. ${ }^{13}$ Although they are not often screened in high-throughput (HT) assays, a recent study found that HTS of natural products had significantly higher hit rates than HTS of traditional synthetic and combinatorial libraries of compounds. ${ }^{14}$ 
Despite all these challenges, natural products have still been regularly used as a source for the discovery of new drugs, with more than half of all small-molecule pharmaceuticals approved in the US (as of 2014) being either natural products or derivatives. ${ }^{15}$ According to Newman and Cragg's reviews, ${ }^{16}$ natural products, their derivatives and their synthetic mimics actually make up approximately 50\% of all approved drugs (Figure 4) and 64\% of all anticancer drugs (Figure 5).

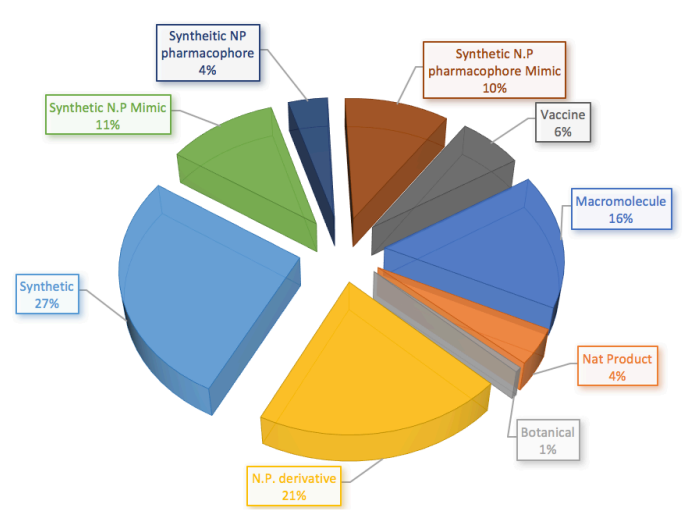

Figure 4. All FDA approved drugs as of $2014(n=1562)$.

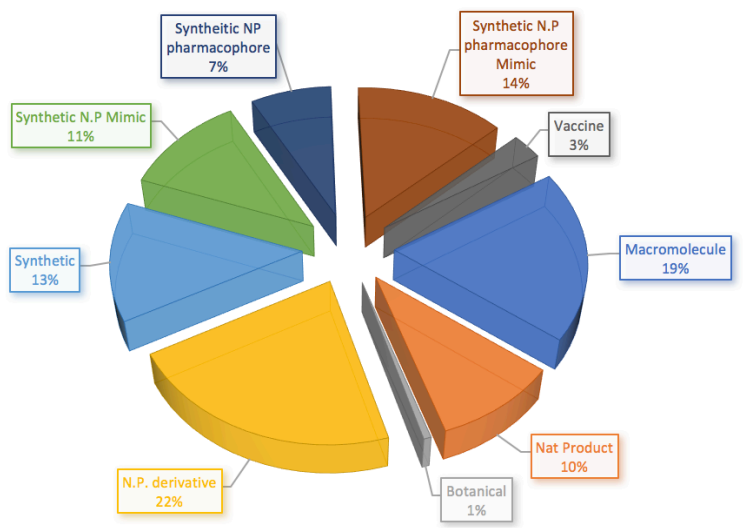

Figure 5. All anti-cancer drugs as of $2014(n=174)$.

\subsubsection{Sources Of Natural Products}

Secondary metabolites have been extracted from a large number of different organisms including: fungi, plants, bacteria and both marine and terrestrial animals. ${ }^{9}$ Of particular interest to this project, are the secondary metabolites isolated from marine sponges. Marine sponges are soft-bodied, immobile, have no circulatory or nervous system and rely on a very primitive immune system. ${ }^{17}$ On account of their lack of defences and advanced signalling systems, sponges rely heavily on the production of secondary metabolites as a means of both biological signalling and defence. ${ }^{17}$ A major difficulty sponges face when utilising secondary metabolites in an underwater environment is that the environment will cause them to quickly become very dilute. To overcome this, the secondary metabolites which are produced are typically very potent, allowing them to exhibit strong effects at low concentrations. ${ }^{17}$ Due to their heavy reliance on secondary metabolites, and the high potency of the metabolites produced, sponges are an ideal source of new bioactive compounds. One common problem with sourcing bioactives from sponges is that the metabolites are often in very low abundance. As a result of 
these low abundances, attempts at the total synthesis of the metabolite are often undertaken once the bioactive secondary metabolite has been isolated and its structure characterised.

\subsection{Analogues in natural product synthesis}

\subsubsection{SIMPLIFICATION}

Common to the total synthesis of many natural products are long sequences of consecutive reactions with resultant low overall yields. ${ }^{18}$ Owing to this, it can sometimes be more advantageous to produce simplified analogues, ideally with similar bioactivity, that require fewer sequential steps. There is arguably no greater example of this kind of major chemical simplification resulting in a simpler drug than the development of eribulin from halichondrin B (Figure 6). Halichondrin B is a large natural product (MW >1000 Da) isolated from the marine sponge Halichondria okadai in 1986 by Yoshimasa Hirata and Daisuke Uemura. ${ }^{19}$ During the early studies into the bioactivity of halichondrin B, it was found to have potent anti-cancer properties against L1210 leukaemia cell lines with an $\mathrm{IC}_{50}$ of $0.3 \mathrm{nM} .^{20}$ Unfortunately, the Halichondria okadai were reported to only yield halichondrin B in around $5 \times 10^{-6} \% .{ }^{19}$ One successful total synthesis was reported by Kishi and co-workers in 1992 but, despite being an incredible achievement, proved to be an inefficient process due to the structural complexity of the target. ${ }^{21-23}$ During these synthetic studies, Kishi and co-workers also found that the right half of the molecule was able to exhibit similar biological activity to halichondrin $\mathrm{B}$ ( $\mathrm{IC}_{50}$ values within one order of magnitude) in over 60 cancer cell lines. ${ }^{24}$ After this discovery, further synthetic and structure-activity relationship studies were done to improve potency and reduce the number of linear steps. ${ }^{25-28}$ This whole process eventually resulted in the more easily produced drug, eribulin.

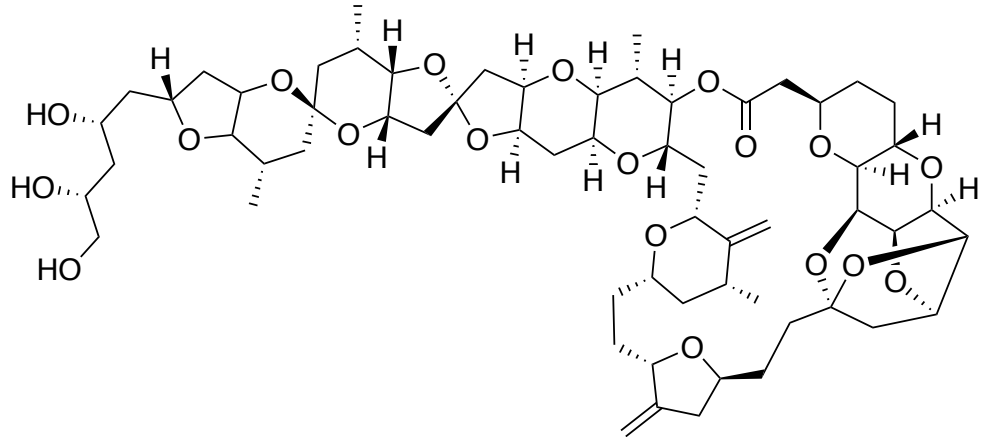

Halichondrin B

(6)

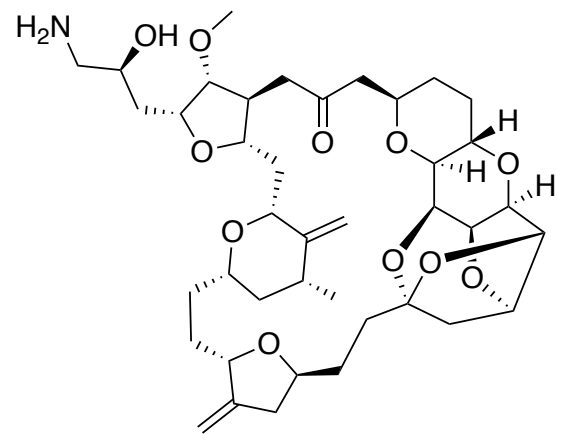

Eribulin

(7)

Figure 6. Structures of the natural products halichondrin B and its drug derivative eribulin 
Another great example of simplification, and perhaps more relevant to this project, is the development of the bryostatin analogue produced by Wender et al. in 2002. ${ }^{29}$ During their work towards a scalable synthesis of bryostatin, Wender et al. hypothesised that the C5-15 section may simply act as a 'spacer' group and the substituents were not necessary for biological function. Fortunately for Wender et al., this analogue turned out to not only be producible in fewer overall steps than bryostatin, but it was also more biologically active (Figure 7). ${ }^{29}$

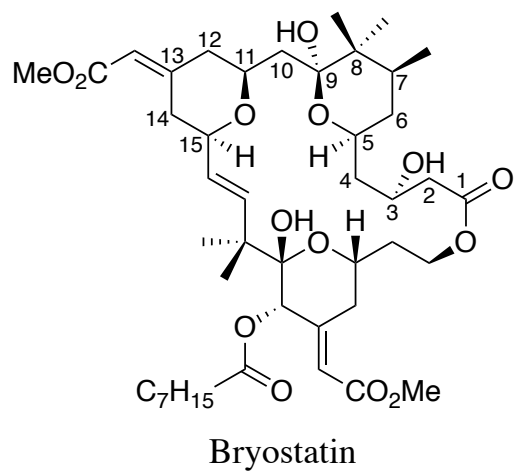

(8)

PKC $K_{\mathrm{i}}=1.4 \mathrm{nM}, 70-30$ steps

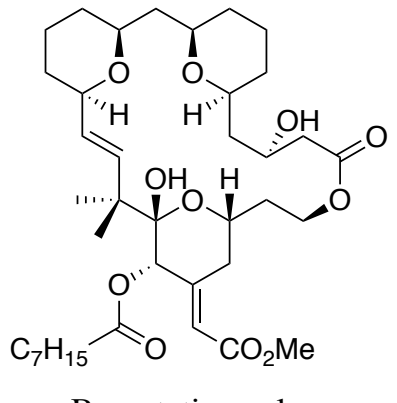

(9)

PKC $K_{\mathrm{i}}=0.25 \mathrm{nM}, 19$ steps

Figure 7. Bryostatin (left) and the Bryostatin analogue generated by Wender et al. (right) along with the PKC inhibitory concentrations and the number of synthetic steps requires for their respective production ${ }^{[29]}$.

The bryostatin and eribulin simplifications are just two examples of a number of successful natural product simplifications. Other simplifications, such as Steadman et al.'s analogue of the immunosuppressant sanglifehrin A, have also been achieved with a high degree of success. ${ }^{30}$

\subsubsection{StruCTURE-ACTIVITY RELATIONSHIP StUdiES}

In the field of medicinal chemistry, one of the principal ideas driving drug development is the idea that the binding of drug molecules to their target is directly related to the drug's observed activity. ${ }^{31}$ As such, understanding the interactions between a drug compound and target are of immense interest to medicinal chemists. One of the most common methods to study these interactions is to produce a variety of analogues, with slight alterations from the original compound, and measure the new bioactivity. ${ }^{32}$ Using this approach, medicinal chemists are able to identify structural alterations which improve the binding between target and drug as well as decrease drug binding to unintended targets in comparison to the original compound. This will then typically result in an improved drug potency and lower toxicity 
profile. ${ }^{32}$ Although the generation of analogues can be very difficult, thereby making structureactivity relationship studies very time consuming, it is still the most accurate way of determining the effect of various compound substitutions on the compound's bioactivity.

\subsection{Peloruside $A$}

\subsubsection{Discovery AND ISOLATION}

Peloruside A (Figure 8, 1) is a secondary metabolite discovered and isolated by A.Prof. Peter Northcote and his PhD student Lyndon West at Victoria University. ${ }^{33}$ It was isolated in 1999 from the marine sponge Mycale hentscheli found in New Zealand's Pelorus Sound. This sea sponge had also been found to contain mycalamide A and pateamine in previous studies (Figure 8, 10 and 11 respectively). ${ }^{34-36}$ With the use of HRFABMS, 1D and $2 \mathrm{D}{ }^{1} \mathrm{H}$ and ${ }^{13} \mathrm{C}$ NMR spectroscopy, Northcote, West and Battershill were able to elucidate the structure of peloruside A (PelA). ${ }^{33}$

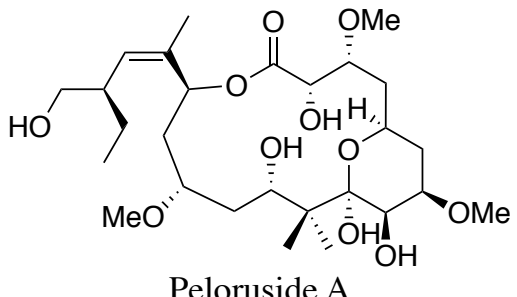

(1)

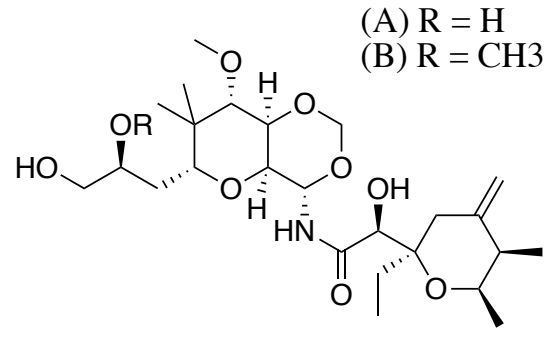

Mycalamide

(10)

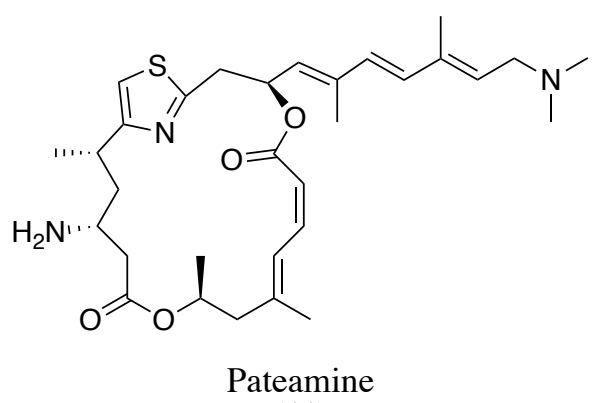

(11)

Figure 8. Structure of the secondary metabolites isolated from Mycale hentscheli, peloruside A (top left), mycalamide A and $B$ (top right), pateamine (bottom middle).

\subsubsection{BIOACTIVITY}

After the discovery and isolation of PelA, various studies led by Prof. John Miller, revealed its ability to act as an anti-cancer agent. ${ }^{33,37-46}$ In the preliminary studies, PelA along 
with the other two products isolated from Mycale hentscheli, mycalamide and pateamine, were used to inhibit proliferation of P388 murine leukemic cells at nanomolar concentrations. ${ }^{33}$ Further studies, both in vitro and in vivo, have shown PelA to be particularly cytotoxic across a large number of different cancer cell types. Of particular note are the HL-60 (human leukaemia), H441 (human lung adenocarcinoma), MCF-7 (human breast carcinoma) and PC3 (human prostate cancer) cell lines in which the $\mathrm{IC}_{50}$ concentrations were at or below $10 \mathrm{nM} .^{42-}$ ${ }^{44}$ Interestingly it was also found that PelA acted via a different mechanism than the two other isolated secondary metabolites. ${ }^{37}$ Further investigation was undertaken into its mode of action by various $\mathrm{PhD}$ students and academics from Victoria University which found that PelA was able to block cells at the G2/M checkpoint of the cell cycle. ${ }^{38-40,44,46}$ These, along with more recent studies, ${ }^{41-43,} 45$ established that PelA was able to cause the arrest of the cell cycle by stabilising the polymerised form of tubulin, similar to the taxane class of drugs. Although PelA was able to cause microtubule stabilisation similar to paclitaxel $\left(\operatorname{Taxol}^{\circledR}\right)$, it was found that rather than acting competitively with paclitaxel, it was actually able to act synergistically. ${ }^{44}$ This suggested that PelA may have potential use in the treatment of paclitaxel resistant strains of cancer or as a combination therapy.

\subsubsection{X-RAY STUDIES}

In 2014, the crystal structures of PelA, laulimalide and epothilone A (Figure 9) binding to $\beta$-tubulin were published by Prota et al. ${ }^{45}$ These structures not only helped prove PelA and laulimolide bound to a separate, unique binding site from paclitaxel ( Taxol $^{\circledR}$ ), but also helped to elucidate the mechanism of action for PelA, which was previously poorly defined. Confirming that PelA and laulimalide both bound to a unique site completely separate from the paclitaxel and epothilone site was a significant achievement as it gave a more detailed understanding as to why PelA could act synergistically with paclitaxel but competitively with laulimalide. ${ }^{46}$ These crystal structures of laulimalide and PelA in their respective $\beta$-tubulin binding site, coupled with previous cryo-EM reconstructions of microtubules, also indicated that laulimalide and PelA may be able to interact with a second tubulin dimer across protofilaments (Figure 10). Superimposing the X-ray crystal structures onto the cryo-EM reconstructions provides a particularly powerful method of visualisation as it can help compensate for each technique's individual weakness. The X-ray crystallography technique, although powerful, is limited by the inability of microtubules to crystalise as intact structures. This means that, by itself, the X-ray data is unable to show any interactions that may occur 
between neighbouring protofilaments. The cryo-EM reconstruction technique on the other hand, is able to visualise the intact microtubules but lacks the atomic resolution of X-ray crystallography. By combining the two methods, one can better visualise the binding and interactions of PelA. As the structures presented were models of the X-ray data superimposed onto cryo-EM reconstructions of natural microtubules rather than X-ray data superimposed onto cryo-EM microtubule reconstructions with bound PelA, the model presented may not accurately reflect the true binding properties of PelA.

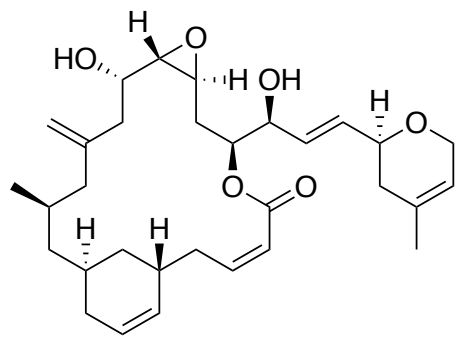

Laulimalide

(12)

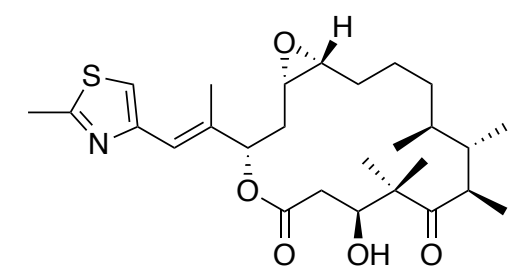

Epothilone A

(4)

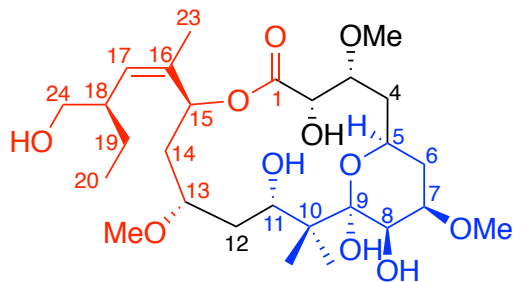

Peloruside A

(1)

Figure 9. Structures of laulimalide (top left), epothilone A (top right) and peloruside A (bottom).
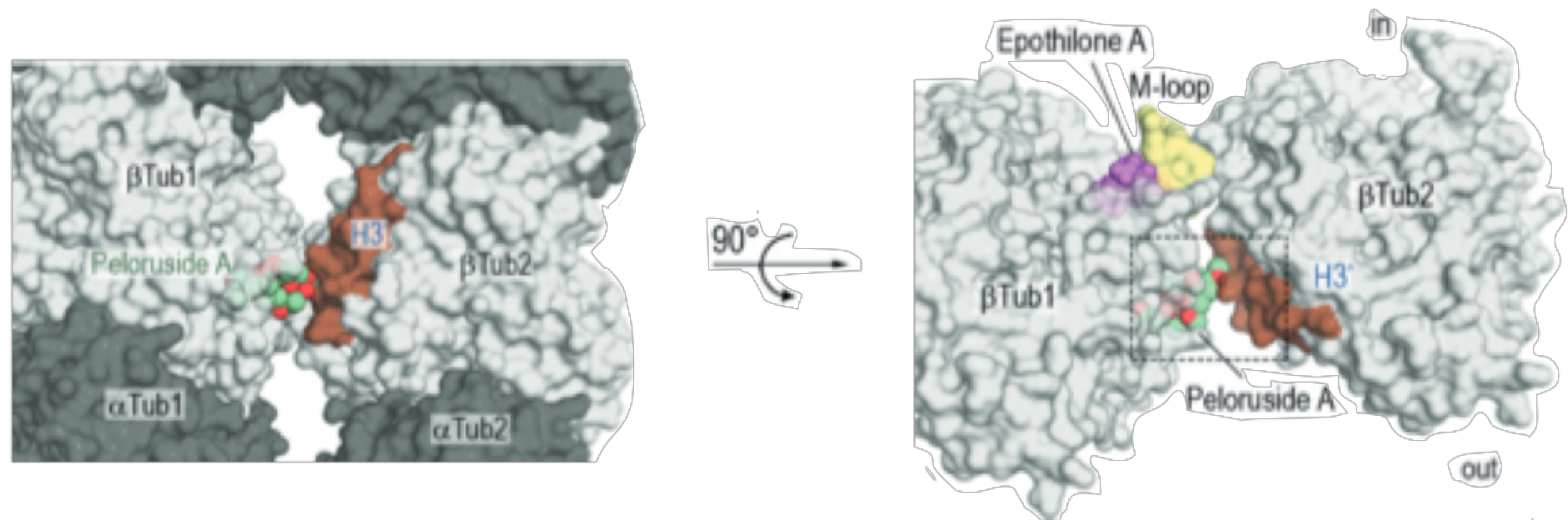

Figure 10. Cryo-EM reconstructions of microtubules by Prota et al. showing the binding sites of peloruside A (green) and epothilone A (purple). ${ }^{45}$ Used with permission (2019) Copyright (C) 2014 John Wiley \& Sons, Inc. All rights reserved.

Regardless of the problems with modelling the inter-protofilament interactions, the Xray data from Prota et al.'s study was able to draw two other major conclusions about the 
binding and activity of PelA. First, the X-ray structures were able to show that crosstalk between the laulimalide/ PelA and taxane sites occurs via the M-loop of $\beta$-tubulin, potentially explaining some of the synergistic effects seen between PelA and paclitaxel. Secondly, this data also showed the importance of the C1, C13-C20, C23-24 section of PelA (Red fragment of PelA in Figure 9) in the $\beta$-tubulin binding (Figure 11).

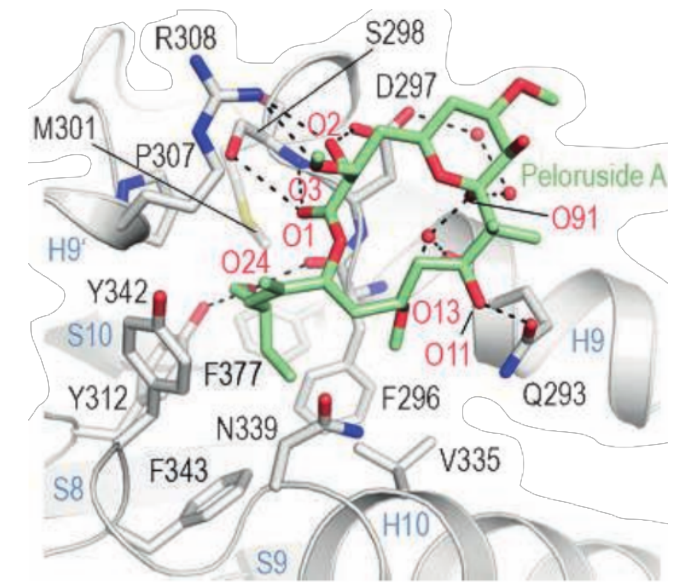

Figure 11. Peloruside A sitting in the $\beta$-tubulin subunit binding site. Used with permission (2019) Copyright (C) 2014 John Wiley \& Sons, Inc. All rights reserved.

In 2017, to help further investigate the protofilament-protofilament interactions caused by PelA, cryo-EM studies were done by Kellog et al. where they obtained cryo-EM reconstructions of microtubules with either PelA bound, paclitaxel bound or a combination. ${ }^{47}$ These studies further indicated that the $\mathrm{C} 5-10$ section of peloruside (Figure 9 blue fragment of PelA) does indeed play a role in the interactions with the neighbouring protofilament (Figure 12). The study also demonstrated that the MSAs paclitaxel, zampanolide, and peloruside have different effects on the MT lattice, indicating different stabilisation mechanisms. It was found that peloruside did indeed appear to strengthen the lateral contacts between adjacent PFs but it also appeared to alter the lateral contacts at the seam, decreasing the offset between adjacent protofilaments at the seam, and thereby improving the overall helical structure of the microtubule. ${ }^{47}$ Interestingly, this study also found that in the doubly bound (both PelA and paclitaxel in their respective binding sites) microtubule structure, the lattice effects of the peloruside binding were dominant over the lattice effects of the paclitaxel. This result makes it difficult to explain the cooperative cytotoxicity effects observed between PelA and other taxane-site drugs. Kellog et al. theorised that this finding may not be applicable to an in vivo context as in their study, the ratio of tubulin to drug was around 1:1, while in an in vivo model the proportion is more typically $100: 1$ or $50: 1$. This, coupled with the fact that peloruside 
binding has no effect on taxane binding, means that the chances that a single tubulin molecule in the cell having both a molecule of PelA and another of taxane bound, are far below 1\%. This would infer that the simultaneous binding is likely not the reason for the synergistic effect observed in peloruside-taxane treatments. Overall, this demonstrates that there may still be considerably more to learn about the mode of action of peloruside.

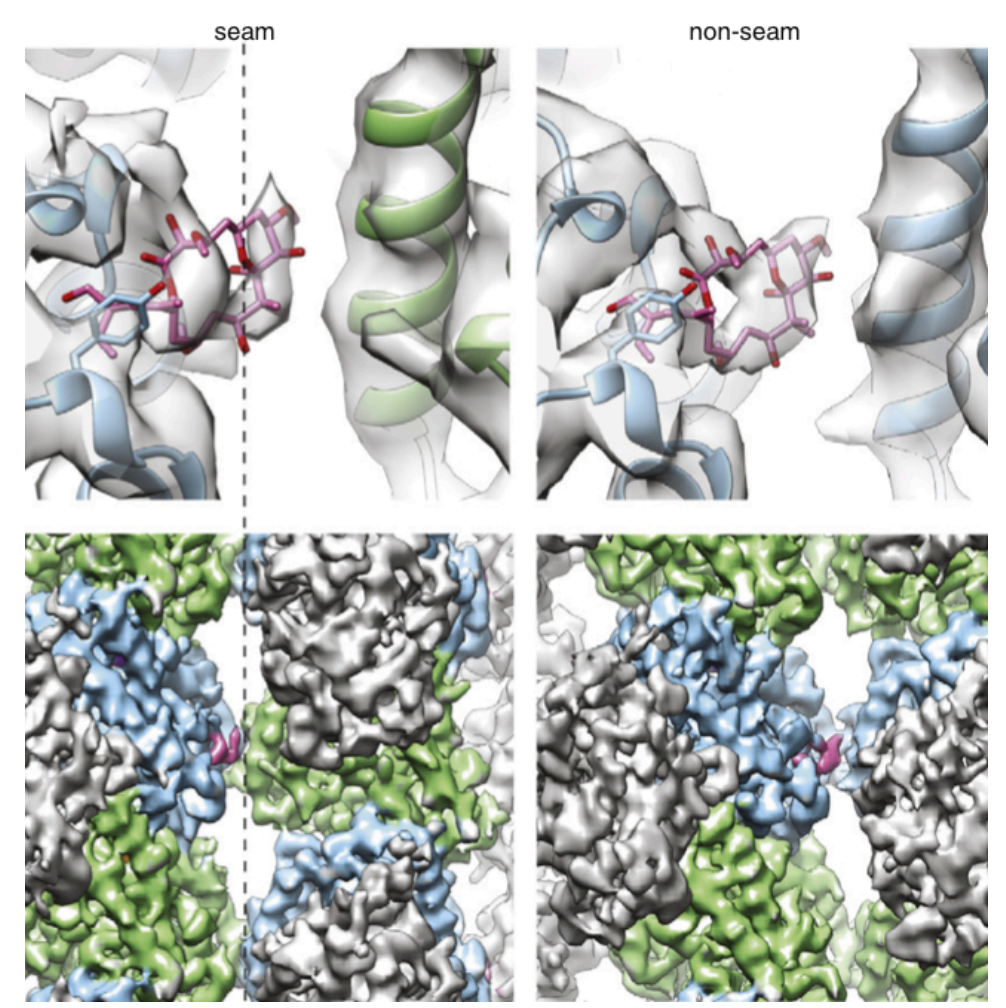

Figure 12. Cryo-EM, peloruside and the protofilament-protofilament interactions. Used with permission (2019) Copyright (C) 2017 Elsevier Ltd. All rights reserved.

\subsubsection{PreVious Synthetic Attempts}

To date, six successful total syntheses of PelA have been published. ${ }^{48}$ The first of these attempts was performed by De Brabander and co-workers in 2003, albeit making the enantiomer of natural peloruside (Scheme 1). This attempt focused on the use of an aldol coupling between fragments $\mathbf{1 3}$ and $\mathbf{1 4}$ to generate the carbon skeleton of PelA followed by a subsequent Mitsunobu macrolactonisation to form the macrocycle. The side-chain fragment 13 was synthesised via an esterification between fragments $\mathbf{1 6}$ and $\mathbf{1 7}$ and a ring closing metathesis (RCM) to form the $Z$-substituted 6-membered ring 15 which was then followed by a subsequent methylation and ring opening to form fragment 13. The aldehyde functionality of the bulkier fragment 14 was installed through an allylation using allyldiethylborane to give a terminal 
double bond followed by diol formation and cleavage using $\mathrm{OsO}_{4}$ and $\mathrm{NaIO}_{4}$ respectively. The pyran section of fragment $\mathbf{1 4}$ was obtained by reduction and functionalisation of intermediate 19 which was made from an aldol addition between aldehyde 21 and ketone 20. Aldehyde 21 was prepared over four steps from aldehyde 22 using a Brown allylation.

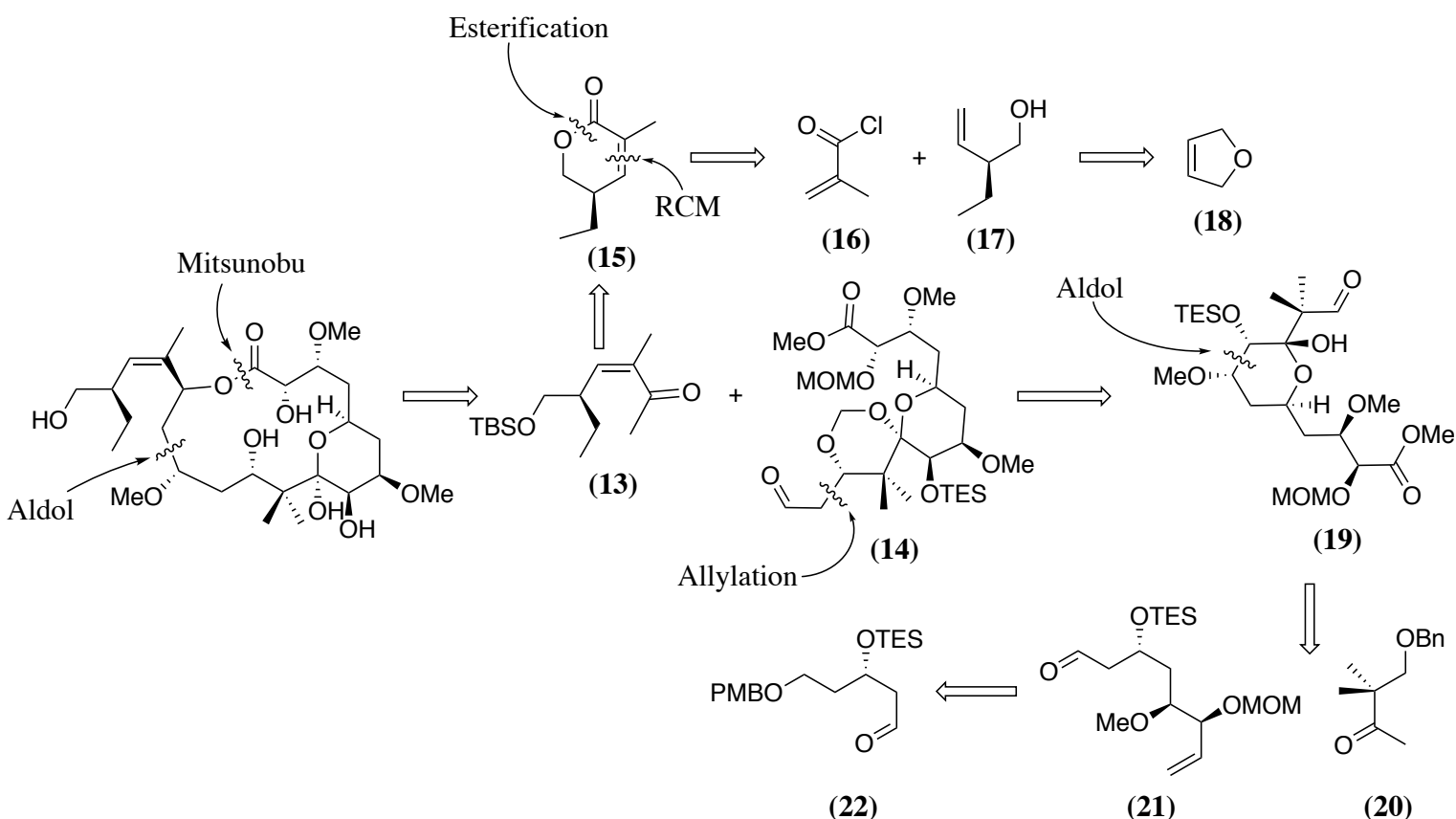

Scheme 1. De Brabander's retrosynthetic strategy.

Jin et al. published a second successful synthesis two years later, in 2005 (Scheme 2). ${ }^{49}$ In this attempt the complete carbon skeleton of PelA was obtained through an aldol reaction between ketone $\mathbf{2 4}$ and aldehyde $\mathbf{2 3}$ followed by a Yamaguchi macrolactonisation to close the macrocycle. Unlike the approach by De Brabander and co-workers, the pyran was formed after the successful macrolactonisation. Ketone $\mathbf{2 4}$ was prepared from $(R)$-4-benzyl-3butyryloxazolidin-2-one 31 using an Evans auxiliary-mediated addition to form the alcohol intermediate 30. This intermediate then underwent a Still-Gennari modification of the HornerWadsworth-Emmons (HWE) olefination to produce the trisubstituted Z-alkene 29. After further modification, a stereoselective Mukaiyama aldol reaction was conducted to give the desired ketone fragment $\mathbf{2 4}$. The synthesis of the aldehyde fragment $\mathbf{2 3}$ was done using a diastereoselective Evans aldol reaction between the oxazolidinone $\mathbf{2 5}$ and aldehyde $\mathbf{2 6}$. 


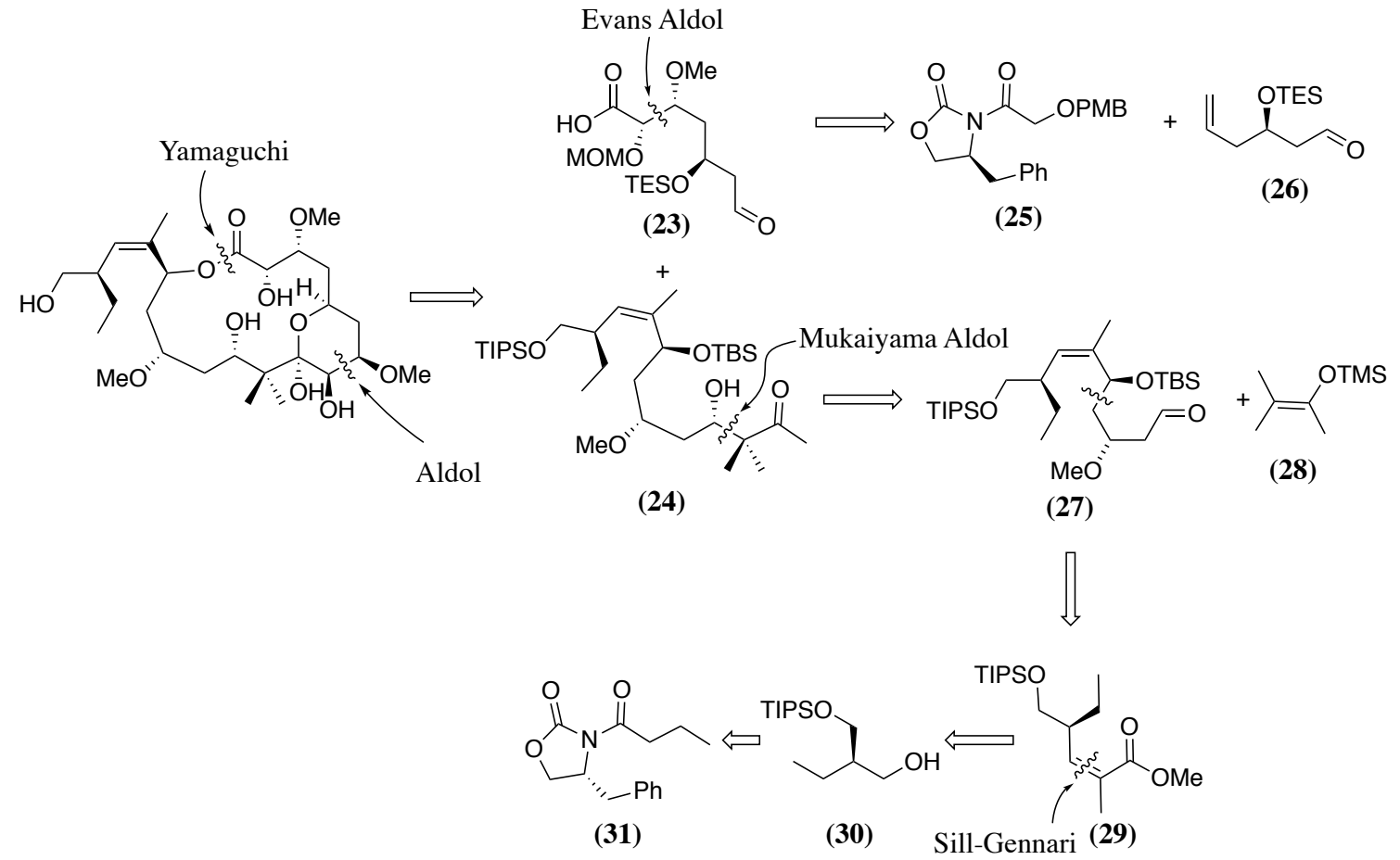

Scheme 2. Jin et al.'s retrosynthetic strategy.

The third total synthesis of PelA was performed by Gosh et al. in 2008 (Scheme 3). ${ }^{50}$ This approach employed a reductive aldol addition between fragments $\mathbf{3 2}$ and $\mathbf{3 3}$ to form the carbon skeleton of PelA followed by a Yamaguchi macrocyclisation. Similar to the strategy of Jin et al., formation of the pyran was done post-macrocyclisation. The enone fragment 31, was synthesised from (-)-2,3-O-ispropylidene-D-threitol 39, which already possesses two of the required stereocenters. After suitable transformation, a Brown allylation was performed on compound 39 to generate alkene 38. After diol formation and oxidative cleavage to form an aldehyde, the Ando HWE olefination was performed to generate the $Z$-alkene 37. Asymmetric Sharpless dihydroxylation of the alkene 37 with AD-mix- $\alpha$, produced the 7,8-diol with the desired stereochemistry. The enone functionality was then installed using a Grignard reagent followed by Dess-Martin periodinane oxidation. The side-chain fragment $\mathbf{3 3}$ was synthesised starting from $(R)$-4- benzyl-3-butyryloxazolidin-2-one 36. The Evans auxiliary-mediated addition to the oxazolidinone $\mathbf{3 6}$ followed by auxiliary cleavage resulted in the production of compound 35. Oxidising compound 35 followed by an Ando HWE olefination, resulted in the formation Z-trisubstituted olefin 34. Successive Brown asymmetric allylborations were employed to eventually produce aldehyde $\mathbf{3 3}$. 


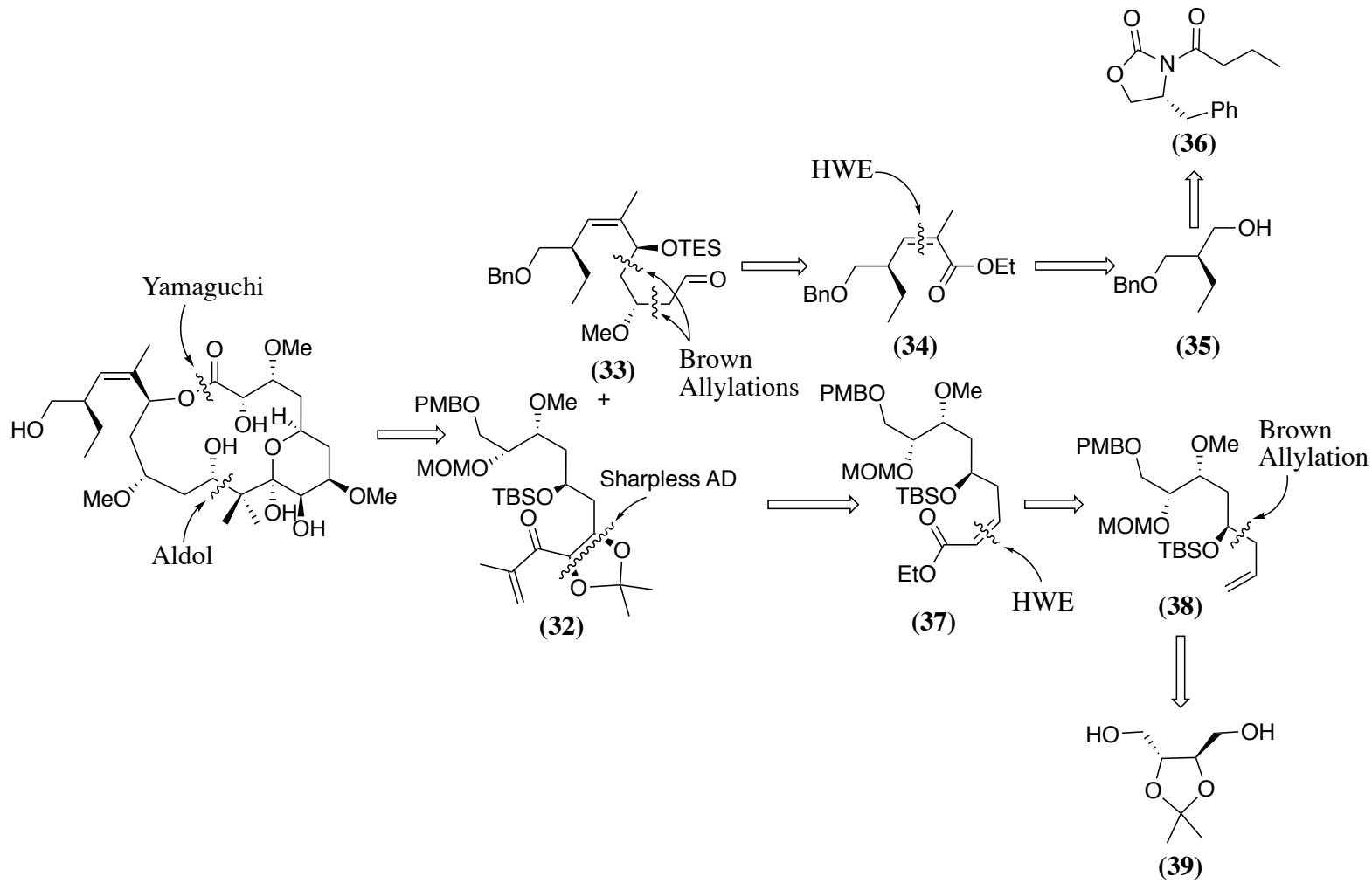

Scheme 3. Gosh et al.'s retrosynthetic strategy.

A year later, in 2009, Evans et al. performed another total synthesis of PelA (Scheme 4). ${ }^{51}$ As with the previous syntheses, the carbon skeleton of the PelA was generated using aldol reactions followed by a macrolactonisation. In this case the carbon skeleton was formed from a series of aldol reactions between fragments 40,42 and 45. A Yamaguchi macrolactonisation procedure was performed to close the macrocycle with the pyran ring forming spontaneously after global deprotection. Ketone fragment $\mathbf{4 0}$ was synthesised from oxazolidinone $\mathbf{4 1}$ using an Evans aldol reaction. The synthesis of aldehyde fragment $\mathbf{4 2}$ was achieved in seven steps from (S)-pantolactone 44. Using a Weinreb-amide ring opening procedure with subsequent olefination on compound 44 resulted in the tri substituted alkene $\mathbf{4 3}$. The side-chain $\mathbf{4 5}$ was produced using via brown allylation of alkene $\mathbf{4 6}$ which in turn was synthesised via an Ando HWE olefination of alcohol 47. 

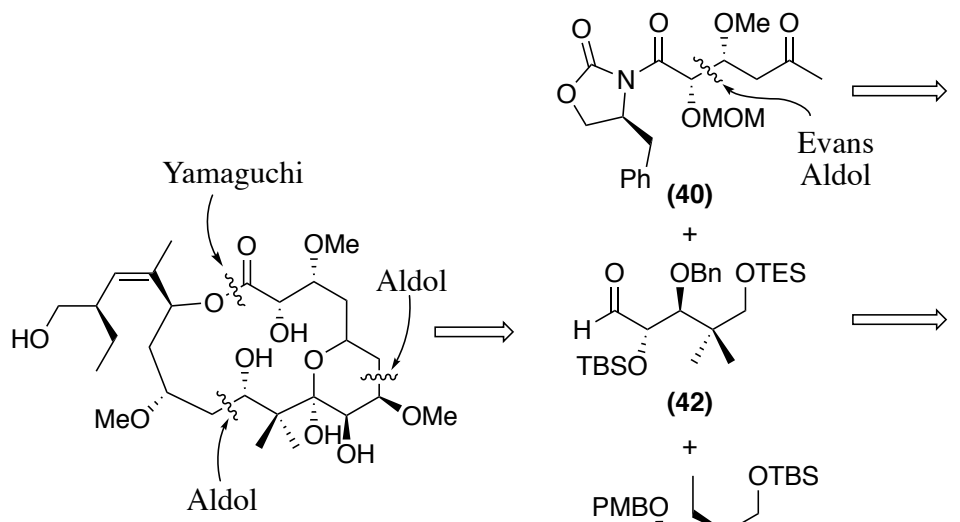

TBSŌ

(42)

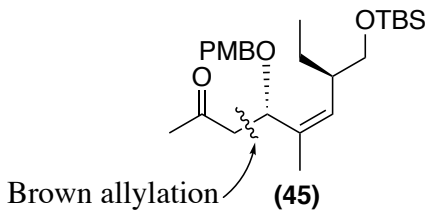

(45)<smiles>COCC(=O)N1C(=O)OCC1Cc1ccccc1</smiles>

(41)

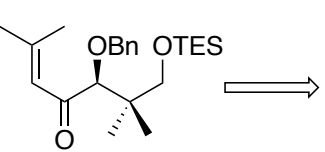

(43)

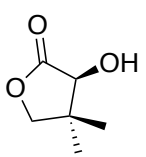

(44)<smiles>C=CCCC(CO)C(CC)C(CC)CO</smiles>

Scheme 4. Evan's et al. 's retrosynthetic strategy.

In 2010 Jacobsen and co-workers performed the fifth successful synthesis again using a combination of aldol and Yamaguchi reactions to form the macrocycle (Scheme 5). ${ }^{52}$ The two main fragments, enone 47 and aldehyde 51, were joined together using an L-selectridemediated reductive aldol reaction to form the carbon skeleton in the same way as Gosh et al. After the assembly of the carbon skeleton, the macrocycle was formed via Yamaguchi macrocyclisation with the pyran ring closed upon global deprotection. The enone fragment $\mathbf{4 7}$ was formed through the ring opening and subsequent Grignard reaction on the pyran $\mathbf{4 8}$. Compound 48 was then generated in turn, through a hetero-Diels-Alder reaction of diene $\mathbf{5 0}$ with the aldehyde derivative of epoxide 49. The diastereoselectivity of the Diels-Alder reaction was effectively controlled by the addition of the chiral chromium-Schiffs base complex. The side chain fragment 51, was generated using a bromine-lithium exchange on the bromoalkene $\mathbf{5 4}$ to facilitate the reaction with aldehyde $\mathbf{5 2}$ and form a $Z$-alkene.

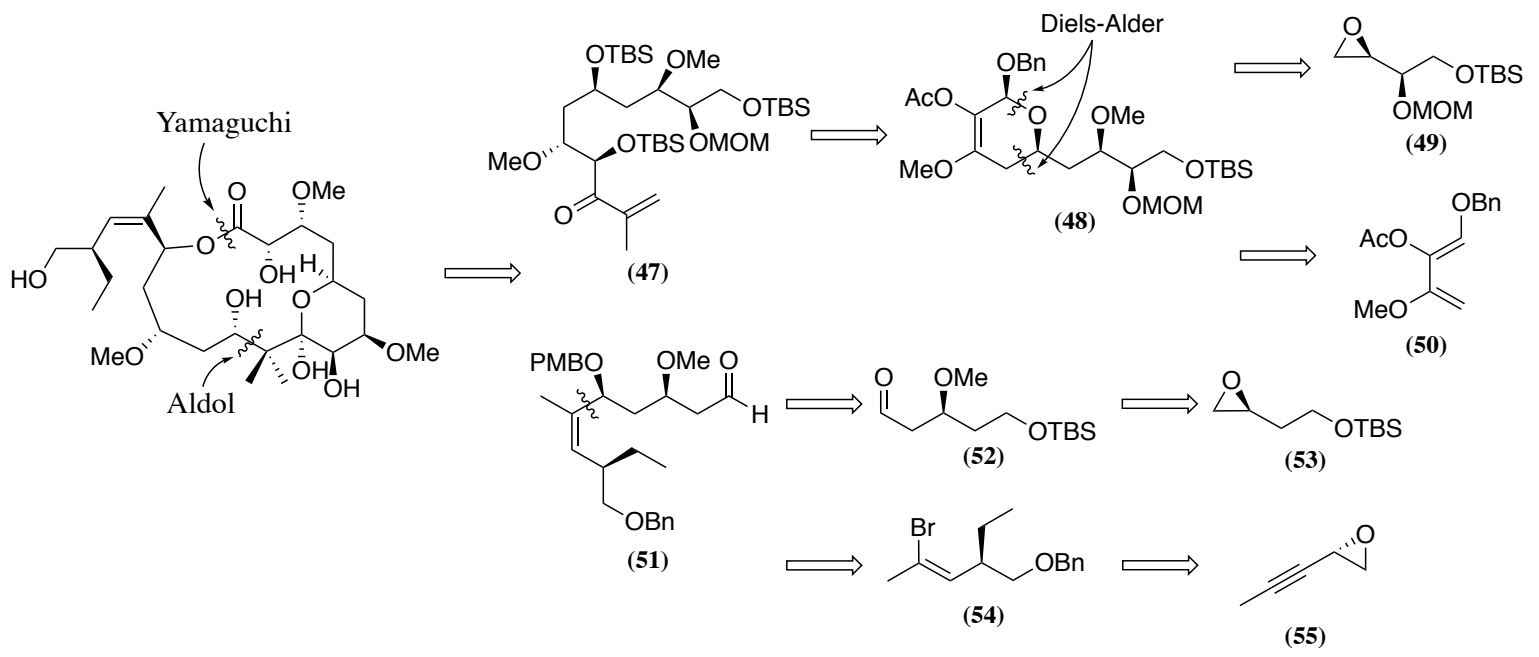


Finally Hoye et al. published a sixth synthesis in 2010 (Scheme 6). ${ }^{53}$ As with the previous syntheses, two main fragments (aldehyde 56 and ketone 60) were coupled using aldol methodology and macrocycle formation achieved by the Yamaguchi protocol (Scheme 6). Of particular importance to this synthesis was the enantioselective tetramethylguanidinepromoted (TMG) desymmetrising lactonisation of compound $\mathbf{5 8}$ in preparation for the generation of the aldehyde fragment 56. Side chain fragment 60 was generated through the ring opening and reduction of intermediate $\mathbf{6 1}$ with subsequent modifications at the ketone position via Blaise reaction, hydrolysis and decarboxylation. Intermediate $\mathbf{6 1}$ was itself generated through a Steglich esterification of oxazolidinone $\mathbf{6 2}$ followed by a relay ring-closing metathesis.

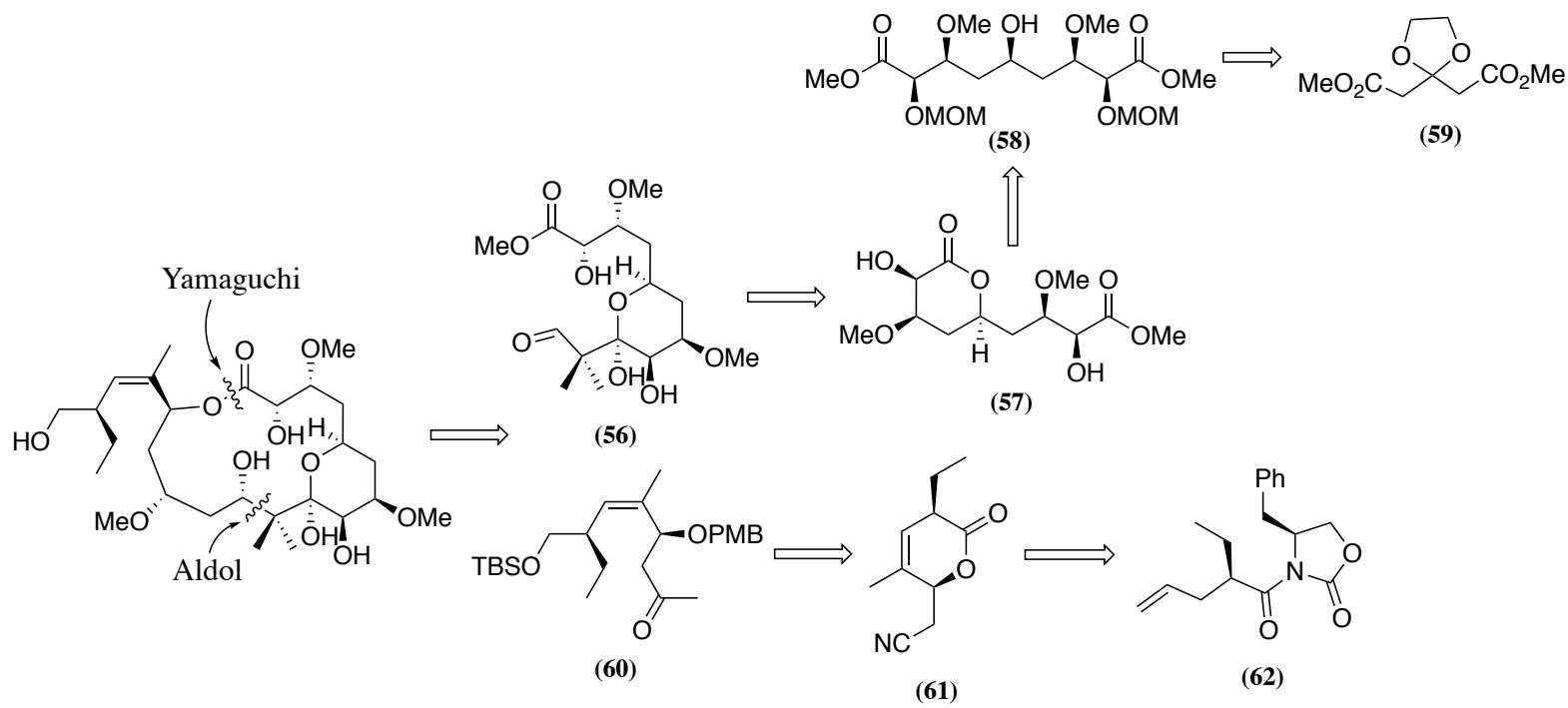

Scheme 6. Hoye et al.'s retrosynthetic strategy.

Unfortunately, even with all of the different recorded approaches, none have been able to successfully develop a method which is suitable for industrial scale up. ${ }^{48}$ 


\subsection{Project Aims and Objectives}

\subsubsection{Peloruside A, ITS KNOWN ANALOGUES AND THE PROPOSED NEW ANALOGUE}

Inspired by the success of previous natural product simplifications, ${ }^{28-30}$ particularly the 'spacer' concept of the bryostatin analogues (see section 1.3.1), Paul Teesdale-Spittle, Joanne Harvey and Ethan Woolly have proposed a simplified analogue of PelA with modifications in line with the observations from the crystal structures/Cryo-EM reconstructions of PelA in $\beta$ tubulin (Figure 13).

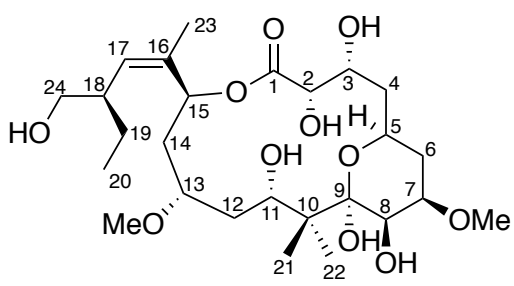

Peloruside A (1)

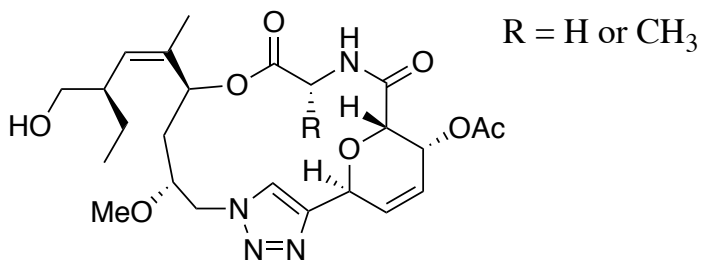

Our proposed PelA analogue (63)

Figure 13. Peloruside A (left) and the proposed peloruside analogue (right).

As previously described (see section 1.4.3), the C1, C13-C20 and C23-24 sections of peloruside are crucial in the binding to the $\beta$-tubulin binding pocket. ${ }^{45}$ Since this is important to binding, it has remained unchanged in the final proposed analogue. Usefully, this fragment or very similar, has also been one of the typical major fragments of previous PelA syntheses (See section 1.4.4). As established in Kellog et al. and Prota et al.'s peloruside studies, the C5C11 section of PelA appears to have some degree of interaction with the neighbouring protofilament. When comparing the sections of PelA and laulimalide which interact across protofilaments (PFs), there appears to be no well-defined stabilising interactions which occur in both compounds as shown below (Figure 14). ${ }^{45,47}$ 
a)

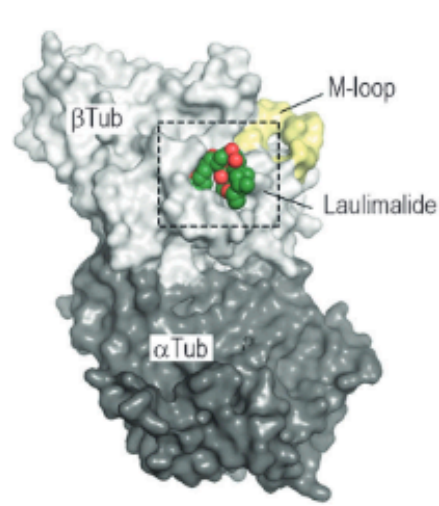

c)

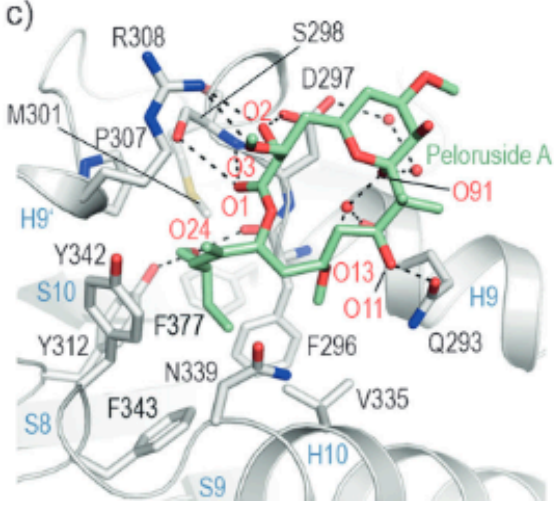

b)

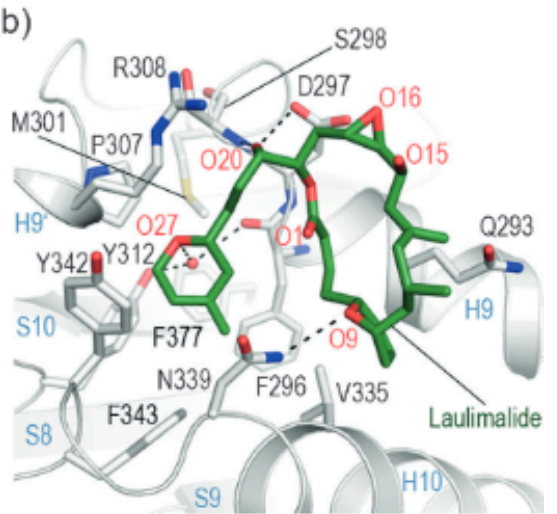

d)

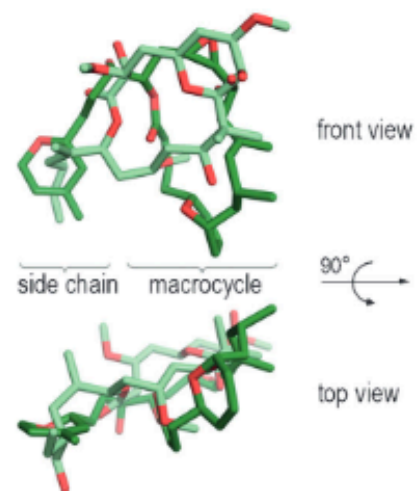

Figure 14. a) Overall view of the tubulin complex with a tubulin dimer. $b$ and c) Close-up views of the interactions observed between $\beta$-tubulin and laulimalide (dark green; (b)) or peloruside (pale green; (c)). d) Close-up view of the superimposed laulimalide- and peloruside-binding sites showing only the bound ligand. Used with permission (2019) Copyright $\odot 2014$

John Wiley \& Sons, Inc. All rights reserved.

To further investigate the effects of substitutions on the C3-C12 section of peloruside, it is useful to compare the bioactivity of PelA against its natural and synthetic analogues. Comparing the bioactivity between the structurally similar PelA and PelB (Figure 15), the exchange of the methoxy group at $\mathrm{C} 3$ for the hydroxy group appears to increase the $\mathrm{IC}_{50}$ values in $1 \mathrm{~A} 9$ cell line $\sim 3$-fold while the $\mathrm{IC}_{50}$ values in the HL-60 cell line remain unchanged (Table 1). ${ }^{48}$ This may potentially imply that the bulk of the substituent at $\mathrm{C} 3$ may not play a large role in either $\beta$-binding or in the adjacent PF interactions. ${ }^{48}$ This would be important for the proposed analogue $\mathbf{6 3}$, as it is planned to exchange the $\mathrm{C} 3$ carbon for an $\mathrm{NH}$ group, meaning that the $\mathrm{C} 3$ methoxy group will no longer be present. As both the amidic and methoxy groups have the ability to hydrogen bond, as well as the findings that the bulk of the polar group at C3 appears to have little effect on overall binding, this substitution should hopefully not affect the bioactivity of the proposed analogue severely. 


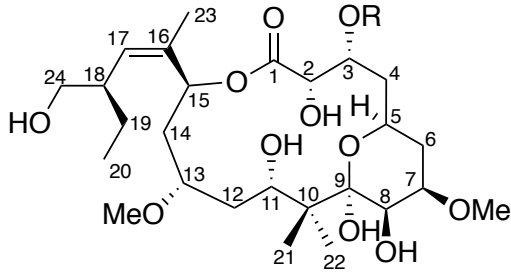

Peloruside A $\left(\mathbf{1} \mathrm{R}=\mathrm{CH}_{3}\right)$

Peloruside $\mathrm{B}(\mathbf{6 4} \mathrm{R}=\mathrm{H})$

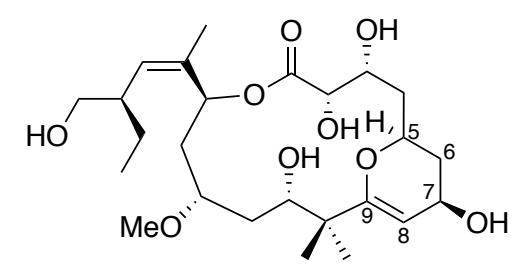

Peloruside C (65)

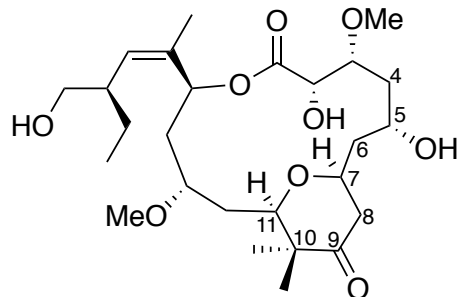

Peloruside D (66)

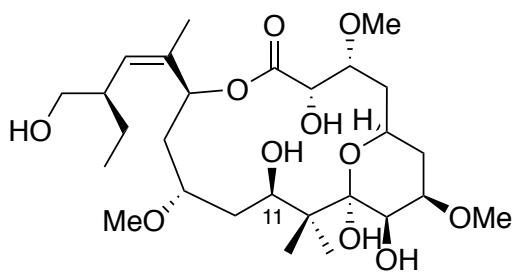

C11-epi-PelA (67)

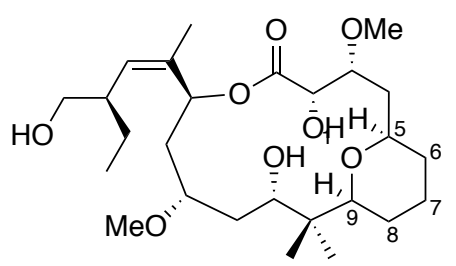

7-Desmethoxy-8,9-dideoxy PelA

(68)

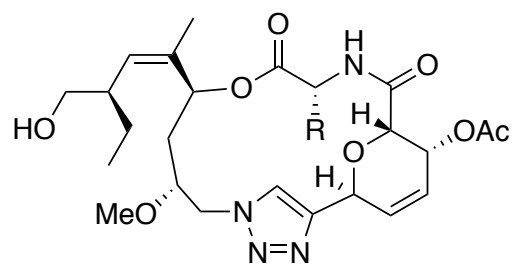

Our proposed PelA analogue (63) $\mathrm{R}=\mathrm{H}$ or $\mathrm{CH}_{3}$

Figure 15. Selected natural (top row) and synthetic (bottom row) analogues of PelA that show changes in the C3-C12 section.

\begin{tabular}{|c|cccc|}
\hline Compound & HL-60 & P388 & 1A9 & MCF-7 \\
\hline PelA (1) & 7 to 35 & 18 & 16 & 4.9 \\
PelB (64) & 33 & & 48 & \\
PelC (65) & 221 & & & \\
PelD (66) & 2,000 & \multirow{2}{6}{10} & & \\
C11-epi (67) & & & & 247 \\
7-Des (68) & & & & \\
\hline
\end{tabular}

Table 1. IC 50 values (nM) of peloruside analogues in various cell lines. $H L-60=$ human leukaemia cells, P388 = murine leukaemia cells, $1 A 9$ = human ovarian carcinoma cells, $M C F-7=$ breast carcinoma cells. ${ }^{48}$

Comparing the structures of peloruside $\mathrm{B}$ and $\mathrm{C}$, the major differences lie in the C7-C9 section where the $\mathrm{C} 7$ methoxy group has been exchanged for a hydroxyl, and the two hydroxyls at $\mathrm{C} 8$ and $\mathrm{C} 9$ have been replaced with a double bond (Figure 15). These changes led to a roughly 6.6-fold decrease in bioactivity. This could suggest that the interactions in the C7-C9 section play an important role in binding but as the $\mathrm{IC}_{50}$ value is still in the mid to low $\mathrm{nM}$ range, this role may not be particularly extensive (Table 1$).{ }^{48}$ Continuing to look at this C7-C9 section, comparing the 7-desmethoxy-8,9-dideoxy PelA analogue with PelA it is apparent that the complete removal of polar substituents in the C7-C9 section appears to drop the bioactivity $\sim 50$-fold. ${ }^{48}$ This may potentially imply that the polar group at C-7 and the double bond between C8-C9 have some role in the binding interaction. Unfortunately, since the cell line in which 7desmethoxy-8,9-dideoxy PelA was tested was not used for testing PelC, no direct correlations can be made between 7-desmethoxy-8,9-dideoxy PelA and PelC. 
Comparing the synthetic analogue C11-epi-PelA against PelA, the sole structural change is the chirality at the $\mathrm{C} 11$ position (Figure 15). The C11-epi analogue is slightly more potent (Table 1) which may imply that some structural changes at the C11 position will not affect the bioactivity greatly. This would be promising for the proposed analogue 63 as it will be making relatively significant changes at the $\mathrm{C} 11-\mathrm{C} 12$ position. As a final comparison, looking at the structures of PelA and PelD, there is a huge degree of structural change in the C3-C12 section (Figure 15). Relating this back to the bioactivity, it is apparent that the bioactivity of PelD is significantly lower than PelA with the $\operatorname{IC}_{50}(>2,000 \mathrm{nM})$ over 100 -fold higher than that of PelA $(15 \mathrm{nM})$ from the same study. ${ }^{54}$ This would then imply that the large structural change observed in the $\mathrm{C} 3-\mathrm{C} 12$ section of PelD dramatically decreases the bioactivity.

The observations implied by the analogue bioactivity data are also backed up by the data from the X-ray/cryo-EM studies. According to these studies, the C2-C4 section may not be interacting strongly with either the primary $\beta$-tubulin binding site or with the neighbouring $\mathrm{PF}$. This ties in well with the observation that alterations of the C3 polar group do not significantly affect bioactivity. As both analogue and X-ray/cryo-EM studies imply the C2-C4 section to be somewhat unimportant for binding, it may be possible to treat it as a "spacer" group in much the same way that was seen in bryostatin. ${ }^{29}$ Based on this, the "spacer group" has been replaced in the proposed analogue $\mathbf{6 3}$ with an amino acid. The amino acid will be either glycine or another small D-amino acid such as D-alanine, to mimic bulk at C2 in PelA, or even D-serine, to mimic the polarity of the $\mathrm{C} 2$ group in PelA. This simplification improves the synthetic ease of the peloruside analogue generation as amino acids are commercially available and can be introduced with reliable, high-yielding coupling reactions.

Continuing with the theme of improving synthetic ease, the $\mathrm{C} 10-\mathrm{C} 13$ section containing the gem-dimethyl moiety has also been substituted with a triazole ring in the proposed analogue. As the gem-dimethyl group may be acting as a conformational lock, it may be possible to replace it with another similarly rigid moiety, the triazole ring, in the equivalent region. This triazole will ideally have similar structural influence but will allow for a copper catalyzed azide-alkyne cycloaddition $(\mathrm{CuAAC})$ to occur. It also means that the gem-dimethyl group does not need to be taken into consideration during the synthesis. The location of the 
triazole ring is also particularly useful as it provides a suitable breaking point for the retrosynthesis (Scheme 7).

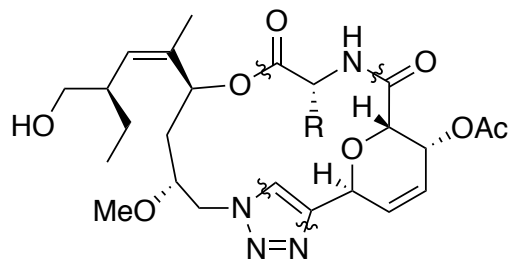

(63)

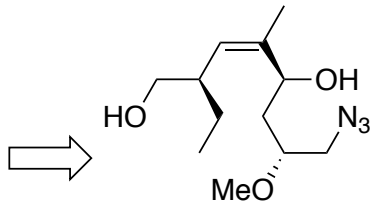

Side chain fragment

(69)
$\underbrace{\mathrm{O}}_{\overline{\overline{\mathrm{R}}}} \mathrm{NH}_{2} \mathrm{CH}_{3}^{\mathrm{R}=\mathrm{H} \text { or }}$

Amino acid

(70)

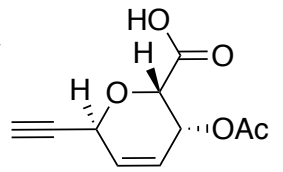

Pyran fragment

(71)

Scheme 7. Proposed peloruside A analogue retrosynthesis.

Interactions between peloruside and the neighbouring protofilament are still relatively unknown. This makes it particularly interesting to probe this interaction by investigating a variety of different substituents at the C-5-C11 section of peloruside. Another important aspect of this project is that the current intellectual property (IP) on PelA is set to expire within the next couple of years. If a biologically active analogue could be produced with improved scale up potential, then the loss of the IP on PelA would be less problematic. This project will look solely at the generation of the pyran fragment (Scheme 7 fragment 71) and will be conducted concurrently with Ethan Woolly's PhD project. The approach taken in this project differs from that in Ethan Woolly's project as this project will start from a commercially available carbohydrate.

\subsubsection{PRoJeCt Aim.}

The aim of this project is to generate pyran fragments, starting from carbohydrate precursors, that may be incorporated into the synthesis of simplified analogues of peloruside (Scheme 8). The generated peloruside analogues will ideally help to elucidate the interactions with the neighboring $\beta$-tubulin protofilament, and will be generated through synthetic routes that have a greater potential for scale up than the current PelA syntheses. 


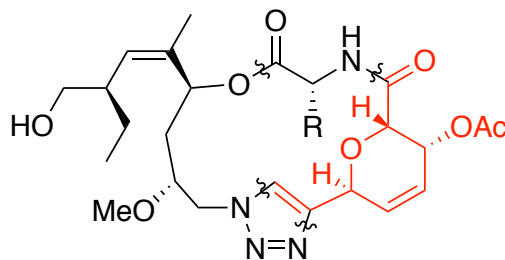

(63)

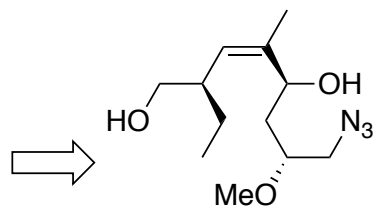

Side chain fragment

(69)
$\underbrace{\stackrel{\mathrm{O}}{\mathrm{N}} \mathrm{NH}_{2} \mathrm{CH}_{3}}_{\dot{\overline{\mathrm{R}}}} \stackrel{\mathrm{R}=\mathrm{H} \text { or }}{\mathrm{CH}_{3}}$

Amino acid

(70)

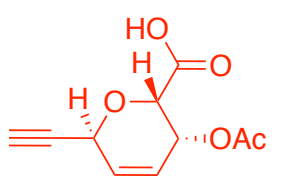

Pyran fragment

(71)

Scheme 8. Proposed peloruside A analogue retrosynthesis with the focus of this project highlighted in red.

\subsubsection{THE Pyran Fragment}

The pyran fragment is one of the three main fragments of the proposed PelA analogue (Scheme 8). Due to the structure of this fragment, a synthesis starting from a commercially available pyranose compound was proposed (Scheme 9). This proposed synthetic strategy will focus primarily on the use of a Ferrier type alkynylation to generate the desired C-glycoside framework from the pyranose compound. The use of suitably protected glycals in Ferrier transformations is well precedented in literature and has been reported by numerous different groups. ${ }^{55-59}$ In general, the Ferrier reaction requires the glycal to have an acetate group, or a similar carbonyl based protecting group, at the $\mathrm{C} 3$ position to be activated by a Lewis acid and act as a leaving group (Scheme 10). Based on this, it was decided that the hydroxyl group at $\mathrm{C} 3$ must be protected using an acetyl group to facilitate the Ferrier transformation.

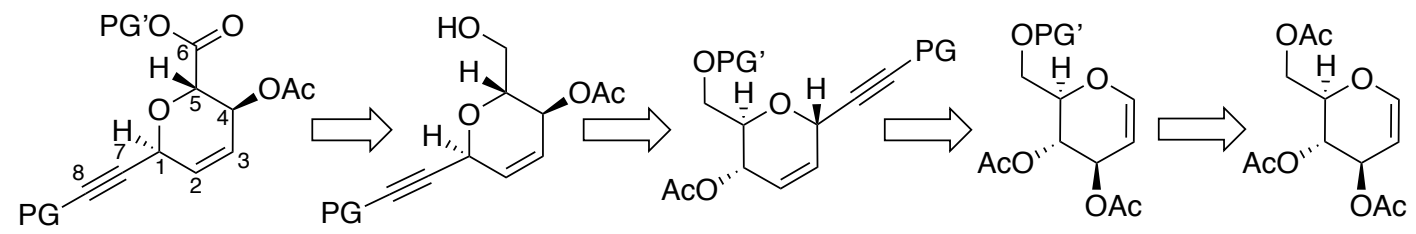

Scheme 9.Proposed pyran fragment retrosynthesis using the numbering from the peloruside system. 


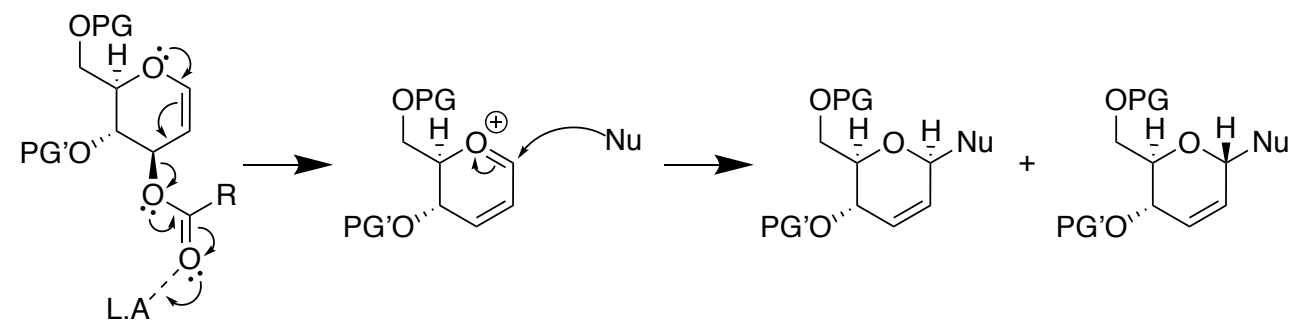

Scheme 10. Ferrier reaction mechanism on a D-glucal derivative.

This approach is different to the approach taken by Ethan, as he is generating the pyran $a b$ initio from a Prins cyclisation. To obtain the stereochemistry observed in the pyran fragment of PelA, the carbohydrate starting material should ideally be an L-pyranose as the stereochemistry at the $\mathrm{C} 5$ will remain fixed throughout the synthesis. Owing to the high cost of L-pyranoses, the fragment will be synthesised using a D-pyranose and upon success, may be attempted using an L- pyranose. As the aim of the project is to generate analogues to probe the interactions of peloruside across PFs, having pyran fragments with varying stereochemistry at the $\mathrm{C} 1$ and $\mathrm{C} 5$ positions will still be very useful for analogue generation. The acetate group at C4 may remain as an oxygen-containing group (e.g. a methoxy or hydroxy group) or may be reduced to hydrogen via a Barton-McCombie reaction. As PelA analogues with an oxygen at the $\mathrm{C} 4$ have not been studied, it would be of interest to generate some analogues with various oxygen containing groups at the $\mathrm{C} 4$ position. 


\section{Chapter 2. Trityl and Acetal Protecting Group Strategies.}

\subsection{Trityl Protection Strategy}

For the first synthetic route, the trityl protecting group was chosen as a potential C6 protecting group for this strategy as it could selectively protect the hyroxyl at C6 while also selectively cleaving in the presence of other protecting groups. The trityl strategy was chosen in preference to silicon-based primary selective protecting groups TBS or TBDPS as it was suspected that conditions which would cleave TBS or TBDPS, may also slightly affect the TMS group that would be introduced with the alkyne. This protection has previously been performed by several past members of our group and found to be a relatively simple and reliably high yielding reaction. Although well-precedented in literature, previous attempts from our group at the selective TBS and TBDPS protections have proven challenging.

\subsubsection{SYNTHESIS OF 6-O-TRITYL-3,4-O-DIACETYL-D-GLUCAL 75.}

In order to obtain a differentially protected glycal that was suitable for a Ferrier-type alkynylation reaction and subsequent selective deprotection, 6- $O$-trityl-3,4-O-diacetate-Dglucal 75 was prepared from tri- $O$-acetyl-D-glucal 72 (Scheme 11). This required the deacetylation of tri- $O$-acetyl-D-glucal 72 to form D-glucal 73, the subsequent trityl protection of the $\mathrm{C} 6$ primary alcohol to form 6-O-trityl-D-glucal 74 and finally, the acetylation of the two free hydroxyls at $\mathrm{C} 3$ and $\mathrm{C} 4$ to facilitate the next Ferrier reaction.

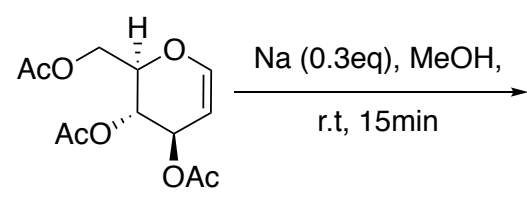

(72)

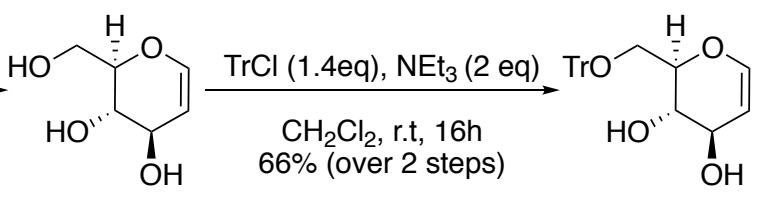

(73)

(74)
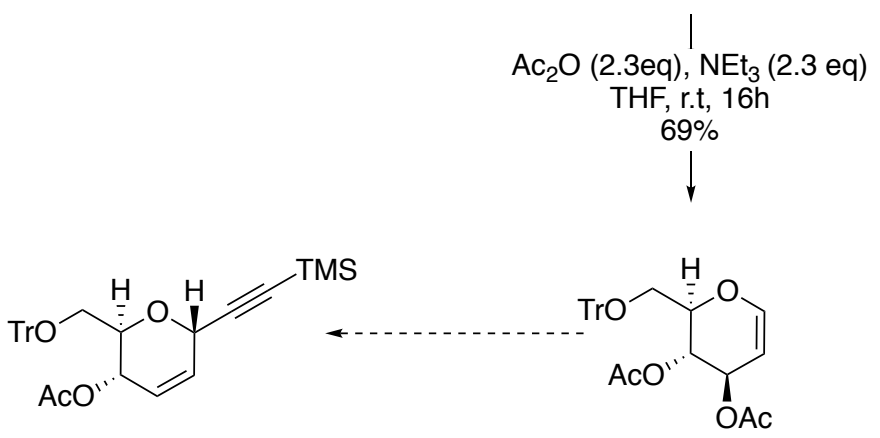

(76)
(75)

Scheme 11. Synthesis of 6-trityl-3,4-diacetate-D-glucal 75 from tri-O-acetal-D-glucal. 
The deacetylation of tri- $O$-acetyl-D-glucal $\mathbf{7 2}$ is a well-documented reaction with a number of established procedures. A number of mild deacetylation conditions, such as $\mathrm{K}_{2} \mathrm{CO}_{3}$ in methanol, have been shown to work in high yields but typically require long/overnight reaction times. ${ }^{60}$ Employing stronger Zemplén conditions had previously decreased the deacetylation reaction time to $\sim 15$ minutes with a high and reproducible yield on the same substrate. ${ }^{61,62}$ Using this sodium-methanol procedure on the tri- $O$-acetyl-D-glucal 72 substrate resulted in the production of D-glucal 73 in a near quantitative yield after only 10 minutes. $^{62}$ This product was then used without further purification in the subsequent reaction.

The first attempt at the primary hydroxyl protection followed a trityl chloride-pyridine procedure modified from that of Schmidt and colleagues by a past group member. ${ }^{62,63}$ This procedure used 1.4 eq of trityl chloride in a solution of D-glucal 73 in a (1:1) mixture of pyridine and dichloromethane. Following this procedure, the primary alcohol of the D-glucal $\mathbf{7 3}$ was successfully protected to generate 6-O-trityl-3,4-D-glucal 74 albeit in a poor $10 \%$ yield. The low yield was attributed to moisture in both the reactants and solvents. To account for this, the reaction was reattempted using carefully dried reagents throughout, which incidentally included substitution of pyridine for high quality dried $\mathrm{NEt}_{3}$. The hygroscopic nature of the triol 73 was also noted as a possible source of moisture. As a means of obtaining dry triol 73, it was freeze-dried three times under reduced pressure prior to use. After the reaction had been reattempted using freeze-dried D-glucal and drier conditions, the yield was increased to a more acceptable $66 \%$.

As Ferrier reactions work poorly when using hydroxyl groups as a leaving group, the free hydroxyls in diol $\mathbf{7 4}$ were protected with acetyl groups to promote the Ferrier transformation. Following a procedure from Adinolfi et al., diol $\mathbf{7 4}$ was dissolved in a dry solution of THF and treated with dry $\mathrm{NEt}_{3}$ and acetic anhydride to generate the 6-trityl-3,4diacetyl-D-glucal 75 in modest $69 \%$ yield. $^{55}$

\subsubsection{FERRIER-TYPE REACTIONS ON 6-TRITYL-3,4- $O$-DIACETYL-D -GLUCAL}

After the generation of the differentially protected glucal 75, a number of Ferrier-type reactions were attempted using a variety of Lewis acids. For all reaction attempts, bis(trimethylsilyl)acetylene was used as the nucleophile as it had previously been shown to give the desired TMS-protected alkyne under Ferrier conditions. ${ }^{58}$ Although unintuitive, the 
TMS alkyne is thought to act as a nucleophile via the coordination between the two $\pi$-electron orbitals of the oxonium and acetylene groups (Scheme 12). ${ }^{64}$

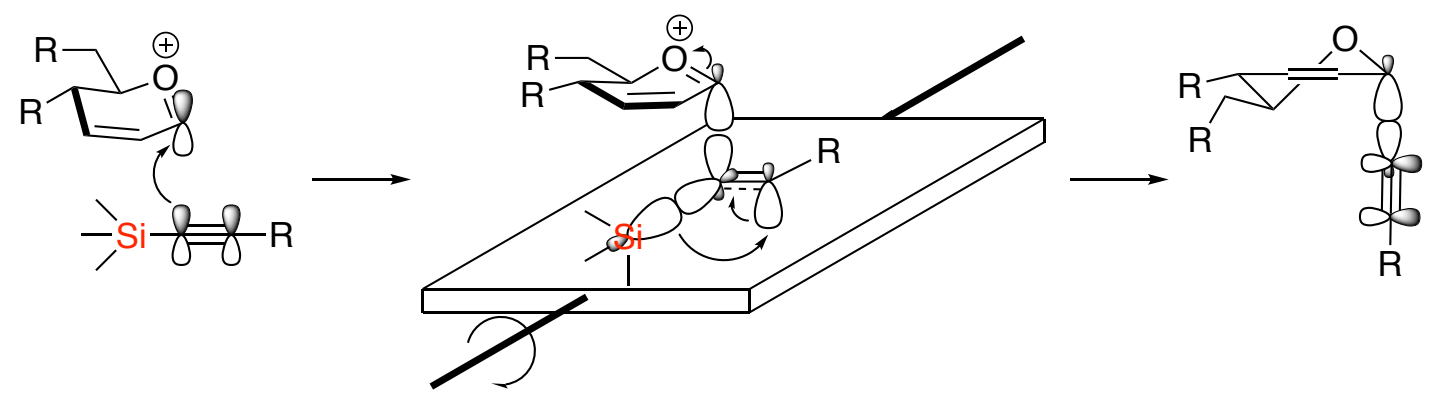

Scheme 12. Proposed mechanism of TMS acetylene neucleophilic attack. ${ }^{65}$

As the C-glycoside $\mathbf{7 6}$ was novel, there was no precedent for its formation through Ferrier transformations of compound 75. In light of this, a selection of Lewis acids including $\mathrm{I}_{2}, \mathrm{InBr}_{3}, \mathrm{BF}_{3} \cdot \mathrm{O}\left(\mathrm{C}_{2} \mathrm{H}_{5}\right)_{2}, \mathrm{SnCl}_{4}, \mathrm{TiCl}_{4}$ and TMSOTf were considered as they had previously been shown to promote the Ferrier transformation on other glycal substrates. ${ }^{58,64-68}$ As one of the concerns with this reaction was that the trityl group may be too acid labile to withstand the Ferrier transformation conditions, the milder Lewis acids $\mathrm{I}_{2}$ and $\mathrm{InBr}_{3}$ were initially chosen. ${ }^{69}$

Following a reaction procedure from Yadav et al. which used indium tribromide $\left(\mathrm{InBr}_{3}\right)$ as a Lewis acid, ${ }^{64} 6$-O-trityl-3,4-O-diacetyl-D-glucal 75 was dissolved in dichloromethane and bis(trimethylsilyl)acetylene (1.2eq) and indium tribromide ( $5 \mathrm{~mol} \%$ ) were subsequently added at room temperature. Unfortunately, based on crude TLC and ${ }^{1} \mathrm{H}$ NMR analysis, the reaction was deemed unsuccessful due to compound degradation and yielded none of the desired product.<smiles>CC(=O)OC1C=COC(CO)C1OC(C)=O</smiles>

(75)

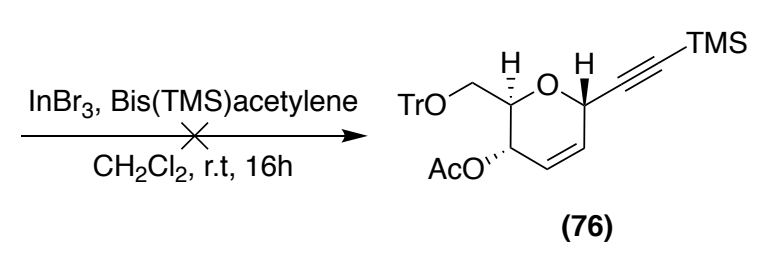

(76)

Scheme 13.Unsuccessful Ferrier reaction using $\mathrm{InBr}_{3}$.

The Ferrier reaction was attempted a second time on the protected glucal $\mathbf{7 5}$ using an $\mathrm{I}_{2}$ catalyzed method from Saeeng et al. Following this method, the protected glucal $\mathbf{7 5}$ was dissolved in $\mathrm{CH}_{2} \mathrm{Cl}_{2}$ followed by the addition of two equivalents of bis(TMS)acetylene and one equivalent of iodine at r.t. After 16 hours, an unexpected product had formed. Rather than addition of the acetylene to the glycal as was anticipated, the trityl group appeared to have been 
cleaved with a bicyclic dioxolane-pyran system being generated (Scheme 14). According to the ${ }^{1} \mathrm{H}$ NMR spectrum of the isolated compound, no TMS or trityl peaks were observed, an acetyl peak had disappeared and the peaks for C1, C2, C3 and C6 had all shifted. Most importantly the peaks observed also matched the reported peaks for compound 77 in literature. $^{70}$

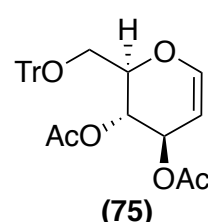

(75)

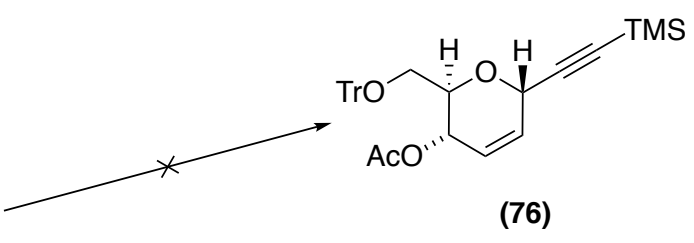

(76)

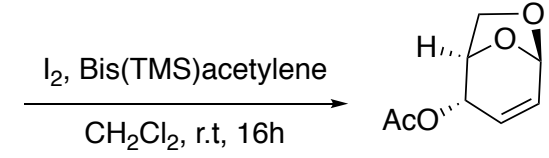

(77)

Scheme 14. Unsuccessful Ferrier reaction using $I_{2}$ on trityl compound 75.

It was not established whether the trityl loss occurs from the cleavage of the trityl group by the Lewis acid, with subsequent nucleophilic attack by the hydroxyl group (Scheme 15) or whether the trityl is lost during or after the nucleophilic attack by the C-6 oxygen on the anomeric centre (Scheme 16). As even the mildest of the possible Lewis acid catalysts caused the loss of the trityl group, a different protecting group strategy was deemed necessary.

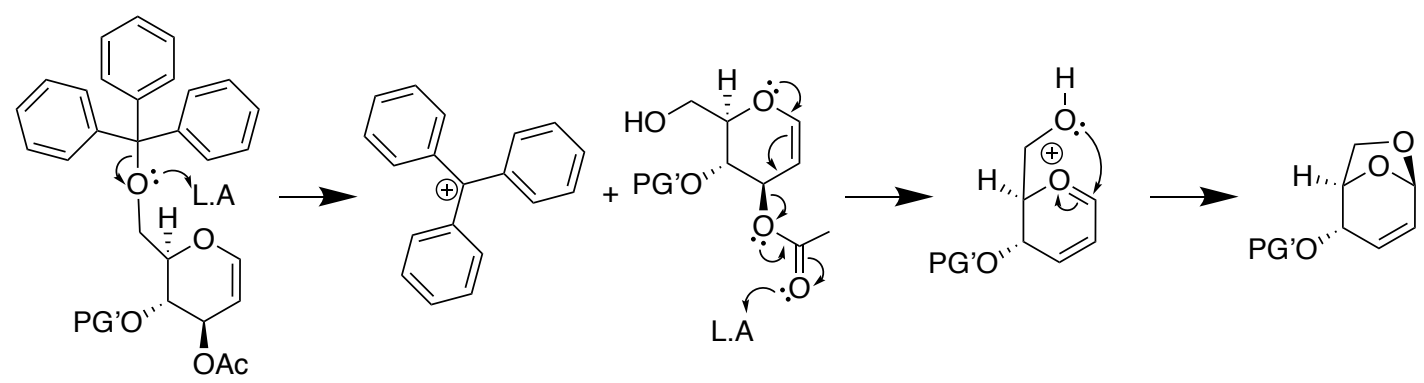

Scheme 15. First potential mechanism of Trityl loss during Ferrier reaction.

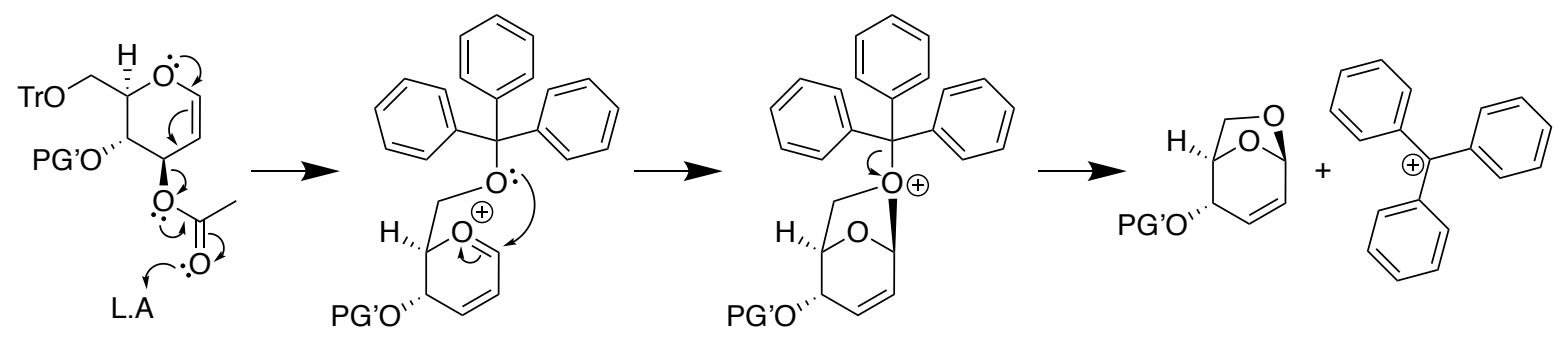

Scheme 16. Second potential mechanism of Trityl loss during Ferrier reaction. 


\section{2 p-Methoxybenzylidine Acetal Protection Strategy}

As previously mentioned, it was initially considered unideal to replace the trityl group with a silicon-based protecting group due to the potential lack of orthogonality between the C6 silicon-based protecting group and the TMS group introduced with the alkyne. Although the selective deprotection may or may not encounter any orthogonality issues, it seemed worthwhile investigating other protecting group strategies so that selective deprotection might still be achieved with relative ease. One possible approach to protecting the $\mathrm{C} 6$ and $\mathrm{C} 4$ oxygens is to employ one of the many acetal protecting group strategies for carbohydrates. ${ }^{71}$ Of the common acetal protecting group strategies, the $p$-methoxybenzylidine acetal strategy appeared to be the most suitable. This protecting group strategy is convenient as, unlike an acetonide, the acetal produced is able to be selectively deprotected from the C6 position, while remaining at the C-4 position, now as a PMB protecting group (Scheme 17). ${ }^{66}$ Use of a more robust benzylidene acetal protection was also considered. However, this would leave a benzyl group on the $\mathrm{C} 4$ which would require harsher conditions for removal, such as hydrogenolysis, which are likely not to be compatible with the functionality of the final molecule. ${ }^{71}$ On the other hand, the $p$-methoxybenzylidine strategy leaves a $p$-methoxybenzyl (PMB) group on the $\mathrm{C} 4$ oxygen which may be more easily removed with a mild oxidiser such as DDQ. ${ }^{66}$

\subsubsection{Proposed Acetal Protection route.}

The proposed acetal route started with the same deacetylation that was used in the trityl protection strategy because it was found to be high yielding and reproducible. Based on a procedure from Roën et al., the D-glucal was to be protected at positions C4 and C6 using anisaldehyde dimethyl acetal and catalytic amounts of pyridinium $p$-toluenesulfonate. ${ }^{56}$ This was to be followed by the same acetylation procedure, that had been used in the trityl protection route, from Adinolfi et al. ${ }^{55}$ Ferrier transformations were to be done using the weaker Lewis acids, iodine and indium tribromide as the PMP acetal protecting group is known to be relatively acid labile. ${ }^{72}$ If the acetal was to remain stable under the Lewis acid conditions, the bicyclic dioxolane-pyran ring system would not be expected to form as the C6 oxygen is unable to reach the position required to attack the $\mathrm{C} 1$ (Scheme 16). In order to get the differential protection desired at the $\mathrm{C} 4$ and $\mathrm{C} 6$ positions, methods were found which enabled the selective deprotection at C6. ${ }^{66,73}$ Following the method used by Schell et al. the acetal was to be selectively deprotected at the C6 position using DIBAL to leave a free hydroxyl at C6 and a PMB protected hydroxyl at C4 (Scheme 17). ${ }^{66}$ 

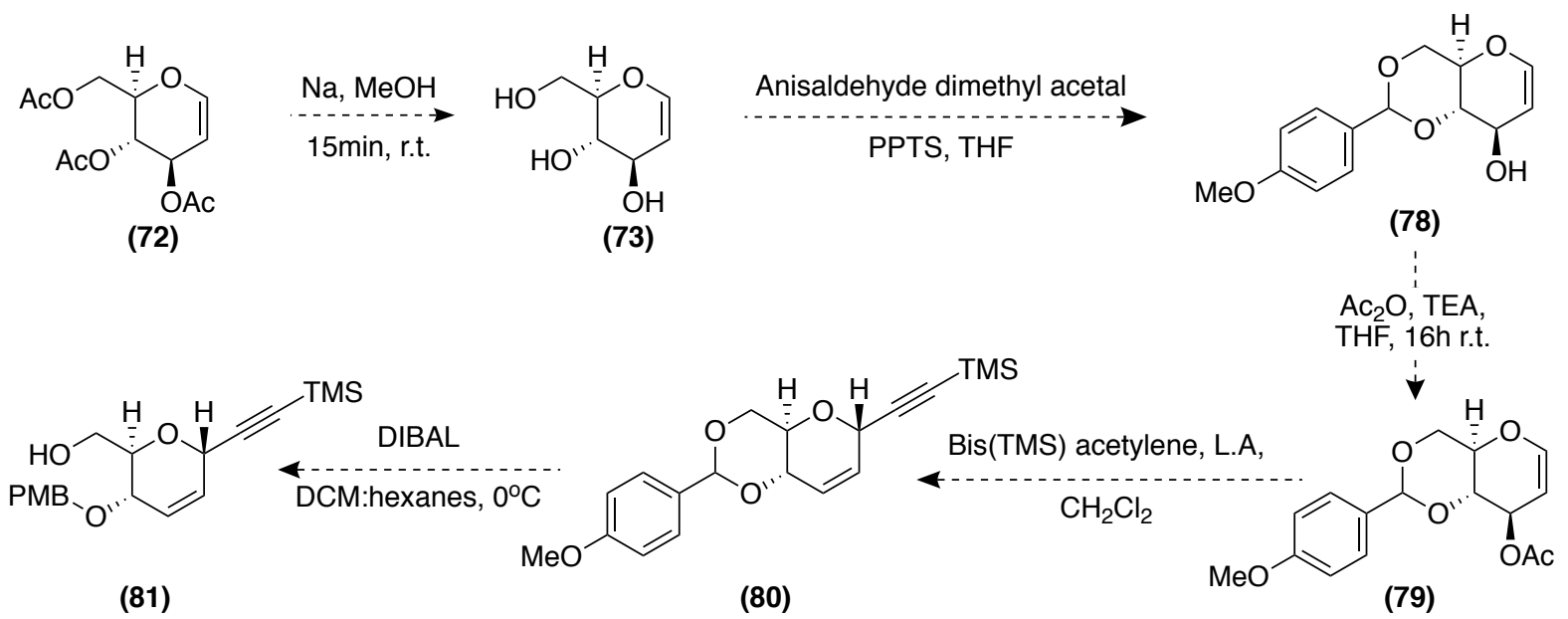

Scheme 17. Proposed acetal protection strategy.

\subsubsection{SyNTHESIS OF 6,4-P-METHOXYBENZYLIDENEACETAL-3- $O$-ACETYL-D-} GLUCAL.

As with the trityl strategy, D-glucal was prepared from tri- $O$-D-glucal in high and reproducible yields using the Zemplén conditions from Moore et al. ${ }^{61}$ Following the method outlined by Roën et al., ${ }^{56}$ the 4,6 diol protection was attempted by dissolving the D-glucal in THF and sequentially adding 1.4 equivalents of anisaldehyde dimethyl acetal and $20 \mathrm{~mol} \%$ PPTS at room temperature. Solubility difficulties arose when attempting to dissolve the glucal in THF. After heating and ultra-sonication to get the glucal into solution, it was left at room temperature to stir. After 16 hours TLC analysis showed no product formation so the temperature was then increased to $50{ }^{\circ} \mathrm{C}$ and left for another 10 hours. Unfortunately, the reaction proved unsuccessful with only starting material recovered (Scheme 18). A second attempt was performed at $60{ }^{\circ} \mathrm{C}$ using $5 \mathrm{~mol} \%$ loading of PPTS. After 16 hours, TLC analysis showed no product formation.

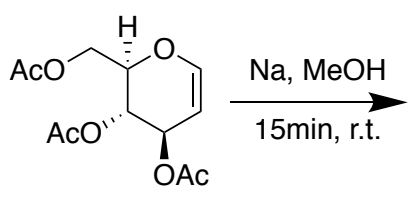

(72)<smiles>OCC1OC=CC(O)C1O</smiles>

(73)

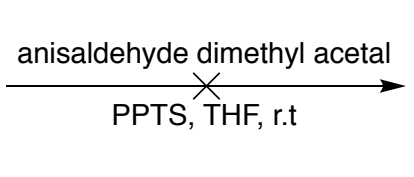

(78)

Scheme 18. Acetal protection strategy difficulty.

Based on this unsatisfactory result, timing constraints, and concerns that the 4,6-acetal product may still be too acid sensitive for the Ferrier transformation, led to the decision that it would be of more value to pursue a synthetic route with more robust protecting groups. 


\section{Chapter 3. The TBS Protection Strategy.}

\subsection{6-O-TBS-3,4-diacetyl-D-glucal synthesis}

Although efforts had originally been made to avoid the primary selective TBS or TBDPS protecting groups due to deprotection orthogonality concerns, it was decided that their acid stability during the Ferrier rearrangment would be more useful to the synthesis than having deprotection orthogonality with the TMS alkyne. Due to this, a third synthetic strategy was developed using the TBS group to protect the primary alcohol at the C6 position. This synthetic strategy again proposed to use the deacetylation conditions from Moore et al. ${ }^{61}$ to prepare Dglucal. Based on the method developed by Corey et al. ${ }^{74}$ a procedure for the TBS protection was proposed using $\mathrm{TBSCl}$, imidazole and DMF. Following this $\mathrm{C} 6$ protection, the acetylation of the $\mathrm{C} 3$ and $\mathrm{C} 4$ hydroxyls was to be done using the previously defined method from Adinolfi et al. (Scheme 19). ${ }^{55}$

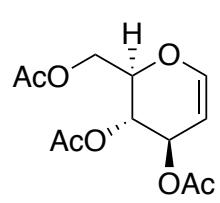

(72)

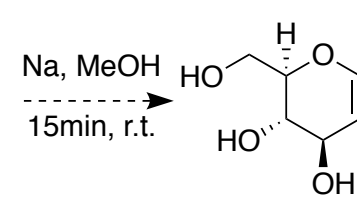

(73)

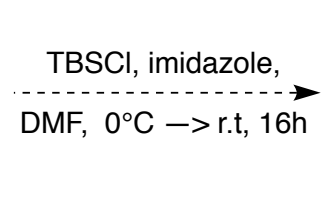

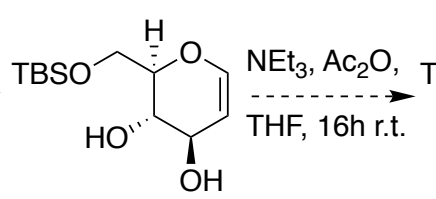

(82)

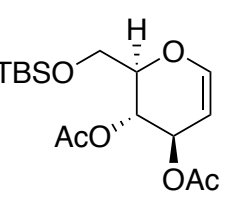

(83)

Scheme 19. Proposed synthetic route for the preparation of a TBS protected Ferrier transformation substrate.

The attempted synthesis of 6-O-TBS-3,4-diacetyl-D-glucal largely focused on the selective protection at $\mathrm{C} 6$ as both the deacetylation and the subsequent re-acetylation had been shown to work with relative success during the trityl protection route. Following a procedure from Yadav and co-workers. ${ }^{75}$ which was based on Corey et al.'s early work. ${ }^{74}$ D-glucal was dissolved in DMF followed by the subsequent addition of 1.2 equivalents of TBSCl and 2 equivalents of imidazole at $0{ }^{\circ} \mathrm{C}$. The reaction was then left to stir overnight. Following the overnight stir, an aqueous workup was performed which was designed to remove some of the DMF solvent from the organic layer. Unfortunately, the 6-O-TBS-D-glucal appeared to be sequestered in the aqueous layer due to the polarity of the diol moiety.

In order to avoid the aqueous partitioning, a second attempt was made using a protocol from Akihiko et al. ${ }^{76}$ which involved the use of TBSCl, $\mathrm{NEt}_{3}, \mathrm{DMAP}$ and $\mathrm{CH}_{2} \mathrm{Cl}_{2}$. This was used so that, rather than needing an aqueous workup to remove the DMF solvent after the reaction, the $\mathrm{CH}_{2} \mathrm{Cl}_{2}$ solvent could be easily removed in vacuo without workup. Following this procedure, D-glucal was added to $\mathrm{CH}_{2} \mathrm{Cl}_{2}$ followed by the subsequent addition of 2 equivalents 
of $\mathrm{NEt}_{3}, 1.2$ equivalents of $\mathrm{TBSCl}$ and $10 \mathrm{~mol} \%$ DMAP. Unfortunately, this approach encountered the solubility issues seen in the acetal protection strategy, where the D-glucal would not easily dissolve in the solvent. This was thought to impact the amount of compound readily available to react with the $\mathrm{TBSCl}$, in turn, leading to a slower reaction and an increased chance of dual silyl protection. After 26 hours, TLC analysis suggested that some of the mono TBS protected glucal was undergoing a second silyl protection, whilst substantial amounts of starting material remained unreacted. Due to this, the reaction was concentrated under reduced pressure and purified via silica gel chromatography avoiding any workup. After purification, some of the desired product was obtained but in a poor $7.5 \%$ yield with mostly starting material recovered.

After the poor yield from the second attempt in $\mathrm{CH}_{2} \mathrm{Cl}_{2}$, a third, one-pot attempt was attempted whereby the acetylation was carried out in situ without isolating the polar-monoTBS protected compound. This was thought to be useful as it would allow the silylation to be carried out in DMF, and once the glycal was acetylated, the reaction could be subjected to an aqueous workup without the product getting sequestered into the aqueous layer. To do this, the original silylation procedure from Yadav and $\operatorname{co}^{75}$ was employed using 1.2 equivalents of $\mathrm{TBSCl}$ and 2 equivalents of imidazole in DMF. After dissolving the D-glucal in DMF and adding the $\mathrm{TBSCl}$ and imidazole at $0^{\circ} \mathrm{C}$, the reaction was left to stir at room temperature. After 40 hours, 2.3 equivalents of $\mathrm{Ac}_{2} \mathrm{O}$ and $\mathrm{NEt}_{3}$ were added and the reaction was again left to stir. After 20 hours, the reaction was worked up and purified by silica chromatography to give four different compounds (Figure 17). After isolation ${ }^{1} \mathrm{H}$ NMR spectra were obtained to check the success of the protections. Fortunately, the spectra obtained for the first and third compounds isolated (compounds 83 and 72), matched the reported literature for 6-O-TBS-3,4-O-diacetylD-glucal and tri- $O$-acetyl-D-glucal respectively. ${ }^{73,77}$

In ${ }^{1} \mathrm{H}$ NMR spectra, TBS groups should show up as one singlet peak at $\sim 0.9 \mathrm{ppm}$ integrating to 9 protons representing the tert-butyl moiety, and a second singlet peak at $\sim 0.08$ ppm integrating to 6 protons representing the two methyl groups. Acetate groups should typically show as a singlet peak between 2 and $2.15 \mathrm{ppm}$ with an integral of 3 protons representing the terminal methyl group of the acetate. Based on the $0-2.5 \mathrm{ppm}$ region of the ${ }^{1} \mathrm{H}$ NMR obtained for the four isolated compounds, the first compound appeared to have two acetyl groups and one TBS group; the second, one acetyl group and one TBS group; the third, three acetyl groups and the fourth two acetyl groups (Figure 16). 


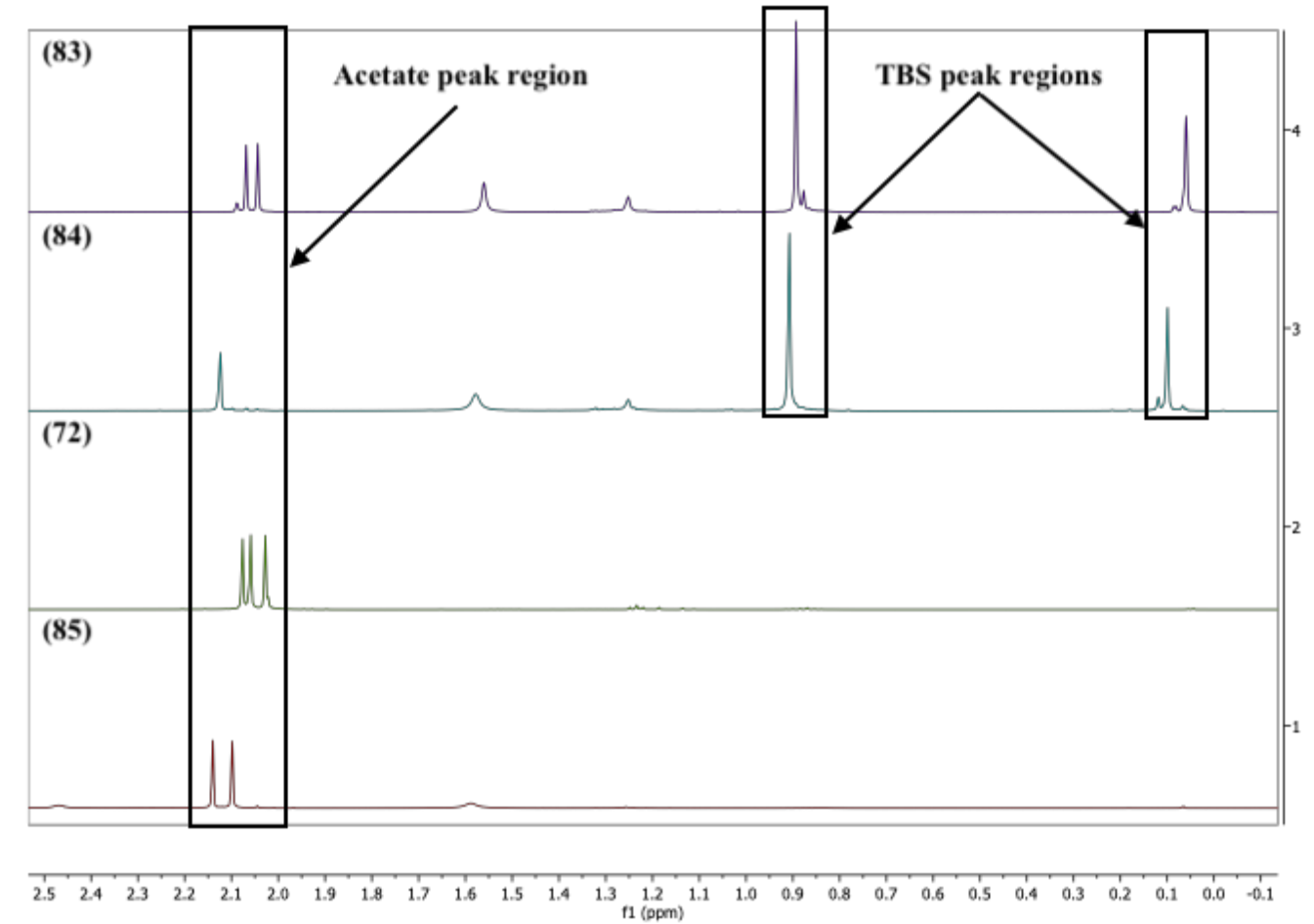

Figure 16. Stacked ${ }^{1} H$ NMR of the four isolated one-pot silylation-acetylation products focusing on the 0-2.5 ppm region.

Based on the ${ }^{1} \mathrm{H}$ NMR data obtained, it was proposed that the four isolated compounds were 6-O-TBS-3,4- $O$-diacetyl-D-glucal, 6-O-TBS-4-hydroxy-3- $O$-acetyl-D-glucal, tri- $O$ acetyl-D-glucal and 6,4-O-diacetyl-3-hydroxy-D-glucal (Figure 17).

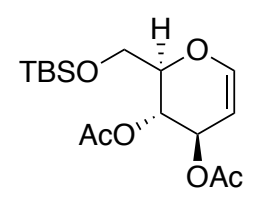

(83)

$5.3 \%$<smiles>CC(C)OC[C@H]1OC=C[C@@H](OC(C)C)[C@H]1O</smiles>

(84)

$1.9 \%$<smiles>CC(=O)OCC1OC=CC(OC(C)=O)C1OC(C)=O</smiles>

(72)<smiles>CC(=O)OCC1OC=CC(O)C1C(C)=O</smiles>

(85)

Figure 17. Four compounds isolated from the one-pot synthesis.

In order to rationalise the position of the protecting groups, further analysis of the 3-7 ppm region of the ${ }^{1} \mathrm{H}$ NMR spectra was performed. Unfortunately, in the reported literature the peaks in the spectra for 6-O-TBS-3,4-O-diacetyl-D-glucal and tri- $O$-acetyl-D-glucal were unassigned. The peaks of the ${ }^{1} \mathrm{H}$ NMR spectra of the first compound, 6-O-TBS-3,4-O-diacetylD-glucal 83 (Figure 18, top purple spectrum), were assigned based on the expected shift, multiplicity, coupling constant and integration of the peaks. A doublet at $3.8 \mathrm{ppm}(J=5 \mathrm{~Hz})$, representing two protons, was assigned as the two C6 protons as it is the only carbon in compound $\mathbf{8 3}$ to have two protons capable of coupling to one neighbouring proton. The upfield 
shift of this doublet also matched the calculated shift for the C6 position in 6-O-TBS-3,4-Odiacetyl-D-glucal. Additionally, the coupling constant of $5 \mathrm{~Hz}$ also falls into the expected range for aliphatic couplings. The peak at $4.1 \mathrm{ppm}$ was assigned as the hydrogen at C5 since the multiplicity suggests it to have three neighbouring protons while the integral suggests it to only represent one proton, a combination unique to the $\mathrm{C} 5$ hydrogen. The most downfield doublet peak at $6.4 \mathrm{ppm}$ which represents a single proton, was assigned as the $\mathrm{C} 1$ proton as that is the only position to have a single proton with only one neighbour. The $6.4 \mathrm{ppm}$ peak also has a coupling constant of $6 \mathrm{~Hz}$ which falls into the expected range of coupling constants for a $Z$ alkene vicinal couplings. The doublet of doublets at $4.8 \mathrm{ppm}(\mathrm{J}=6 \mathrm{~Hz}, 2 \mathrm{~Hz})$ representing one proton, was assigned the proton at C2 as the peak's larger coupling constant of $6 \mathrm{~Hz}$ matched the coupling constant of the $\mathrm{C} 1$ proton peak while the second smaller coupling constant of 2 $\mathrm{Hz}$ matched the expected coupling for an allylic proton coupling. The apparent triplet at 5.3 ppm representing a single proton has a coupling constant of $\sim 3 \mathrm{~Hz}$, nearly matching the coupling constant of the $\mathrm{C} 2$ peak. This is the only peak to have a coupling constant in this range, other than the $\mathrm{C} 2$ peak, suggesting that the $5.3 \mathrm{ppm}$ peak is most likely from the C3 proton which is coupling to the $\mathrm{C} 2$ proton. The $\mathrm{C} 3$ proton peak is expected to be a doublet of doublets coupling with both the $\mathrm{C} 2$ proton $(\sim 2 \mathrm{~Hz})$ and the $\mathrm{C} 4$ proton (expect $\sim 6 \mathrm{~Hz}$ ) but may be appearing as a triplet since the minor and major couplings are of similar magnitude. The last unassigned proton at $\mathrm{C} 4$ is expected to appear as a triplet around $5.5 \mathrm{ppm}$ with a single coupling constant of $\sim 6 \mathrm{~Hz}$. As is seen in the spectra (Figure 18 top [purple] spectrum), a triplet with a $6 \mathrm{~Hz}$ coupling constant is observed at $5.2 \mathrm{ppm}$ which integrates to one. In addition to this, the observed chemical shifts for the protons identified at positions $\mathrm{C} 1, \mathrm{C} 2, \mathrm{C} 3, \mathrm{C} 4, \mathrm{C} 5$ and $\mathrm{C} 6$, match the calculated ${ }^{1} \mathrm{H}$ NMR peak shifts at the corresponding positions in 6-O-TBS-3,4-Odiacetyl-D-glucal. Expected ${ }^{1} \mathrm{H}$ NMR peak shift calculations were performed using PerkinElmer's NMR prediction tool in ChemDraw $^{\circledR}$, ChemNMR $^{\circledR}$. 


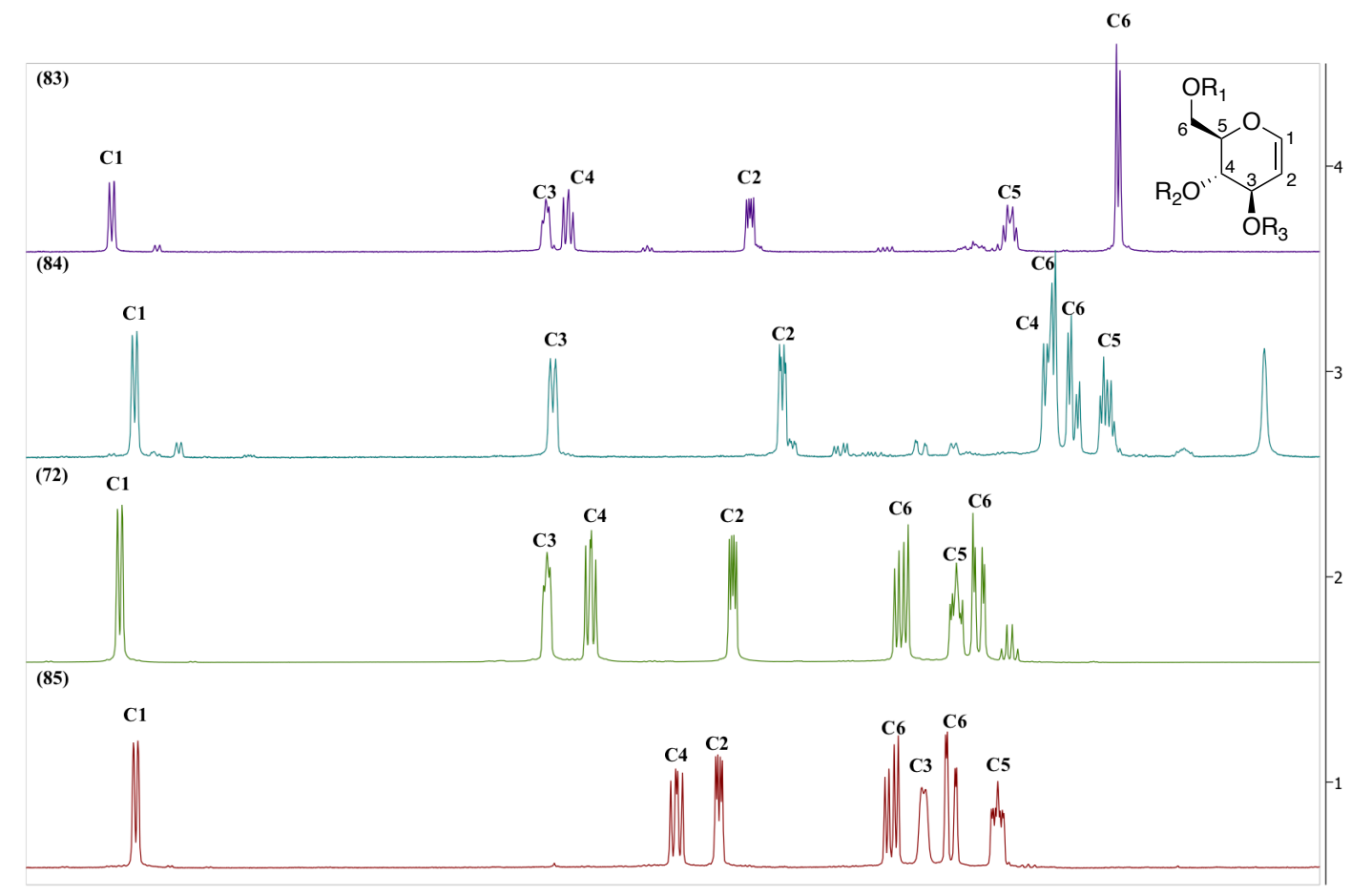

$\begin{array}{lllllllllllllllllllllllllllllllllllllllllll}6.6 & 6.5 & 6.4 & 6.3 & 6.2 & 6.1 & 6.0 & 5.9 & 5.8 & 5.7 & 5.6 & 5.5 & 5.4 & 5.3 & 5.2 & 5.1 & 5.0 & 4.9 & 4.8 & 4.7 & 4.6 & 4.5 & 4.4 & 4.3 & 4.2 & 4.1 & 4.0 & 3.9 & 3.8 & 3.7 & 3.6 & 3.5 & 3.4 & 3.3\end{array}$

Figure 18. Stacked 1H NMR of one-pot silylation-acetylation focusing on the 3.3 - 6.6 ppm region.

Comparing the spectra from the first isolated compound, 6-O-TBS-3,4-O-diacetyl-Dglucal 83 against the second isolated compound $\mathbf{8 4}$, the major changes are seen to occur at the C4, C5 and C6 positions (Figure 18, comparison of top spectrum [purple] against second spectrum [teal]). As the $\mathrm{C} 1, \mathrm{C} 2$ and $\mathrm{C} 3$ peaks still have a similar shift and multiplicity as were observed in the 6-O-TBS-3,4-O-diacetyl-D-glucal 83 spectrum, it is likely that the double bond between $\mathrm{C} 1$ and $\mathrm{C} 2$ is present in compound $\mathbf{8 4}$ and the $\mathrm{C} 3$ oxygen is acetate protected. The multiplicity of the $\mathrm{C} 3$ doublet of doublets peak in the second compound's spectrum (Figure 18 second [teal] spectrum), is slightly different from the broad triplet previously observed. This change from broad triplet to a doublet of doublets was attributed to the slight decrease in coupling constant for the allylic coupling between C2 and C3 in compound 84. The decrease in the C3 peak's coupling constant also matched the smaller observed minor coupling constant in the $\mathrm{C} 2$ peak of compound 84. Based on the 0-2.5 ppm region of the ${ }^{1} \mathrm{H}$ NMR spectrum (Figure 16 second [teal] spectrum), compound 84 should contain one TBS protected hydroxyl group and one acetate protected hydroxyl group. As the acetate group was identified to be at the $\mathrm{C} 3$ position, the TBS group will likely be either at the $\mathrm{C} 6$ or $\mathrm{C} 4$ position. As the shift of the C6 proton peaks is similar to the shift observed in compound $\mathbf{8 3}$, and TBS should theoretically 
protect primary alcohols over secondary alcohols, it was suspected that the TBS group was at the C6 position while the $\mathrm{C} 4$ position had a free hydroxyl group.

As mentioned previously, the ${ }^{1} \mathrm{H}$ NMR spectrum for the third isolated compound matched the ${ }^{1} \mathrm{H}$ NMR spectrum in literature for tri-O-acetyl-D-glucal 72. The peaks for compound 72 were assigned based on the same logic used for compound $\mathbf{8 3}$ as all peak shifts, integrals, multiplicities and coupling constants were very similar to compound $\mathbf{8 3}$ other than the $\mathrm{C} 6$ proton peaks. As was expected, the $\mathrm{C} 6$ proton peaks in tri- $O$-acetyl-D-glucal 72 were shifted further downfield than the $\mathrm{C} 6$ proton peak in 6-O-TBS-3,4-O-diacetyl-D-glucal 83. The C6 peaks in the tri- $O$-acetyl-D-glucal 72 had also been split into two different doublet of doublet peaks which tented towards each other. Due to the conformation of the ring in the tri$O$-acetyl-D-glucal, the C5-C6 bond may be unable to rotate freely leading to the generation of two separate proton environments at $\mathrm{C} 6$. This restriction then causes the protons to couple to each other and to the $\mathrm{C} 5$ proton with different coupling constants. This leads to the two tenting doublet of doublet peaks for the C6 protons, as well as a more complicated coupling for the C5 proton peak.

Comparing the ${ }^{1} \mathrm{H}$ NMR for the tri- $O$-acetyl-D-glucal 72 and the fourth isolated compound 85, the 0-2.5 ppm region suggested the major difference to be the lack of a single acetate protecting group. Looking at the $3.3-6.6 \mathrm{ppm}$ region, the major changes are the significant upfield shift of the $\mathrm{C} 3$ peak and the moderate upfield shift of the $\mathrm{C} 4$ peak. This would indicate the lack of the acetate group at $\mathrm{C} 3$ suggesting the compound to be 6,4-Odiacetyl-3-hydroxy-D-glucal.

These results indicated that the TBS protection appeared to again be proceeding in a very poor yield but uninfluenced by the previously suspected workup and solubility difficulties. This suggested that there may be a problem with either the reaction conditions or the purity of the reactants. In an attempt to overcome this, a fourth attempt was made where the reaction was started with 1.2 equivalents of TBSCl present and during the reaction, with TLC monitoring, additional equivalents of TBSCl were added. To do this, the procedure employed by Yadav and co-workers ${ }^{75}$ was again used whereby the D-glucal was dissolved in DMF and 1.2 equivalents of TBSCl and 2 equivalents of imidazole were added at $0{ }^{\circ} \mathrm{C}$. The solution was stirred at room temperature and after 10 hours, TLC analysis revealed the presence of both product and starting material. The reaction was then cooled to $0{ }^{\circ} \mathrm{C}$ and another one equivalent 
of TBSCl and two equivalents of imidazole were added. After a further 4.5 hours, TLC analysis showed the formation of dual silylated product while also showing some remaining starting material. The solution was concentrated in vacuo and purified via silica chromatography without workup. This resulted in an improved $41 \%$ yield of 6-O-TBS-3,4-hydroxy-D-glucal 82. Although this yield was much better than the previous $<10 \%$ yields, a fifth attempt was made to improve the yield further.

As the previous attempt had the presence of both dual silylated product and starting material in the reaction, it was decided to try to drive the reaction by heating it to $40{ }^{\circ} \mathrm{C}$ and slightly decreasing the equivalents of TBSCl. One of the main concerns with heating the reaction was that it may cause a decrease in the primary alcohol regioselectivity as well as potentially induce a silyl migration from $\mathrm{O} 6$ to $\mathrm{O} 4$. Using this approach, the D-glucal was dissolved in DMF, cooled to $0{ }^{\circ} \mathrm{C}, 2$ equivalents of imidazole and 1.6 equivalents of TBSCl were added. The reaction was then warmed to $40{ }^{\circ} \mathrm{C}$ and left to stir for 16 hours. The reaction was reduced in vacuo without workup and purified via silica gel chromatography to give 6-OTBS-3,4-diacetyl-D-glucal 83 in a $61 \%$ yield. This was a great improvement over the previous $40 \%$ and earlier sub- $10 \%$ yields.

After generating the 6-O-TBS-3,4-hydroxy-D-glucal 82 in good yield, the same acetylation from Adinolfi et al. ${ }^{55}$ was used to re-acetylate the hydroxyl groups at $\mathrm{C} 3$ and $\mathrm{C} 4$. As before, the diol 82 was dissolved in THF and treated with dry triethylamine and acetic anhydride to generate 6-O-TBS-3,4-O-diacetyl-D-glucal in an excellent $96 \%$ yield.

\subsection{Ferrier reaction of 6-O-TBS-3,4-O-diacetyl-D-glucal}

After the successful generation of 6-O-TBS-3,4-diacetyl-D-glucal 83, a series of Ferrier-type alkynylations were attempted using a variety of Lewis acids. Based on work from Ichikawa et al., ${ }^{58}$ Isobe et al. ${ }^{65}$ and Saeeng et al. ${ }^{68}$ three Ferrier transformation protocols were developed which used each of the Lewis acids $\mathrm{TiCl}_{4}, \mathrm{SnCl}_{4}$, and $\mathrm{I}_{2}$ respectively, to catalyse the alkynylation. Following these protocols in separate reaction vessels, 6-O-TBS-3,4-diacetyl-Dglucal 83 was dissolved in $\mathrm{CH}_{2} \mathrm{Cl}_{2}$ and cooled to $-20{ }^{\circ} \mathrm{C}$ in a salt-ice cooling bath. Two equivalents of bis(trimethylsilyl)acetylene were added to each solution followed by the slow addition of one equivalent of the respective Lewis acid (Scheme 20). 


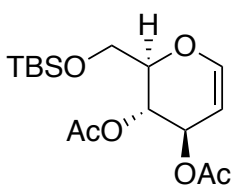

(83)

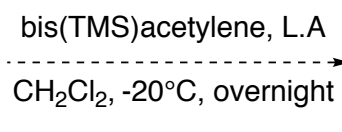

$\mathrm{CH}_{2} \mathrm{Cl}_{2},-20^{\circ} \mathrm{C}$, overnight

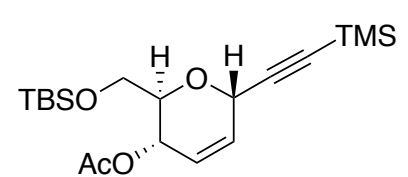

(86)

Scheme 20. First proposed Ferrier transformation protocol.

In the interest of time, the three reactions were done in parallel and the ${ }^{1} \mathrm{H}$ NMR spectra of the crude material were compared to choose the Lewis acid which generated the cleanest crude product. Based on the ${ }^{1} \mathrm{H}$ NMR spectra of the crude material (Figure 19), the $\mathrm{I}_{2}$ catalysed Ferrier transformation showed no distinct product and still had a slight amount of starting material present. The $\mathrm{TiCl}_{4}$ catalysed Ferrier transformation showed no starting material but also lacked clear product peaks while the $\mathrm{SnCl}_{4}$ catalysed Ferrier transformation showed no starting material and had distinct product peaks (Figure 19). As the ${ }^{1} \mathrm{H}$ NMR spectrum of the crude $\mathrm{SnCl}_{4}$ catalysed Ferrier transformation showed the cleanest product, the reaction was purified and the $\mathrm{SnCl}_{4}$ Lewis acid selected for further use.

$\mathrm{I}_{2}$

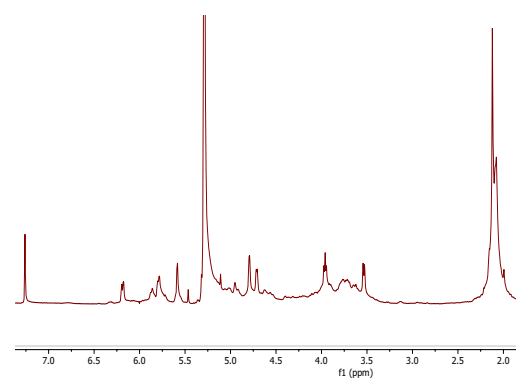

$\mathrm{TiCl}_{4}$

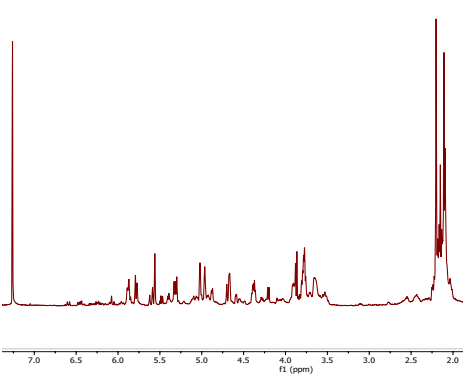

$\mathrm{SnCl}_{4}$

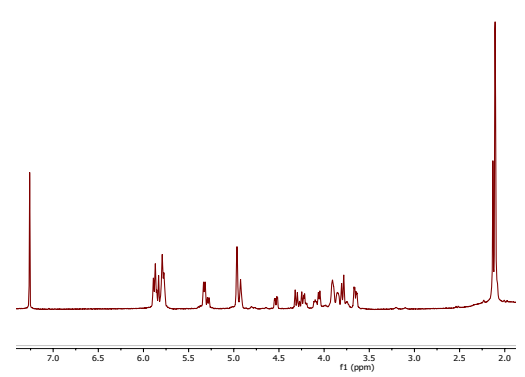

Figure 19.Crude 1H NMR spectra of the three different Lewis acid catalysed Ferrier style alkynylations focusing on the 2-7 ppm region.

Due to the overnight stir time specified in the protocol from Ichikawa et al., ${ }^{58}$ the $20{ }^{\circ} \mathrm{C}$ cooling bath melted allowing the reaction to warm to room temperature. This unfortunately, led to the partial evaporation of the $\mathrm{CH}_{2} \mathrm{Cl}_{2}$ solvent which, in turn, caused the $\mathrm{SnCl}_{4}$ to become significantly more concentrated. After purification of the reaction, three $\mathrm{C}$ glycoside compounds were isolated (Figure 20). 


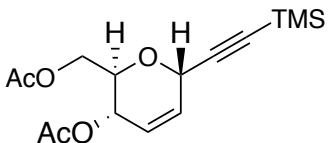

(87)

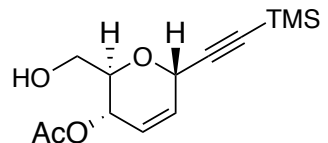

(88)

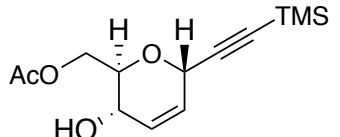

(89)

Figure 20. Compounds isolated from the preliminary SnCl4 Ferrier reaction attempt.

The first isolated compound (compound 87), was confirmed to have undergone the Ferrier transformation but had lost the TBS group that was originally at C6 and instead gained an acetate group. The next two compounds (compounds $\mathbf{8 8}$ and $\mathbf{8 9}$ ), were isolated together and were inseparable from each other via silica gel chromatography. Based on the ${ }^{1} \mathrm{H}$ NMR spectrum of the compound mixture, both compounds ( $\mathbf{8 8}$ and $\mathbf{8 9}$ ), appeared to have undergone a Ferrier type alkynylation, lost the TBS group and retained an acetate group. Based on a comparison of the integrals for the H-4 and H-6 peaks between compounds $\mathbf{8 8}$ and $\mathbf{8 9}$, as seen in the ${ }^{1} \mathrm{H}$ NMR spectrum (Figure 21), the products appeared to be in a 1.6:1 ratio favouring compound $\mathbf{8 8}$.

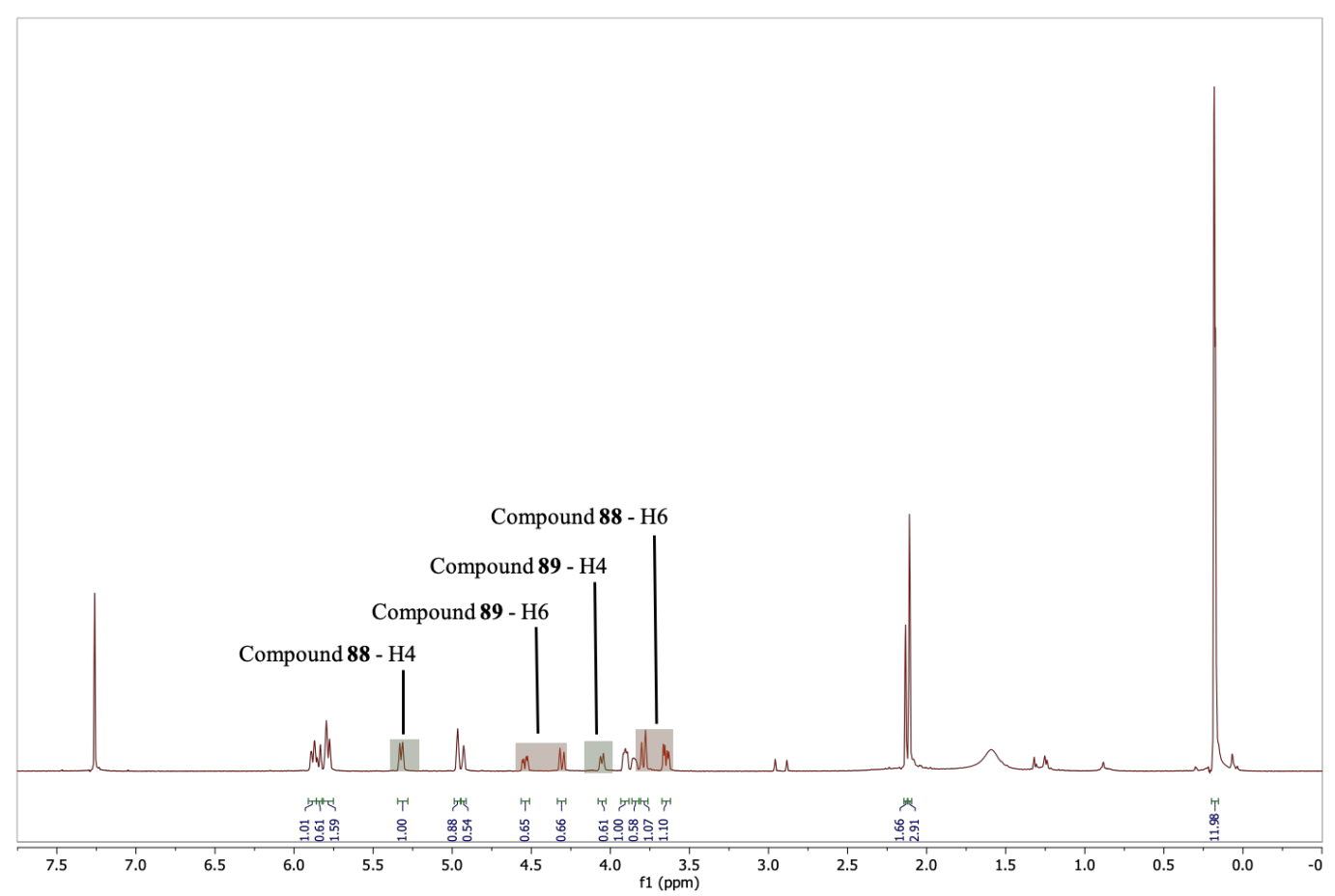

Figure 21. ${ }^{1} H$ NMR spectrum of compound $\mathbf{8 8 - 8 9}$ mixture.

What was particularly interesting with this reaction was that after stirring overnight at room temperature in a relatively concentrated reaction mixture containing $\mathrm{SnCl}_{4}$, the C6 position hydroxyl had gained an acetyl group at the C6 position which was not originally present. It was proposed that this was able to occur through either a Lewis acid mediated acetyl 
exchange between pyran compounds or through an intramolecular Lewis acid mediated acetyl transfer (Scheme 21).
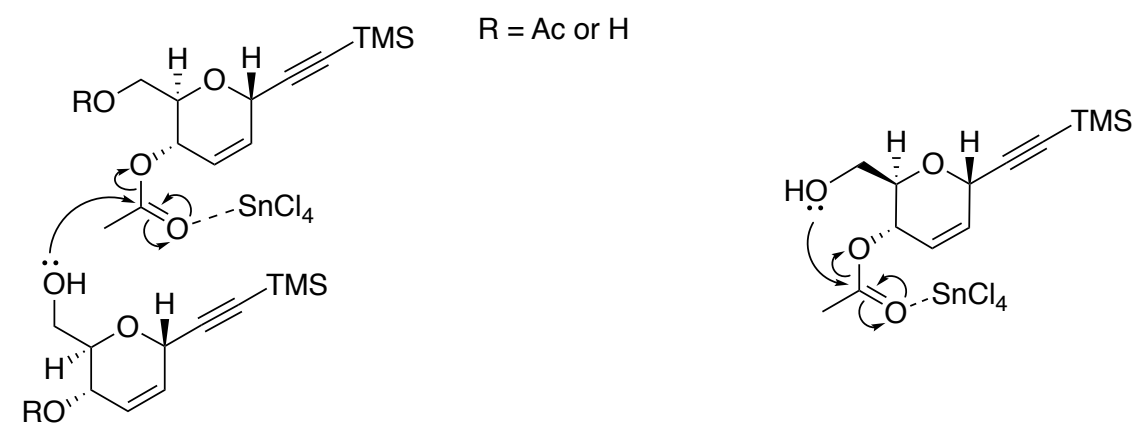

Scheme 21. Proposed intermolecular (left) and intramolecular (right) mechanisms for the acetyl transfer observed in the overnight $\mathrm{SnCl}_{4}$ Ferrier alkynylation.

After discovering that the overnight reaction conditions caused a C6 acetyl transfer, a second protocol based on Alvarez et al.'s work was employed. ${ }^{59}$ In this second protocol, the reaction time was drastically decreased from 16 hours to 15 minutes and the temperature dropped from $-20^{\circ} \mathrm{C}$ to $-78^{\circ} \mathrm{C}$. This was relatively successful and generated the TBS protected C-glycoside 86 in a 40\% yield and the TBS deprotected C-glycoside 88 in a 17\% yield (Scheme 22).

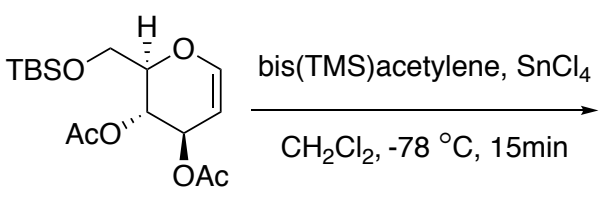

(83)

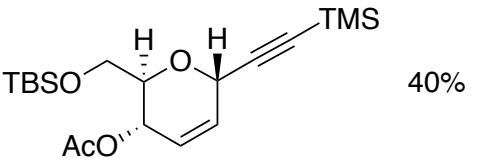

(86)

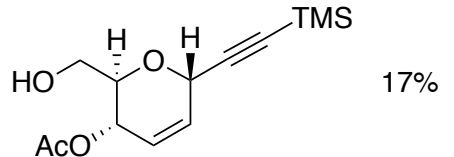

(88)

Scheme 22. Second Ferrier alkynylation with shorter, colder conditions.

Usefully, no C6 re-acetylation was observed with the TBS deprotected C-glycoside product during this Ferrier alkynylation. Encouraged by these results, it was decided to try to perform the Ferrier transformation and deprotection in situ to turn what was two planned steps into a single step. To do this, the reaction time was increased to 30 minutes to favour the deprotected product formation. This was relatively successful producing the TBS protected Cglycoside 86 in a 4\% yield and the desired TBS deprotected C-glycoside $\mathbf{8 8}$ in a $36 \%$ yield (Scheme 23). As compounds $\mathbf{8 6}$ and $\mathbf{8 8}$ were novel, full NMR characterisation was obtained. The spectroscopic NMR data for compound $\mathbf{8 6}$ are presented below (Table 2) along with the numbering system used for the position assignments (Figure 22). 


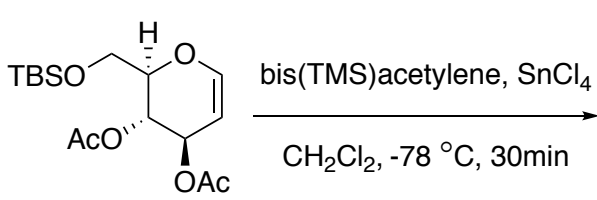

(83)
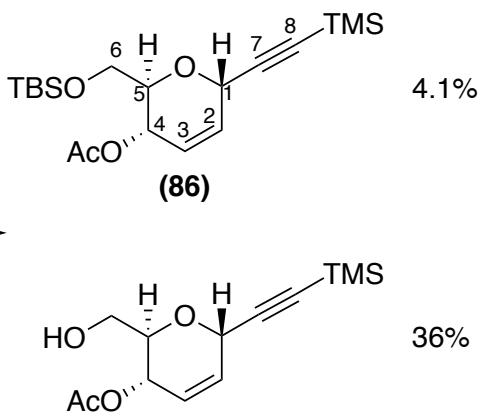

(88)

Scheme 23. Third attempt at the $\mathrm{SnCl}_{4}$ catalysed Ferrier alkynylation designed to favour the generation of the deprotected product, compound $\mathbf{8 8}$.

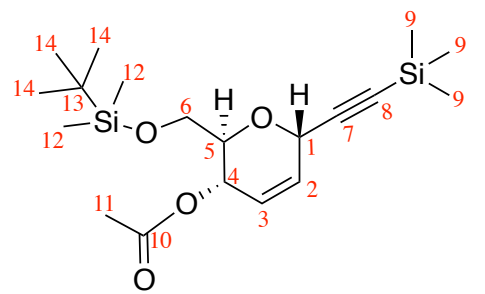

Figure 22. Numbered carbon environments of compound $\mathbf{8 6}$.

\begin{tabular}{|c|c|c|c|c|c|c|}
\hline ID & $\delta_{\mathrm{C}}$, Type & $\delta_{\mathrm{H}}$ & ${ }^{1} \mathrm{H}$ (multiplicity, integral, $J$ ) & COSY & HBMC & position \\
\hline $\mathrm{A}$ & $170.4, \mathrm{C}$ & - & - & - & - & $\mathrm{C} 10$ \\
\hline $\mathrm{B}$ & 129.3, $\mathrm{CH}$ & 5.86 & $\mathrm{~d}, 1 \mathrm{H}, 10.3 \mathrm{~Hz}$ & $\mathrm{C}, \mathrm{G}, \mathrm{H}$ & $\mathrm{C}, \mathrm{D}, \mathrm{G}, \mathrm{H}$ & $\mathrm{C} 2$ \\
\hline $\mathrm{C}$ & $125.6, \mathrm{CH}$ & 5.77 & $\mathrm{~d}, 1 \mathrm{H}, 10.2 \mathrm{~Hz}$ & $\mathrm{~B}, \mathrm{G}, \mathrm{H}$ & $\mathrm{D}, \mathrm{F}, \mathrm{G}, \mathrm{H}$ & $\mathrm{C} 3$ \\
\hline $\mathrm{D}$ & $101.4, \mathrm{C}$ & - & - & - & - & $\mathrm{C} 7$ \\
\hline $\mathrm{E}$ & $91.1, \mathrm{C}$ & - & - & - & - & $\mathrm{C} 8$ \\
\hline $\mathrm{F}$ & $72.8, \mathrm{CH}$ & 3.94 & $\mathrm{~m}, 1 \mathrm{H}$ & G,Ia,Ib & $\mathrm{C}, \mathrm{G}, \mathrm{H}, \mathrm{I}$ & $\mathrm{C} 5$ \\
\hline G & $65.1, \mathrm{CH}$ & 5.25 & $\mathrm{~d}, 1 \mathrm{H}, 8.8 \mathrm{~Hz}$ & $\mathrm{~F}, \mathrm{H}, \mathrm{B}, \mathrm{C}$ & $\mathrm{B}, \mathrm{C}, \mathrm{D}, \mathrm{F}, \mathrm{I}$ & $\mathrm{C} 4$ \\
\hline $\mathrm{H}$ & $64.1, \mathrm{CH}$ & 4.95 & $\mathrm{~s}, 1 \mathrm{H}$ & $\mathrm{G}, \mathrm{B}, \mathrm{C}$ & $\mathrm{B}, \mathrm{C}, \mathrm{D}, \mathrm{E}$ & $\mathrm{C} 1$ \\
\hline Ia & 63.1, $\mathrm{CH}_{2}$ & 3.8 & $\mathrm{~d}, 1 \mathrm{H}, 11.5 \mathrm{~Hz}$ & $\mathrm{Ib}, \mathrm{F}$ & $\mathrm{F}, \mathrm{G}$ & C6 \\
\hline $\mathrm{Ib}$ & - & 3.74 & $\mathrm{dd}, 1 \mathrm{H}, 5.3 \mathrm{~Hz}, 11.4 \mathrm{~Hz}$ & $\mathrm{Ia}, \mathrm{F}$ & $\mathrm{F}, \mathrm{G}$ & \\
\hline $\mathrm{J}$ & $25.9, \mathrm{CH}_{3}$ & 0.9 & $\mathrm{~s}, 9 \mathrm{H}$ & - & $\mathrm{L}$ & $\mathrm{C} 14$ \\
\hline $\mathrm{K}$ & $21.1, \mathrm{CH}_{3}$ & 2.08 & $\mathrm{~s}, 3 \mathrm{H}$ & - & $\mathrm{A}, \mathrm{G}$ & $\mathrm{C} 11$ \\
\hline $\mathrm{L}$ & $18.4, \mathrm{C}$ & - & - & - & - & $\mathrm{C} 13$ \\
\hline M & $-0.19, \mathrm{CH}_{3}$ & 0.17 & $\mathrm{~s}, 9 \mathrm{H}$ & - & $\mathrm{D}, \mathrm{E}$ & C9 \\
\hline $\mathrm{N}$ & $-5.26, \mathrm{CH}_{3}$ & 0.08 & $\mathrm{~s}, 3 \mathrm{H}$ & - & $\mathrm{L}, \mathrm{O}$ & $\mathrm{C} 12$ \\
\hline $\mathrm{O}$ & $-5.32, \mathrm{CH}_{3}$ & 0.06 & $\mathrm{~s}, 3 \mathrm{H}$ & - & $\mathrm{L}, \mathrm{N}$ & $\mathrm{C} 12$ \\
\hline
\end{tabular}


In order to prove the identity of compound $\mathbf{8 6}$ the NMR data were assigned as follows. Based on the ${ }^{13} \mathrm{C}$ NMR shift, type, ${ }^{1} \mathrm{H}$ NMR peak multiplicity, ${ }^{1} \mathrm{H}$ NMR shift and HMBC correlation data, the ${ }^{13} \mathrm{C}$ NMR peaks at $170.4 \mathrm{ppm}$ and $21.1 \mathrm{ppm}$ were assigned as the carbonyl and methyl positions of the acetate protecting group respectively. Using the ${ }^{13} \mathrm{C}$ NMR shift, type, ${ }^{1} \mathrm{H}$ NMR peak multiplicity, ${ }^{1} \mathrm{H}$ NMR shift and HMBC correlation data, the ${ }^{13} \mathrm{C}$ NMR peaks at $25.9 \mathrm{ppm}, 18.4 \mathrm{ppm},-5.26 \mathrm{ppm}$ and $-5.32 \mathrm{ppm}$ were assigned as the tert-butyl methyl groups, tert-butyl quaternary centre and the two silyl bound methyl groups respectively. Again, based on NMR shifts, ${ }^{1} \mathrm{H}$ NMR multiplicity and HMBC correlations, the ${ }^{13} \mathrm{C}$ NMR peak at 0.19 ppm was assigned the as the methyl carbons of the TMS group.

The ${ }^{13} \mathrm{C}$ NMR peaks at $129.3 \mathrm{ppm}$ and $125.6 \mathrm{ppm}$ were identified as the two alkene protons of the pyran ring based on the ${ }^{13} \mathrm{C}$ NMR peak shifts, ${ }^{1} \mathrm{H}$ NMR peak shifts, and the $10 \mathrm{~Hz}$ ${ }^{1} \mathrm{H}$ NMR peak coupling constants which are typical of $Z$-alkenes. The remaining two unassigned quaternary carbons $\left({ }^{13} \mathrm{C}\right.$ NMR peaks $101.4 \mathrm{ppm}$ and $\left.91.1 \mathrm{ppm}\right)$ were identified as the two alkyne carbons C7 and C8. Since the alkene protons of the pyran ring had HMBC correlations to the ${ }^{13} \mathrm{C}$ peak at $101.4 \mathrm{ppm}$ but not the peak at $91.1 \mathrm{ppm}$, the $101.4 \mathrm{ppm}$ peak was assigned to $\mathrm{C} 7$ and the $91.1 \mathrm{ppm}$ peak to $\mathrm{C} 8$. As the proton represented by the ${ }^{1} \mathrm{H}$ NMR peak at 4.95 ppm was the only one to show an $\mathrm{HMBC}$ correlation to $\mathrm{C} 8$, it was assigned as the proton at the anomeric $\mathrm{C} 1$ position in the pyran ring. Based on the HSQC correlation this then meant the ${ }^{13} \mathrm{C}$ NMR peak at $64.1 \mathrm{ppm}$ was assigned as $\mathrm{C} 1$. This assignment also matched the observed COSY correlations and expected the ${ }^{13} \mathrm{C}$ NMR and ${ }^{1} \mathrm{H}$ NMR shifts. As indicated above (Table 2), the COSY correlations of the alkene protons indicate the protons represented by the ${ }^{1} \mathrm{H}$ NMR peaks at $5.25 \mathrm{ppm}$ and $4.95 \mathrm{ppm}$ lie to either side of the alkene. Since the 4.95 ppm ${ }^{1} \mathrm{H}$ NMR peak has already been assigned to $\mathrm{C} 1$ then the $5.25 \mathrm{ppm}$ is likely the $\mathrm{C} 4$ proton. This assignment also matched the observed ${ }^{1} \mathrm{H}$ NMR multiplicity and the expected ${ }^{1} \mathrm{H}$ NMR peak shift for a proton at the $\mathrm{C} 4$ position. Matching these ${ }^{1} \mathrm{H}$ NMR peaks to their corresponding carbons using the HSQC data, the ${ }^{13} \mathrm{C}$ NMR peak at $64.1 \mathrm{ppm}$ represents $\mathrm{C} 1$ and the $65.1 \mathrm{ppm}$ peak represents $\mathrm{C} 4$. Based on the ${ }^{1} \mathrm{H}$ NMR integration and HSQC data, the carbon represented by the ${ }^{13} \mathrm{C}$ NMR peak at $63.1 \mathrm{ppm}$ should have two hydrogens. The only carbon in the Cglycoside 86 to have two bound hydrogens is the C6 position. The observed ${ }^{13} \mathrm{C}$ NMR and ${ }^{1} \mathrm{H}$ NMR shifts also match the expected shifts for the C6 position. The presence of HMBC 
correlations between the proposed C4 and C6 without any COSY correlations also provide further validation to the two assignments. Based on the COSY correlation data for H-6 and H4 , both appear to neighbour the proton represented by the ${ }^{1} \mathrm{H}$ NMR peak at $3.94 \mathrm{ppm}$. This would indicate the ${ }^{1} \mathrm{H}$ NMR peak at $3.94 \mathrm{ppm}$ to be the H-5 proton and therefore, based on the HSQC correlation, the ${ }^{13} \mathrm{C}$ NMR peak at $72.8 \mathrm{ppm}$ should be $\mathrm{C} 5$. Looking at the HMBC correlations of the $\mathrm{H}-5$ proton, the expected correlations to $\mathrm{C} 4$ and $\mathrm{C} 6$ are observed as well as two other useful correlations, one to $\mathrm{C} 1$ and another to the ${ }^{13} \mathrm{C}$ NMR peak at $125.6 \mathrm{ppm}$ (an alkene carbon). The HMBC coupling between $\mathrm{C} 1$ and $\mathrm{C} 5$ provides evidence that no ring opening of the pyran has occurred, while the correlation to the ${ }^{13} \mathrm{C}$ NMR peak at $125.6 \mathrm{ppm}$ allows the two alkene positions to be assigned. As C5 is more likely to show an HMBC correlation to $\mathrm{C} 3$ rather than $\mathrm{C} 2$, due to the increased distance of $\mathrm{C} 2$ from $\mathrm{C} 5$ compared to $\mathrm{C} 3$ from $\mathrm{C} 5$, the ${ }^{13} \mathrm{C}$ NMR peak at $125.6 \mathrm{ppm}$ will most likely represent the $\mathrm{C} 3$ carbon. Based on the assignment of this 1D and 2D NMR data, the compound isolated appears to be the expected TBS protected Ferrier transformed C-glycoside compound $\mathbf{8 6}$ as assigned below (Figure 23).

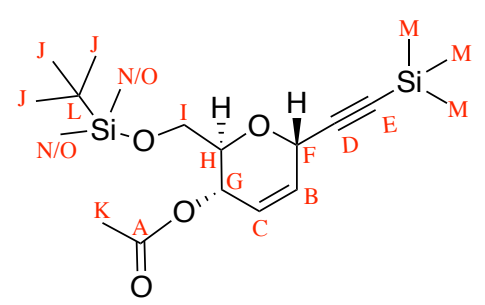

Figure 23. Compound 86 showing the ID assignments based on the $1 D$ and $2 D N M R$ data.

As with compound $\mathbf{8 6}$, to prove the identity of compound $\mathbf{8 8}$ full NMR characterisation was performed and the NMR data assigned to the compound. Based on the similar logic to that used in the assignment of compound $\mathbf{8 6}$, the carbons of compound $\mathbf{8 8}$ were assigned to the spectroscopic NMR data presented below (Table 3Error! Reference source not found.). For the assignment of the 2D NMR data, the numbering system shown below (Figure 24) was used.

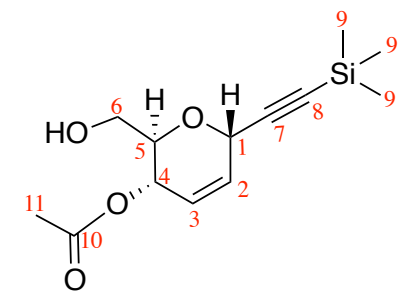

Figure 24. Numbered carbon environments of compound $\mathbf{8 8}$. 


\begin{tabular}{cccllll}
\hline ID & \multicolumn{1}{c}{$\delta_{\mathrm{C}}$, Type } & $\delta_{\mathrm{H}}$ & ${ }^{1} \mathrm{H}$ (multiplicity, integral, $J$ ) & COSY & HBMC & position \\
\hline A & $170.94, \mathrm{C}$ & - & - & - & - & $\mathrm{C} 10$ \\
$\mathrm{~B}$ & $129.18, \mathrm{CH}$ & 5.86 & $\mathrm{~d}, \mathrm{~J}=10.2 \mathrm{~Hz}, 1 \mathrm{H}$ & $\mathrm{C}, \mathrm{H}, \mathrm{G}$ & $\mathrm{D}, \mathrm{H}$ & $\mathrm{C} 2$ \\
$\mathrm{C}$ & $125.79, \mathrm{CH}$ & 5.77 & $\mathrm{~d}, \mathrm{~J}=10.3 \mathrm{~Hz}, 1 \mathrm{H}$ & $\mathrm{B}, \mathrm{H}, \mathrm{G}$ & $\mathrm{D}, \mathrm{F}, \mathrm{H}$ & $\mathrm{C} 3$ \\
$\mathrm{D}$ & $101.11, \mathrm{C}$ & - & - & - & - & $\mathrm{C} 7$ \\
$\mathrm{E}$ & $91.88, \mathrm{C}$ & - & - & - & - & $\mathrm{C} 8$ \\
$\mathrm{~F}$ & $72.12, \mathrm{CH}$ & 3.9 & $\mathrm{~m}, 1 \mathrm{H}$ & $\mathrm{I}, \mathrm{Ib}, \mathrm{G}$ & $\mathrm{G}, \mathrm{I}$ & $\mathrm{C} 5$ \\
$\mathrm{G}$ & $64.88, \mathrm{CH}$ & 5.32 & $\mathrm{~d}, \mathrm{~J}=8.9 \mathrm{~Hz}, 1 \mathrm{H}$ & $\mathrm{F}, \mathrm{H}, \mathrm{B}, \mathrm{C}$ & $\mathrm{A}, \mathrm{B}, \mathrm{C}, \mathrm{D}, \mathrm{F}, \mathrm{I}$ & $\mathrm{C} 4$ \\
$\mathrm{H}$ & $64.42, \mathrm{CH}$ & 4.96 & $\mathrm{~s}, 1 \mathrm{H}$ & $\mathrm{G}, \mathrm{B}, \mathrm{C}$ & $\mathrm{B}, 4, \mathrm{~F}$ & $\mathrm{C} 1$ \\
$\mathrm{I}$ & $62.18, \mathrm{CH} 2$ & 3.79 & $\mathrm{~d}, \mathrm{~J}=12.3 \mathrm{~Hz}, 1 \mathrm{H}$ & $\mathrm{F}, \mathrm{Ib}$ & $\mathrm{F}, \mathrm{G}$ & $\mathrm{C} 6$ \\
$\mathrm{Ib}$ & - & 3.64 & $\mathrm{dd}, \mathrm{J}=12.3,5.1 \mathrm{~Hz}, 1 \mathrm{H}$ & $\mathrm{F}, \mathrm{I}$ & $\mathrm{F}, \mathrm{G}$ & \\
$\mathrm{J}$ & $21.21, \mathrm{CH}_{3}$ & 2.11 & $\mathrm{~s}, 3 \mathrm{H}$ & - & $\mathrm{A}, \mathrm{G}$ & $\mathrm{C} 11$ \\
$\mathrm{~K}$ & $-0.06, \mathrm{CH}_{3}$ & 0.18 & $\mathrm{~s}, 9 \mathrm{H}$ & - & $\mathrm{D}, \mathrm{E}$ & $\mathrm{C} 9$ \\
\hline
\end{tabular}

Table 3. Tabulated NMR spectroscopic data (500MHz, CDCl3) for compound $\mathbf{8 8}$.

Based on the same reasoning used in compound 86, the ${ }^{13} \mathrm{C}$ NMR peaks at $170.94 \mathrm{ppm}$ and $21.21 \mathrm{ppm}$ were assigned the carbonyl and methyl carbons of the acetate group respectively and the -0.06 ppm peak the methyl carbons of the TMS group. In accord with compound $\mathbf{8 6}$, the ${ }^{13} \mathrm{C}$ NMR peaks at $129.18 \mathrm{ppm}$ and $125.79 \mathrm{ppm}$ were assigned as the alkene peaks, C2 and $\mathrm{C} 3$ respectively, while the peaks at $101.11 \mathrm{ppm}$ and $91.88 \mathrm{ppm}$ were assigned as the alkyne peaks, $\mathrm{C} 7$ and $\mathrm{C} 8$. The ${ }^{13} \mathrm{C}$ NMR peak at 62.18 ppm was assigned as the $\mathrm{C} 6$ carbon based on the ${ }^{1} \mathrm{H}$ NMR integration and HSQC correlation data. The ${ }^{13} \mathrm{C}$ NMR peaks at $72.12 \mathrm{ppm}, 64.88$ ppm and 64.42 ppm were assigned as $\mathrm{C} 5, \mathrm{C} 4$ and $\mathrm{C} 1$ respectively, based on the same logic used in the assignment of compound 86 (Figure 25).

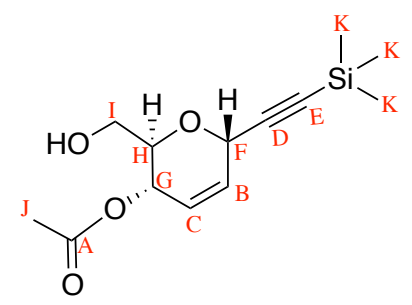

Figure 25. Compound 88 showing the ID assignments based on the $1 D$ and $2 D$ NMR data. 


\subsection{Oxidation of the primary hydroxyl group in compound $\mathbf{8 8}$}

Following on from the success of the Ferrier transformation, oxidation of the primary alcohol at C6 was attempted using a procedure from Sridar et al. ${ }^{78}$ In this procedure the radical oxidant TEMPO, and co-oxidant BAIB, were used to oxidise the primary alcohol to a carboxylic acid in a biphasic solvent mixture (Scheme 24).

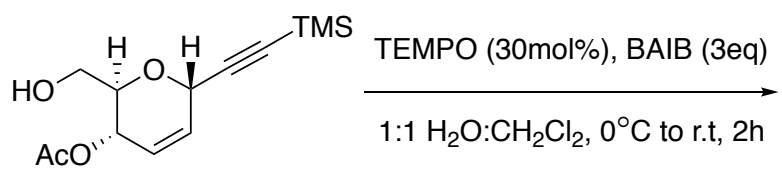

(88)

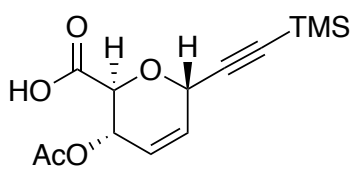

(90)

Scheme 24. TEMPO-BAIB oxidation of primary alcohol.

Following this procedure, carboxylic acid 90 was successfully obtained in a $29 \%$ yield. As TLC analysis of the reaction indicated good conversion from starting material to product, this yield was surprisingly low. After re-examination of the protocol set out by Sridar et al., it was noted that the reaction workup was at a neutral $\mathrm{pH}$. Since carboxylic acids typically have a $\mathrm{pKa}$ of $\sim 5$, in a neutral solution ( $\mathrm{pH} 7$ ) they will primarily exist in the carboxylate form. This means that during a neutral workup the majority of the product will sequester to the aqueous layer. To counteract this, a second attempt of the reaction was performed whereby acetic acid was added to the workup procedure to help favour the protonated form of the acid. This was expected to protonate the carboxylate ion, forming the carboxylic acid, and help it sequester to the organic layer. As the carboxylic acid would require a $1 \%$ acetic acid solvent system during silica purification, it was not considered problematic to contaminate the organic layer with acetic acid during workup. The addition of acetic acid to the workup then lead to an improved yield of 54\%. This yield again seemed a little low based on the good conversion observed in the TLC analysis. To further improve upon this yield, a third attempt was made whereby the workup was acidified using acetic acid and $\mathrm{KHSO}_{4}$. This was expected to acidify both the aqueous and organic layers more effectively. This led to a greatly improved yield of $87 \%$. As with the previous Ferrier transformation products, this compound was novel and as such, full NMR characterisation data was obtained to prove the identity of the compound and are presented below (Table 4) along with the numbering system used for the position assignments (Figure 26). 


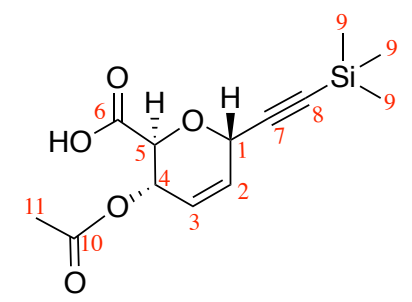

Figure 26. Numbered carbon environments of compound 90.

\begin{tabular}{ccclllc}
\hline ID & $\delta_{\mathrm{C}}$, Type & $\delta_{\mathrm{H}}$ & ${ }^{1} \mathrm{H}$ (multi, integral, J) & COSY & HBMC & position \\
\hline $\mathrm{A}$ & $172.87, \mathrm{C}$ & - & - & - & - & $\mathrm{C} 10$ \\
$\mathrm{~B}$ & $170.62, \mathrm{C}$ & - & - & - & - & $\mathrm{C} 6$ \\
$\mathrm{C}$ & $129.89, \mathrm{CH}$ & 5.95 & $\mathrm{~d}, \mathrm{~J}=10.3 \mathrm{~Hz}, 1 \mathrm{H}$ & $\mathrm{I}, \mathrm{D}, \mathrm{H}^{*}$ & $\mathrm{D}, \mathrm{E}, \mathrm{H}, \mathrm{I}$ & $\mathrm{C} 2$ \\
$\mathrm{D}$ & $123.96, \mathrm{CH}$ & 5.82 & $\mathrm{~d}, \mathrm{~J}=10.2 \mathrm{~Hz}, 1 \mathrm{H}$ & $\mathrm{I}, \mathrm{H}, \mathrm{C}$ & $\mathrm{C}, \mathrm{G}, \mathrm{I}$ & $\mathrm{C} 3$ \\
$\mathrm{E}$ & $99.88, \mathrm{C}$ & - & - & - & - & $\mathrm{C} 7$ \\
$\mathrm{~F}$ & $92.79, \mathrm{C}$ & - & - & - & - & $\mathrm{C} 8$ \\
$\mathrm{G}$ & $71.27, \mathrm{CH}$ & 4.54 & $\mathrm{~d}, \mathrm{~J}=6.9 \mathrm{~Hz}, 1 \mathrm{H}$ & $\mathrm{H}$ & $\mathrm{A}, \mathrm{D}, \mathrm{H}, \mathrm{I}$ & $\mathrm{C} 5$ \\
$\mathrm{H}$ & $64.89, \mathrm{CH}$ & 5.54 & $\mathrm{~d}, \mathrm{~J}=5.7 \mathrm{~Hz}, 1 \mathrm{H}$ & $\mathrm{G}, \mathrm{I}, \mathrm{D}, \mathrm{C}^{*}$ & $\mathrm{~A}, \mathrm{~B}, \mathrm{C}, \mathrm{D}, \mathrm{G}$ & $\mathrm{C} 4$ \\
$\mathrm{I}$ & $63.97, \mathrm{CH}$ & 5.17 & $\mathrm{~s}, 1 \mathrm{H}$ & $\mathrm{C}, \mathrm{D}, \mathrm{H}^{*}$ & $\mathrm{C}, \mathrm{D}, \mathrm{E}, \mathrm{F}, \mathrm{G}$ & $\mathrm{C} 1$ \\
$\mathrm{~J}$ & $21.11, \mathrm{CH}$ & 2.12 & $\mathrm{~s}, 3 \mathrm{H}$ & - & $\mathrm{B}$ & $\mathrm{C} 11$ \\
$\mathrm{~K}$ & $-0.14, \mathrm{CH}_{3}$ & 0.18 & $\mathrm{~s}, 9 \mathrm{H}$ & - & E,F & $\mathrm{C} 9$ \\
\hline
\end{tabular}

Table 4. Tabulated NMR spectroscopic data (500MHz, CDCl3) for compound 90.

Based on the previous assignments of compounds 86 and $\mathbf{8 8}$, the ${ }^{13} \mathrm{C}$ NMR peaks were assigned to compound 90 (Figure 27). Of particular note during the assignments for compound 90, was the disappearance of the ${ }^{13} \mathrm{C}$ NMR peak at $62 \mathrm{ppm}$ observed in compound $\mathbf{8 8}$, representing a $\mathrm{CH}_{2}$ group, and the appearance of a new 173 ppm peak representing a carbonyl carbon in compound 90. As both $\mathrm{C} 4$ and $\mathrm{C} 5$ appear to show HMBC correlations to this new peak, it would appear that it does indeed represent the C6 position. This result is in line with the expected changes caused by $\mathrm{C} 6$ oxidation.

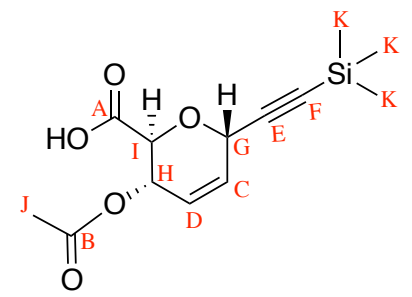

Figure 27. Compound 90 showing ID assignments based on the $1 D$ and $2 D N M R$ data. 


\subsection{Amide Coupling}

After the successful generation of the carboxylic acid, which was the anticipated end point for the project, a proof of concept peptide coupling was performed. This coupling was done to prove that the generated carboxylic acid 90, was compatible with the coupling chemistry required in the assembly of the proposed peloruside analogue. To do this coupling, a procedure used by Woon et al. based on a classical carbodiimide coupling strategy was followed. ${ }^{79}$ Using the carbodiimide EDCI, the peptide coupling additive HOBt and the hindered base DIPEA, the coupling of methyl glycinate (glycine methyl ester) to compound 90 was performed (Scheme 25).

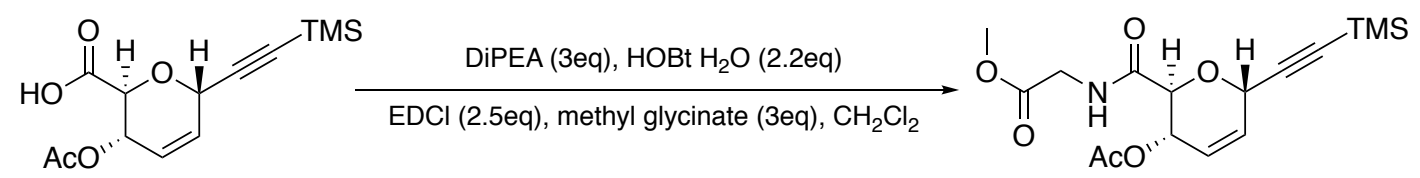

(90)

(91)

Scheme 25. Peptide coupling using Woon et al.'s conditions.

Following this procedure on a $20 \mathrm{mg}$ scale, resulted in the successful formation of the glycine adduct 91 in a $40 \%$ yield post-purification. Of particular interest with this attempt at the reaction, was that the glycine adduct was obtained in a crude yield of $70 \%$. Based on a comparison of the ${ }^{1} \mathrm{H}$ NMR spectra for the crude and pure material (Figure 28), it seems unlikely that there were enough contaminants in the crude mixture to cause a 30 percentage point decrease in yield post-purification. Due to the scale of the reaction, any loss of material even a single milligram, will have a significant effect on the total yield. Since the ${ }^{1} \mathrm{H}$ NMR of the crude material appears to be relatively clean and the reaction was done on a small scale, it may be possible that the true yield of the reaction is higher than $40 \%$. Although this step remains unoptimized, it was able to prove that the peptide coupling chemistry is compatible with the pyran compound produced from this project. 


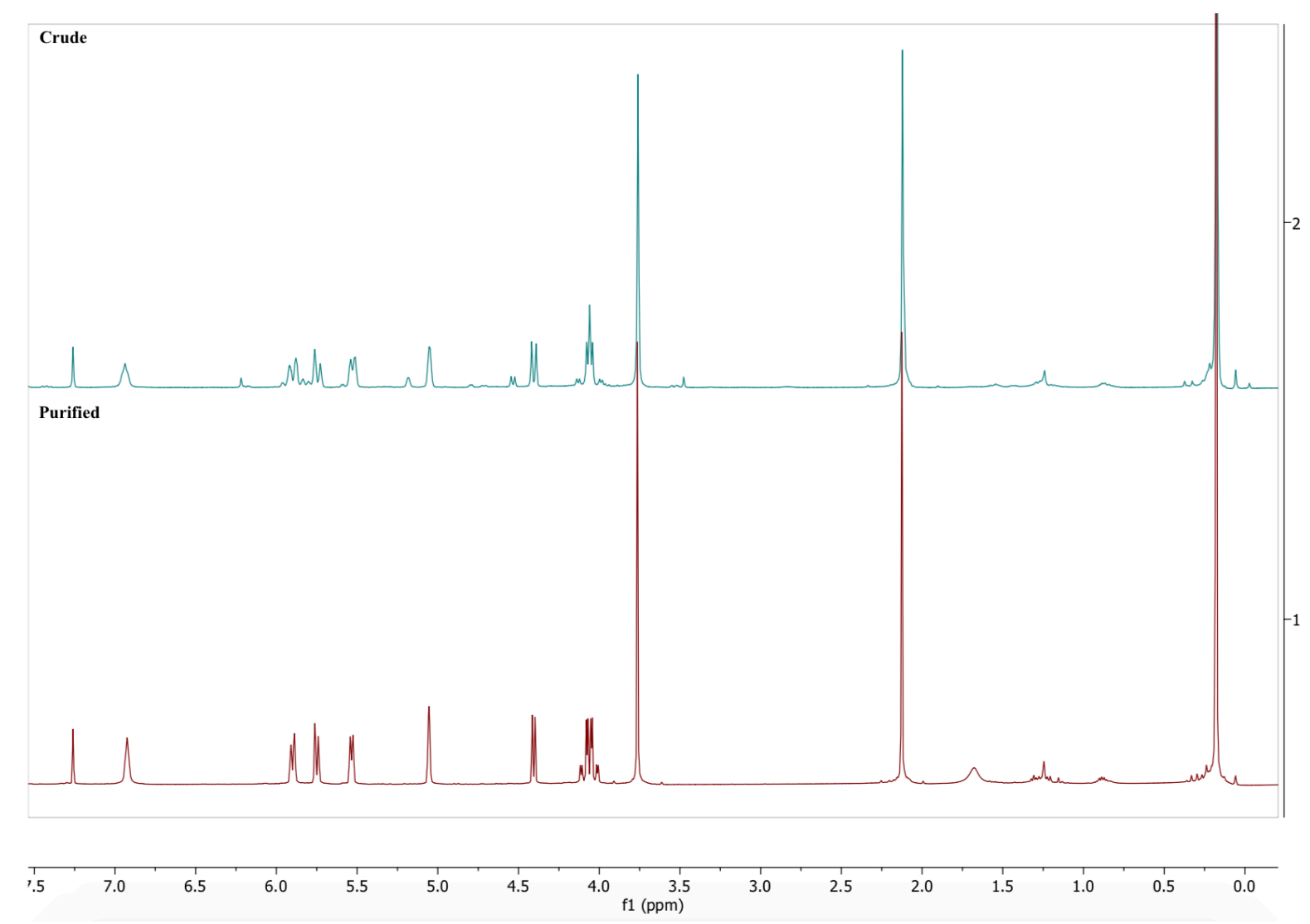

Figure 28. ${ }^{I} H$ NMR spectra of crude glycine adduct reaction (top, teal) and purified glycine adduct (bottom, red).

As with the previously made novel compounds, full NMR characterisation was obtained for the peptide coupled pyran compound 91 shown below (Table 5) along with the numbering system used for the position assignments (Figure 29).

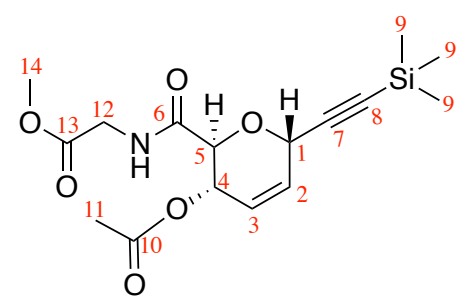

Figure 29. Numbered carbon environments of compound 91. 


\begin{tabular}{|c|c|c|c|c|c|c|}
\hline ID & $\delta_{\mathrm{C}}$, Type & $\delta_{\mathrm{H}}$ & ${ }^{1} \mathrm{H}$ (multi, integral, $J$ ) & COSY & HBMC & position \\
\hline $\mathrm{A}$ & $170.3, \mathrm{C}$ & - & - & - & - & $\mathrm{C} 10$ \\
\hline $\mathrm{B}$ & $169.9, \mathrm{C}$ & - & - & - & - & $\mathrm{C} 13$ \\
\hline $\mathrm{C}$ & $168.9, \mathrm{C}$ & - & - & - & - & C6 \\
\hline $\mathrm{D}$ & $128.6, \mathrm{CH}$ & 5.90 & $\mathrm{dd}, 1 \mathrm{H}, 10.2 \mathrm{~Hz}, 1.1 \mathrm{~Hz}$ & $\mathrm{E}, \mathrm{J}, \mathrm{I}^{*}$ & $\mathrm{E}, \mathrm{I}, \mathrm{J}$ & $\mathrm{C} 2$ \\
\hline $\mathrm{E}$ & $125.4, \mathrm{CH}$ & 5.75 & $\mathrm{dd}, 1 \mathrm{H}, 10.1 \mathrm{~Hz}, 1.3 \mathrm{~Hz}$ & $\mathrm{D}, \mathrm{I}, \mathrm{J}$ & $\mathrm{D}, \mathrm{H}, \mathrm{J}$ & $\mathrm{C} 3$ \\
\hline $\mathrm{F}$ & $99.8, \mathrm{C}$ & - & - & - & - & $\mathrm{C} 7$ \\
\hline $\mathrm{G}$ & $92.9, \mathrm{C}$ & - & - & - & - & $\mathrm{C} 8$ \\
\hline $\mathrm{H}$ & $70.7, \mathrm{CH}$ & 4.41 & $\mathrm{~d}, 1 \mathrm{H}, 8.3 \mathrm{~Hz}$ & I & $\mathrm{J}, \mathrm{I}, \mathrm{E}, \mathrm{C}$ & $\mathrm{C} 5$ \\
\hline I & $65.2, \mathrm{CH}$ & 5.53 & $\mathrm{dt}, 1 \mathrm{H}, 8.3 \mathrm{~Hz}, 1.7 \mathrm{~Hz}$ & $\mathrm{D}, \mathrm{E}, \mathrm{H}, \mathrm{J}$ & $\mathrm{H}, \mathrm{E}, \mathrm{D}, \mathrm{A}, \mathrm{C}$ & $\mathrm{C} 4$ \\
\hline $\mathrm{J}$ & $64.1, \mathrm{CH}$ & 5.05 & broad $\mathrm{s}, 1 \mathrm{H}$ & $\mathrm{D}, \mathrm{E}, \mathrm{I}$ & $\mathrm{H}, \mathrm{G}, \mathrm{F}, \mathrm{D}, \mathrm{E}$ & $\mathrm{C} 1$ \\
\hline $\mathrm{K}$ & $52.4, \mathrm{CH}_{3}$ & 3.76 & $\mathrm{~s}, 3 \mathrm{H}$ & - & B & $\mathrm{C} 14$ \\
\hline $\mathrm{L}$ & $40.7, \mathrm{CH}_{2}$ & 4.09 & $\mathrm{dd}, 1 \mathrm{H}, 18.4 \mathrm{~Hz}, 5.5 \mathrm{~Hz}$ & $\mathrm{O}$ & $\mathrm{C}, \mathrm{B}$ & $\mathrm{C} 12$ \\
\hline $\mathrm{Lb}$ & & 4.03 & $\mathrm{dd}, 1 \mathrm{H}, 18.4 \mathrm{~Hz}, 5.5 \mathrm{~Hz}$ & $\mathrm{O}$ & $\mathrm{C}, \mathrm{B}$ & \\
\hline M & $21.1, \mathrm{CH}_{3}$ & 2.13 & $\mathrm{~s}, 3 \mathrm{H}$ & - & A,I & $\mathrm{C} 11$ \\
\hline $\mathrm{N}$ & $-0.3, \mathrm{CH}_{3}$ & 0.18 & $\mathrm{~s}, 9 \mathrm{H}$ & - & $\mathrm{G}$ & C9 \\
\hline $\mathrm{O}$ & - & 6.92 & $\mathrm{t}, 1 \mathrm{H}, 4.9 \mathrm{~Hz}$ & $\mathrm{~L}, \mathrm{Lb}$ & $\mathrm{L}, \mathrm{B}, \mathrm{C}$ & $\mathrm{NH}$ \\
\hline
\end{tabular}

Table 5. Tabulated NMR spectroscopic data (500MHz, CDCl3) for compound 91.

Based on the logic used for previous compound assignments, the ${ }^{13} \mathrm{C}$ NMR peaks were assigned for the carbon positions 1 through to 11 . The ${ }^{1} \mathrm{H}$ NMR peak for the NH position was identified as the only peak to have no HSQC correlation. As the ${ }^{13} \mathrm{C} N M R$ had a new peak at $40.7 \mathrm{ppm}$ which had two associated protons that both coupled to the NH peak $(J=4.9 \mathrm{~Hz})$ in the ${ }^{1} \mathrm{H}$ NMR spectrum, this $40.7 \mathrm{ppm}$ peak was assigned as the $\mathrm{C} 12$ carbon. The new $52.4 \mathrm{ppm}$ peak in the ${ }^{13} \mathrm{C}$ NMR spectra, was identified as a $\mathrm{CH}_{3}$ group based on HSQC and ${ }^{1} \mathrm{H}$ NMR data. As the only unassigned $\mathrm{CH}_{3}$ group was that at the $\mathrm{C} 14$ position, the $13 \mathrm{C}$ NMR peak at 52.4 ppm was assigned as the $\mathrm{C} 14$ carbon. This position also showed an HMBC correlation to the new ${ }^{13} \mathrm{C}$ NMR peak at 169.9 ppm indicating it to be the carbon at $\mathrm{C} 13$.

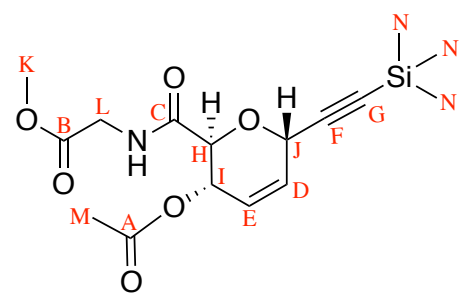

Figure 30. Compound 91 showing ID assignments based on the $1 D$ and $2 D$ NMR data. 


\section{Chapter 4. Summary and Future Work.}

\subsection{Summary}

The aim of this project was to develop a synthetic pathway, starting from a basic carbohydrate that was capable of generating a novel pyran fragment for the incorporation into a simplified analogue of peloruside. After a series of unsuccessful attempts at generating the functionalised pyran fragment using a trityl or acetal protecting strategy, a TBS protection strategy proved to be successful (Scheme 26). The synthesis of the functionalised pyran fragment 90 was successfully achieved, after a series of optimisations, in a respectable $18 \%$ yield over 5 steps. Additionally, using the synthetic strategy developed, it was possible to reduce the number of linear steps to form the functionalised pyran $\mathbf{9 0}$ from six steps down to five. As the primary end point was reached ahead of time, a peptide coupling was performed which demonstrated the functionalised pyran 90 to be compatible with the peptide coupling conditions that would be required in the final peloruside analogue formation.

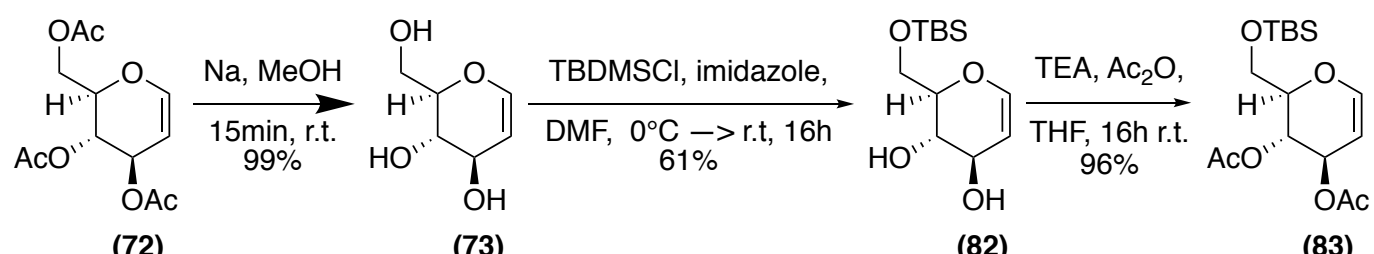

(83)

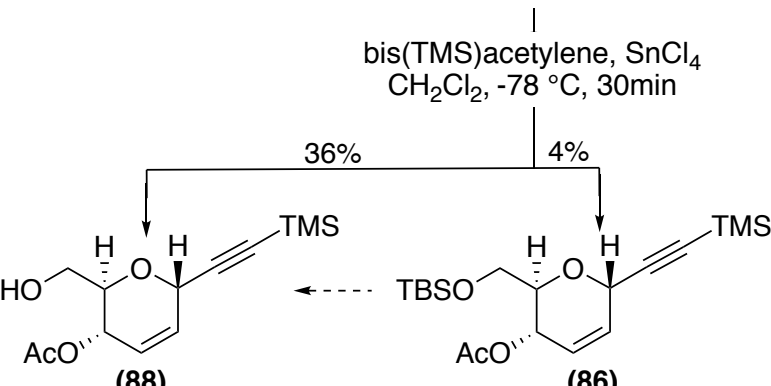

(90)

DiPEA, HOBt $\mathrm{H}_{2} \mathrm{O}$

$\mathrm{EDCl}$, methyl glycinate, $\mathrm{CH}_{2} \mathrm{Cl}_{2}$<smiles>COC(=O)CNC(=O)[C@H]1O[C@H](C#CC(C)(C)C)C=C[C@H]1O</smiles>

(91) 


\subsection{Future work}

\subsubsection{Copper CATALyZED CyClOADDition REACTION}

As another proof of concept reaction, it would be worthwhile attempting a copper catalyzed azide-alkyne cycloaddition (CuAAC) on pyran $\mathbf{9 0}$ to test whether it would be compatible with the reaction conditions (Scheme 27). The CuAAC is a well-documented reaction developed by Sharpless in 2001 and is intended to be used for coupling the sidechain fragment to the pyran ring. ${ }^{80}$ As this reaction will be a crucial step in the production of the overall analogue, it is worth testing whether the reaction will work properly with the pyran fragment. Before the CuAAC can be performed, the protection of the carboxylic acid and subsequent deprotection of the TMS acetylene will likely be required. Protection of the carboxylic acid should theoretically be relatively non-problematic as similar protections are well precedented in literature, such as Niek et al.'s potassium carbonate and methyl iodide in DMF, ${ }^{81}$ Jiang et al.'s thionyl chloride methanol, ${ }^{82}$ and even Doi et al.'s TMS diazomethane in diethyl ether method. ${ }^{83}$ After the carboxylic acid is protected following one of these procedures, the TMS group may potentially be removed using a TBAF-THF procedure similar to that used by Vasella et al. ${ }^{84}$ If the suitably protected pyran can be prepared using these methods, it would be interesting to attempt the reaction using the standard CuAAC conditions developed by Sharpless. ${ }^{80}$

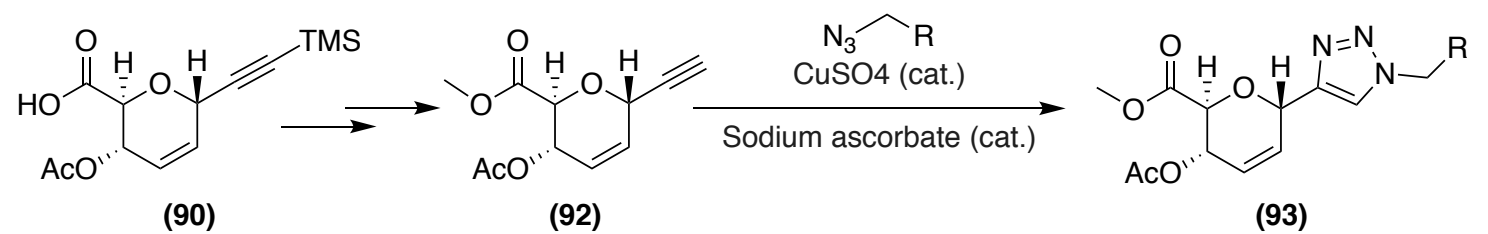

Scheme 27. Proposed future CuAAC reaction.

\subsubsection{ANOMERIC STEREOCHEMICAL INVERSION}

Since the synthetic strategy developed only produces the 2,6-trans substituted pyran ring, for the sake of analogue generation, it would be interesting to perform an inversion of the stereochemistry at the anomeric position to form the 2,6-cis substituted pyran ring. This type of chemistry has been performed on a similar substrate by Tanaka et al. ${ }^{85}$ but never on substrate with the same functionality. Since there is no precedent of a substrate with the same functionality undergoing this type of reaction, it is unknown whether the substrate will be compatible.$^{85}$ In order to attempt the stereochemical inversion, the alkyne will need to be 
transformed using cobalt octacarbonyl, and then treated with triflic acid. This should cause the pyran ring to open, forming a planar carbocation, and then recyclise to generate the $\beta$-anomer preferentially. ${ }^{85}$ After forming the $\beta$-anomer, the cobalt carbonyl complex may be removed via iodine oxidation (Scheme 28).

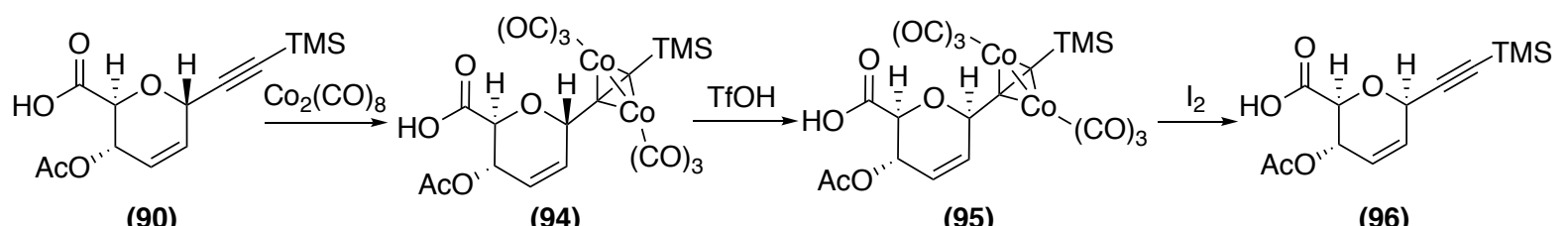

(90)

(94)

(95)

(96)

Scheme 28. Proposed stereochemical inversion at the anomeric position using cobalt octacarbonyl and triflic acid.

\subsubsection{MODIFICATIONS AT THE PYRAN C4}

As PelA has no functionality at the C6 position, it would be interesting to generate a variety of different pyran analogues with various substituents at the equivalent position (Scheme 29). This would enable further SAR studies to be performed using these new peloruside analogues. The first proposed $\mathrm{C} 4$ modification would be to remove the acetate at $\mathrm{C} 4$ to produce an analogue with a free hydroxyl. This could potentially be done by treating compound 86 with DIBAL following a method similar to Wang et al. ${ }^{86}$ After the acetate deprotection, the alcohol of compound 97 could be retained, transformed to a methoxy group through treatment with methyl iodide and silver oxide in DMF, ${ }^{87}$ or even methyl iodide and sodium hydride in THF. ${ }^{88}$ This would enable the generation of further peloruside analogues for SAR studies. As peloruside has no polar functionality at the C6 position, it would be worth investigating the activity of analogues with no polar functionality at the equivalent position. To do this, the free hydroxyl in compound $\mathbf{9 7}$ may be converted to a xanthate using methods such as Comba et al.'s methyl iodide-carbon disulfide stratergy. ${ }^{89}$ After the generation of the xanthate, the $\mathrm{C} 4$ position may be deoxygenated using a classical Barton-McCombie procedure involving the radical initiator AIBN and $\mathrm{Bu}_{3} \mathrm{SnH} .{ }^{90}$ This will make the pyran fragment more similar to the original pyran section of peloruside A, enabling better comparison of the differences between PelA and the proposed analogue. These modifications may potentially generate new analogues which will give better insight into the effect of polar groups at the C6 position in peloruside. 


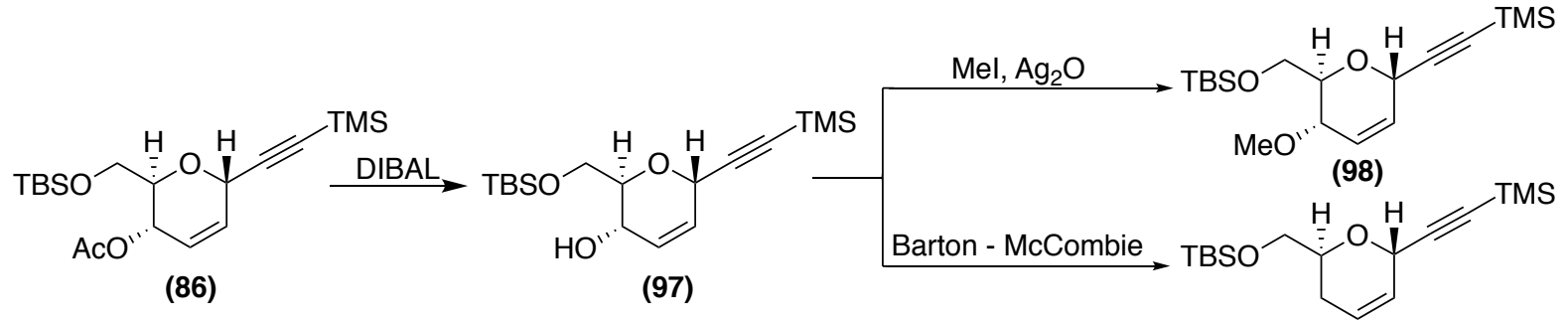

(99)

Scheme 29. Potential C4 modified analogues.

\subsection{Conclusion}

Despite the difficulties encountered with the earlier synthetic routes, an approach using the TBS protecting group ultimately proved successful. Using this approach, the proposed endpoint of this project was successfully reached and extended upon, to prove functional compatibility with the peptide coupling conditions required in the assembly of the overall peloruside analogue. Through a series of optimisations, including an optimisation to reduce the number of linear steps, the target compound for the project was successfully generated in an overall 18\% yield. This synthetic route increases the number of different possible approaches towards the generation of the proposed peloruside analogue. Further functionalisation of the pyran fragment, as suggested in section 4.2, will lead to a greater array of peloruside analogues which, in turn, will enable further elucidation of the binding properties of peloruside A. Through the elucidation of these binding properties, it may be possible to improve the bioactivity of the analogue, potentially leading to a new chemotherapeutic agent. 


\section{Experimental.}

\subsection{General Experimental}

Unless otherwise stated, the following conditions were applied. Common solvents: dichloromethane $\left(\mathrm{CH}_{2} \mathrm{Cl}_{2}\right)$, tetrahydrofuran (THF) and diethylether $\left(\mathrm{Et}_{2} \mathrm{O}\right)$, were taken from Innovative Technology's PureSolv solvent purification system. Triethylamine was used freshly distilled from $\mathrm{CaH}_{2}$. Methanol (MeOH) was distilled from magnesium turnings and iodine then dried over activated $3 \AA$ molecular sieves. Other reagents were used as obtained from commercial suppliers without further purification. All reaction glassware was flame-dried under vacuum before use. All reactions were performed under an inert atmosphere of argon delivered via balloon unless the reaction was performed in $\mathrm{H}_{2} \mathrm{O}$ or an $\mathrm{H}_{2} \mathrm{O}$-solvent system. Reaction progress was monitored using thin layer chromatography (TLC) with silica G/UV254 pre-coated polyester plates and visualised by ceric ammonium molybdate or $p$-anisaldehyde stains. Retention factor ( $\mathrm{Rf}$ ) values were calculated by dividing the run distance of the compound by the run distance of the solvent system. Purification of products via flash chromatography was conducted using a column filled with Silica Zeoprep 60 (40-63 microns) as the matrix, obtained from Pure Science Ltd, with solvent systems as indicated. ${ }^{1} \mathrm{H},{ }^{13} \mathrm{C}$, COSY, HSQC and HMBC NMR spectra were recorded on a Varian Unity Inova 500. The spectrometer was operating at $500 \mathrm{MHz}$ for ${ }^{1} \mathrm{H}$ nuclei and $125 \mathrm{MHz}$ for ${ }^{13} \mathrm{C}$ nuclei. In certain cases spectra were also obtained on Varian Unity Inova 600 (operating at $600 \mathrm{MHz}$ for ${ }^{1} \mathrm{H}$ nuclei and $151 \mathrm{MHz}$ for ${ }^{13} \mathrm{C}$ nuclei). Spectra were recorded in the solvent indicated, typically chloroform-d. Proto-deuterated solvent signals were used as internal references $\left(\mathrm{CDCl}_{3}: \delta \mathrm{H}\right.$ $7.26, \delta \mathrm{C} 77.16)$ with the chemical shifts, expressed in parts per million (ppm), relative to the expected value of tetramethylsilyl. Mass spectra were obtained using electrospray ionisation (ESI) technique on an Agilent 6530 Accurate Mass Q-TOF LC/MS instrument. Mass spectral data are quoted as molecular ion peaks $\mathrm{m} / \mathrm{z}$. Infrared spectra were obtained on a Bruker Tensor 27 FTIR spectrometer with ATR accessory and quoted as wavelengths $(v)$ in $\mathrm{cm}^{-1}$. All novel compounds are presented with structure, method of preparation, Rf, ${ }^{1} \mathrm{H}$ NMR, ${ }^{13} \mathrm{C}$ NMR, HRMS and IR. Non-novel compounds are presented with structure, method of preparation, Rf, ${ }^{1} \mathrm{H}$ NMR and ${ }^{13} \mathrm{C}$ NMR where applicable. Compounds that were unintentionally produced are presented with structure, $\mathrm{Rf}$ and ${ }^{1} \mathrm{H}$ NMR. 


\section{D-Glucal (73)}

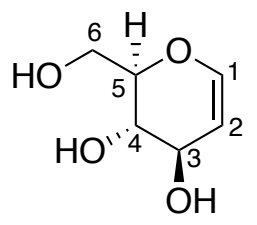

To a solution of tri- $O$-acetyl-D-glucal $72(9.72 \mathrm{~g}, 35.70 \mathrm{mmol})$ in $\mathrm{MeOH}(180 \mathrm{~mL}, 0.2$ $\mathrm{M})$, sodium $(0.26 \mathrm{~g}, 10.71 \mathrm{mmol}, 0.3 \mathrm{eq})$ was added and the reaction mixture was left to stir at r.t. After 15 minutes the reaction was deemed complete via TLC analysis (1:1 Hex:EtOAc) and the solution was reduced in vacuo giving a viscous yellow oil that was used crude in the next step (5.165 g, 99\% yield). The spectral data obtained matched those previously reported in the literature. $^{91}$

$\mathbf{R}_{\mathbf{f}}=0.18\left(\right.$ EtOAc); ${ }^{1} \mathbf{H}$ NMR $\left(500 \mathrm{MHz}, \mathrm{D}_{2} \mathrm{O}\right) \delta 6.39(\mathrm{dd}, J=6.3 \mathrm{~Hz}, 1.5 \mathrm{~Hz}, 1 \mathrm{H}, \mathrm{H}-1), 4.20$ (dt, $J=7.0 \mathrm{~Hz}, 2.0 \mathrm{~Hz}, 1 \mathrm{H}, \mathrm{H}-2), 3.88$ (m, 1H, H-5), 3.85 (m, 2H, H-6), 3.65 (dd, $J=9.0 \mathrm{~Hz}$, $7.0 \mathrm{~Hz}, 1 \mathrm{H}, \mathrm{H}-4), 3.32$ (s, 1H, H-3)

\section{6-O-Trityl-D-glucal (74)}

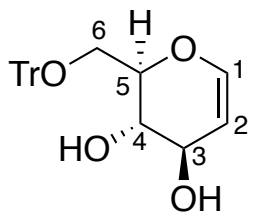

At room temperature, trityl chloride (1.699 g, $6.096 \mathrm{mmol}, 1.5 \mathrm{eq})$ was added to Dglucal (73) (0.5939 g, $4.064 \mathrm{mmol})$ in a solution of $\mathrm{CH}_{2} \mathrm{Cl}_{2}(9.3 \mathrm{~mL})$ and $\mathrm{NEt}_{3}(1.1 \mathrm{~mL}, 8.128$ mmol, 2 eq) over a period of three minutes. The solution was stirred for 16 hours after which, TLC analysis showed completion of the reaction. The sample was concentrated in vacuo and extracted with $\mathrm{CHCl}_{3}(3 \times 10 \mathrm{~mL})$. The organic layers were combined and washed with sat. aq. $\mathrm{NaHCO}_{3}(3 \times 10 \mathrm{~mL})$ and dried over anhydrous $\mathrm{MgSO}_{4}$. The solution was filtered and concentrated in vacuo to obtain a yellow oil. The crude yellow oil was purified via silica gel chromatography (1:1 Hex:EtOAc, v:v) to afford 3 as a white solid (1.048 g, 66\% yield). The spectral data obtained matched those previously reported in the literature. ${ }^{92}$ 
$\mathbf{R}_{\mathbf{f}}=0.35\left(1: 1 \mathrm{Hex}:\right.$ EtOAc); ${ }^{1} \mathbf{H}$ NMR $\left(500 \mathrm{MHz}, \mathrm{CDCl}_{3}\right) \delta 7.45(\mathrm{dt}, J=7.4 \mathrm{~Hz}, 1.7 \mathrm{~Hz}, 6 \mathrm{H}$, Trityl), 7.29 (td, $J=7.2 \mathrm{~Hz}, 1.7 \mathrm{~Hz}, 6 \mathrm{H}$, Trityl), 7.22 (tt, $J=7.3 \mathrm{~Hz}, 1.3 \mathrm{~Hz}, 3 \mathrm{H}$, Trityl), 6.40 $(\mathrm{dd}, J=6.0 \mathrm{~Hz}, 1.7 \mathrm{~Hz}, 1 \mathrm{H}, \mathrm{H}-1), 4.76(\mathrm{dd}, J=6.0,2.2 \mathrm{~Hz}, 1 \mathrm{H}, \mathrm{H}-2), 4.25$ (dt, $J=7.0 \mathrm{~Hz}, 1.7$ Hz, 1H, H-5), 3.90 (dd, $J=9.6 \mathrm{~Hz}, 7.1 \mathrm{~Hz}, 1 \mathrm{H}, \mathrm{H}-3$ ), 3.84 (dt, $J=9.6 \mathrm{~Hz}, 3.5 \mathrm{~Hz}, 1 \mathrm{H}, \mathrm{H}-4$ ), 3.57 (dd, $J=10.6,3.6 \mathrm{~Hz}, 1 \mathrm{H}, \mathrm{H}-6 \mathrm{a}), 3.35$ (dd, $J=10.4,3.7 \mathrm{~Hz}, 1 \mathrm{H}, \mathrm{H}-6 \mathrm{~b})$.

\section{6-O-Trityl-3,4-diacetyl-D-glucal (75)}

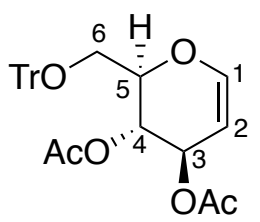

Acetic anhydride $(0.482 \mathrm{~mL}, 5.099 \mathrm{mmol}, 2.3 \mathrm{eq})$ and $\mathrm{NEt}_{3}(0.711 \mathrm{~mL}, 5.099 \mathrm{mmol}$, $2.3 \mathrm{eq})$ were added to a solution of diol $74(1.048 \mathrm{~g}, 2.217 \mathrm{mmol})$ in THF $(5.55 \mathrm{~mL})$. The reaction mixture was stirred overnight and after 16 hours was deemed complete via TLC analysis. The reaction was then diluted with $\mathrm{CH}_{2} \mathrm{Cl}_{2}(5 \mathrm{~mL})$, washed three times with a saturated $\mathrm{Na}_{2} \mathrm{CO}_{3}$ aqueous solution $(3 \times 5 \mathrm{~mL})$ and the combined aqueous phases were extracted with $\mathrm{CH}_{2} \mathrm{Cl}_{2}(10 \mathrm{~mL})$. The organic layer was dried over anhydrous $\mathrm{MgSO}_{4}$, filtered and reduced in vacuo to obtain a yellow oil. The crude yellow oil was purified via silica gel chromatography short silica gel column to yield 4 (0.8845 g, 69\% yield). The spectral data obtained matched those previously reported in the literature. ${ }^{93}$

$\mathbf{R}_{\mathbf{f}}=0.35$ (5:1 Hex:EtOAc); ${ }^{1} \mathbf{H}$ NMR $\left(500 \mathrm{MHz}, \mathrm{CDCl}_{3}\right) \delta 7.46(\mathrm{~d}, J=7.4 \mathrm{~Hz}, 6 \mathrm{H}$, Trityl), 7.31 (t, $J=7.4 \mathrm{~Hz}, 6 \mathrm{H}$, Trityl), 7.25 (d, $J=7.2 \mathrm{~Hz}, 3 \mathrm{H}$, Trityl), 6.53 (d, $J=6.2 \mathrm{~Hz}, 1 \mathrm{H}, \mathrm{H}-1$ ), 5.29 (dd, $J=7.2 \mathrm{~Hz}, 5.6 \mathrm{~Hz}, 1 \mathrm{H}, \mathrm{H}-3$ ), 5.25 (t, $J=3.9 \mathrm{~Hz}, 1 \mathrm{H}, \mathrm{H}-4), 4.79$ (dd, $J=6.1,3.3 \mathrm{~Hz}$, 1H, H-2), 4.24 (d, $J=7.7$ Hz, 1H, H-5), 3.29 (dd, $J=10.5$ Hz, 5.4 Hz, 1H, H-6a), 3.25 (dd, $J$ $=10.5 \mathrm{~Hz}, 3.2 \mathrm{~Hz}, 1 \mathrm{H}, \mathrm{H}-6 \mathrm{~b}), 1.96$ (s, 3H, Acetate), 1.88 (s, 3H, Acetate). 


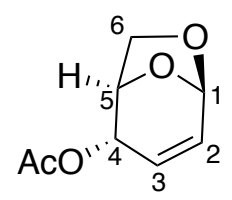

Trityl diacetate $75(0.020 \mathrm{~g}, 0.042 \mathrm{mmol})$ was dissolved in $\mathrm{CH}_{2} \mathrm{Cl}_{2}(0.45 \mathrm{~mL}, 0.1 \mathrm{M})$ with Bis(trimethylsilyl)acetylene $(0.02 \mathrm{~mL}, 0.0 .085 \mathrm{mmol}, 2 \mathrm{eq})$ added slowly at r.t. followed directly by $\mathrm{I}_{2}(0.014 \mathrm{~g}, 0.055 \mathrm{mmol}, 1.3 \mathrm{eq})$. The reaction was deemed complete via ${ }^{1} \mathrm{H}$ NMR analysis after 16 hours. The reaction was then diluted with $\mathrm{CH}_{2} \mathrm{Cl}_{2}(5 \mathrm{~mL})$. The organic layer was washed using sat. aq. $\mathrm{NaHCO}_{3}$, and $\mathrm{Na}_{2} \mathrm{~S}_{2} \mathrm{O}_{3}(3 \times 5 \mathrm{~mL})$, dried with $\mathrm{MgSO}_{4}$ and reduced in vacuo to provide a crude oil. The oil was purified via silica gel chromatography $(5: 1$ Hex:EtOAc). This resulted in the isolation of the bicyclic by-product 77 as a pale-yellow oil. ( $0.004 \mathrm{~g}, 58 \%$ yield) The spectral data obtained for this by product matched those previously reported in the literature. ${ }^{70,94}$

$\mathbf{R}_{\mathbf{f}}=0.2(5: 1 \mathrm{Hex}: \mathrm{EtOAc}) ;{ }^{1} \mathbf{H}$ NMR $\left(500 \mathrm{MHz}, \mathrm{CDCl}_{3}\right) \delta 6.22(\mathrm{dd}, J=9.6 \mathrm{~Hz}, 3.4 \mathrm{~Hz}, 1 \mathrm{H}, \mathrm{H}-$ 1), 5.83 (ddd, $J=9.5 \mathrm{~Hz}, 4.2 \mathrm{~Hz} 1.2 \mathrm{~Hz}, 1 \mathrm{H}, \mathrm{H}-2), 5.62$ (d, $J=3.4 \mathrm{~Hz}, 1 \mathrm{H}, \mathrm{H}-3$ ), 4.78 (d, $J=$ $4.3 \mathrm{~Hz}, 1 \mathrm{H}, \mathrm{H}-4), 4.70$ (dd, $J=6.6 \mathrm{~Hz}, 1.1 \mathrm{~Hz}, 1 \mathrm{H}, \mathrm{H}-5), 3.95$ (t, $J=7.4 \mathrm{~Hz}, 1 \mathrm{H}, \mathrm{H}-6 \mathrm{a}), 3.52$ (dd, $J=8.0 \mathrm{~Hz}, 2 \mathrm{~Hz}, 1 \mathrm{H}, \mathrm{H}-6 \mathrm{~b}), 2.16$ (s, 3H, Ac).

\section{6-O-tert-Butyldimethylsilyl-D-glucal (82)}

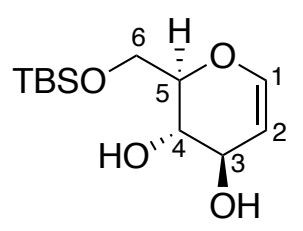

tert-Butyldimethylsilyl chloride (7.533 g, $49.98 \mathrm{mmol}, 1.4 \mathrm{eq})$ was added to a solution of crude D-glucal 73 (5.165 g, $35.34 \mathrm{mmol})$ and imidazole (4.861 g, $71.40 \mathrm{mmol}, 1.4 \mathrm{eq})$ in DMF $(180 \mathrm{~mL}, 0.2 \mathrm{M})$ at $0{ }^{\circ} \mathrm{C}$ then warmed to $40{ }^{\circ} \mathrm{C}$. The reaction was stirred overnight, deemed complete after 16 hours via TLC analysis (1:1 Hex:EtOAc). The reaction was quenched using brine $(150 \mathrm{~mL})$ and the aqueous layer was extracted using $\mathrm{CH}_{2} \mathrm{Cl}_{2}(3 \times 80 \mathrm{~mL})$. The organic layers were combined, dried over anhydrous $\mathrm{Na}_{2} \mathrm{SO}_{4}$ and reduced in vacuo. The crude reaction mixture was purified via silica chromatography $(1: 1 \mathrm{Hex}$ :EtOAc) to give the 
TBS protected diol 82 as a pale-yellow oil (5.608 g, 61\% yield). The spectral data obtained matched those previously reported in the literature. ${ }^{75}$

$\mathbf{R}_{\mathbf{f}}=0.53\left(1: 1 \mathrm{Hex}:\right.$ EtOAc); ${ }^{1} \mathbf{H}$ NMR $\left(500 \mathrm{MHz}, \mathrm{CDCl}_{3}\right) \delta 6.31(\mathrm{~d}, J=6.0 \mathrm{~Hz}, 1 \mathrm{H}, \mathrm{H}-1), 4.73$ (d, $J=6.1 \mathrm{~Hz}, 1 \mathrm{H}, \mathrm{H}-2), 4.26$ (br s, 1H, H-4), 3.99 (d, $J=11.0 \mathrm{~Hz}, 1 \mathrm{H}, \mathrm{H}-6 \mathrm{a}), 3.91$ (dd, $J=$ $10.5 \mathrm{~Hz}, 2.1 \mathrm{~Hz}, 1 \mathrm{H}, \mathrm{H}-6 \mathrm{~b}$ ), 3.80 (t, $J=2.2 \mathrm{~Hz}, 2 \mathrm{H}, \mathrm{H}-5$ and H-3), 3.18 (s, 1H, OH), 2.51 (s, $1 \mathrm{H}, \mathrm{OH}), 0.91$ (s, 9H, ${ }^{\mathrm{t}} \mathrm{Bu}$ of TBS), 0.10 (s, 6H, methyls of TBS); ${ }^{13} \mathbf{C} \mathbf{N M R}\left(126 \mathrm{MHz}, \mathrm{CDCl}_{3}\right)$ $\delta 144.3(\mathrm{CH}, \mathrm{C}-1), 102.5$ (CH, C-2), 76.7 (CH, C-5), 72.5 (CH, C-3), 69.4 (CH, C-4), 64.0 (CH, C-6), $26.0\left(\mathrm{CH}_{3},{ }^{\mathrm{t}} \mathrm{Bu}\right.$ of TBS ), $18.4(\mathrm{C}, \mathrm{TBS}),-5.3\left(\mathrm{CH}_{3}, \mathrm{TBS}\right),-5.4\left(\mathrm{CH}_{3}, \mathrm{TBS}\right)$.

\section{6-O-tert-Butyldimethylsilyl-3,4-diacetyl-D-glucal (83)}

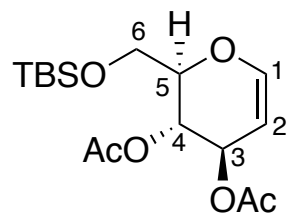

At room temperature, acetic anhydride $(5.46 \mathrm{~mL}, 57.77 \mathrm{mmol}, 2.5 \mathrm{eq})$ was added to a solution of TBS diol 82 (6.0177 g, $23.11 \mathrm{mmol}), \mathrm{NEt}_{3}(8.05 \mathrm{~mL}, 57.77 \mathrm{mmol}, 1.4 \mathrm{eq})$ and DMAP (10 mol\%) in dry $\mathrm{CH}_{2} \mathrm{Cl}_{2}(120 \mathrm{~mL}, 0.2 \mathrm{M})$. The reaction was stirred overnight, deemed complete via TLC analysis (5:1 Hex:EtOAc) after 16 hours and quenched using $\mathrm{NaHCO}_{3}$ $(100 \mathrm{~mL})$. The aqueous layer was extracted using $\mathrm{CH}_{2} \mathrm{Cl}_{2}(3 \times 50 \mathrm{~mL})$ and the organic layers combined, dried over anhydrous $\mathrm{Na}_{2} \mathrm{SO}_{4}$ and reduced in vacuo. The crude reaction mixture was purified via silica chromatography (5:1 Hex:EtOAc) to give the TBS diacetate $\mathbf{8 3}$ as a pale yellow oil (7.675 g, 96\% yield). The spectral data obtained matched those previously reported in the literature. ${ }^{95}$

$\mathbf{R}_{\mathbf{f}}=0.43$ (5:1 Hex:EtOAc); ${ }^{1} \mathbf{H}$ NMR $\left(500 \mathrm{MHz}, \mathrm{CDCl}_{3}\right) \delta 6.46(\mathrm{~d}, J=6.2 \mathrm{~Hz}, 1 \mathrm{H}, \mathrm{H}-1), 5.31$ (app. t, $J=2.0 \mathrm{~Hz} 1 \mathrm{H}, \mathrm{H}-3$ ), 5.25 (t, $J=6.4 \mathrm{~Hz}, 1 \mathrm{H}, \mathrm{H}-4), 4.77$ (dd, $J=5.5,2.4 \mathrm{~Hz}, 1 \mathrm{H}, \mathrm{H}-2$ ), 4.08 (q, $J=6.1 \mathrm{~Hz}, 1 \mathrm{H}, \mathrm{H}-5), 3.80$ (d, $J=4.9 \mathrm{~Hz}, 2 \mathrm{H}, \mathrm{H}-6), 2.06$ (s, 3H, Ac), 2.03 (s, 3H, Ac), 0.88 (s, 9H, TBS), 0.05 (s, 6H, TBS). ${ }^{13}$ C NMR (126 MHz, $\left.\mathrm{CDCl}_{3}\right) \delta 170.7$ (C, Ac), $169.6(\mathrm{C}$, Ac), 146.1 (CH, C-1), 98.4 (CH, C-2), 76.9 (CH, C-5), 67.7 (CH, C-3), 67.7 (CH, C-4), 61.3 $\left(\mathrm{CH}_{2}, \mathrm{C}-6\right), 25.9\left(\mathrm{CH}_{3}, \mathrm{TBS}\right), 21.2\left(\mathrm{CH}_{3}, \mathrm{Ac}\right), 21.0\left(\mathrm{CH}_{3}, \mathrm{Ac}\right), 18.4(\mathrm{C}, \mathrm{TBS}),-5.3\left(\mathrm{CH}_{3}, \mathrm{TBS}\right)$. 


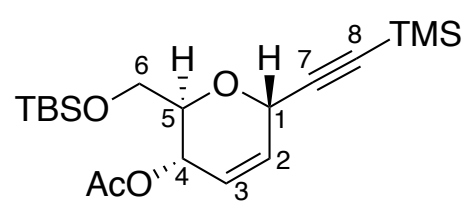

TBS diacetate 83 (0.0816 g, $0.237 \mathrm{mmol})$ was dissolved in $\mathrm{CH}_{2} \mathrm{Cl}_{2}(161.2 \mathrm{~mL}, 0.2 \mathrm{M})$ and cooled to $-78{ }^{\circ} \mathrm{C}$. Bis(trimethylsilyl)acetylene $(0.10 \mathrm{~mL}, 0.474 \mathrm{mmol}, 2 \mathrm{eq})$ was added slowly followed directly by $1 \mathrm{M} \mathrm{SnCl}_{4}$ in $\mathrm{CH}_{2} \mathrm{Cl}_{2}(0.28 \mathrm{~mL}, 0.237 \mathrm{mmol}, 1 \mathrm{eq})$. The reaction was deemed complete via TLC analysis (5:1 Hex:EtOAc) after 15 minutes. The reaction was then quenched in $10 \%$ potassium sodium tartrate solution $(5 \mathrm{~mL})$ for 30 minutes and extracted using $\mathrm{CH}_{2} \mathrm{Cl}_{2}(3 \times 5 \mathrm{~mL})$. The organic layer was washed using sat. aq. $\mathrm{NaHCO}_{3}$, and brine, dried with $\mathrm{MgSO}_{4}$ and reduced in vacuo to provide a crude pale-yellow oil. The oil was purified via silica gel chromatography (3:1 Hex:EtOAc) to give compound $\mathbf{8 6}$ as a as a pale-yellow oil $(0.027 \mathrm{~g}, 41 \%$ yield $)$.

$\mathbf{R}_{\mathbf{f}}=0.61(5: 1 \mathrm{Hex}: E t O A c) ;{ }^{1} \mathbf{H}$ NMR $\left(500 \mathrm{MHz}, \mathrm{CDCl}_{3}\right) \delta 5.87(\mathrm{~d}, J=10.2 \mathrm{~Hz}, 1 \mathrm{H}, \mathrm{H}-2)$, 5.77 (d, $J=10.1 \mathrm{~Hz}, 1 \mathrm{H}, \mathrm{H}-3), 5.25$ (d, $J=8.6 \mathrm{~Hz}, 1 \mathrm{H}, \mathrm{H}-4), 4.95$ (s, 1H, H-1), $3.97-3.90$ (m, 1H, H-5), 3.80 (d, $J=11.5$ Hz, 1H, H-6a), 3.74 (dd, $J=11.4,5.4$ Hz, 1H, H-6b), 2.08 (s, 3H, Ac), 0.90 (s, 9H, TBS), 0.17 (s, 9H, TMS), 0.07 (s, 3H, TBS), 0.06 (s, 3H, TBS). ${ }^{13} \mathbf{C ~ N M R}$ $\left(126 \mathrm{MHz} \mathrm{CDCl}_{3}\right) \delta 170.4(\mathrm{C}, \mathrm{Ac}), 129.3(\mathrm{CH}, \mathrm{C} 2), 125.6(\mathrm{CH}, \mathrm{C} 3), 101.4(\mathrm{C}, \mathrm{C} 7), 91.1(\mathrm{C}$, C8), 72.8 (CH, C1), 65.1 (CH, C4), 64.1 (CH, C5), $63.1\left(\mathrm{CH}_{2}, \mathrm{C} 6\right), 25.9\left(\mathrm{CH}_{3}, \mathrm{TBS}\right), 21.1$ $\left(\mathrm{CH}_{3}, \mathrm{Ac}\right), 18.4(\mathrm{C}, \mathrm{TBS}),-0.2\left(\mathrm{CH}_{3}, \mathrm{TMS}\right)-5.26\left(\mathrm{CH}_{3}, \mathrm{TBS}\right),-5.32\left(\mathrm{CH}_{3}, \mathrm{TBS}\right)$. HRMS (ESI) Found 383.12072 Calculated for $\mathrm{C}_{19} \mathrm{H}_{35} \mathrm{O}_{4} \mathrm{Si}_{2}{ }^{+}[\mathrm{M}+\mathrm{H}]^{+} 383.2068 \Delta=1.04$ ppm; IR (Film from $\left.\mathrm{CH}_{2} \mathrm{Cl}_{2}\right) v_{\max } 2956,2929,2856,2171,2166,1740,1369,1230,836 \mathrm{~cm}^{-1}$

$(2 R, 3 S, 6 S)-2-(H y d r o x y m e t h y l)-6-((t r i m e t h y l s i l y l) e t h y n y l)-3,6-d i h y d r o-2 H$-pyran-3-yl acetate (88)

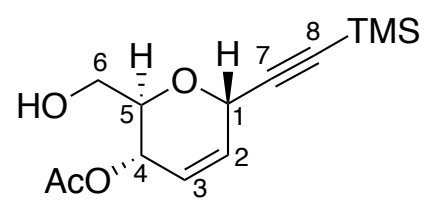


TBS diacetate 83 (8.39 g, $24.37 \mathrm{mmol})$ was dissolved in $\mathrm{CH}_{2} \mathrm{Cl}_{2}(160 \mathrm{~mL}, 0.15 \mathrm{M})$ and cooled to $-78{ }^{\circ} \mathrm{C}$. Bis(trimethyl)acetylene $(10.5 \mathrm{~mL}, 48.74 \mathrm{mmol}, 2 \mathrm{eq})$ was added slowly followed directly by $1 \mathrm{M} \mathrm{SnCl}_{4}(24.37 \mathrm{~mL}, 24.37 \mathrm{mmol}, 1 \mathrm{eq})$. The reaction was deemed complete via TLC analysis (5:1 Hex:EtOAc) after 30 minutes. The reaction was then quenched in $10 \%$ potassium sodium tartrate solution $(80 \mathrm{~mL})$ for 30 minutes and extracted using $\mathrm{CH}_{2} \mathrm{Cl}_{2}$ (3 x $30 \mathrm{~mL}$ ). The organic layer was washed using sat. aq. $\mathrm{NaHCO}_{3}$, and brine, dried with $\mathrm{MgSO}_{4}$ and reduced in vacuo to provide a crude pale-yellow oil. The oil was purified via silica gel chromatography (5:1 Hex:EtOAc) to give compound $\mathbf{8 8}$ as a as a pale-yellow oil (2.33 $\mathrm{g}$, $36 \%$ yield).

$\mathbf{R}_{\mathbf{f}}=0.73(1: 1 \mathrm{Hex}: E t O A c) ;{ }^{1} \mathbf{H}$ NMR $\left(500 \mathrm{MHz}, \mathrm{CDCl}_{3}\right) \delta 5.88(\mathrm{~d}, J=10.2 \mathrm{~Hz}, 1 \mathrm{H}, \mathrm{H}-2)$, $5.78(\mathrm{~d}, J=10.3 \mathrm{~Hz}, 1 \mathrm{H}, \mathrm{H}-3), 5.32$ (d, $J=8.9 \mathrm{~Hz}, 1 \mathrm{H}, \mathrm{H}-4), 4.96$ (s, 1H, H-1), $3.93-3.88$ (m, 1H, H-5), 3.79 (d, $J=12.3 \mathrm{~Hz}, 1 \mathrm{H}, \mathrm{H}-6), 3.65$ (dd, $J=12.3,5.1 \mathrm{~Hz}, 1 \mathrm{H}, \mathrm{H}-6 \mathrm{~b}$ ), 2.11 (s, 3H, Ac), 1.64 (s, 1H, OH), 0.18 (s, 9H, TBS). $\left.{ }^{13} \mathbf{C ~ N M R ~ ( 1 2 6 ~ M H z , ~ C D C l ~}{ }_{3}\right) \delta 170.9$ (C, Ac), 129.2 (CH, C-2), 125.8 (CH, C-3), 101.1 (C, C-7), 91.9 (C, C-8), 72.1 (CH, C-5), 64.9 (CH, C-4), 64.4 (CH, C-1), $62.2\left(\mathrm{CH}_{2}, \mathrm{C}-6\right), 21.2\left(\mathrm{CH}_{3}, \mathrm{Ac}\right),-0.1\left(\mathrm{CH}_{3}, \mathrm{TBS}\right)$. HRMS (ESI) Found 269.1204 Calculated for $\mathrm{C}_{13} \mathrm{H}_{21} \mathrm{O}_{4} \mathrm{Si}^{+}[\mathrm{M}+\mathrm{H}]^{+} 269.1204 \Delta=0$ ppm; IR (Film from $\mathrm{CH}_{2} \mathrm{Cl}_{2}$ ) $v_{\max } 3463,2959,2169,1735,1370,1230,841 \mathrm{~cm}^{-1}$.

\section{((2R,3S,6S)-3-Acetoxy-6-((trimethylsilyl)ethynyl)-3,6-dihydro- $2 H$-pyran-2-yl)methyl} acetate (87)

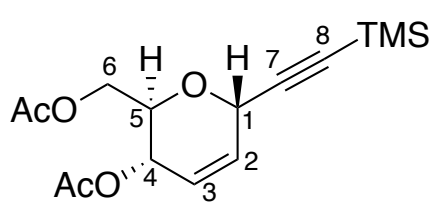

Isolated as a by-product of the first $\mathrm{SnCl}_{4}$ mediated Ferrier reaction. The spectral data obtained matched those previously reported in the literature. ${ }^{94,96}$

$\mathbf{R}_{\mathbf{f}}=0.41(5: 1 \mathrm{Hex}: E t O A c) ;{ }^{1} \mathbf{H}$ NMR $\left(600 \mathrm{MHz}, \mathrm{CDCl}_{3}\right) \delta 5.88(\mathrm{dq}, J=10.2 \mathrm{~Hz}, 1.6 \mathrm{~Hz}, 1 \mathrm{H}$, H-2), 5.78 (dt, $J=9.9 \mathrm{~Hz}, 1.6 \mathrm{~Hz}, 1 \mathrm{H}, \mathrm{H}-3), 5.28$ (dd, $J=8.9 \mathrm{~Hz}, 1.8 \mathrm{~Hz}, 1 \mathrm{H}, \mathrm{H}-4), 4.97$ (t, $J$ $=1.5 \mathrm{~Hz}, 1 \mathrm{H}, \mathrm{H}-1), 4.26(\mathrm{dd}, J=12.1 \mathrm{~Hz}, 2.4 \mathrm{~Hz}, 1 \mathrm{H}, \mathrm{H}-6 \mathrm{a}), 4.21$ (dd, $J=12.2,5.7 \mathrm{~Hz}, 1 \mathrm{H}$, H-6b), 4.13 - 4.07 (m, 1H, H-5), 2.10 (s, 6H), 0.19 (s, 8H). $\left.{ }^{13} \mathbf{C ~ N M R ~ ( 1 5 1 ~ M H z , ~ C D C l ~}\right) \delta$ 
$171.0(\mathrm{C}, \mathrm{Ac}), 170.5$ (C, Ac), 129.2 (CH, C-2), 125.6 (CH, C-3), 100.9 (C, C-7), 92.0 (C, C8), $70.2(\mathrm{CH}, \mathrm{C}-5), 64.9$ (CH, C-4), $64.6(\mathrm{CH}, \mathrm{C}-1), 63.2\left(\mathrm{CH}_{2}, \mathrm{C}-6\right), 21.2\left(\mathrm{CH}_{3}, \mathrm{Ac}\right), 21.0$ $\left(\mathrm{CH}_{3}, \mathrm{Ac}\right),-0.1\left(\mathrm{CH}_{3}, \mathrm{TMS}\right)$. HRMS (ESI) Found 311.1316 Calculated for $\mathrm{C}_{15} \mathrm{H}_{23} \mathrm{O}_{5} \mathrm{Si}^{+}$ $[\mathrm{M}+\mathrm{H}]^{+} 311.1309 \Delta=2.24 \mathrm{ppm}$.

\section{((2R,3S,6S)-3-Hydroxy-6-((trimethylsilyl)ethynyl)-3,6-dihydro-2H-pyran-2-yl)methyl} acetate (89)

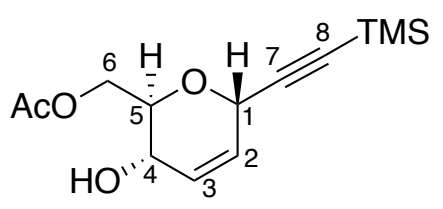

Isolated as an inseparable mixture with compound $\mathbf{8 8}$ during the first $\mathrm{SnCl}_{4}$ mediated Ferrier reaction.

$\mathbf{R}_{\mathbf{f}}=0.73\left(1: 1 \mathrm{Hex}:\right.$ EtOAc); ${ }^{1} \mathbf{H}$ NMR $\left(500 \mathrm{MHz}, \mathrm{CDCl}_{3}\right) \delta 5.84(\mathrm{~d}, J=9.6 \mathrm{~Hz}, 1 \mathrm{H}), 5.78(\mathrm{~d}$, $J=10.3 \mathrm{~Hz}, 2 \mathrm{H}), 4.93(\mathrm{~s}, 1 \mathrm{H}), 4.54(\mathrm{dd}, J=12.1,4.7 \mathrm{~Hz}, 1 \mathrm{H}), 4.31(\mathrm{~d}, J=12.3 \mathrm{~Hz}, 1 \mathrm{H}), 4.05$ $(\mathrm{d}, J=9.1 \mathrm{~Hz}, 1 \mathrm{H}), 3.88-3.82(\mathrm{~m}, 1 \mathrm{H}), 2.13(\mathrm{~s}, 3 \mathrm{H}), 0.18(\mathrm{~s}, 9 \mathrm{H})$.

\section{(2S,3S,6S)-3-Acetoxy-6-((trimethylsilyl)ethynyl)-3,6-dihydro- $2 H$-pyran-2-carboxylic acid (90)}

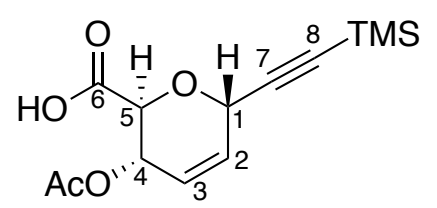

C-glycoside $88(0.15 \mathrm{~g}, 0.560 \mathrm{mmol})$ was dissolved in $1: 1 \mathrm{H}_{2} \mathrm{O}: \mathrm{CH}_{2} \mathrm{Cl}_{2}(6 \mathrm{~mL}, 0.1 \mathrm{M})$ and cooled to $0{ }^{\circ} \mathrm{C}$. At $0{ }^{\circ} \mathrm{C}$ TEMPO (0.026 g, $\left.0.168 \mathrm{mmol}, 30 \mathrm{~mol} \%\right)$ was added slowly followed directly by BAIB $(0.541 \mathrm{~g}, 1.680 \mathrm{mmol}, 3 \mathrm{eq})$. The reaction was then allowed to warm to room temperature. The reaction was deemed complete via a combination of TLC and ${ }^{1} \mathrm{H}$ NMR analysis after 1.5 hours. The reaction was then diluted with $\mathrm{CH}_{2} \mathrm{Cl}_{2}(10 \mathrm{~mL})$ and washed

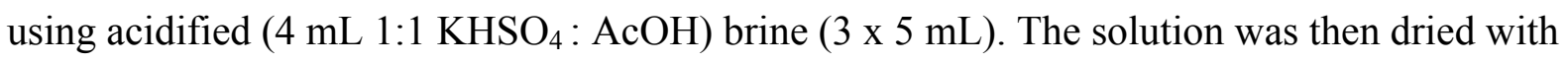
$\mathrm{MgSO}_{4}$ and reduced in vacuo to provide a crude yellow oil. The oil was purified via silica gel 
chromatography $(2: 1 \mathrm{Hex}: \mathrm{EtOAc}+1 \% \mathrm{AcOH})$ to give compound $\mathbf{9 0}$ as a as a pale-yellow oil (0.1377 g, 87\% yield).

$\mathbf{R}_{\mathbf{f}}=0.34(2: 1 \mathrm{Hex}:$ EtOAc $+1 \% \mathrm{AcOH}) ;{ }^{1} \mathbf{H} \mathbf{N M R}\left(500 \mathrm{MHz}, \mathrm{CDCl}_{3}\right) \delta 5.95(\mathrm{~d}, J=10.3 \mathrm{~Hz}$, 1H, H-2), 5.82 (d, $J=10.2 \mathrm{~Hz}, 1 \mathrm{H}, \mathrm{H}-3), 5.54$ (d, $J=5.7 \mathrm{~Hz}, 1 \mathrm{H}, \mathrm{H}-4), 5.17$ (s, 1H, H-1), 4.55 $(\mathrm{d}, J=6.9 \mathrm{~Hz}, 1 \mathrm{H}, \mathrm{H}-5), 2.12$ (s, 3H, Ac), 0.18 (s, 8H, TMS). ${ }^{13} \mathbf{C} \mathbf{N M R}\left(126 \mathrm{MHz}, \mathrm{CDCl}_{3}\right) \delta$ 170.9 (C, Ac), 170.6 (C, C-6), 129.9 (CH, C-2), 124.0 (CH, C-3), 99.9 (C, C-7), 92.8 (C, C-8), $71.3(\mathrm{CH}, \mathrm{C}-5), 64.9(\mathrm{CH}, \mathrm{C}-4), 64.0(\mathrm{CH}, \mathrm{C}-1), 21.1\left(\mathrm{CH}_{3}, \mathrm{Ac}\right),-0.1\left(\mathrm{CH}_{3}, \mathrm{TMS}\right)$. HRMS (ESI) Found 305.0816 Calculated for $\mathrm{C}_{13} \mathrm{H}_{18} \mathrm{NaO}_{5} \mathrm{Si}^{+}[\mathrm{M}+\mathrm{Na}]^{+} 305.0816 \Delta=0$ ppm; IR (Film from $\mathrm{CH}_{2} \mathrm{Cl}_{2}$ ) $v_{\max } 2959,2171,1740,1371,1228,837 \mathrm{~cm}^{-1}$.

\section{Methyl ((2S,3S,6S)-3-acetoxy-6-((trimethylsilyl)ethynyl)-3,6-dihydro-2H-pyran-2- carbonyl) glycinate. (91)}

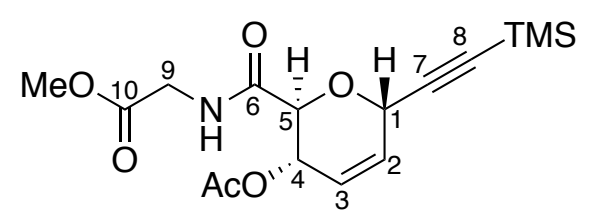

Carboxylic acid 90 (0.03 g, $0.108 \mathrm{mmol})$ was dissolved in $\mathrm{CH}_{2} \mathrm{Cl}_{2}(2 \mathrm{~mL}, 0.1 \mathrm{M})$ at room temperature. To the solution, DIPEA $(0.06 \mathrm{~mL}, 0.324 \mathrm{mmol}, 3 \mathrm{eq}) \mathrm{HOBt}(0.032 \mathrm{~g}$, $0.238 \mathrm{mmol}, 2.2 \mathrm{eq})$ and EDCI (0.052 g, $0.270 \mathrm{mmol}, 2.5 \mathrm{eq})$ were added slowly and left to stir for 10 minutes. O-methyl glycine $(0.029 \mathrm{~g}, 0.324 \mathrm{mmol}, 3 \mathrm{eq})$ was then added and left to stir at r.t. The reaction was deemed complete via TLC analysis after 6 hours. The reaction was then diluted with $\mathrm{CH}_{2} \mathrm{Cl}_{2}(5 \mathrm{~mL})$ and washed with $\mathrm{KHSO}_{4}(3 \times 5 \mathrm{~mL})$, then $\mathrm{NaHCO}_{3}(3 \times 5$ $\mathrm{mL}$ ), and finally Brine ( $3 \times 5 \mathrm{~mL})$. The organic layer was then dried with $\mathrm{MgSO}_{4}$ and reduced in vacuo to provide a crude yellow film. The oil was purified via silica gel chromatography (3:1 Hex:EtOAc) to give compound 91 as a as a pale-yellow oil (0.015 g, 40\% yield).

$\mathbf{R}_{\mathbf{f}}=0.64$ (1:1 Hex:EtOAc); ${ }^{1} \mathbf{H}$ NMR $\left(500 \mathrm{MHz}, \mathrm{CDCl}_{3}\right) \delta 6.93(\mathrm{t}, J=4.8 \mathrm{~Hz}, 1 \mathrm{H}, \mathrm{NH}), 5.90$ (d, $J=10.0 \mathrm{~Hz}, 1 \mathrm{H}, \mathrm{H}-2), 5.75$ (d, $J=10.4 \mathrm{~Hz}, 1 \mathrm{H}, \mathrm{H}-3), 5.54$ (d, $J=8.3 \mathrm{~Hz}, 1 \mathrm{H}, \mathrm{H}-4), 5.06$ (s, 1H, H-1), 4.41 (d, $J=8.2 \mathrm{~Hz}, 1 \mathrm{H}, \mathrm{H}-5), 4.09$ (dd, $J=18.5,5.3 \mathrm{~Hz}, 1 \mathrm{H}, \mathrm{H}-9 \mathrm{a}), 4.03$ (dd, $J$ $=18.4,4.9 \mathrm{~Hz}, 1 \mathrm{H}, \mathrm{H}-9 \mathrm{~b}), 3.76$ (s, 3H, OMe), 2.13 (s, 3H, Ac), 0.18 (s, 9H, TMS). ${ }^{13} \mathbf{C ~ N M R}$ $\left(126 \mathrm{MHz}^{\mathrm{CDCl}}{ }_{3}\right) \delta 170.5$ (C, Ac), 170.0 (C, C-10), 169.1 (C, C-6), 128.8 (CH, C-2), 125.5 
(CH, C-3), 99.9 (C, C-7), 93.0 (C, C-8), 70.8 (CH, C-5), 65.4 (CH, C-4), 64.3 (CH, C-1), 52.6 $\left(\mathrm{CH}_{3}, \mathrm{OMe}\right), 40.9\left(\mathrm{CH}_{2}, \mathrm{C}-9\right), 21.2\left(\mathrm{CH}_{3}, \mathrm{Ac}\right),-0.1\left(\mathrm{CH}_{3}, \mathrm{TMS}\right)$. HRMS (ESI) Found 354.1370 Calculated for $\mathrm{C}_{16} \mathrm{H}_{24} \mathrm{NO}_{6} \mathrm{Si}^{+}[\mathrm{M}+\mathrm{H}]^{+} 354.1367 \Delta=0.85 \mathrm{ppm}$; 


\section{Appendix}

D-Glucal (73) ${ }^{1} \mathrm{H}$ NMR (500 MHz, $\left.\mathrm{D}_{2} \mathrm{O}\right)$

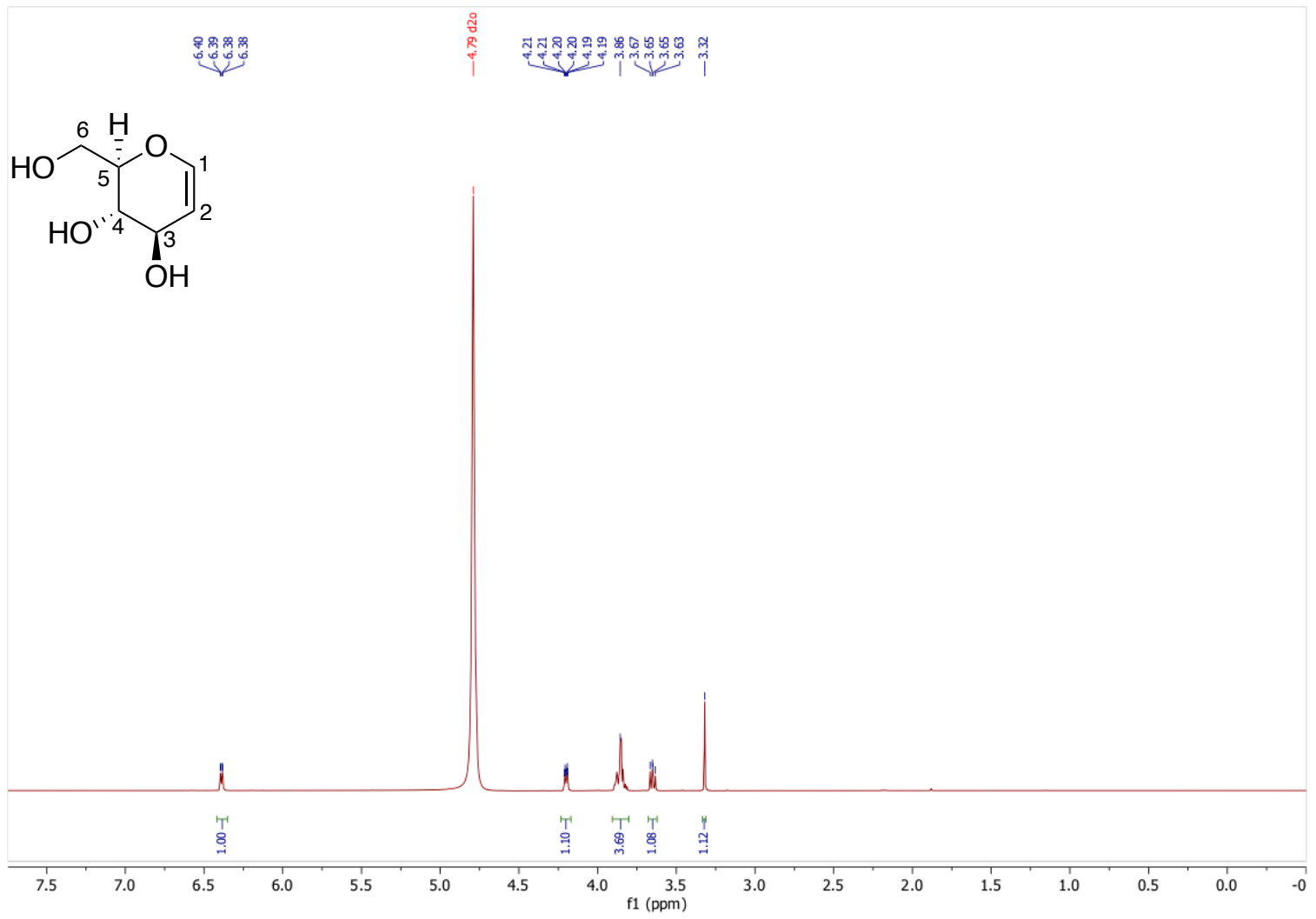

6-O-Trityl-D-glucal (74) ${ }^{1} \mathrm{H}$ NMR (500 MHz, $\mathrm{CDCl}_{3}$ )

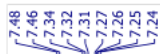

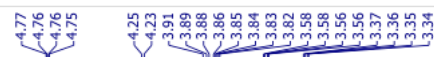<smiles>O[C@H]1C=CO[C@@H](CO[Tl])[C@@H]1O</smiles>

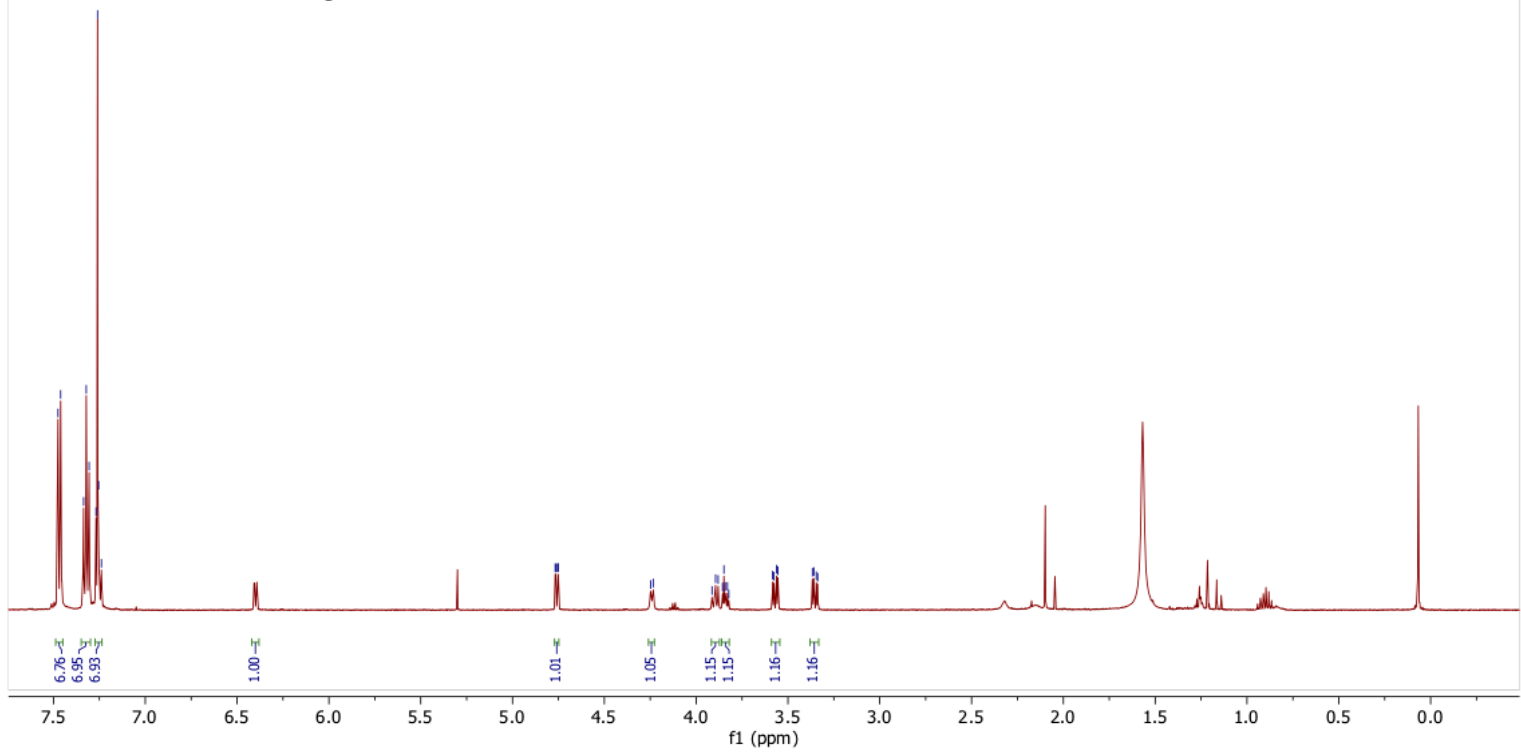

Page | 64 
6-O-trityl-3,4-diacetyl-D-glucal (75) ${ }^{1} \mathrm{H}$ NMR (500 MHz, $\left.\mathrm{CDCl}_{3}\right)$

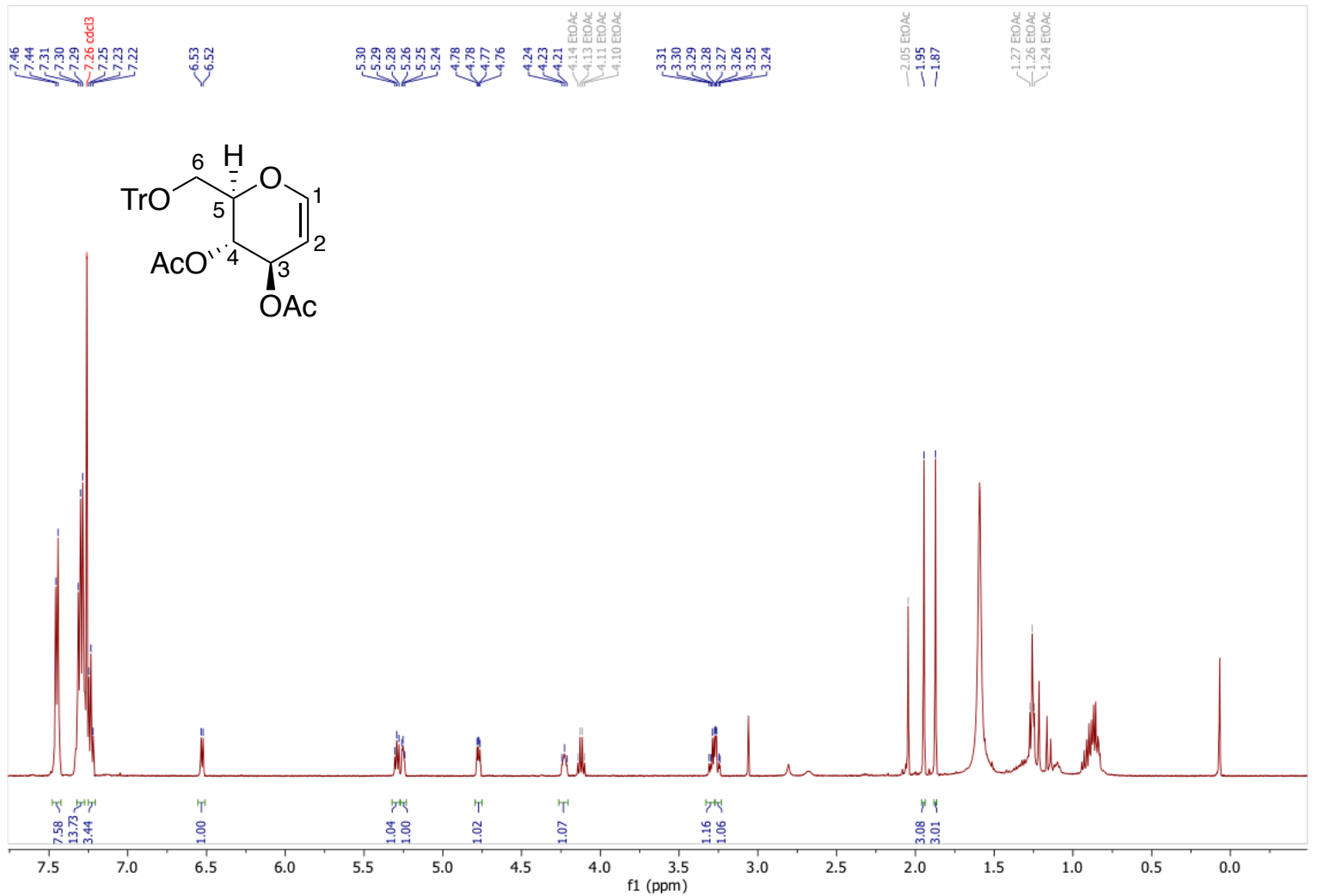

$(1 R, 2 S, 5 R)-6,8$-Dioxabicyclo[3.2.1]oct-3-en-2-yl acetate (77) ${ }^{1} \mathrm{H}$ NMR (500 $\left.\mathrm{MHz}, \mathrm{CDCl}_{3}\right)$

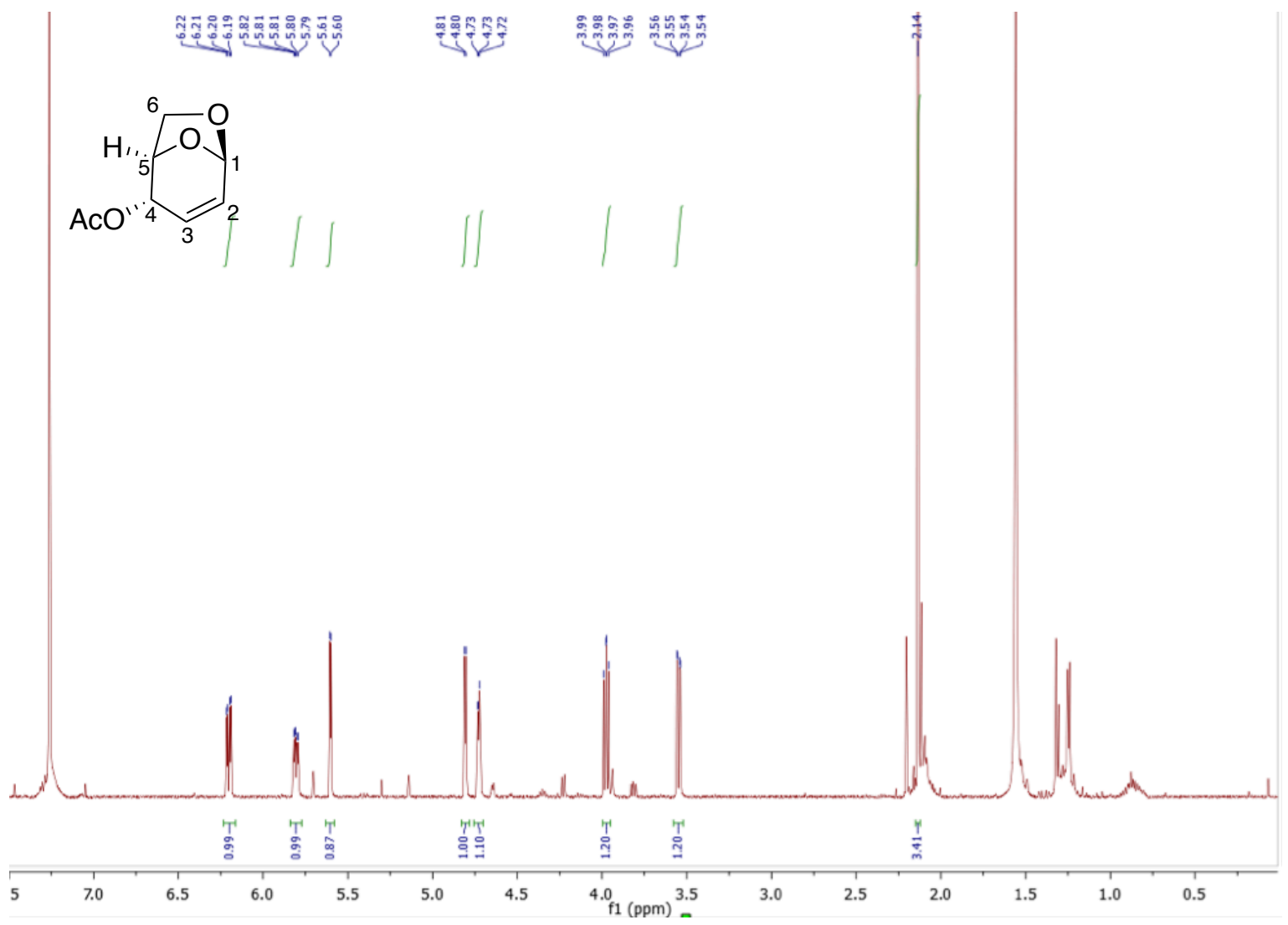



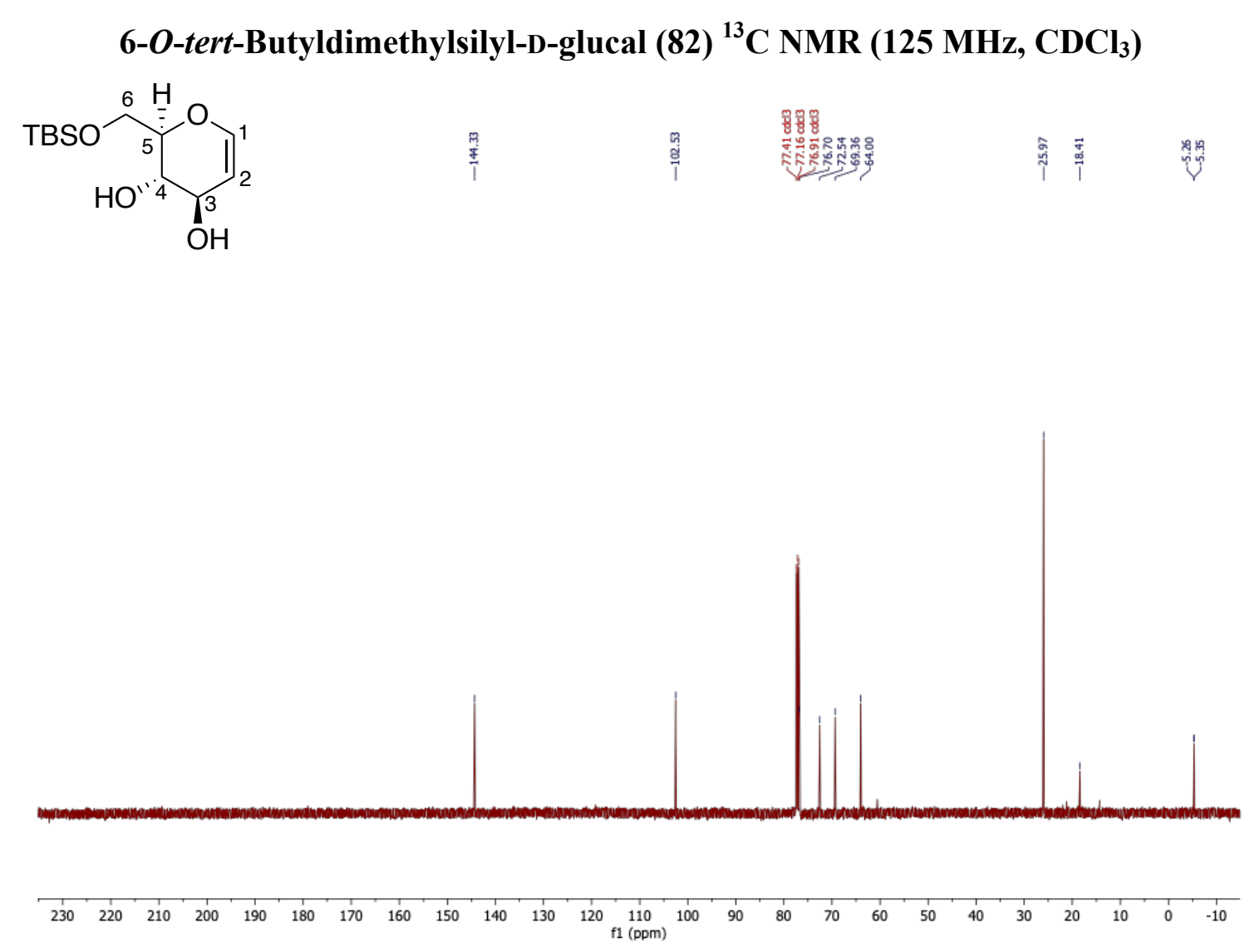

6-O-tert-Butyldimethylsilyl-D-glucal (82) ${ }^{1} \mathrm{H}$ NMR (500 MHz, $\mathrm{CDCl}_{3}$ )

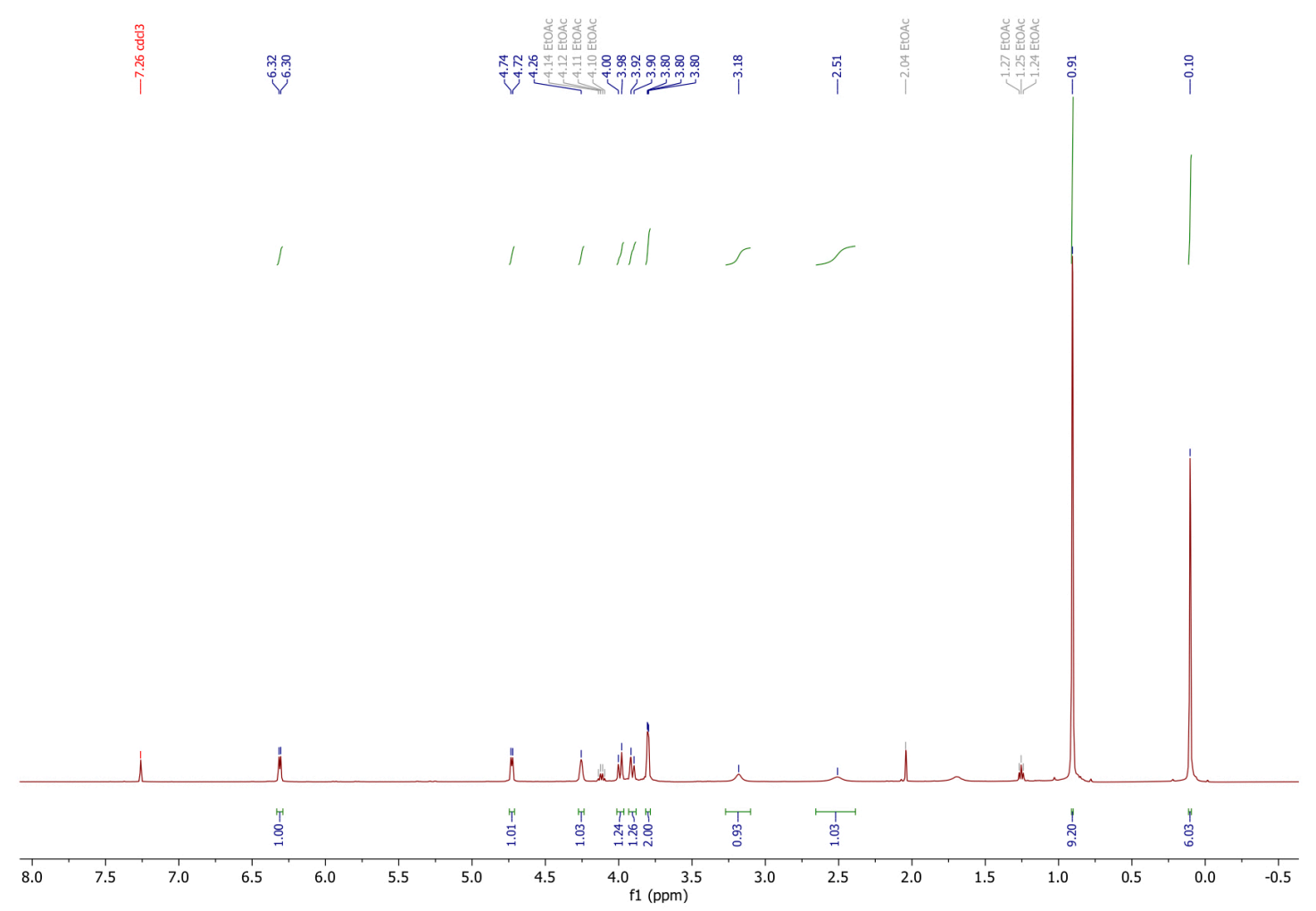


6-O-tert-Butyldimethylsilyl-3,4-diacetyl-D-glucal (83) ${ }^{13} \mathrm{C}$ NMR (125 $\left.\mathrm{MHz}, \mathrm{CDCl}_{3}\right)$<smiles>CC(C)(C)OC[C@H]1OC=C[C@@H](OC(C)(C)C)[C@@H]1OC(C)(C)C</smiles>

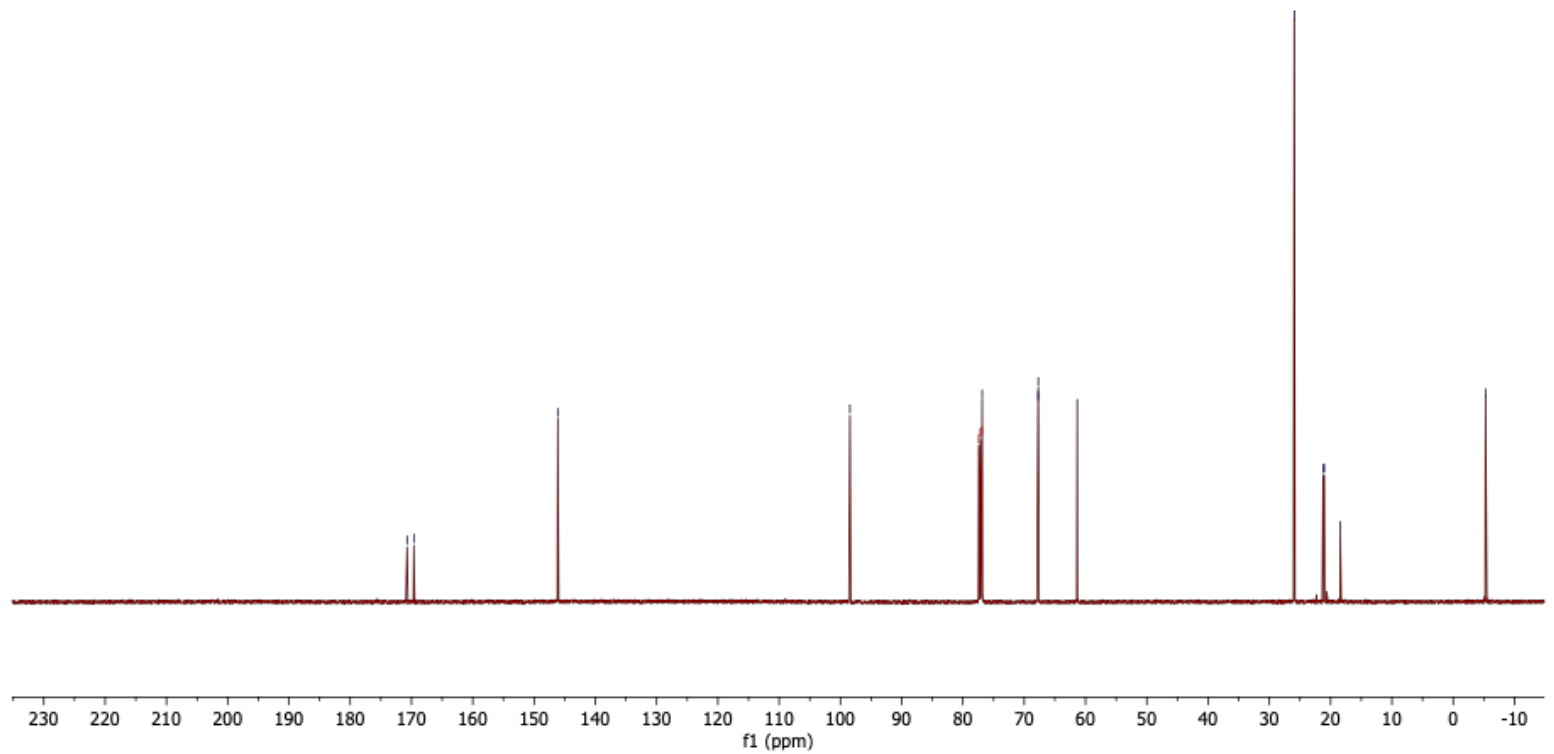

6-O-tert-Butyldimethylsilyl-3,4-diacetyl-D-glucal (83) ${ }^{1} \mathrm{H}$ NMR (500 $\left.\mathrm{MHz}, \mathrm{CDCl}_{3}\right)$

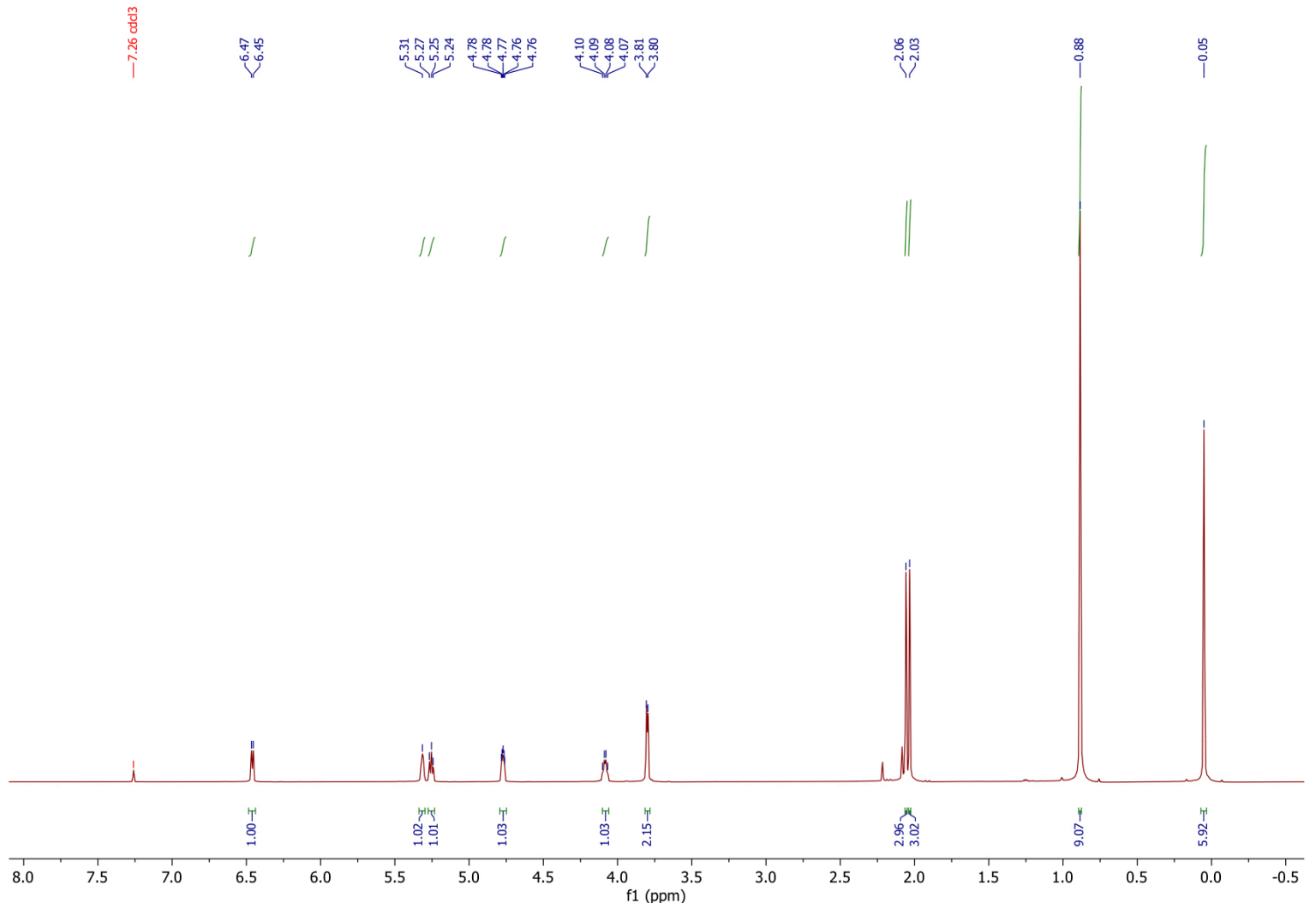


(2R,3S,6S)-2-(((tert-Butyldimethylsilyl)oxy)methyl)-6-((trimethylsilyl)ethynyl)-3,6dihydro-2H-pyran-3-yl acetate (86) ${ }^{13} \mathrm{C}$ NMR (125 $\left.\mathrm{MHz}^{\mathrm{C}} \mathrm{CDCl}_{3}\right)$

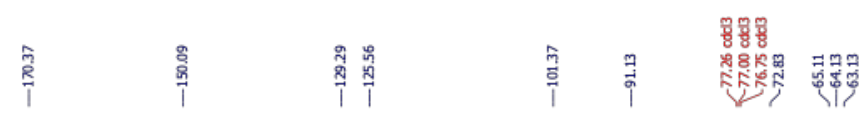

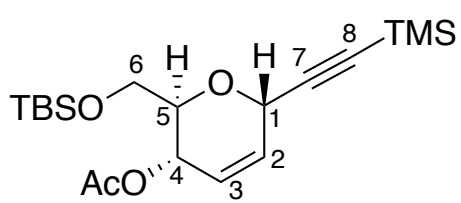

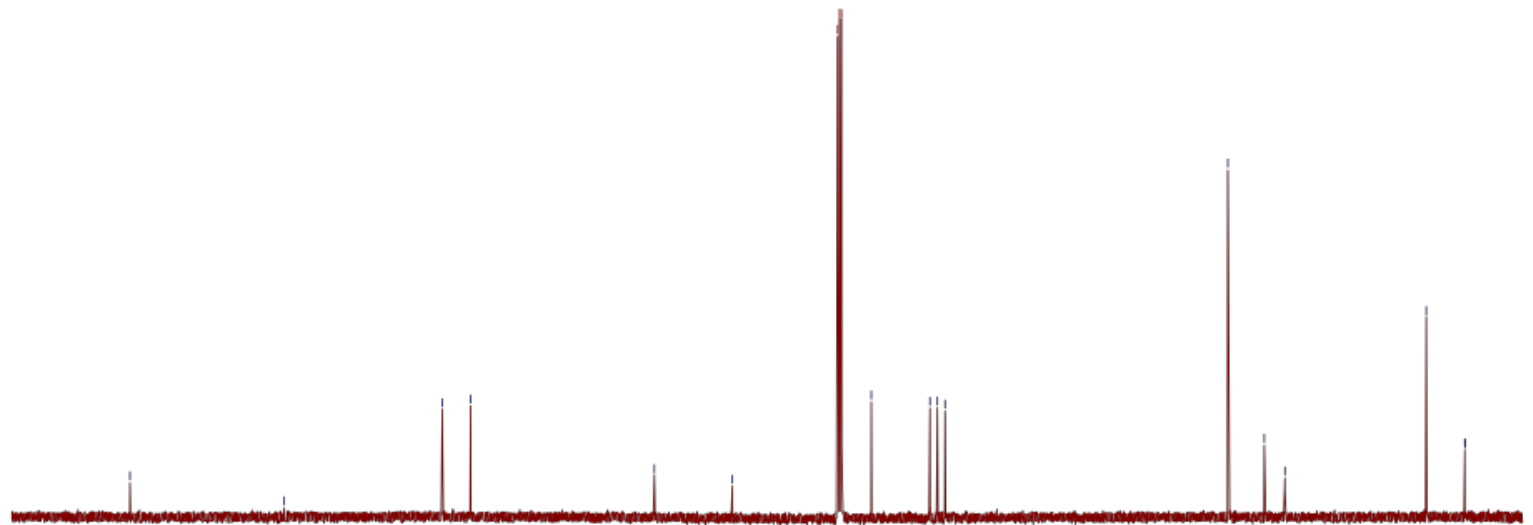

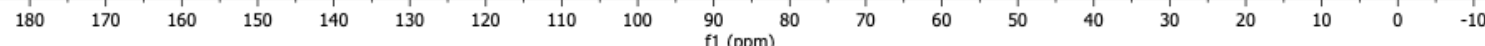

(2R,3S,6S)-2-(((tert-Butyldimethylsilyl)oxy)methyl)-6-((trimethylsilyl)ethynyl)-3,6dihydro- $2 \mathrm{H}$-pyran-3-yl acetate (86) ${ }^{1} \mathrm{H}$ NMR (500 $\left.\left.\mathrm{MHz}^{\mathrm{CDCl}}\right)_{3}\right)$

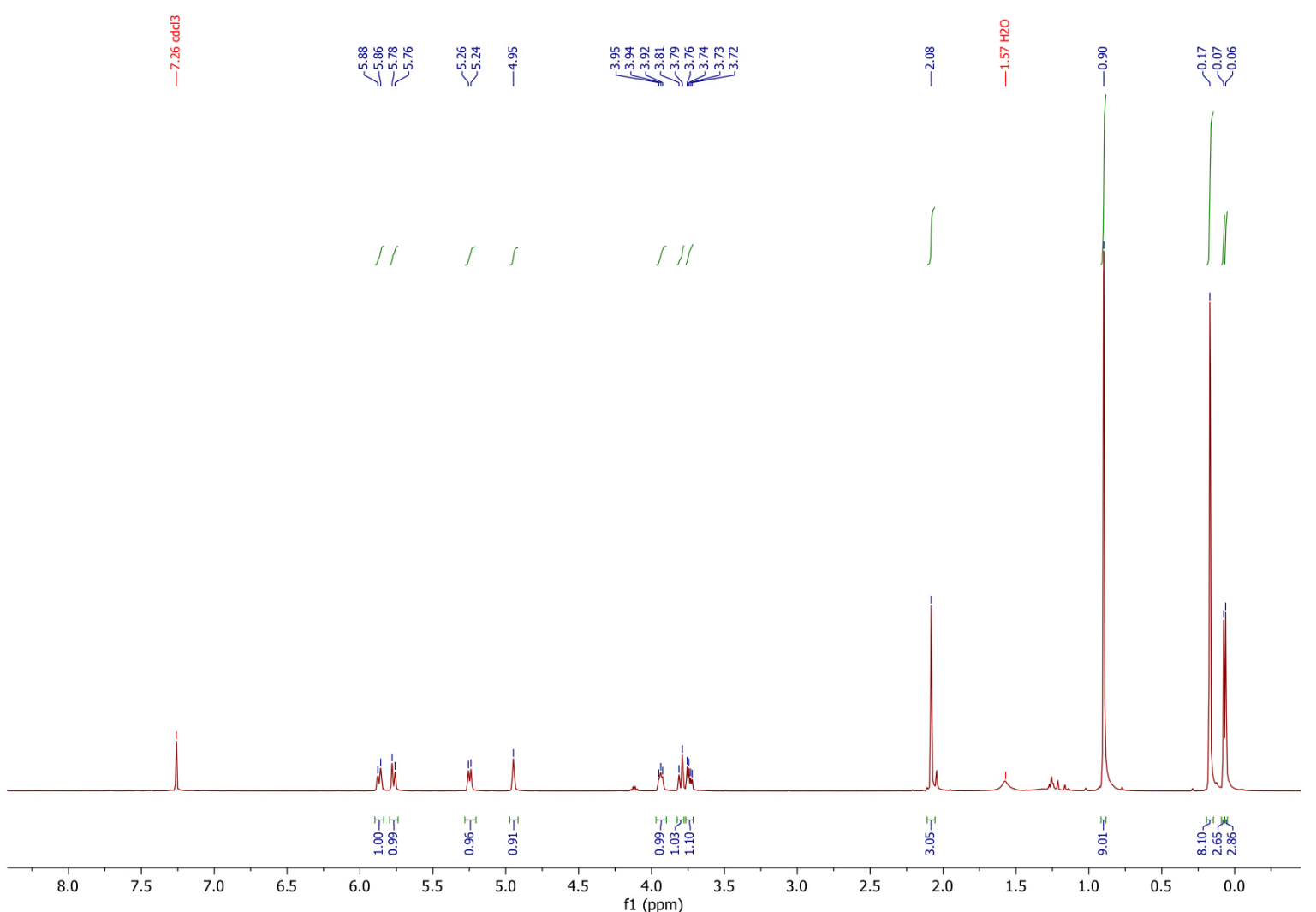


(2R,3S,6S)-2-(((tert-Butyldimethylsilyl)oxy)methyl)-6-((trimethylsilyl)ethynyl)-3,6dihydro-2H-pyran-3-yl acetate (86) HSQC $\left(\mathrm{CDCl}_{3}\right)$

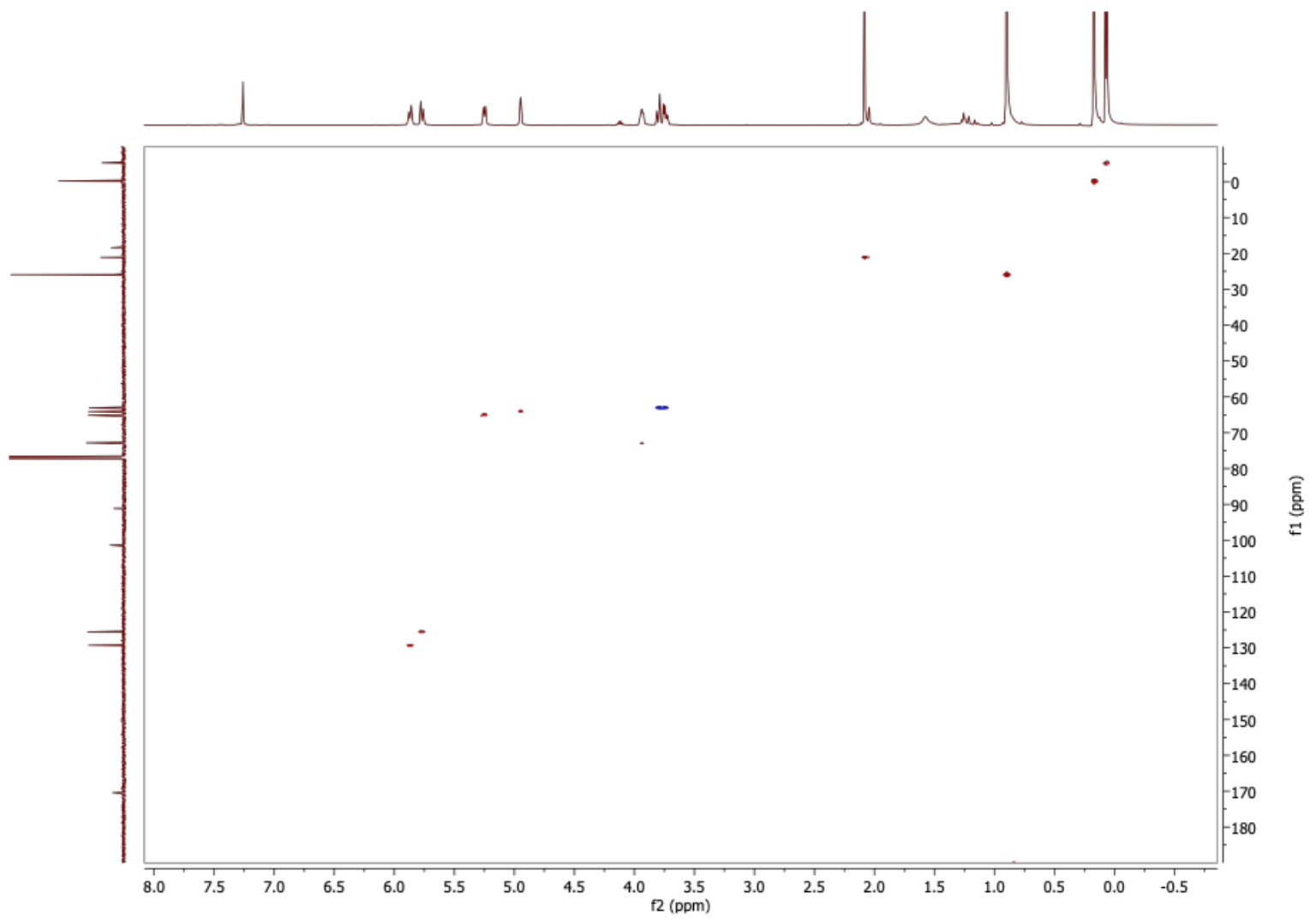

(2R,3S,6S)-2-(((tert-Butyldimethylsilyl)oxy)methyl)-6-((trimethylsilyl)ethynyl)-3,6dihydro-2H-pyran-3-yl acetate (86) $\mathrm{COSY}\left(\mathrm{CDCl}_{3}\right)$

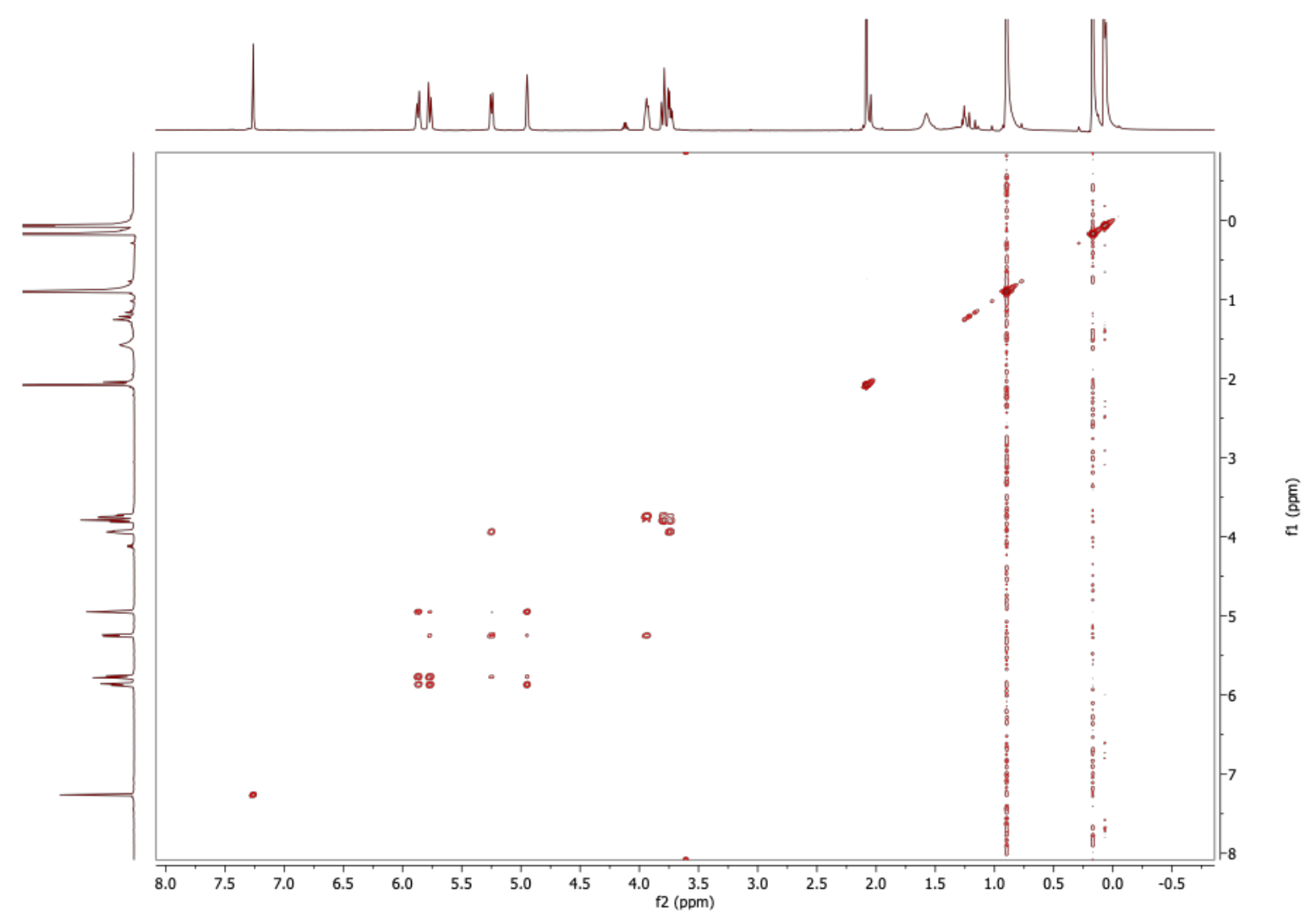


(2R,3S,6S)-2-(((tert-Butyldimethylsilyl)oxy)methyl)-6-((trimethylsilyl)ethynyl)-3,6dihydro-2H-pyran-3-yl acetate (86) $\mathrm{HMBC}\left(\mathrm{CDCl}_{3}\right)$

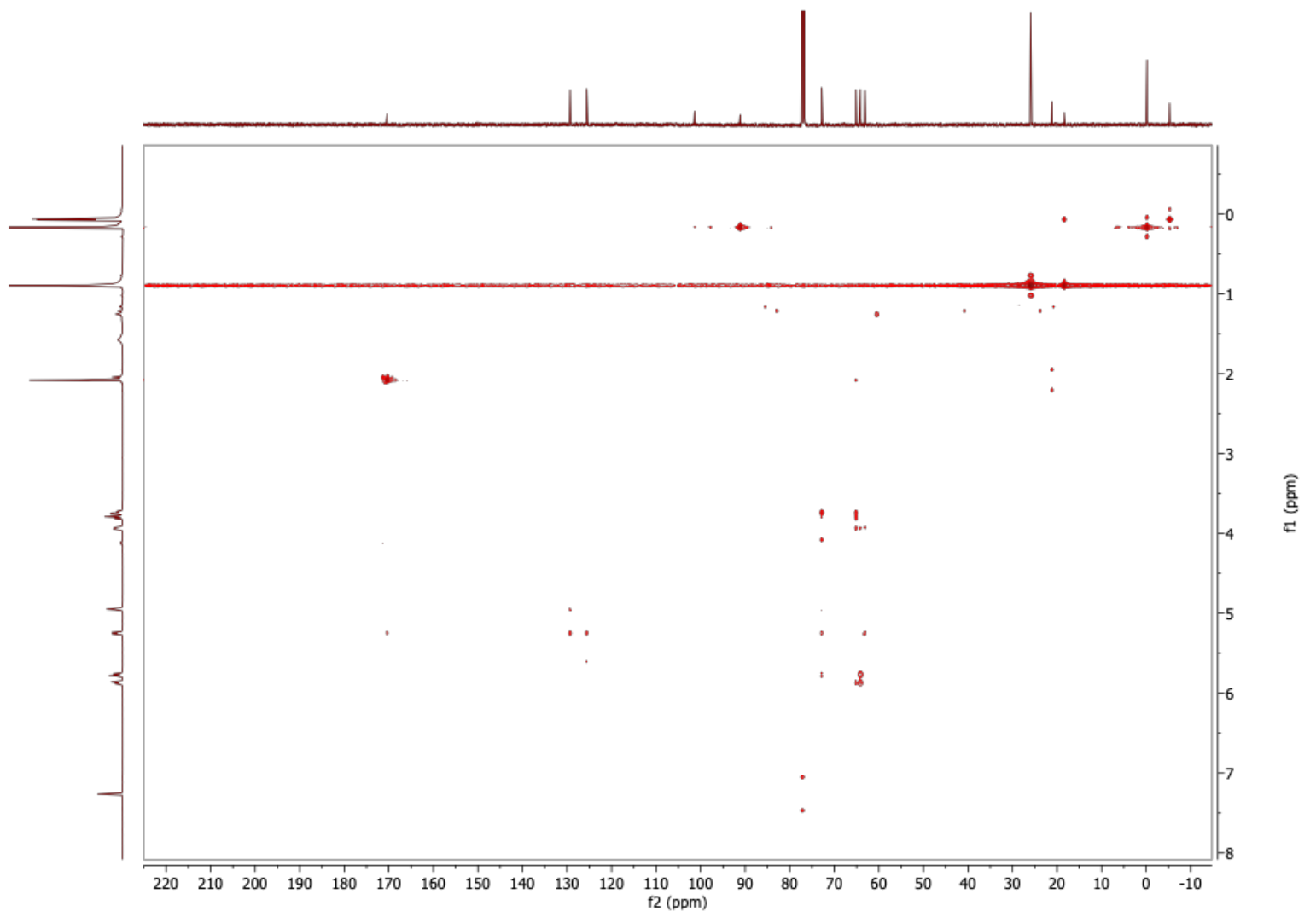


(2R,3S,6S)-2-(Hydroxymethyl)-6-((trimethylsilyl)ethynyl)-3,6-dihydro-2H-pyran-3-yl acetate (88) ${ }^{13} \mathrm{C}$ NMR (125 MHz, $\left.\mathrm{CDCl}_{3}\right)$

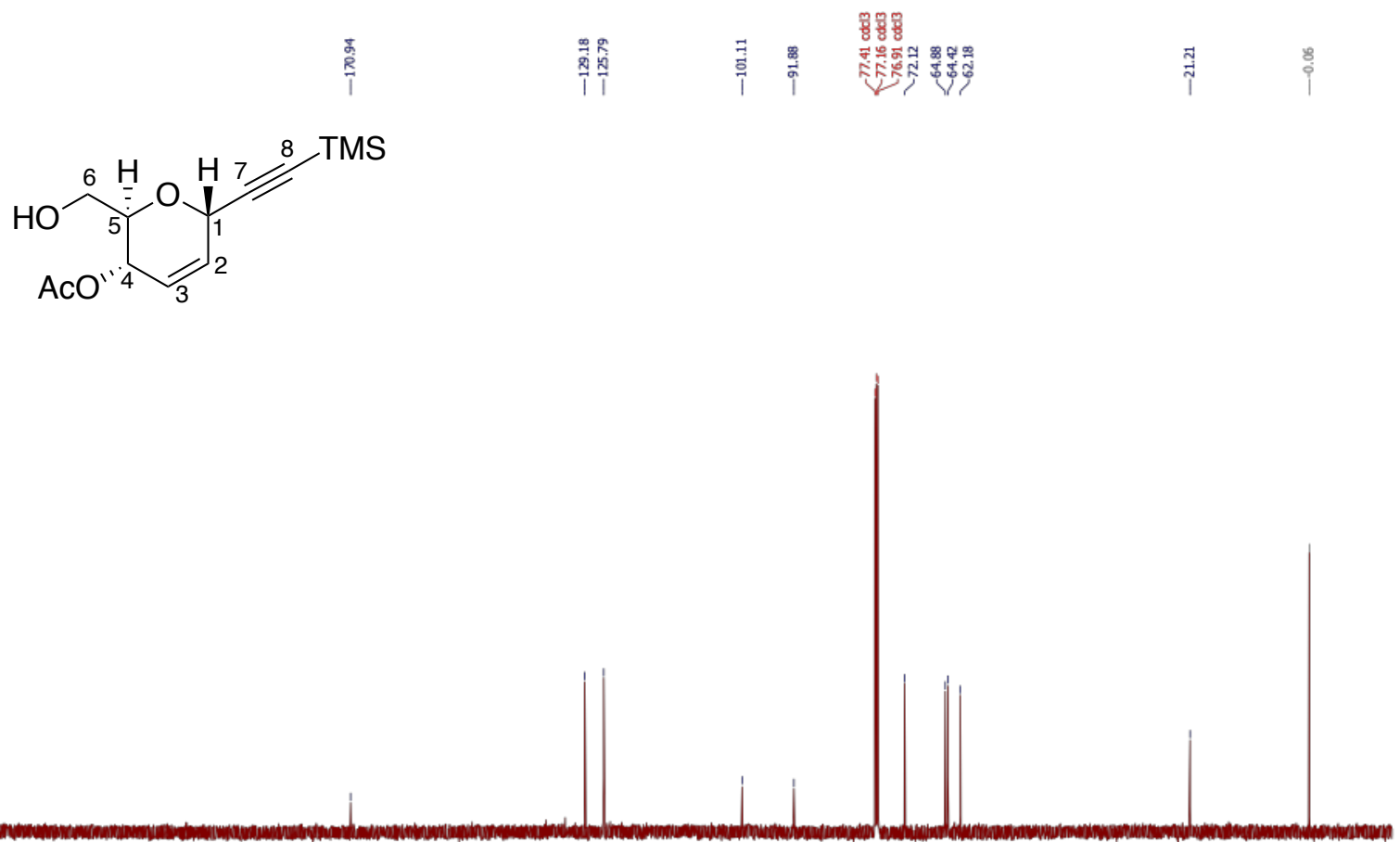

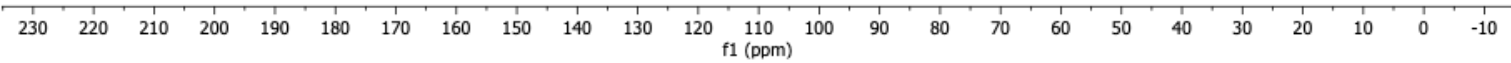

(2R,3S,6S)-2-(Hydroxymethyl)-6-((trimethylsilyl)ethynyl)-3,6-dihydro-2H-pyran-3-yl acetate (88) ${ }^{1} \mathrm{H}$ NMR (500 $\left.\mathrm{MHz} \mathrm{CDCl}_{3}\right)$

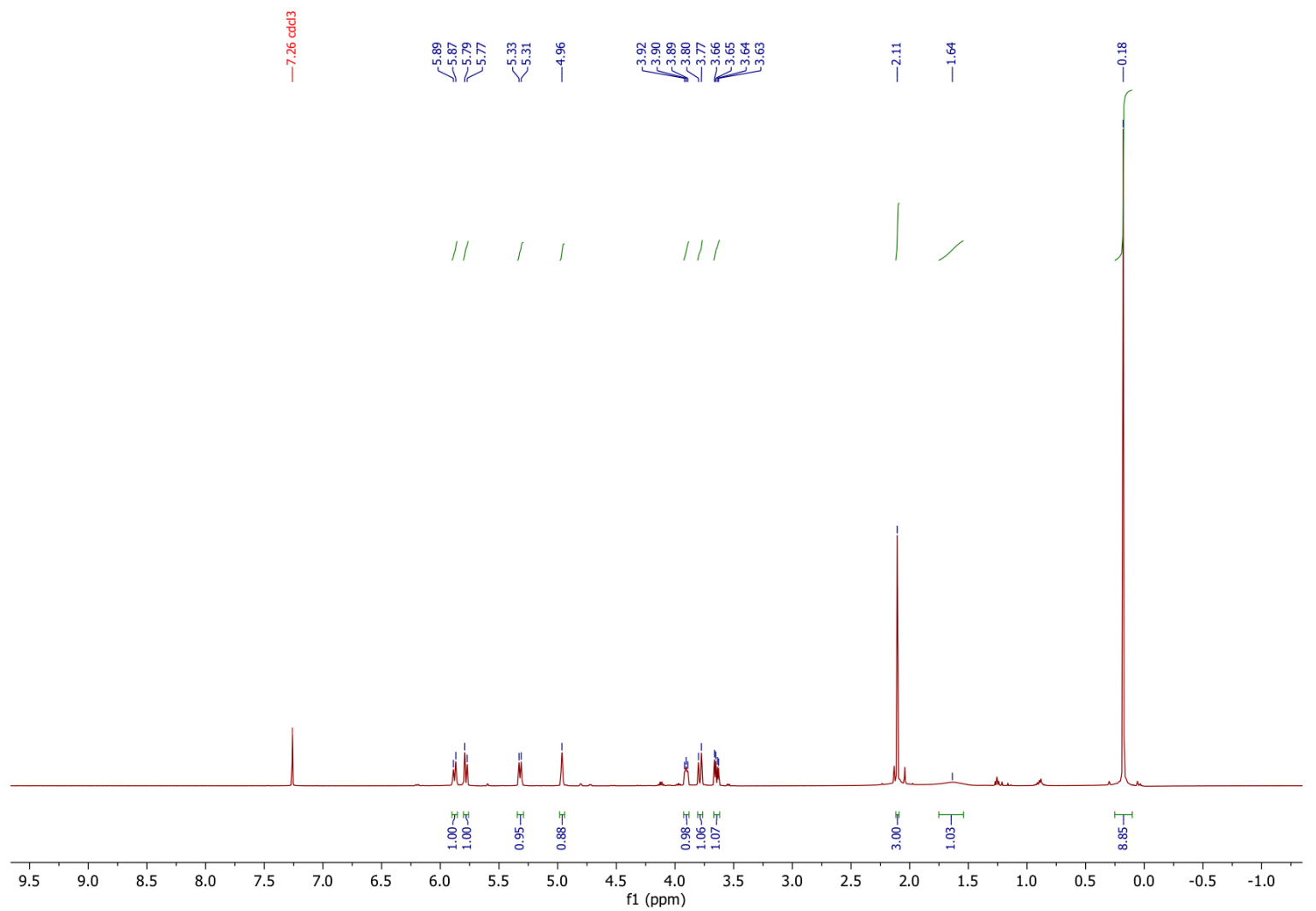




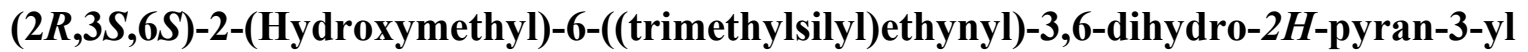
acetate (88) HSQC $\left(\mathrm{CDCl}_{3}\right)$

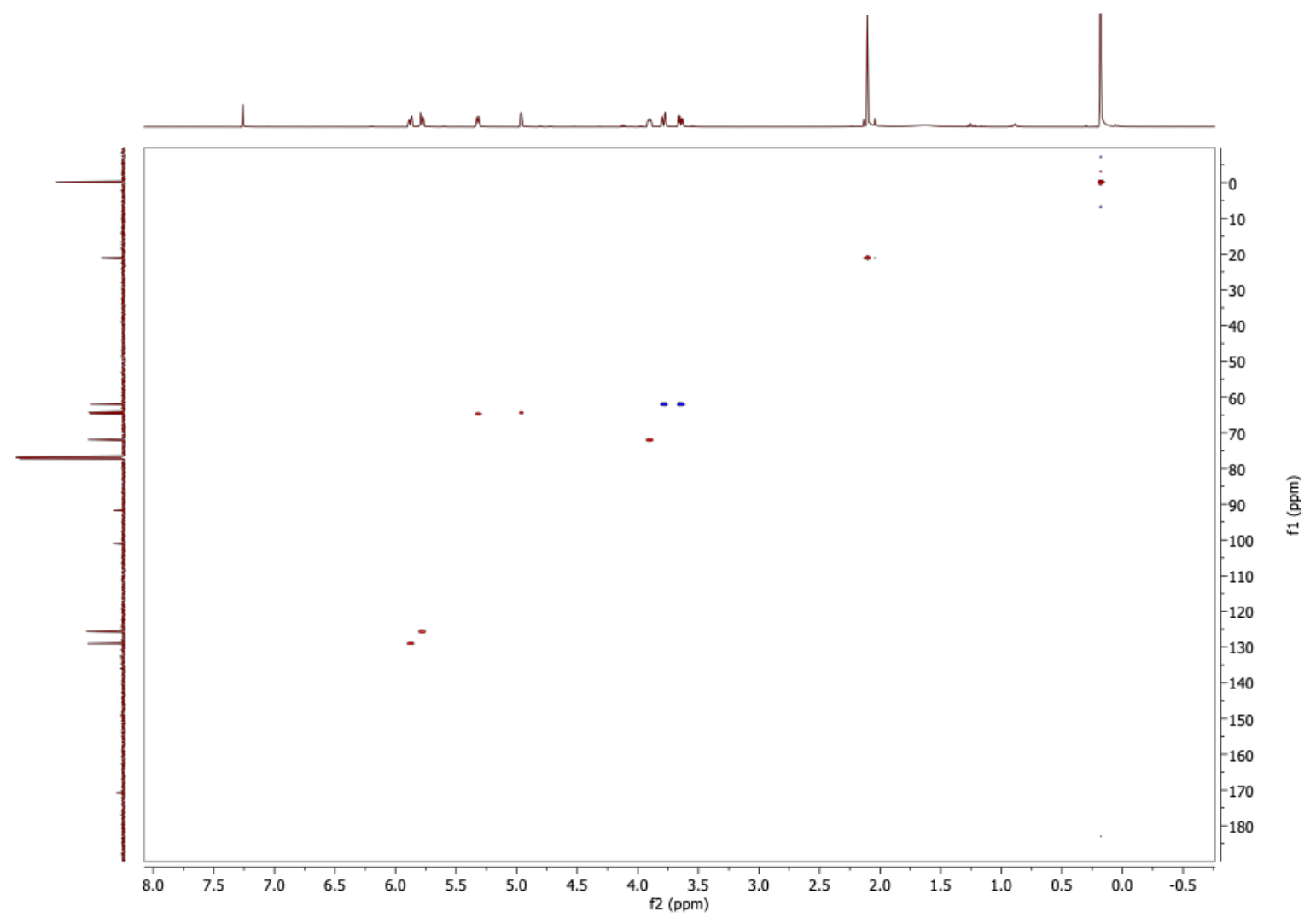

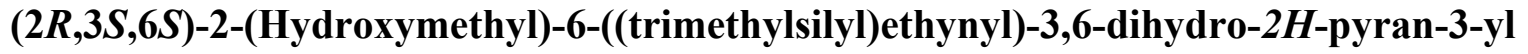
acetate (88) COSY $\left(\mathrm{CDCl}_{3}\right)$

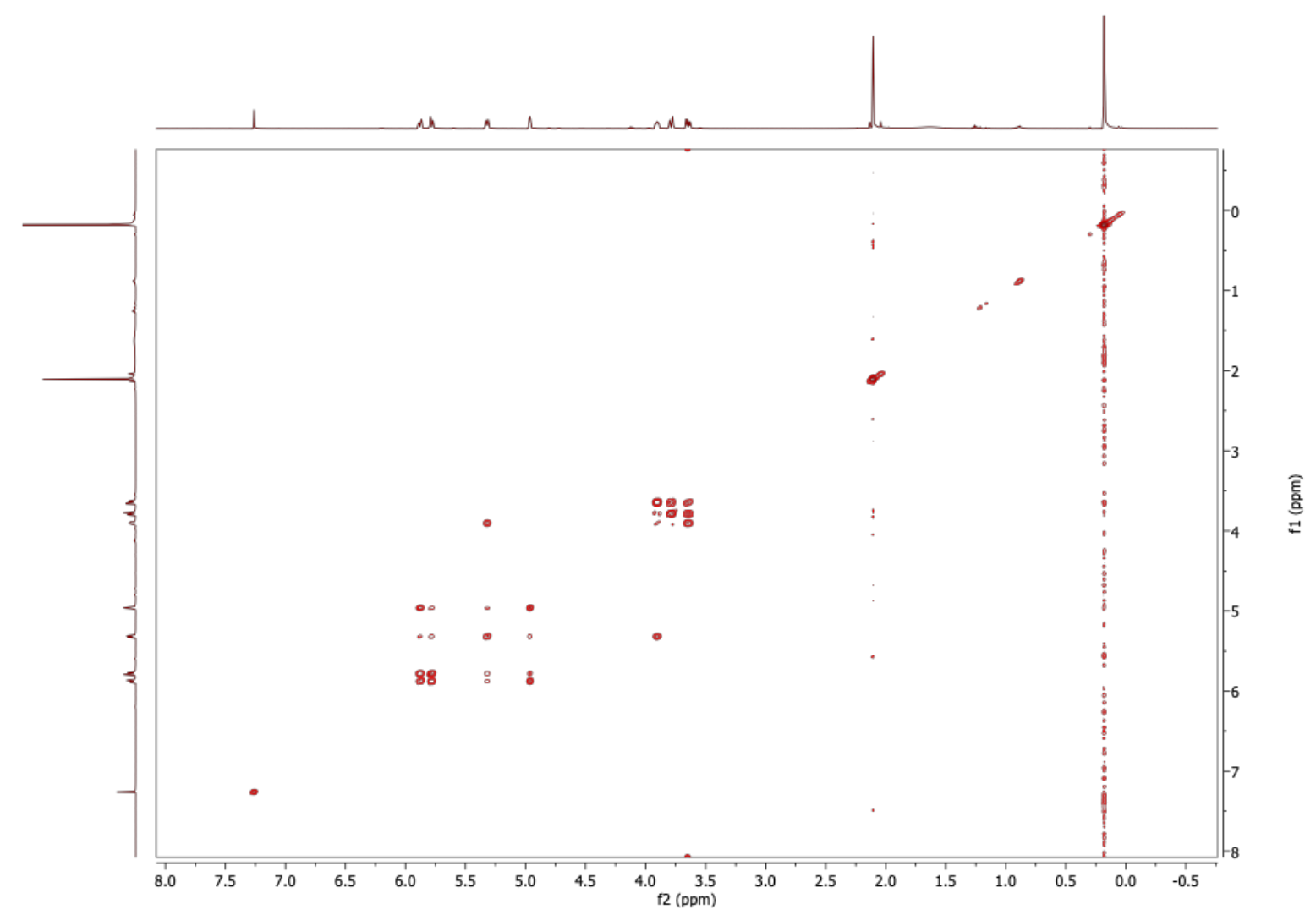


(2R,3S,6S)-2-(Hydroxymethyl)-6-((trimethylsilyl)ethynyl)-3,6-dihydro-2H-pyran-3-yl acetate (88) $\mathrm{HMBC}\left(\mathrm{CDCl}_{3}\right)$

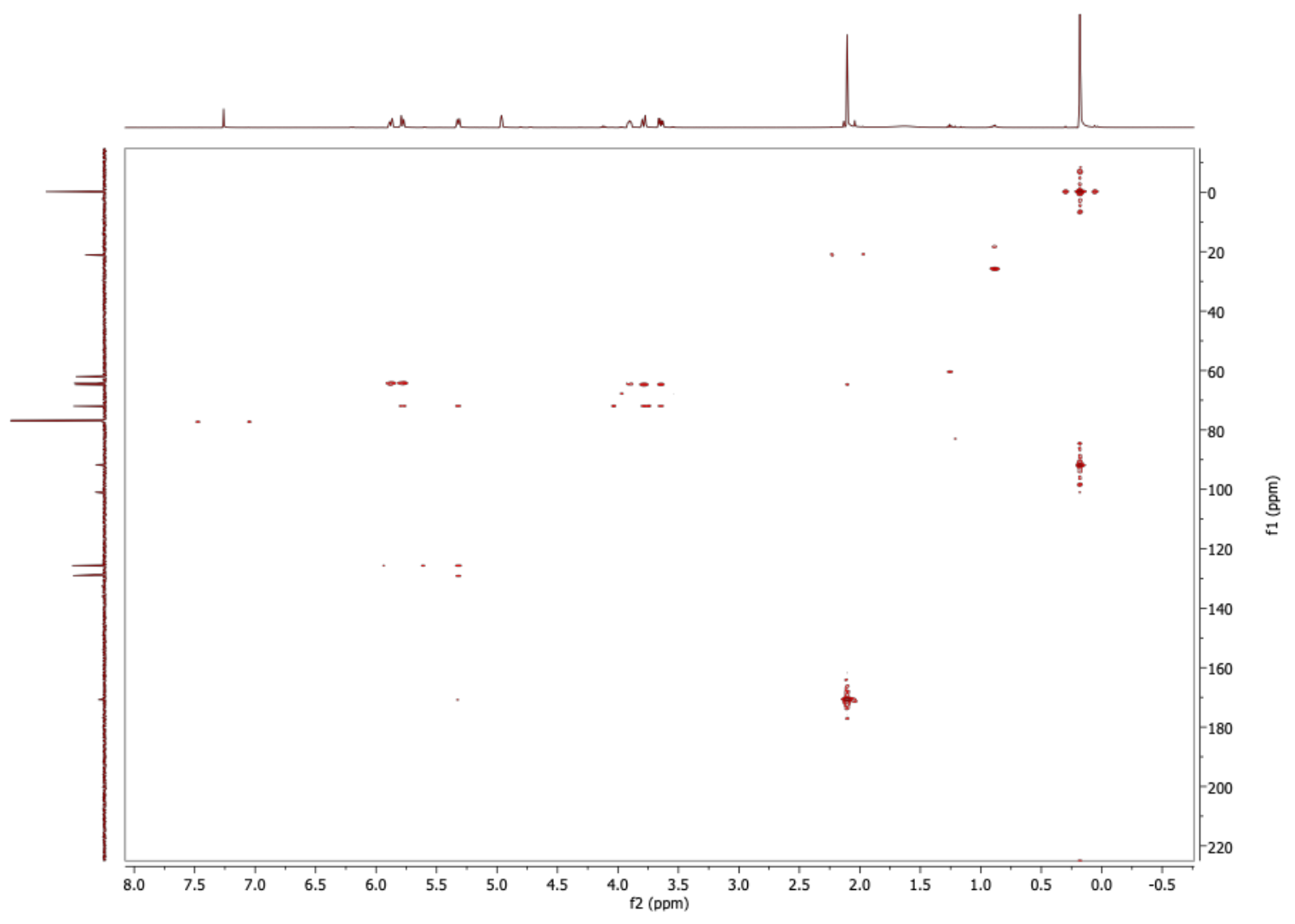


(2S,3S,6S)-3-Acetoxy-6-((trimethylsilyl)ethynyl)-3,6-dihydro- $2 H$-pyran-2-carboxylic acid (90) ${ }^{13} \mathrm{C}$ NMR (125 MHz, $\left.\mathrm{CDCl}_{3}\right)$

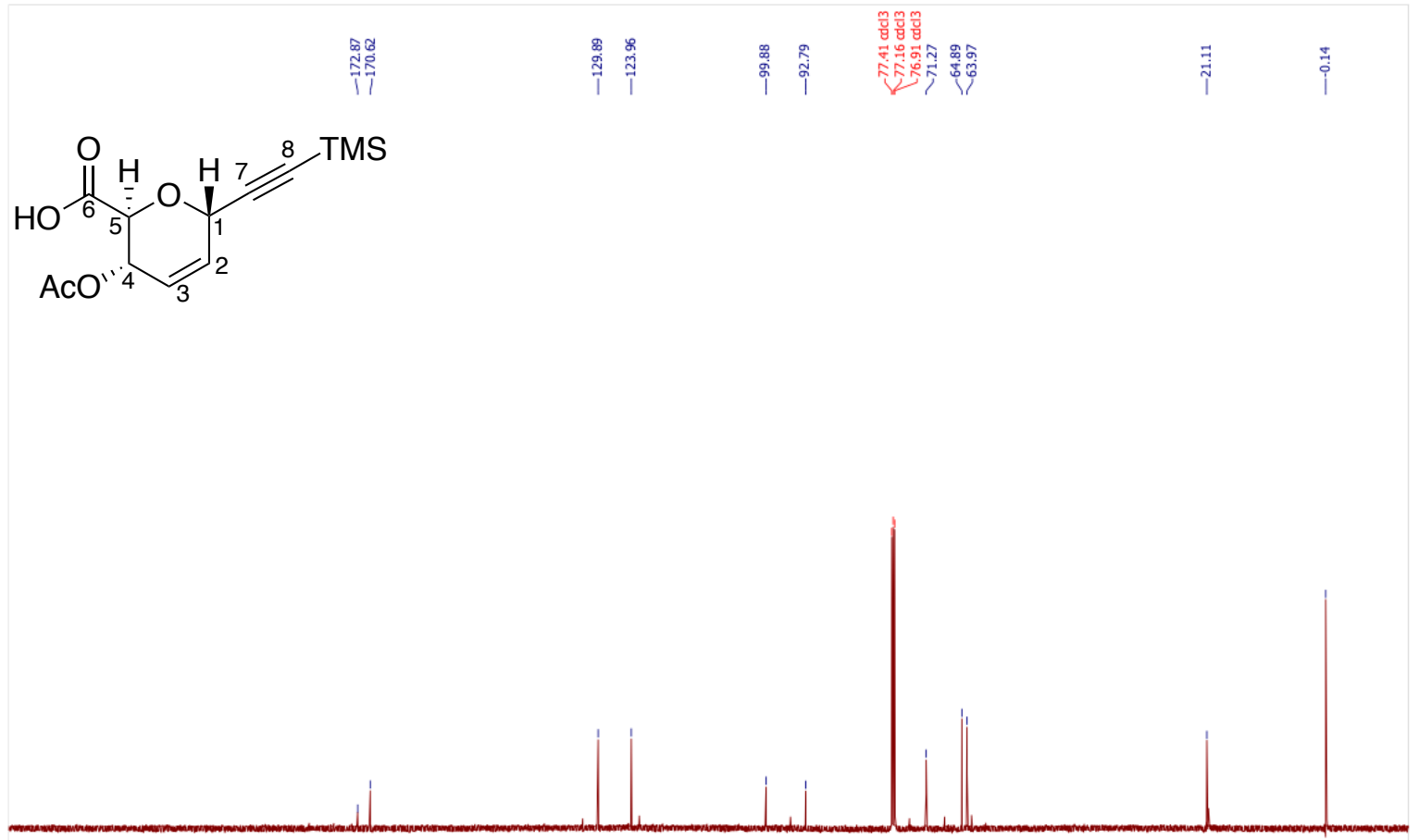

\begin{tabular}{lllllllllllllllllllllllllllllll}
\hline 230 & 220 & 210 & 200 & 190 & 180 & 170 & 160 & 150 & 140 & 130 & 120 & 110 & 100 & 90 & 80 & 70 & 60 & 50 & 40 & 30 & 20 & 10 & 0 & -10
\end{tabular}

(2S,3S,6S)-3-Acetoxy-6-((trimethylsilyl)ethynyl)-3,6-dihydro- $2 H$-pyran-2-carboxylic acid (90) ${ }^{1} \mathrm{H}$ NMR (500 $\left.\mathrm{MHz}, \mathrm{CDCl}_{3}\right)$

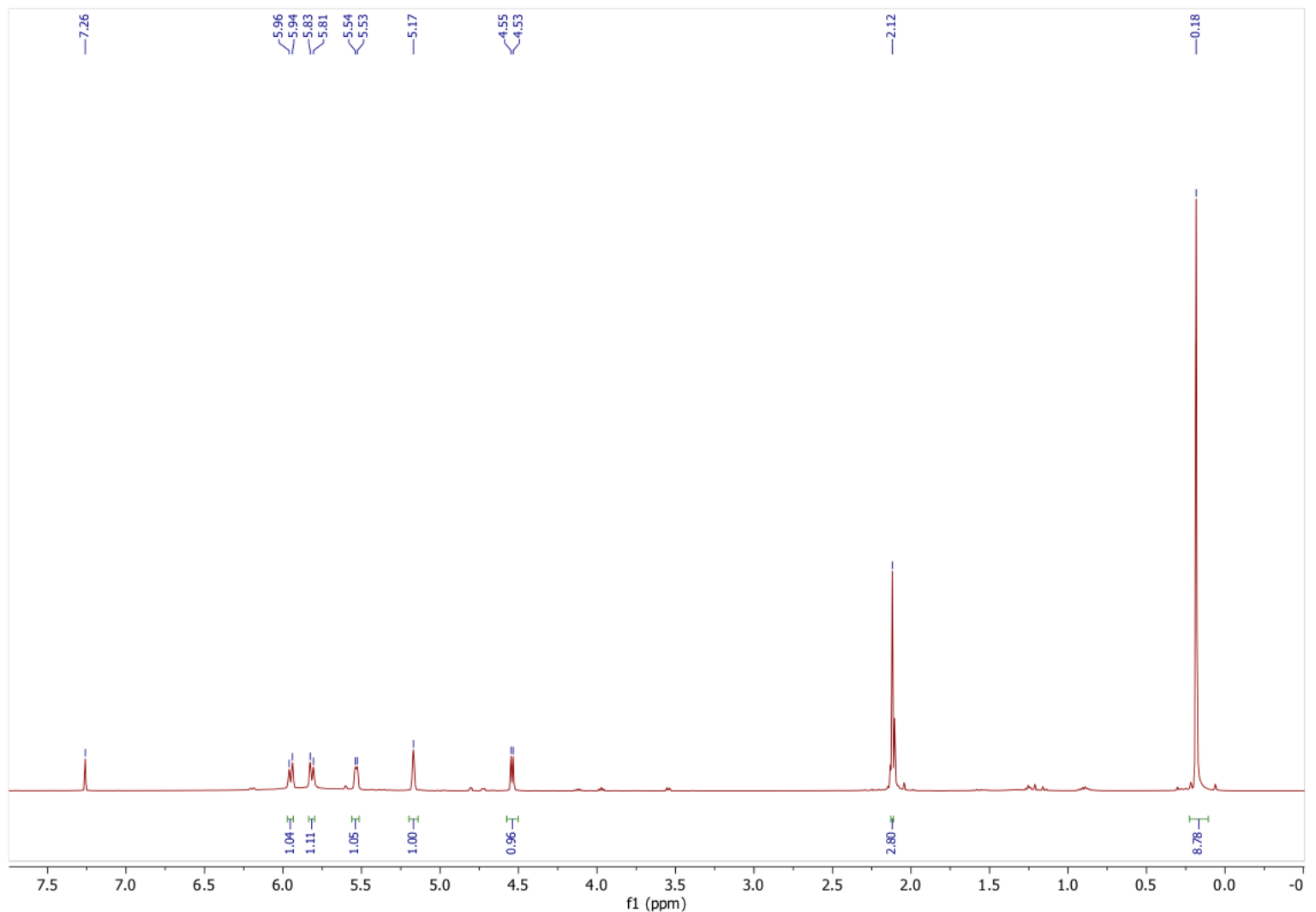


(2S,3S,6S)-3-Acetoxy-6-((trimethylsilyl)ethynyl)-3,6-dihydro-2H-pyran-2-carboxylic acid (90) HSQC ( $\left.\mathrm{CDCl}_{3}\right)$

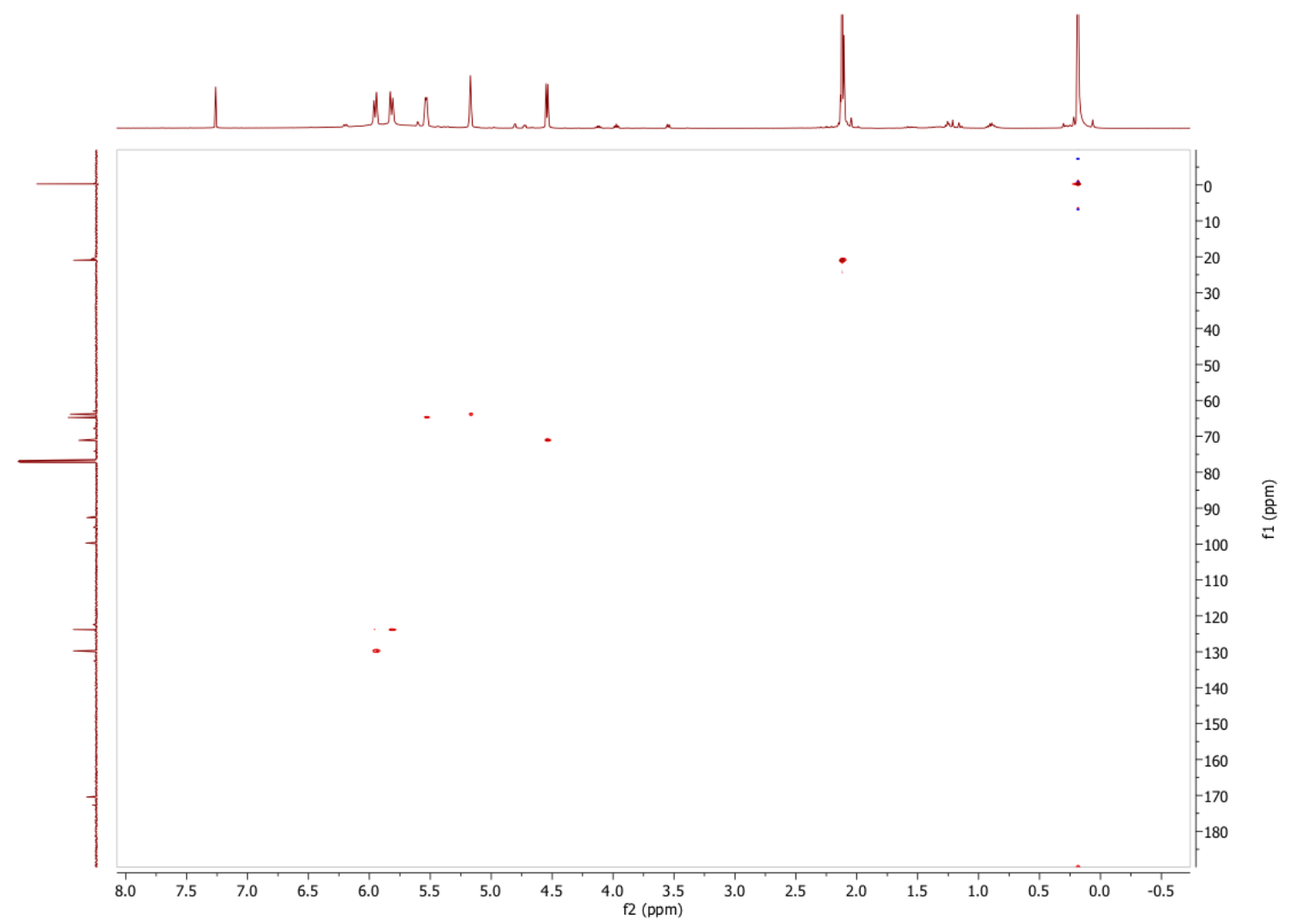

(2S,3S,6S)-3-Acetoxy-6-((trimethylsilyl)ethynyl)-3,6-dihydro-2H-pyran-2-carboxylic acid (90) COSY $\left(\mathrm{CDCl}_{3}\right)$

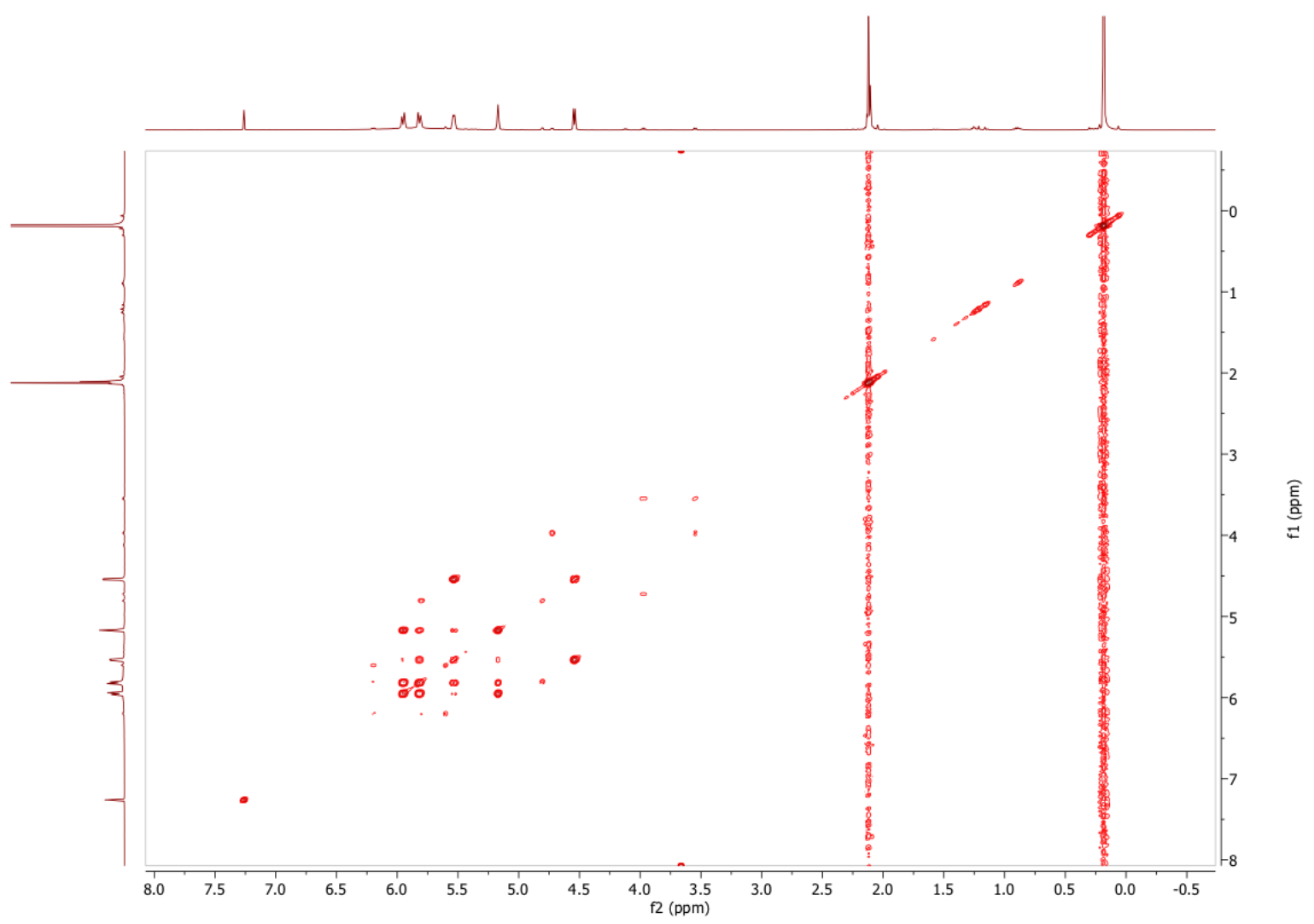

Page | 75 
(2S,3S,6S)-3-Acetoxy-6-((trimethylsilyl)ethynyl)-3,6-dihydro-2H-pyran-2-carboxylic acid (90) HMBC ( $\left.\mathrm{CDCl}_{3}\right)$

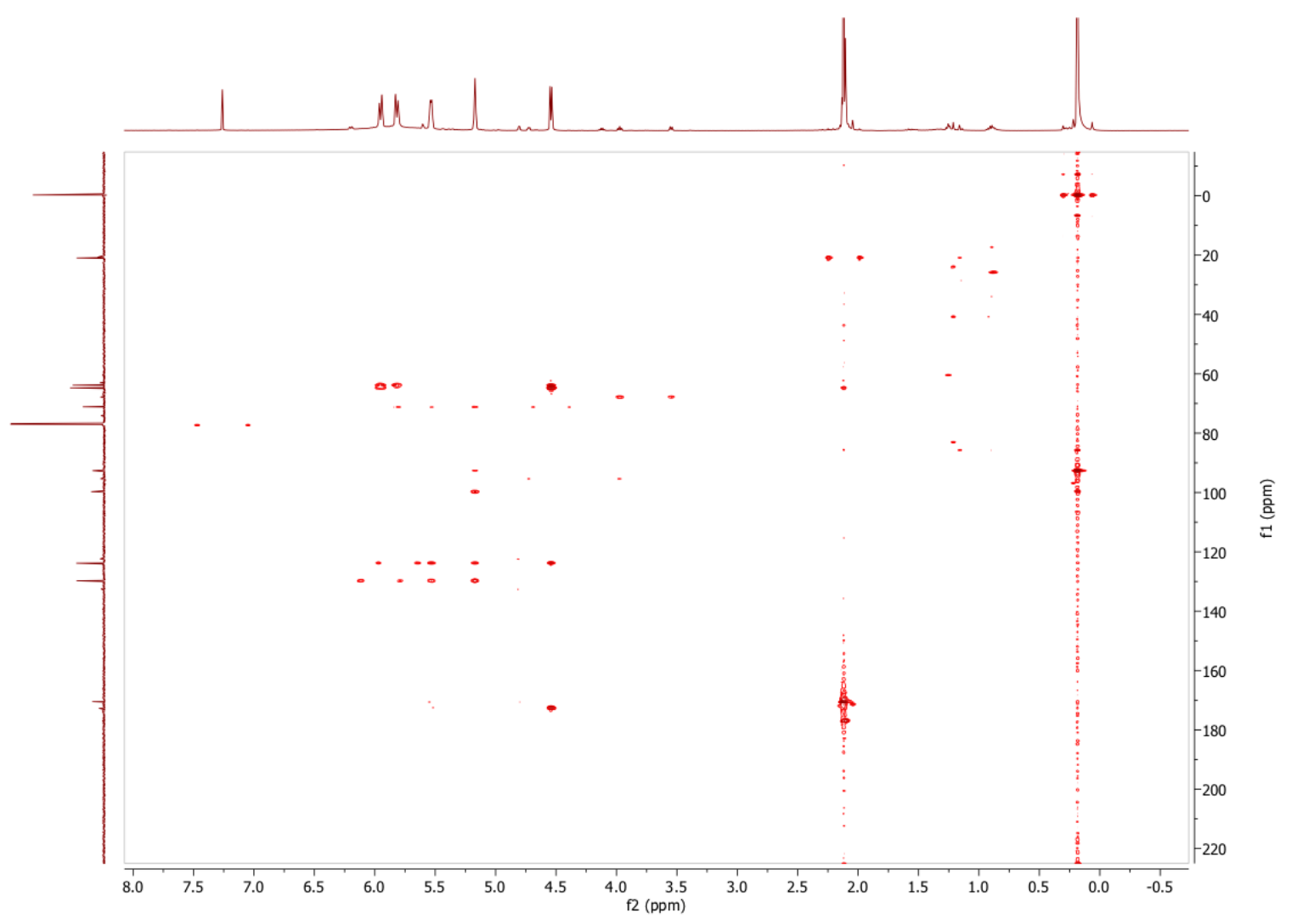


Methyl ((2S,3S,6S)-3-acetoxy-6-((trimethylsilyl)ethynyl)-3,6-dihydro-2H-pyran-2carbonyl) glycinate. (91) ${ }^{13} \mathrm{C}$ NMR (125 $\mathrm{MHz}, \mathrm{CDCl}_{3}$ )
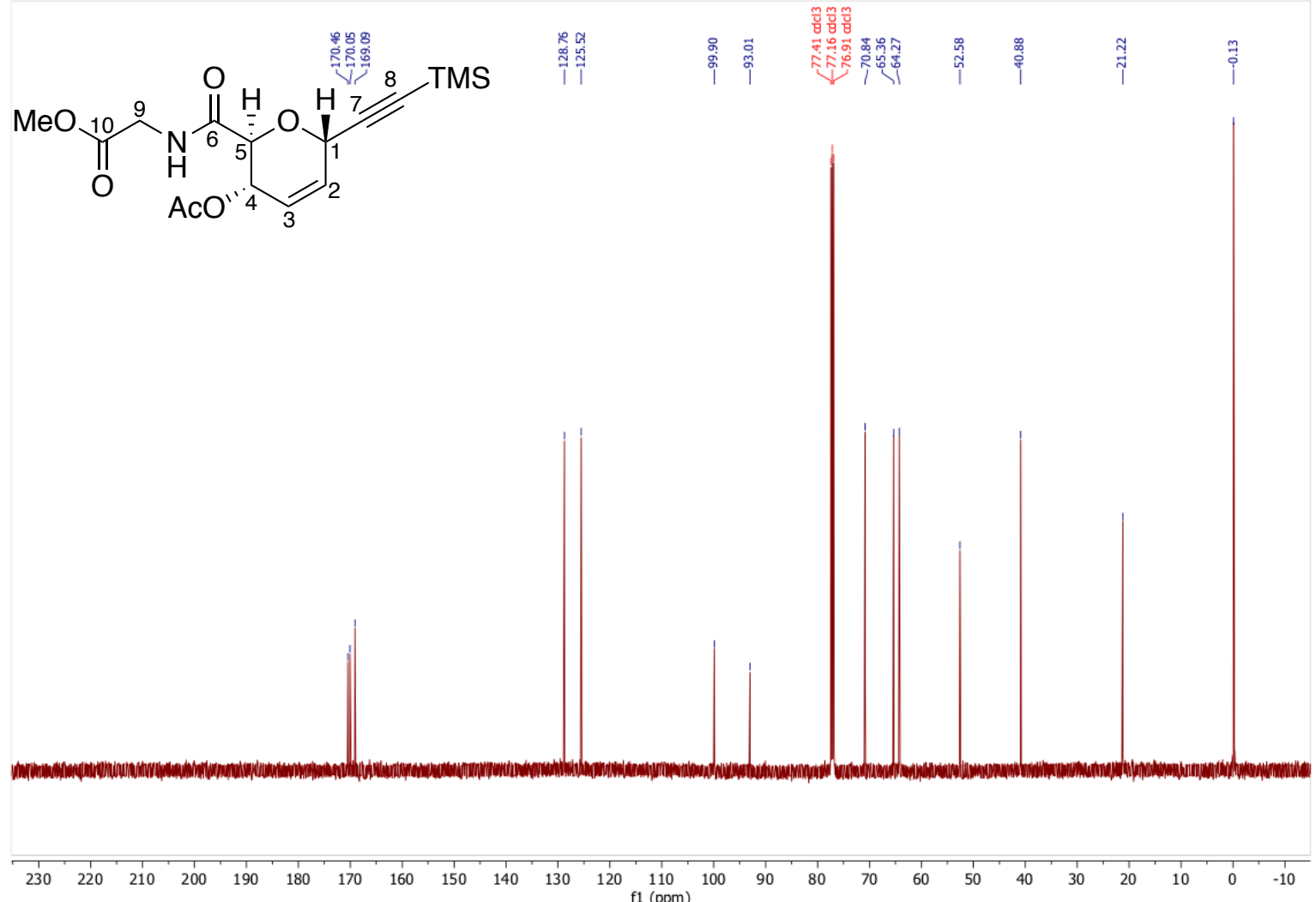

Methyl ((2S,3S,6S)-3-acetoxy-6-((trimethylsilyl)ethynyl)-3,6-dihydro-2H-pyran-2carbonyl) glycinate. (91) ${ }^{1} \mathrm{H}$ NMR (500 $\left.\mathrm{MHz}, \mathrm{CDCl}_{3}\right)$

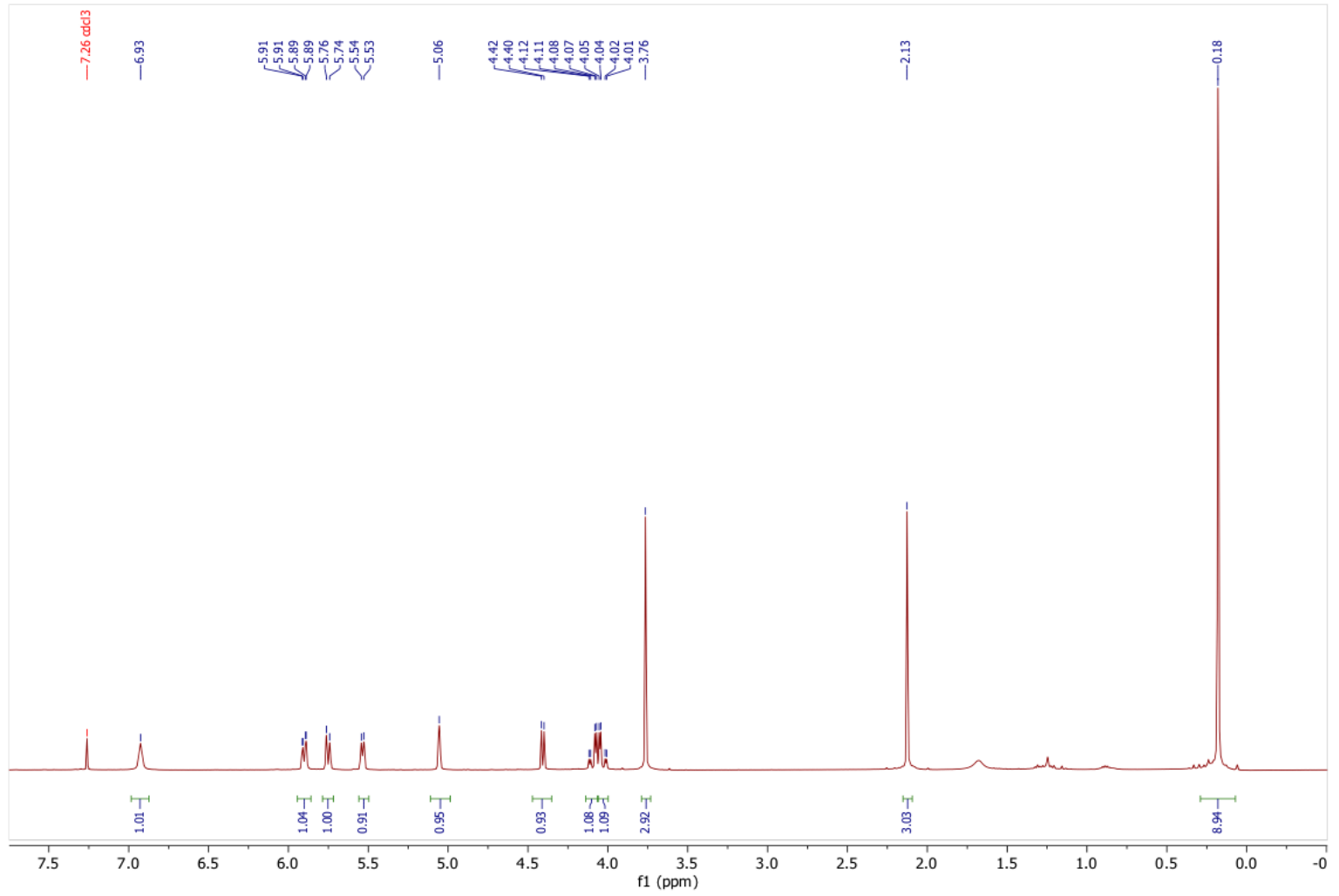


Methyl ((2S,3S,6S)-3-acetoxy-6-((trimethylsilyl)ethynyl)-3,6-dihydro-2H-pyran-2carbonyl) glycinate. (91) HSQC $\left(\mathrm{CDCl}_{3}\right)$

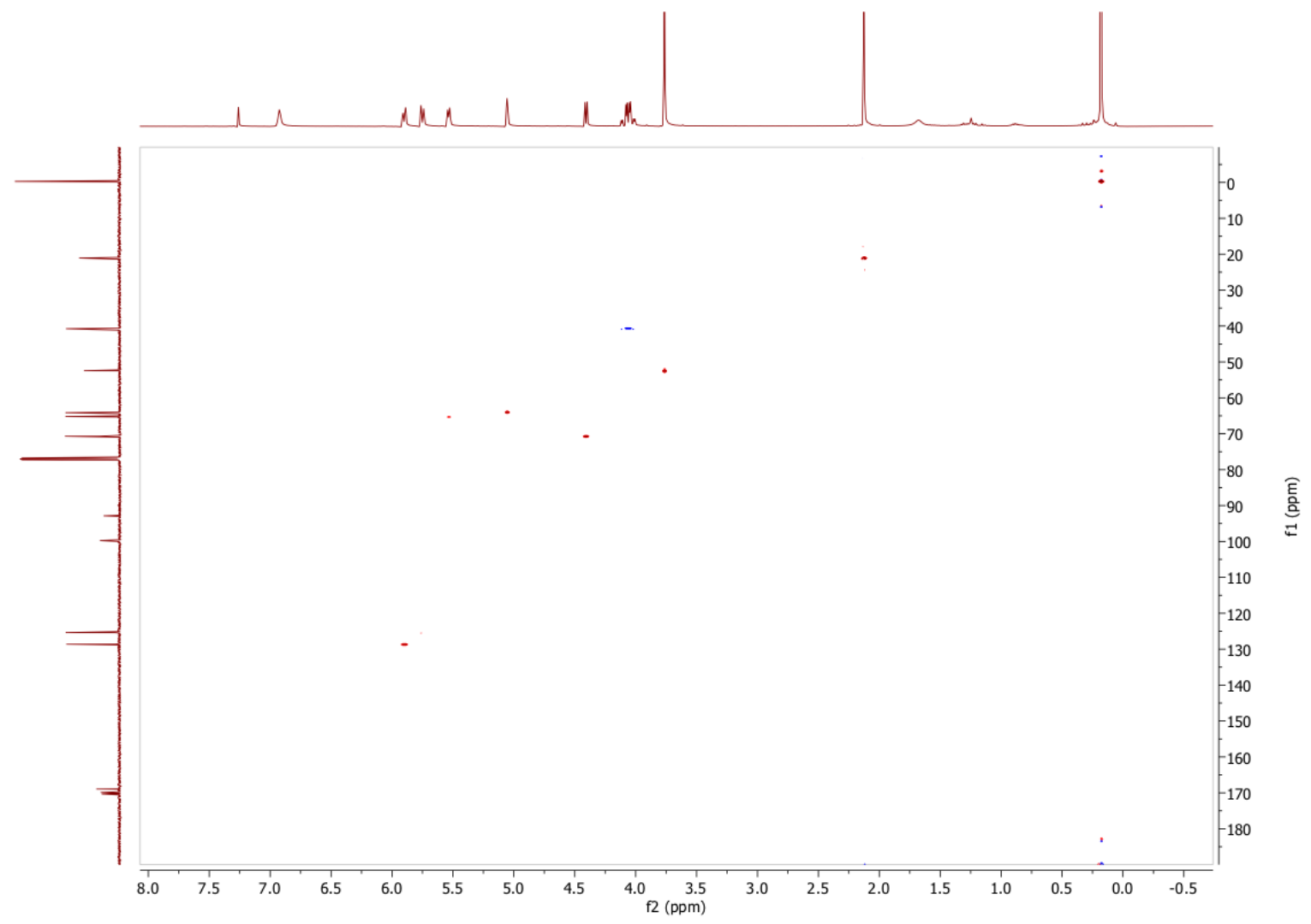

Methyl ((2S,3S,6S)-3-acetoxy-6-((trimethylsilyl)ethynyl)-3,6-dihydro-2H-pyran-2carbonyl) glycinate. (91) $\mathrm{COSY}\left(\mathrm{CDCl}_{3}\right)$

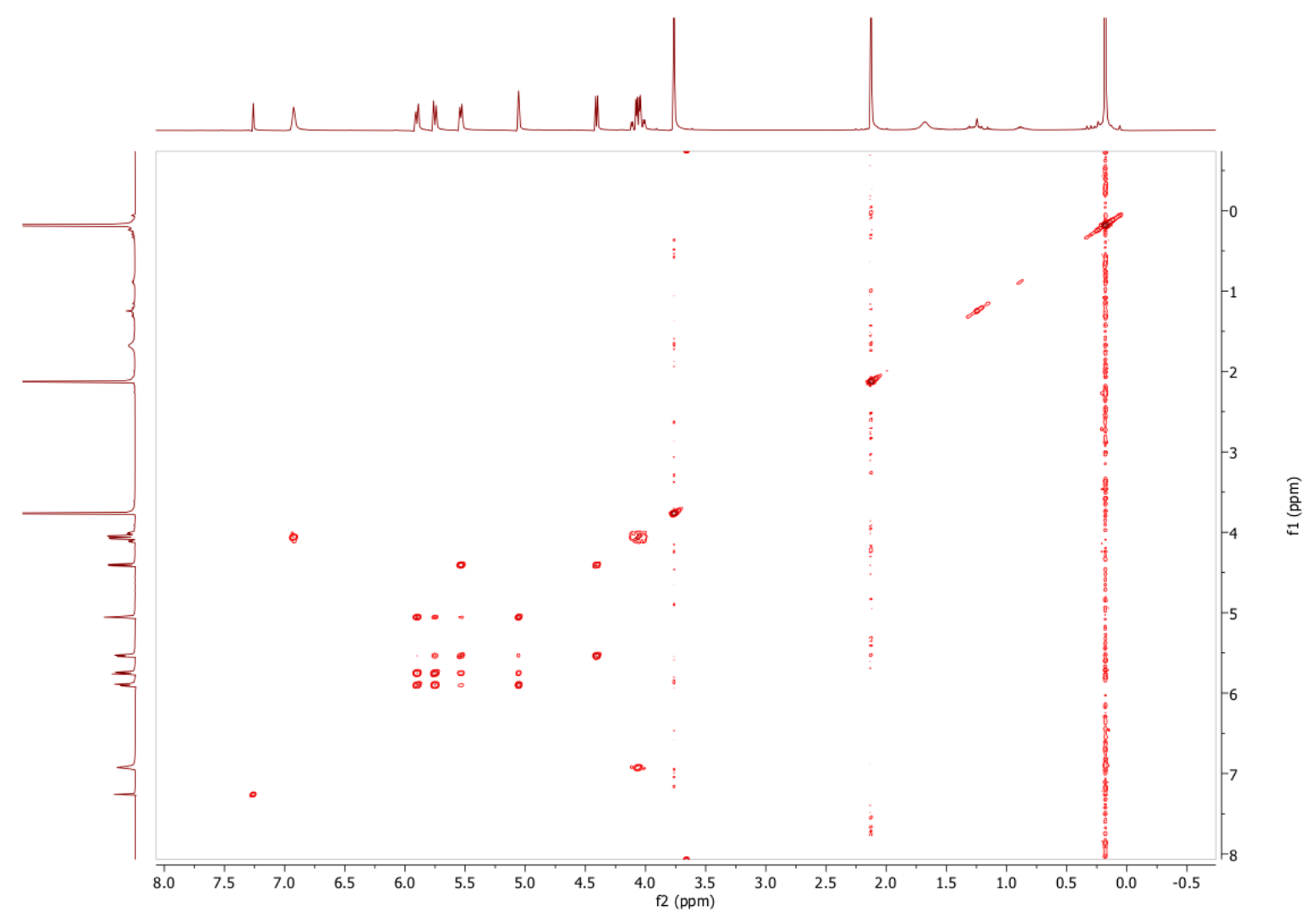


Methyl ((2S,3S,6S)-3-acetoxy-6-((trimethylsilyl)ethynyl)-3,6-dihydro-2H-pyran-2carbonyl) glycinate. (91) $\mathrm{HMBC}\left(\mathrm{CDCl}_{3}\right)$

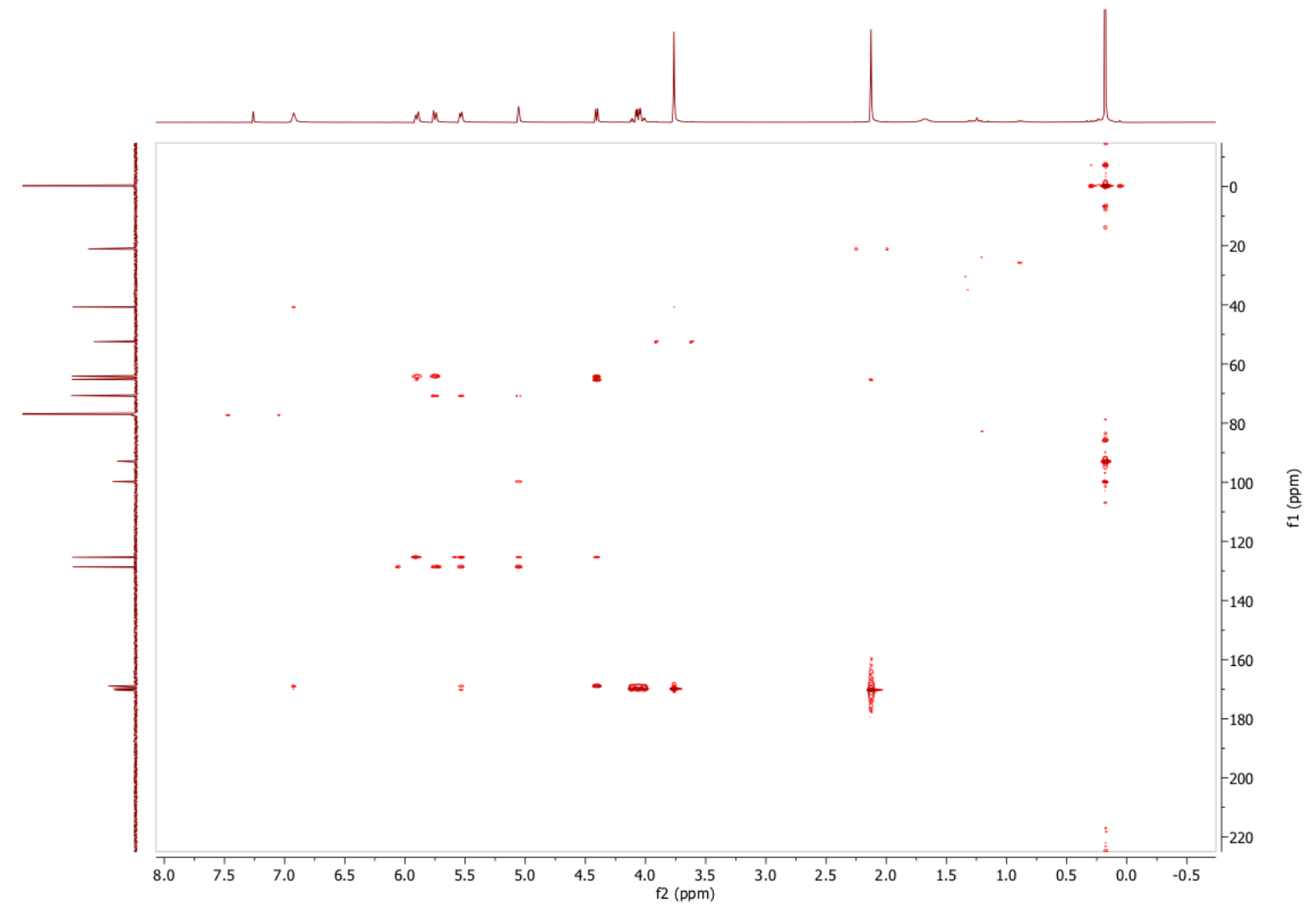


((2R,3S,6S)-3-Acetoxy-6-((trimethylsilyl)ethynyl)-3,6-dihydro-2H-pyran-2-yl)methyl acetate (87) ${ }^{13} \mathrm{C}$ NMR (125 MHz, $\left.\mathrm{CDCl}_{3}\right)$

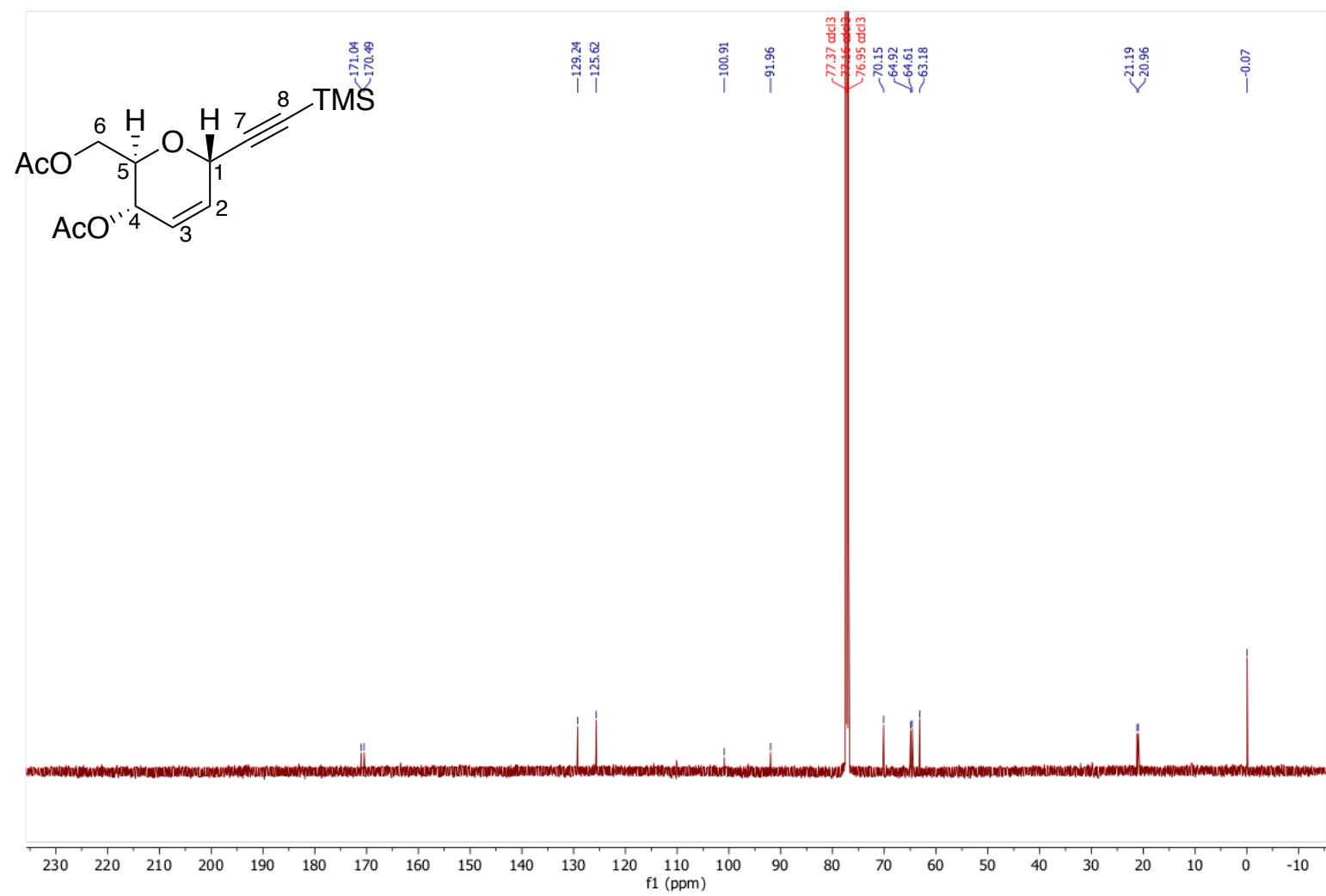

((2R,3S,6S)-3-Acetoxy-6-((trimethylsilyl)ethynyl)-3,6-dihydro-2H-pyran-2-yl)methyl acetate (87) ${ }^{1} \mathrm{H}$ NMR (500 $\mathrm{MHz}^{\left.-\mathrm{CDCl}_{3}\right)}$

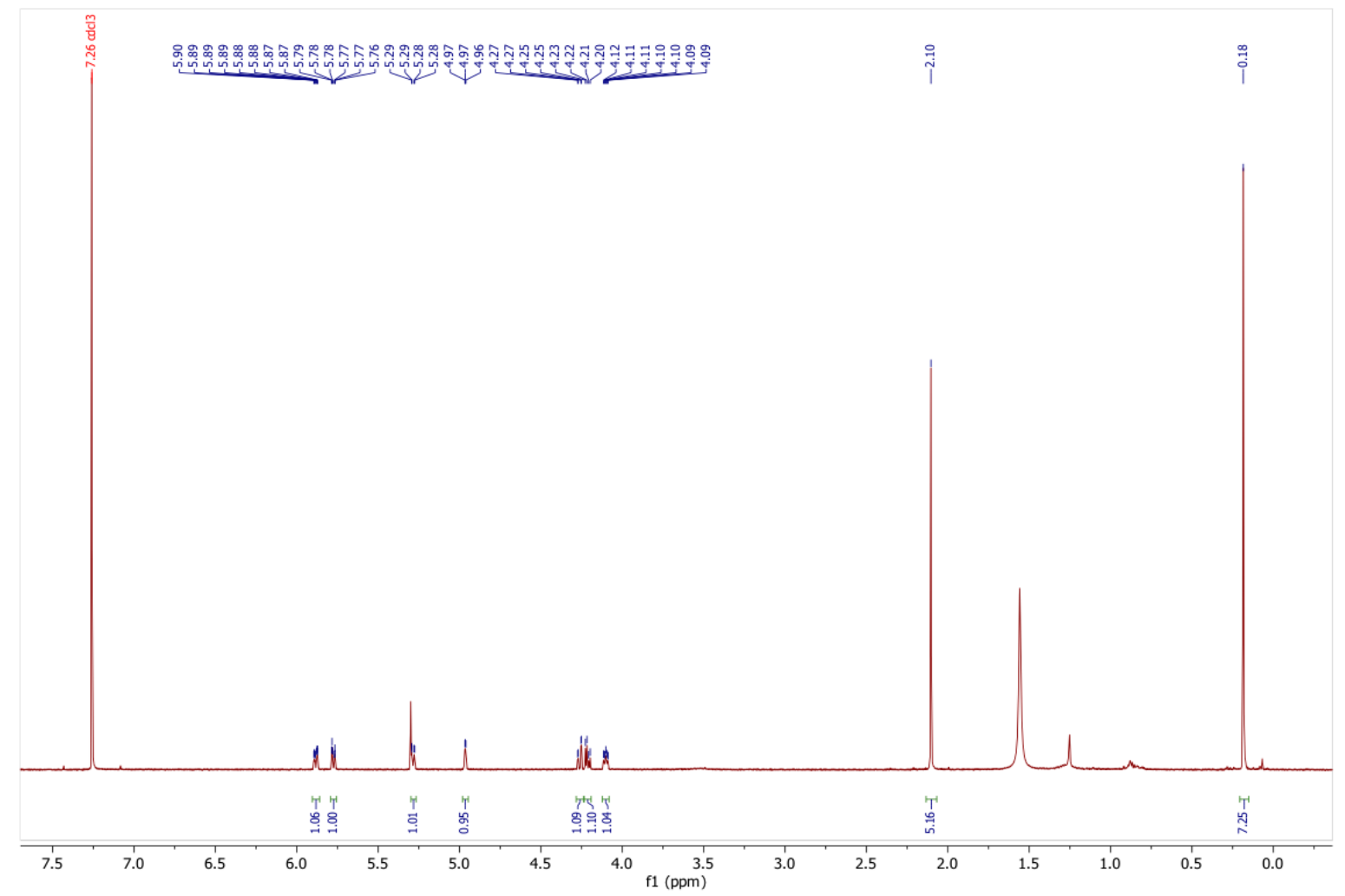


((2R,3S,6S)-3-Acetoxy-6-((trimethylsilyl)ethynyl)-3,6-dihydro-2H-pyran-2-yl)methyl acetate (87) HSQC $\left(\mathrm{CDCl}_{3}\right)$

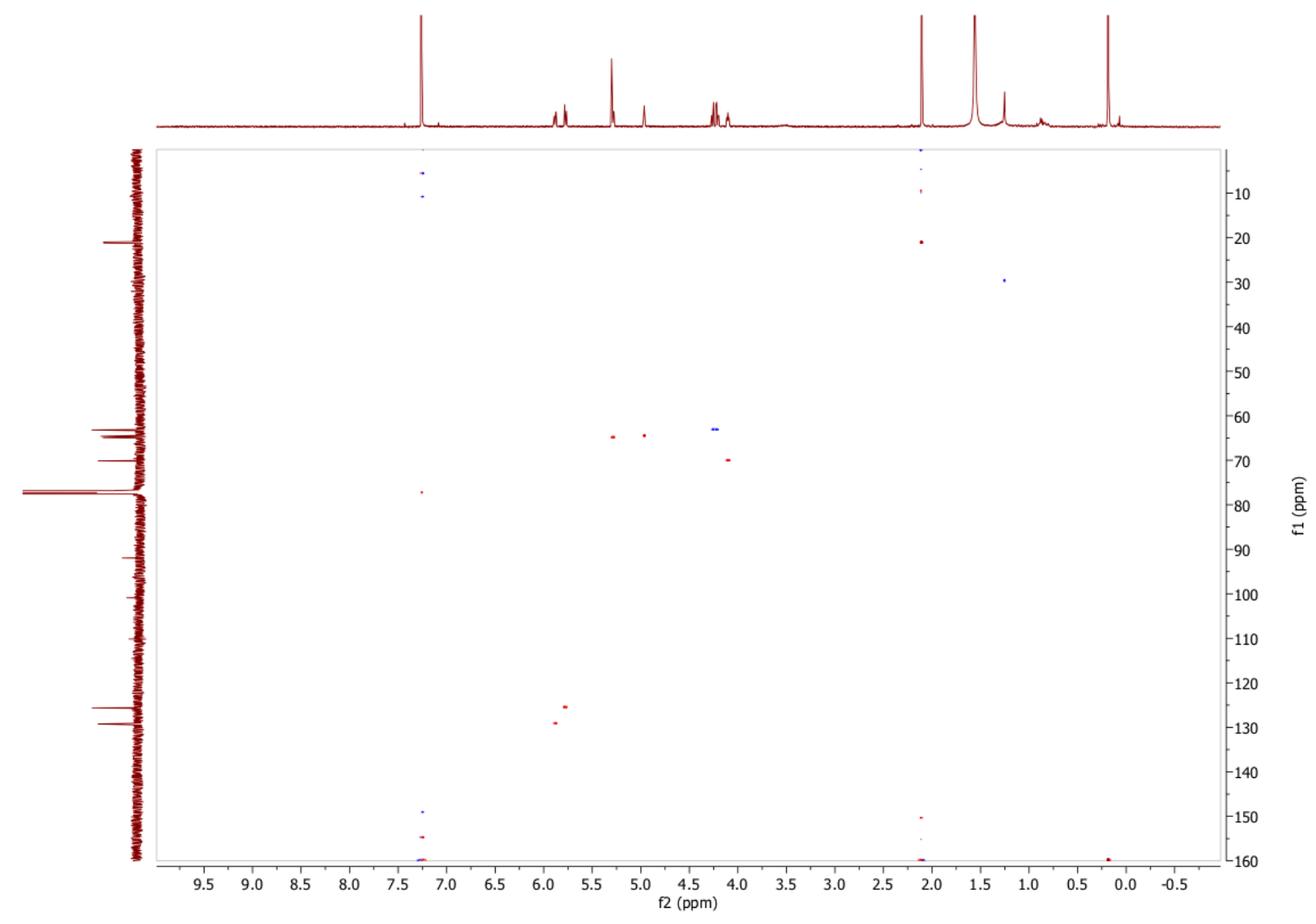

((2R,3S,6S)-3-Acetoxy-6-((trimethylsilyl)ethynyl)-3,6-dihydro-2H-pyran-2-yl)methyl acetate (87) COSY $\left(\mathrm{CDCl}_{3}\right)$

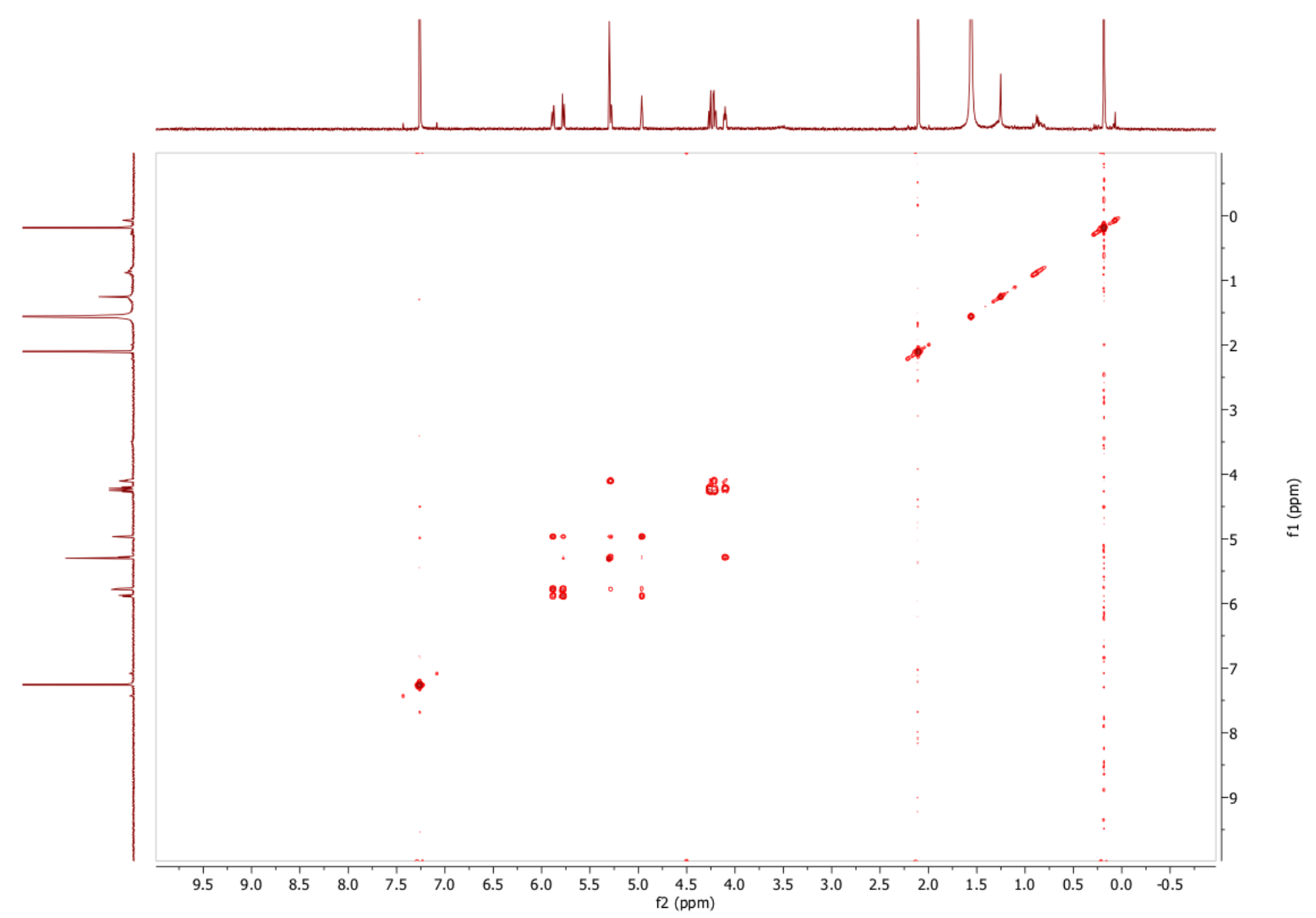




\section{References}

1. Garber, K., Synthetic Lethality: Killing Cancer With Cancer. Cancer Spectrum Knowledge Environment 2002, 94 (22), 1666-1668.

2. Who.int. Cancer. https://www.who.int/news-room/fact-sheets/detail/cancer.

3. Jones, R., Cytotoxic chemotherapy: clinical aspects. Medicine 2016, 44 (1), 25-29.

4. Lind, M., Principles of cytotoxic chemotherapy. Medicine 2008, 36 (1), 19-23.

5. Hall, A. a. T., M., Mechanisms of action of, and modes of resistance to, alkylating agents used in the treatment of haematological malignancies. Blood Reviews 1992, 6 (3), 163-173.

6. Parker, W., Enzymology of Purine and Pyrimidine Antimetabolites Used in the Treatment of Cancer. Chemical Reviews 2009, 109 (7), 2880-2893.

7. Goodsell, D., The Molecular Perspective: DNA Topoisomerases. Stem Cells 2002, 20 (5), pp.470-471.

8. Desai, A. a. M., T., Microtubule Polymerization Dynamics. Annual Review of Cell and Developmental Biology 1997, 13 (1), 83-117.

9. Cutler, S. a. C., H., Biologically active natural products. CRC Press.: 2000.

10. Maplestone, R. A. S., M. J.; Williams, D. H. , The Evolutionary Role of Secondary Metabolites - a Review. Gene 1992, 115 (1-2), 151.

11. Davies, J. W. G., M.; Jenkins, J. L., Streamlining Lead Discovery by Aligning in Silico and High-Throughput Screening. Current Opinion in Chemical Biology 2006, 10 (4), 343.

12. K.P. Mishra, L. G., M. Sairam, P.K. Banerjee, R.C. Sawhney, A review of high throughput technology for the screening of natural products. Biomedicine \& Pharmacotherapy 2008, 62, 94-98.

13. Battersby, B. J. T., M., Novel Miniaturized Systems in High-Throughput Screening. Trends in Biotechnology 2002, 20 (4), 167.

14. Sukuru, S. C. K. J., J. L.; Beckwith, R. E. J.; Scheiber, J.; Bender, A.; Mikhailov, D.; Davies, J. W.; Glick, M., Plate-Based Diversity Selection Based on Empirical HTS Data to Enhance the Number of Hits and Their Chemical Diversity. Journal of Biomolecular Screening 2009, 14 (6), 690.

15. Butler, M., Robertson, A. and Cooper, M., Natural product and natural product derived drugs in clinical trials. Natural Product Reports 2014, 31 (11), 1612-1661. 
16. Newman, D. a. C., G., Natural Products as Sources of New Drugs from 1981 to 2014. Journal of Natural Products 2016, 79 (3), 629-661.

17. Ruppert, E. a. B., R., Invertebrate zoology. Cengage Learning Services.: 2009.

18. ApSimon, J., The total synthesis of natural products. Wiley: New York, 1994.

19. Hirata, Y., \& Uemura, D. , Halichondrins-antitumor polyether macrolides from a marine sponge. Pure and Applied Chemistry 1986, 58 (5), 701-710.

20. Bai, R. L., Paull, K. D., Herald, C. L., Malspeis, L., Pettit, G. R., \& Hamel, E. , Halichondrin B and homohalichondrin B, marine natural products binding in the vinca domain of tubulin. Discovery of tubulin- based mechanism of action by analysis of differential cytotoxicity data. Journal of Biological Chemistry 1991, 266 (24), 1588215889.

21. AThomas D. Aicher, K. R. B., Francis G. Fang, Craig J. Forsyth, Sun Ho Jung, Yoshito Kishi, Michael C. Matelich, Paul M. Scola, Denice M. Spero, and Suk Kyoon Yoon, Total synthesis of halichondrin B and norhalichondrin B. Journal of the American Chemical Society 1992, 114 (8), 3162-3164.

22. Aicher, T. D., Buszek, K. R., Fang, F. G., Forsyth, C. J., Jung, S. H., Kishi, Y., \& Scola, P. M. , Synthetic Studies towards Halichondrins: Synthesis of the C. 27-C. 38 Segment. . Tetrahedron letters 1992, 33 (12), 1549-1552.

23. Fang, F. G., Kishi, Y., Matclich, M. C., \& Scola, P. M., Synthetic studies towards halichondrins: synthesis of the left halves of norhalichondrins and homohalichondrins. Tetrahedron Letters 1992, 33 (12), 1557-1560.

24. Stamos, D. P., Chen, S. S., \& Kishi, Y., New Synthetic Route to the C. 14- C. 38 Segment of Halichondrins. Journal of Organic Chemistry 1997, 62 (22), 7552-7553.

25. Seletsky, B. M., Wang, Y., Hawkins, L. D., Palme, M. H., Habgood, G. J., DiPietro, L. V.,\& Kishi, Y, Structurally simplified macrolactone analogues of halichondrin B. . Bioorganic \& medicinal chemistry letters 2004, 14 (22), 5547-5550.

26. Zheng, W., Seletsky, B. M., Palme, M. H., Lydon, P. J., Singer, L. A., Chase, C. E., \& Towle, M. J. , Macrocyclic ketone analogues of halichondrin B. Bioorganic \& medicinal chemistry letters 2004, 14 (22), 5551-5554.

27. Horita, K., Nagasawa, M., Hachiya, S. I., Sakurai, Y., Yamazaki, T., Uenishi, J. I., \& Yonemitsu, O., Synthetic studies of halichondrin B, an antitumor polyether macrolide isolated from a marine sponge. 8. Synthesis of the lactone part (C1-C36) via horneremmons coupling between $\mathrm{C} 1 \quad \mathrm{C} 15$ and C16 C36 fragments and Yamaguchi lactonization. Tetrahedron Letters 1997, 38 (52), 8965-8968. 
28. Towle, M. J., Salvato, K. A., Budrow, J., Wels, B. F., Kuznetsov, G., Aalfs, K. K., \& Habgood, G. J., In vitro and in vivo anticancer activities of synthetic macrocyclic ketone analogues of halichondrin B. Cancer research 2001, 61 (3), 1013-1021.

29. Wender, P., Baryza, J., Bennett, C., Bi, F., Brenner, S., Clarke, M., Horan, J., Kan, C., Lacôte, E., Lippa, B., Nell, P. and Turner, T., The Practical Synthesis of a Novel and Highly Potent Analogue of Bryostatin. Journal of the American Chemical Society 2002, 124 (46), 13648-13649.

30. Steadman, V., Pettit, S., Poullennec, K., Lazarides, L., Keats, A., Dean, D., Stanway, S., Austin, C., Sanvoisin, J., Watt, G., Fliri, H., Liclican, A., Jin, D., Wong, M., Leavitt, S., Lee, Y., Tian, Y., Frey, C., Appleby, T., Schmitz, U., Jansa, P., Mackman, R. and Schultz, B., Discovery of Potent Cyclophilin Inhibitors Based on the Structural Simplification of Sanglifehrin A. Journal of Medicinal Chemistry 2017, 60 (3), 10001017.

31. Salahudeen, M. a. N., P., An overview of pharmacodynamic modelling, ligand-binding approach and its application in clinical practice. . Saudi Pharmaceutical Journal 2017, 25 (2), 165-175.

32. Guha, R., On Exploring Structure-Activity Relationships. Methods in Molecular Biology, 2013, 81-94.

33. West, L., Battershill, C., Northcote, P., Peloruside A: A Potent Cytotoxic Macrolide Isolated from the New Zealand Marine Sponge Mycale sp. Journal of Organic Chemistry 65 (2), 445-449.

34. Perry, N. B. B., J. W.; Munro, H. G., Mycalamide A, an antiviral compound from a New Zealand sponge of the genus Mycale. Journal of the American Chemical Society 1998, 110 (14), 48504851.

35. Perry, N. B. B., J. W.; Munro, H. G.; Thompson, A. M., Antiviral and antitumor agents from a New Zealand sponge, Mycale sp. 2. Structures and solution conformations of mycalamides A and B. Journal of Organic Chemistry 1990, 55 (1), 223-227.

36. Robert M.Rzasa, D. R., David J. Stirling, John W. Blunt, Murray H.G.Munro, Structural and synthetic studies of the pateamines: Synthesis and absolute configuration of the hydroxydienoate fragment. Tetrahedron Letters 1995, 36 (30), 5307-5310.

37. Miller, J., Singh, A. and Northcote, P. , Microtubule-Stabilizing Drugs from Marine Sponges: Focus on peloruside A and Zampanolide. Marine Drugs 2010, 8 (4), 10591079. 
38. Miller, J., Berridge, M., Northcote, P., West, L., Bäckström, B. and Hood, K., The novel cytotoxic sponge metabolite peloruside A, structurally similar to bryostatin-1, has unique bioactivity independent of protein kinase C. Anticancer Drug Design 2001, 16 (2-3), 155-166.

39. Miller, J., Rouwé, B., Gaitanos, T., Hood, K., Crume, K., Bäckström, B., La Flamme, A., Berridge, M. and Northcote, P., Peloruside A enhances apoptosis in H-rastransformed cells and is cytotoxic to proliferating T cells. Apoptosis 2004, 9 (6), 785796.

40. Hood, K., West, LM., Rouwé, B., Northcote, PT., Berridge, MV., Wakefield, StJ., Miller, JH., Peloruside A, a novel anti-mitotic agent with paclitaxel-like microtubulestabilizing activity. Cancer Research 2002, 62 (12), 3356-3360.

41. Meyer, C., Krauth, M., Wick, M., Shay, J., Gellert, G., De Brabander, J., Northcote, P. and Miller, J., Peloruside A Inhibits Growth of Human Lung and Breast Tumor Xenografts in an Athymic nu/nu Mouse Model. Molecular Cancer Therapeutics 2015, $14(8), 1816-1823$.

42. Wilmes, A., Rawson, P., Peng, L., McLauchlan, D., Northcote, P., Jordan, T. and Miller, J., Effects of the microtubule stabilizing agent peloruside A on the proteome of HL-60 cells. Investigational New Drugs 2010, 29 (4), 544-553.

43. Chan, A., Singh, A., Northcote, P. and Miller, J., Inhibition of human vascular endothelial cell migration and capillary-like tube formation by the microtubulestabilizing agent peloruside A. Investigational New Drugs 2015, 33 (3), 564-574.

44. Gaitanos, T., Buey, R., Díaz, J., Northcote, P., Teesdale-Spittle, P., Andreu, J. and Miller, J., Peloruside A Does Not Bind to the Taxoid Site on $\beta$-Tubulin and Retains Its Activity in Multidrug-Resistant Cell Lines. Cancer Research 2004, 64 (15), 5063-5067.

45. Prota, A., Bargsten, K., Northcote, P., Marsh, M., Altmann, K., Miller, J., Díaz, J. and Steinmetz, M., Rücktitelbild: Structural Basis of Microtubule Stabilization by Laulimalide and peloruside A. Angewandte Chemie 2014, 126 (6), 1738-1738.

46. Wilmes, A., Bargh, K., Kelly, C., Northcote, P. and Miller, J., Peloruside A Synergizes with Other Microtubule Stabilizing Agents in Cultured Cancer Cell Lines. Molecular Pharmaceutics 2007, 4 (2), 269-280.

47. Kellog, E., Hejab, N., Howes, S., Northcote, P,. Miller, J,. Diaz, F,. Downing, K,. Nogales, E., Insights into the distinct mechanisms of action of taxane and non-taxane microtubule stabilizers from cryo-EM structures. Journal of Molecular Biology 2017, $429(5), 633-646$. 
48. Brackovic, A. a. H., J., Synthetic, semisynthetic and natural analogues of peloruside A. Chemical Communications 2015, 51 (23), 4750-4765.

49. Jin, M. a. T., R., Total Synthesis of (+)-peloruside A. Organic Letters 2005, 7 (7), 13031305.

50. Ghosh, A., Xu, X., Kim, J. and Xu, C., Enantioselective Total Synthesis of peloruside A: A Potent Microtubule Stabilizer. Organic Letters, 2008, 10 (5), 1001-1004.

51. Evans, D., Welch, D., Speed, A., Moniz, G., Reichelt, A. and Ho, S. (2009). An AldolBased Synthesis of (+)-Peloruside A, A Potent Microtubule Stabilizing Agent. Journal of the American Chemical Society 2009, 131 (11), 3840-3841.

52. McGowan, M., Stevenson, C., Schiffler, M. and Jacobsen, E., An Enantioselective Total Synthesis of (+)-Peloruside A. Angewandte Chemie 2010, 49 (35), 6147-6150.

53. Hoye, T., Jeon, J., Kopel, L., Ryba, T., Tennakoon, M. and Wang, Y., Total Synthesis of Peloruside A through Kinetic Lactonization and Relay Ring-Closing Metathesis Cyclization Reactions. Angewandte Chemie International Edition 2010, 49 (35), 61516155.

54. A. Jonathan Singh, M. R., Paul Teesdale-Spittle, Thomas N. Gaitanos, Anja Wilmes, Ian Paterson, Jonathan M. Goodman, John H. Miller and Peter T. Northcote, Structureactivity studies of the pelorusides: new congeners and semi-synthetic analogues. Organic \& Biomolecular Chemistry 2011, (9), 4456-4466.

55. Adinolfi, M., Barone, G., Iadonisi, A. and Schiattarella, M., An Easy Approach for the Acetylation of Saccharidic Alcohols. Applicability for Regioselective Protections. Tetrahedron Letters 2003, 44 (25), 4661-4663.

56. Roën, A., Padrón, J., Mayato, C. and Vázquez, J., Conformational Domino Effect in Saccharides: A Prediction from Alkyl $\beta-(1 \rightarrow 6)$-Diglucopyranosides. The Journal of Organic Chemistry 2008, 73 (9), 3351-3363.

57. Konstantinovic, S., Predojevic, J., Gojkovic, S., Pavlovic, V. and Csanádi, J., The Ferrier rearrangement as the key step in the synthesis of C7-C16-alkyl 2,3-dideoxy glucosides from glucose and C7-C16-alkanols1-3. Journal of the Serbian Chemical Society 2001, 66 (8), 499-505.

58. Ichikawa, Y., Isobe, M., Konobe, M. and Goto, T. , Synthesis of C -glycosyl compounds from 3,4,6-tri- O -acetyl-1,5-anhydro- d - arabino -hex-1-enitol and allyltrimethylsilane and bis(trimethylsilyl)acetylene. Carbohydrate Research 1987, $171(1), 193-199$. 
59. Eleuterio Alvarez, M. a. T. D., Ricardo Pérez, José L. Ravelo, Alicia Regueiro, José A. Vera, Dácil Zurita, and Julio D. Martin, Simple Designs for the Construction of Complex Trans-Fused Polyether Toxin Frameworks. A Linear Strategy Based on Entropically Favored Oxirane Ring Enlargement in Epoxycycloalkenes Followed by Carbon-Carbon or Carbon-Oxygen Bond-Forming Cyclizations. Journal of Organic Chemistry 1994, 59 (10), 2848-2879.

60. Xiao, R. D., Eric L.; Zeng, Jialiu; McKnight, Christopher J.; Grinstaff, Mark W, Synthesis of Altrose Poly-amido-saccharides with $\beta-\mathrm{N}-(1 \rightarrow 2)$-d-amide Linkages: A Right-Handed Helical Conformation Engineered in at the Monomer Level. Journal of the American Chemical Society 2017, 139 (40), 14217-14223.

61. Moore, P. W. S., J. K.; Hewitt, R. J.; Stone, M. R. L.; Teesdale-Spittle, P. H.; Harvey, J. E., Divergent synthesis of 2-C-branched pyranosides and oxepines from 1,2-gemdibromocyclopropyl carbohydrates. Tetrahedron 2014, 70 (39), 7032-7043.

62. Lassueur, L. Identifying the Mechanism of Action of Bioactive 1,2-Cyclopropyl Carbohydrates. Victoria University of Wellington, 2015.

63. Esswein, A. R., H.; Schmidt, R. R., O-Alkylation at the anomeric centre for the stereoselective synthesis of Kdo- $\alpha$-glycosides. Carbohydrate Research 1990, 200, 287 305.

64. Yadav, J., Reddy, B., Raju, A. and Rao, C., Indium tribromide-catalyzed highly stereoselective synthesis of alkynylsugars. Tetrahedron Letters 2002, 43 (31), 54375440.

65. Minoru Isobe, R. N., Seijiro Hosokawa and Toshio Nishikawa, Stereocontrolled synthesis and reactivity of sugar acetylenes Chemical Communications 1998, 26652676.

66. Schell, P., Orgueira, H., Roehrig, S. and Seeberger, P., Synthesis and transformations of d-glucuronic and 1-iduronic acid glycals. Tetrahedron Letters 2001, 42 (23), 38113814.

67. Shekaraiah Devari, M. K., Ramesh Deshidi, Masood Rizvi and Bhahwal Ali Shah, A general metal-free approach for the stereoselective synthesis of C-glycals from unactivated alkynes. Beilstein Journal of Organic Chemistry 2014, 10, 2649-2653.

68. Rungnapha Saeeng, U. S., Poolsak Sahakitpichan, Minoru Isobe, Iodine catalyzes Cglycosidation of D-glucal with silylacetylene. Tetrahedron Letters 2003, 44 (33), 62116215. 
69. Kadereit, D., Deck, P., Heinemann, I. and Waldmann, H., Acid-Labile Protecting Groups for the Synthesis of Lipidated Peptides. Chemistry 2001, 7 (6), 1184-1193.

70. Kohei Kadota, A. S. E., Takahiko Taniguchi, Kunio Ogasawara, Lipase-Mediated Preparation of Enantiopure Isolevoglucosenone. Synthesis 2000, (10), 1372-1374.

71. Pétursson, S., Protecting Groups in Carbohydrate Chemistry. Journal of Chemical Education 1997, 74 (11), 1297.

72. Greene, P. M. W. a. T. W., GREENE'S PROTECTIVE GROUPS IN ORGANIC SYNTHESIS 4th edition. John Wiley \& Sons, Inc.: 2007.

73. Yeager, A., Min, G., Porco,, J. and Schaus, S., Exploring Skeletal Diversity via Ring Contraction of Glycal-Derived Scaffolds. Organic Letters 2006, 8 (22), 5065-5068.

74. E. J. Corey, a. A. V., Protection of hydroxyl groups as tert-butyldimethylsilyl derivatives. Journal of the American Chemical Society 1972, 94 (17), 6190-6191.

75. Gowravaram Sabitha, S. S. S. R., J.S.Yadav, Total synthesis of cryptopyranmoscatone B1 from 3,4,6-tri-O-acetyl-d-glucal. Tetrahedron Letters 210, 51 (48), 6259-6261.

76. Akihiko Kojima, T. T., Mikiko Sodeoka, and Masakatsu Shibasaki, Catalytic Asymmetric Synthesis of Halenaquinone and Halenaquinol. Journal of Organic Chemistry 1996, 61 (15), 4876-4877.

77. Vankar, A. C. a. Y. D., One-Step TEMPO-Catalyzed and Water-Mediated Stereoselective Conversion of Glycals into 2-Azido-2-deoxysugars with a PIFATrimethylsilyl Azide Reagent System. Organic Letters 2018, 20 (9), 2611-2614.

78. Gattu Sridhar, M. H. G. V. M. S., Synthesis of Novel Pyran $\beta$-Amino Acid and 5,6Dihydro-2H-pyran $\beta$-aminoxy Acid from Carbohydrate Derivatives. Synthetic Communications 2015, 45 (15), 1768-1776.

79. Esther C. Y. Woon, M. D., Eleanor A. L. Bagg, WeiShen Aik, Svetlana M. Krylova, Jerome H. Y. Ma, MunChiang Chan, Louise J. Walport, David W. Wegman, Kevin N. Dack, Michael A. McDonough, Sergey N. Krylov, and Christopher J. Schofield, Dynamic Combinatorial Mass Spectrometry Leads to Inhibitors of a 2-OxoglutarateDependent Nucleic Acid Demethylase. Journal of Medicinal Chemistry 2012, 55 (5), 2173-2184.

80. Kolb, H., Finn, M. and Sharpless, K., Click Chemistry: Diverse Chemical Function from a Few Good Reactions. Angewandte Chemie International Edition 2001, 40 (11), 2004-2021. 
81. Niek N. H. M. Eisink, M. D. W., and Adriaan J. Minnaard, Regioselective Carbohydrate Oxidations: A Nuclear Magnetic Resonance (NMR) Study on Selectivity, Rate, and Side-Product Formation. ACS Catalysis 2017, 7 (2), 1438-1445.

82. Xue-Yang Jiang, X.-C. L., Wen-Yuan Liu, Yun-Hui Xu, Feng Feng, Wei Qu, An efficient, scalable approach to hydrolyze flavonoid glucuronides via activation of glycoside bond. Tetrahedron 2017, 73 (14), 1895-1903.

83. Ryusuke Doi, M. S., Tsukasa Murayama, Yoshihiko Yamamoto, and Yoshiharu Iwabuchi, Development of an Azanoradamantane-Type Nitroxyl Radical Catalyst for Class-Selective Oxidation of Alcohols. Journal of Organic Chemistry 2015, 80 (1), 401-413.

84. Vasella, J. A. A., Oligosaccharide Analogues of Polysaccharides. Part 2. Regioselective deprotection of monosaccharide-derived monomers and dimers. Helvetica 1995, 78 (1), 177-193.

85. Shigeyoshi Tanaka, T. T., Minoru Isobe, Epimerization of C-1 alkynyl group on pyranose ring through dicobalt hexacarbonyl complexes. Tetrahedron Letters 1993, 34 (36), 5757-5760.

86. Bing-Lin Wang, Z.-X. J., Zheng-Wei You, Feng-Ling Qing, Total synthesis of trifluoromethylated analogs of macrosphelide A. Tetrahedron 2007, 63 (51), 1267112680.

87. Ting Chi Wong, R. R. T., Yuan Chuan Lee, Synthesis of D-galactosamine derivatives and binding studies using isolated rat hepatocytes. Carbohydrate Research 1987, 170 (1), 27-46.

88. Malacria, M. P. C. A. M., Diastereoselective approach to 11-aryl steroid skeletons through a cobalt(I)-mediated [2+2+2] cyclization of allenediynes. Tetrahedron 2006, 62 (45), 10582-10593.

89. Spanevello, M. B. C. M. I. M. A. G. S. A. M. S. R. A., A Domino Epoxide RingOpening Xanthate Migration Reaction: An Alternative Entry to Thiosugars. European Journal of Organic Chemistry 2018, 2018 (48), 6848-68.

90. McCombie, D. H. R. B. a. S. W., A new method for the deoxygenation of secondary alcohols. Journal of the Chemical Society, Perkin Transactions 1 1975, 16 (16), 15741585.

91. Draeger, G. K., Csilla; Kunz, Ulrich; Kirschning, Andreas, Enzyme-purification and catalytic transformations in a microstructured PASSflow reactor using a new tyrosine- 
based Ni-NTA linker system attached to a polyvinylpyrrolidinone-based matrix. Organic \& Biomolecular Chemistry 2007, 5 (22), 3657-3664.

92. Esswein, A. R., Hansjoerg; Schmidt, Richard R., Anomeric O-alkylation. 7. OAlkylation at the anomeric center for the stereoselective synthesis of Kdo- $\alpha$-glycosides. Cancer Research 1990, 200, 287-305.

93. Fischer, S. H., Carl Heinz, The alkylation and acylation of glycals via an initializing electrochemical step. Carbohydrate Chemistry 1995, 14 (3), 327-339.

94. Robert J. Ferrier, O. A. Z., Transformation of Glycals into 2,3-Unsaturated Glycosyl Derivatives. Organic Reactions 2004.

95. Dunkerton, L. V. B., K. T.; Mohamed, F.; McKillican, B. P., Palladium-promoted allylic rearrangement route to 6-substituted 2-O-acetyl-3-hexenopyranosides. Carbohydrate Chemistry 1988, 7 (1), 49-65.

96. Lubin-Germain, N. H., Agnes; Huguenot, Florent; Palmier, Sara; Uziel, Jacques; Auge, Jacques, Ferrier-Type Alkynylation Reaction Mediated by Indium. Organic Letters 2007, 9 (18), 3679-3682. 